\title{
Democracy and the new
}

\section{Communication Technologies}

(C) Kristine Kay Klugman

1996

A thesis submitted for the degree of Doctor of Philosophy, Department of Political Science, Faculty of Arts, The Australian National University 
I certify this is entirely my own original work except where referenced and save for the normal and permissible use of primary sources, plus guidance of supervisors, academic colleagues and friends.

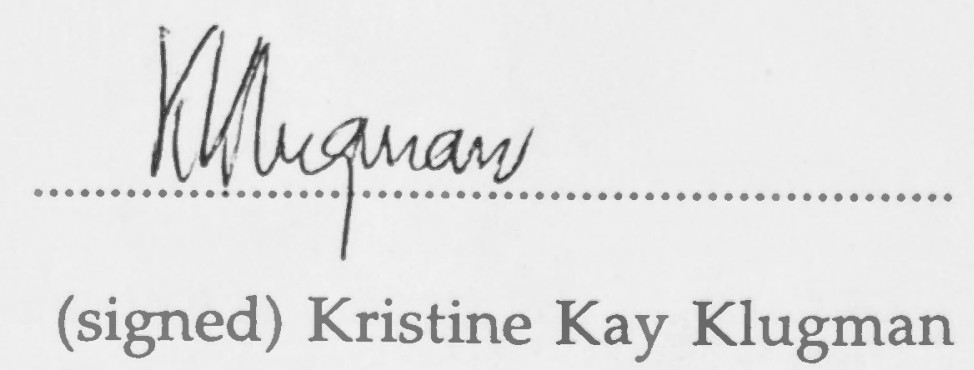

July, 1996 


\section{Acknowledgements:}

I acknowledge and am appreciative of the guidance of supervisor David Adams and panel Don Lamberton, John Warhurst and Scott Bennett; the resources of Members of Parliament Jim Snow, John Langmore and Barry Jones; advice from academics Clive Bean and Malcolm Mackerras and computer consultants Norm Braidwood and Graeme Hamilton; the responsiveness of people interviewed (sourced in the text) and many others who gave of their time and expertise: Kay Sweeney; daughter Julie and Gabrielle Castree; my patient family and, most particularly, the advice and loving support of partner Bill Rowlings, without whom the thesis would not have happened. 


\begin{abstract}
The focus of this thesis is on the political aspects of the changes in Communication Technologies (CTs). Are the new CTs being used to entrench communication power in the politician and political parties or are they helping to make Australia a more democratic country?

This thesis investigates both sides of a political coin with reference to the new CTs: the marketing of politics through sophisticated use of CTs in campaigning, and the examples of increased citizen participation through 'teledemocracy' type projects.
\end{abstract}

The thesis attempts to address the basic question by:

- surveying voters, Parliamentarians, their staff and others in relation to direct mail and the marketing of politics;

- analysing relevant commentaries directly and indirectly related to these processes;

- reviewing trends in the United States and locally in projects aimed at enhancing people's participation and the democratic process; and, finally,

- $\quad$ proposing ways of shaping and organising community discussion in relation to the evolving technologies to produce the best-possible outcomes for the future political communication environment.

Uncertainty surrounds the task because there are no definitive answers: but the underlying premise is that, in a democracy, leadership by government can ensure that the increasing use of CTs does not make the information rich/poor dichotomy more asymmetrical. 


\section{Contents}

Acknowledgements

Abstract

List of Tables

vi

List of Figures

vii

Acronyms, etc

viii

Chapter 1

Political communication in a democracy

Chapter 2

Consequences and Studies of

Communication Technologies

Chapter 3

Surveying the impact of direct mail

Chapter 4

Interest groups and Communication

Technologies

Chapter 5

The impact of Communication

Technologies on campaigning

Chapter 6

The experience of Communication

Technologies in the United States

Chapter 7

What Communication Technologies

mean for Australian participation

Chapter 8

Advance Australia Where?

Bibliography

Appendix

a Methodology Fremantle survey

b Interest groups interviewed

c Tables of electorate staff perceptions

d Analysis of 1993 Federal election results re the MPs interviewed

Confidential section

Sealed attachment for examiners only

at rear 


\section{List of Tables:}

1.01 The Media

2.01 Generic Properties of the New Media

Fremantle survey:

3.01 Attitude to letters from candidates 89

3.02 Attitude to direct mail by party identification 89

3.03 Attitude to letter by strength of party identification 90

3.04 Attitude to letter by employment 91

3.05 Read letters by party 92

3.06 Read letters by strength of party identification 92

3.07 Why letters not read 93

3.08 Main message recall by party identification 94

3.09 Opinion of messages 94

3.10 Amount of information by party identification 95

3.11 Opinion of lists by strength of party identification 96

3.12 Attitude to letters by party/floating identification 97

3.13 Why letters not read by party/floater 97

3.14 Main message by party/floater 98

3.15 Opinion of message by party/floater 98

3.16 Floater attitude to letters by their qualifications 99

3.17 Comparing surveys for amount of information 102

ALP surveys:

3.18 Confidential at rear

3.19 Confidential at rear

3.20 Confidential at rear

3.21 Confidential at rear

Interest Groups:

4.01 CTs use by interest groups - Nos. items of equipment 138

4.02 Weighted ranking of CTs by interest groups 139 


\section{List of Figures:}

5.01 Use of various communication methods (outgoing) by 178 electorate offices and rating by staff of relative importance

5.02 Pattern of use of various communication methods by constituents as reported by electorate office staff (incoming)

5.03 Frequency rating of various communication methods (outgoing)

5.04 Frequency rating of various communication methods (incoming from constituents)

5.05 Electorate office rating of communication methods (outgoing)

5.06 Constituent use of communication methods, rated by electorate office staff (incoming) 
List of acronyms, etc:

\begin{tabular}{|c|c|}
\hline AARNet & Australian Academic and Research Network \\
\hline $\mathrm{ABC}$ & Australian Broadcasting Corporation \\
\hline $\mathrm{ABC}$ & (News Poll) American Broadcasting Companies Inc. survey \\
\hline $\mathrm{ABN}$ & Australian Biographical Network \\
\hline ABS & Australian Bureau of Statistics \\
\hline ACS & Australian Computer Society \\
\hline ACT & Australian Capital Territory (ie, a 'state' of Australia) \\
\hline ACTEIN & $\begin{array}{l}\text { Australian Capital Territory Education Information } \\
\text { Network }\end{array}$ \\
\hline ACTU & Australian Council of Trade Unions \\
\hline AEC & Australian Electoral Commission \\
\hline AES & Australian Election Study \\
\hline ACF & Australian Conservation Foundation \\
\hline ACM & Australian Chamber of Manufactures, a peak industry body \\
\hline AGPS & Australian Government Publishing Service \\
\hline ALIA & Australian Library and Information Association \\
\hline ALCT & Americans to Limit Congressional Terms \\
\hline ALP & Australian Labor Party \\
\hline ANOP & Australian National Opinion Polls organisation \\
\hline ANU & Australian National University, Canberra \\
\hline APA & Australian Physiotherapists Association \\
\hline ARC & Australian Research Council \\
\hline ARM & Australian Republican Movement \\
\hline ASTEC & Australian Science and Technology Council \\
\hline $\operatorname{ATM}(s)$ & Automatic Teller Machine(s) \\
\hline ATUG & Australian Telecommunications Users Group \\
\hline AUSTEL & Australian Telecommunications Authority \\
\hline AV & Australian Vice Chancellors' Committee \\
\hline BCA & Business Council of Australia \\
\hline BEV & Blacksburg Electronic Village \\
\hline BSEG & Broadband Services Expert Group \\
\hline BTCE & Bureau of Transport and Communication Economics \\
\hline Budget & The annual Australian Government statement of accounts \\
\hline $\mathrm{Cab}$ & $\begin{array}{l}\text { executive group of the most senior Australian } \\
\text { Government Ministers }\end{array}$ \\
\hline $\mathrm{CAB}(\mathrm{s})$ & Citizens Advice Bureau(s) \\
\hline CATI & Computer Assisted Telephone Interviews \\
\hline CCL & Council for Civil Liberties \\
\hline CEG & Civics Expert Group \\
\hline $\mathrm{CEO}(\mathrm{s})$ & Chief Executive Officer(s) \\
\hline CFA & Consumers Federation of Australia \\
\hline $\mathrm{CIN}$ & Community Information Network \\
\hline $\mathrm{CIR}$ & Citizens Initiated Referendum \\
\hline CD-ROM & Compact Disk - Read Only Memory \\
\hline CFA & Consumers' Federation of Australia \\
\hline CMC & Computer-Mediated Communication \\
\hline Coalition & The Australian Liberal Party and National Party combined \\
\hline & Casualties of Telecom (q.v.), a disaffected customer group \\
\hline & $\begin{array}{l}\text { Cable-Satellite Public Affairs Network } \\
\text { Commonwealth Scientific and Inductrial Reconmo }\end{array}$ \\
\hline & $\begin{array}{l}\text { Commonwealth Scientific and Industrial Research } \\
\text { Organisation }\end{array}$ \\
\hline $\mathrm{CT}(\mathrm{s}$ & Communication Technology(ies) \\
\hline
\end{tabular}


Cyber- Notionally a mystic, non-physical world in which electronic space messages exist/travel: hence Cyberterrorists, etc
DAS Department of Administrative Services (Australia)
DC District of Columbia (US)
Democrats Australian Democrats: third, numerically, political party in
DM Direct Mail
DSS Department of Social Security, Australia

$\begin{array}{ll}\text { EARC } & \begin{array}{l}\text { Electoral and Administrative Review Commission } \\ \text { (Queensland) }\end{array} \\ \text { EDI } & \begin{array}{l}\text { Electronic Data Interchange } \\ \text { Australian national education computer network }\end{array} \\ \text { EdNA } & \text { Extended Parliamentary Network } \\ \text { EPN } & \text { Electronic Funds Transfer at Point of Sale } \\ \text { EFTPOS } & \text { Electronic Town Meeting(s) } \\ \text { ETM(s) } & \text { Foundation, a (Labor, q.v.) think-tank } \\ \text { Evatt } & \text { External Access to the Parliamentary DataBase Services }\end{array}$

FAX Transmission of data by facsimile, or 'telefax', means

Faxstream Commercial Telstra (q.v.) method of sending multiple faxes

Feedback Liberal Party data base

Fightback! Political manifesto of the Liberal Party for the 1993 election

Floater(s) floating (or swinging) voter(s)

FPS Forest Protection Society (Australia)
GDP Gross Domestic Product
GEF Global Environmental Facility
GMMB\&A Greer, Margolis, Mitchell, Burns and Associates
'green'
Greens
generic description of environment-oriented groups
GST Goods and Services Tax
Hansard Formal transcript of Australia's parliamentary debates
HFC Hybrid Fibre-Copper
H\&K Hill and Knowlton

ID (political party) Identification

Internet Worldwide electronic data base and information exchange

ISDN Integrated Services Digital Network in telecommunications

IT Information Technology

JSCEM Joint Standing Committee on Electoral Matters (Australia)
Labor Australian Labor Party
Lib Liberal Party
LIVENET Video conferencing project for a remote (the Pilbara) region of Western Australia
m million
MDS Multipoint Distribution Services for sending TV signals
Medicare Australia's system of universal medical/hospital benefits
MHR Member of the (Australian) House of Representatives
MP/MPs Member of Parliament/Members of Parliament 


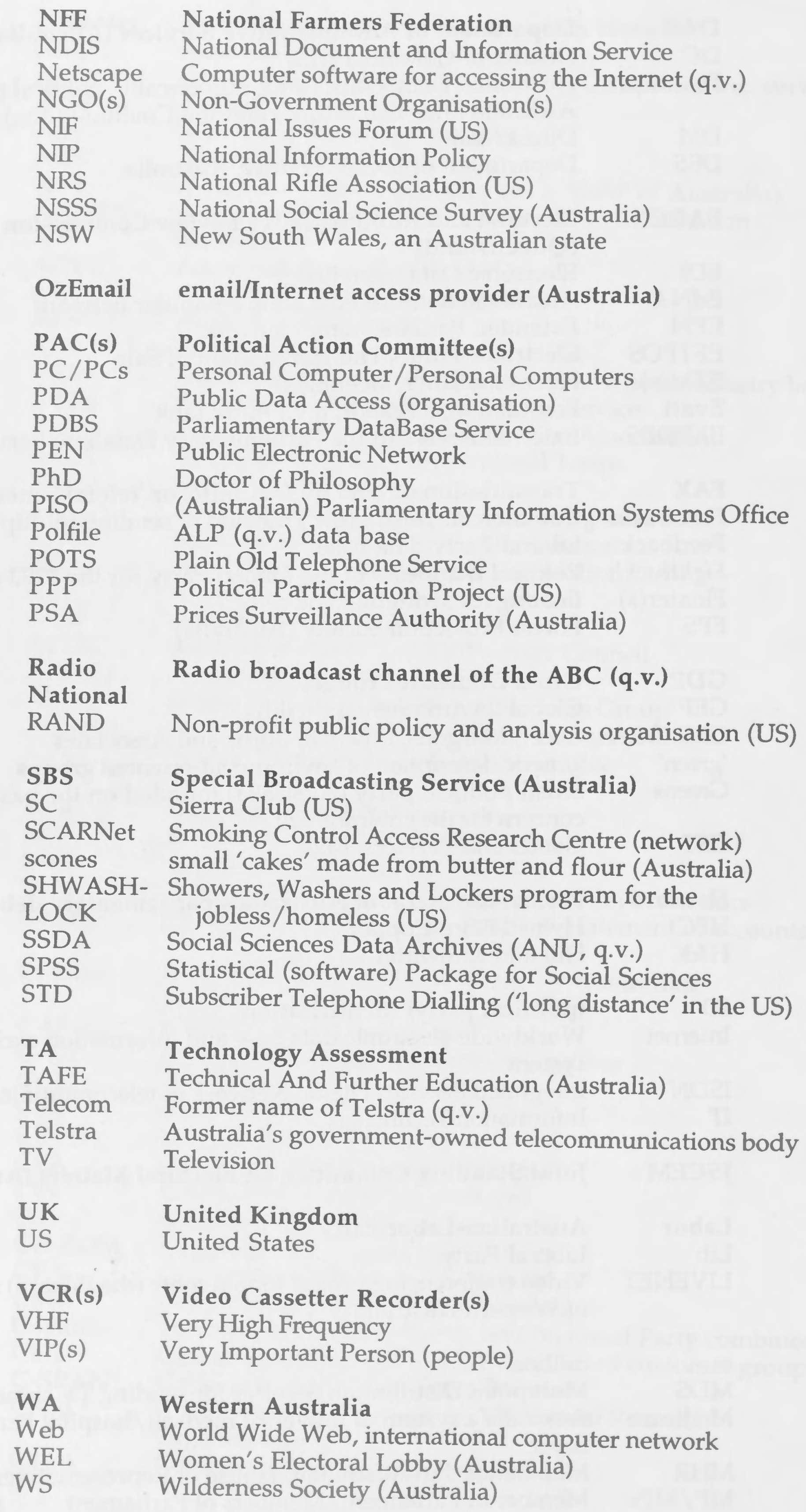


British television comedy series which parodies the 


\section{Political communication in}

\section{a democracy}

Liberal democracies have long recognised that access to adequate information and to a diversity of debate and representations is a basic precondition for the effective functioning of the democratic polity and the full exercise of citizenship rights (Murdock and Golding 1989, 183).

\section{Introduction}

This thesis adopts the premise that, in a democracy, information and communication are fundamental. To simplify the complex reality of the political communication processes, I will approach political information flows by asking:

- how politicians get the information they need;

- how politicians convey messages;

- how citizens gather information;

- how citizens participate; and

- the role of communication technologies (CTs) in this interaction.

Thus the focus of the discussion which follows is on the politician and the citizen but set in the broader context of other societal interests. To the individual citizen and the individual politician is added the interest groups, the party machines, and to a limited extent the bureaucracy and commercial business interests which make up the political environment. 
Analysing the five points above, it is self-evident firstly that citizens and politicians need information to make educated choices and secondly that each group needs to be able to communicate with the other. It is also apparent that the quality of this interchange decisively influences the quality of the democracy.

Politicians constantly need information for policy-making and to operate and survive in their political environment. To fulfil their representative responsibilities, politicians need to communicate with their constituents through all the strategic campaigning techniques as well as traditional methods of attending electorate and other functions, contact by telephone or letter, meetings with constituents in the electoral office and public meetings, and through the conventional media.

Additionally, citizens need information to make decisions on all manner of life matters. In the political arena up-to-date information is one of the factors people use to make voting judgements and to participate in the political process. However information of itself may be useless; information is necessary but not sufficient. To be of value to the citizen information should be affordable, accessible, relevant and comprehensible. Under these conditions, which obviously vary widely between individuals, voters in theory make considered choices between competing claims. In reality of course, voting behaviour is influenced by a whole plethora of factors (Kelley 1988, 73) of which information in this ideal sense is only one. The majority of people still in fact vote according to their party identification under most circumstances and campaigning information tends to reinforce their beliefs (see Fremantle survey of direct mail, chapter three). However an informed and reasonably involved populace is an essential element in concepts of democracy.

Citizens need to be able to communicate their needs and wants to politicians. The most formal way is by voting in which the people as a whole can dismiss a government which is judged to be unsatisfactory, incompetent or dishonest, and elect a new government which promises a better alternative. In fact a 
minority of voters in marginal seats usually determine whether the government changes. Citizens join groups to further or protect their economic or idealistic aims. These interest groups may achieve political influence which the individual citizen acting in isolation cannot muster. Even so, in contrast to the substantial business and government resources in CTs, the paucity of $\mathrm{CT}$ resources available to most interest groups means that CTs contribute little to enhancing their influence (see chapter four). Who benefits from CTs in the continual struggle for power and political influence, the problem of information inequalities and whether asymmetry is increased or decreased by CTs will be addressed in subsequent chapters.

The role of CTs in providing a means of information for and communication between politicians and citizens is becoming increasingly influential (eg computer networks, data bases for direct mail and for information gathering, electronic polling [Computer Assisted Telephone Interviews or CATI], email and video/teleconferencing). Further discussion of what constitutes the 'new' as opposed to the 'old' CTs appears shortly.

CTs enable politicians to quickly access information, such as that held on data bases, and project their message to vast numbers of people, especially via television and direct mail founded on data bases containing information on constituents. Though less commonly to date (end of 1995), citizens can gather information via data bases at work or from home computers and modems as well as through traditional libraries. Talk-back radio and letters to the editor provide people with the opportunity to express political opinions in more conventional ways. However public opinion polling using sophisticated technologies is influential in politicians' monitoring of public reaction to policies and popularity of leaders. By way of this two-way communication, at least in theory, people are aware of politicians' plans and actions and politicians are aware of what at least segments of people want.

In actuality, the political communication process is far more complicated than this mechanistic description suggests. It is important to ask other vital questions: what is the quality of the 
information flow; is true interactive communication taking place; is the communication comprehended by and relevant to the citizens; and are the citizens' views genuinely heeded by the Member of Parliament (MP)? There are many factors governing the use of information in political communication, and it cannot be assumed that because information exists, it is equally useful to all citizens. Factors such as economic cost, the ability of the individual to comprehend, the individual's time available, and the individual's interest and willingness to participate are powerful determinants on the quality of political communication. In fact, in the presence of information costs and uncertainty of outcomes, as Anthony Downs pointed out (Downs 1957), voters rely on information shortcuts in what has been termed lowinformation rationality (Popkin 1991, 212). Under this approach, the costs of information gathering result in reliance on peer opinion, past life experience and 'gut' feeling.

In a critique of the traditional assumptions which underlie the information/democracy relationship, Dervin (1994) argued that these concepts need redefining to incorporate the complexity of human communication processes involving the new technologies. She questioned, amongst other things, whether available information means accessible information (Dervin 1994, 369). While acknowledging Dervin's point that availability of information certainly does not ensure it will be accessible, the basic contention that information is essential to the proper functioning of democracy is maintained.

Demonstrating the link between information and democracy, a recent study concluded that 'Despite inherent limitations of statistical analyses, every analytic perspective of this study coherently and repeatedly emphasises that interconnectivity is a powerful predictor of democracy, more so than any of democracy's traditional correlates' [such as schooling or per capita GDP] (Kedzie 1995, 168). Here 'interconnectivity' referred to the way people could communicate and gain information electronically. The study found that the exchange of information through email is conducive to communication for individuals, for communities, and for the operation of democracy. The research team concluded 
that the United States (US) should support universal access to email through public policies (Anderson, Bikson, Law and Mitchell 1995, 169). Thus empirical studies have highlighted the importance of information (however gained) on the quality of democracy.

\section{Information and political communication}

As it is assumed that information is central to the operation of a democratic system, it is necessary to consider some ways of defining it. However, theorists from different disciplines have found this task is not simple. More than 40 academic fields have been identified that involve discussion of information and researchers concluded that understandings of the meaning of information varied so widely as to not have very much more in common than the term (Braman 1989, 233). However, accepting that defining information is complex, it may be more useful to rather adopt a definition of political communication. Most relevant is the Blackwell Encyclopedia of Political Science definition which gives an appropriate conception of the dynamic and purposeful nature of the process (though this definition also incorporates information):

The flow of messages and information that gives structure and meaning to the political process (Bogdanor ed. 1991, 442).

It is the influence of the new CTs on this flow of messages and information which is a core concern of this thesis, as well as the new CTs' impact on the political process, as the research questions (below) outline.

\section{Communication Technologies}

What I term communication technologies (CTs) has been called 'The Media' and differentiated into categories of New, Old, and Non-News media by American political scientists Jeffery B. 
Abramson, Christopher F. Arterton and Gary R. Orren. Their table serves as a useful way of describing the range of technologies which the new CTs embrace.

Table 1.01

The Media

$\begin{array}{ll}\text { New Media } & \text { Computers } \\ & \text { Satellites } \\ & \text { Cable Television } \\ & \text { Videocassette Recorders } \\ & \text { Direct Broadcast Satellite } \\ & \text { Multipoint Distribution Service } \\ & \text { Satellite Master Antennae Television } \\ & \text { Subscription Television } \\ & \text { Low-Power Television } \\ & \text { VHF Drop-in Television } \\ & \text { Videotext } \\ & \text { Lasers } \\ & \text { Fibre Optics }\end{array}$

Old Media

Broadcast Television

Radio

Newspapers

Magazines

Telephone

Telegraph

Non-News Media Direct Mail

Electronic Mail

Polling

Videoconferencing

Computer Conferencing

Teleconferencing

(adapted from Abramson, Arterton and Orren 1988, 5).

Some explanation is necessary here. I will include television in discussion of the impact of the 'new' CTs. The reason for this inclusion is that, although broadcast television is an 'old' technology, Australian Election Studies have shown it is the 
main source of political information for many citizens, in that 42 percent often followed election news on TV and 37 percent followed it sometimes (Social Science Data Archives 1990,1) so that it would be inappropriate not to include it. As pay TV is new in Australia and its widespread penetration is far from assured, the role played by broadcast television in political campaigning remains crucial.

An example of the continuing adaptation of technology is the screening of televised election debates monitored by a studio audience using the 'worm' electronic monitoring device (see chapter five on the 1993 federal election). In the same way, telephone adaptations have changed the POTS (plain old telephone service) into more sophisticated communication devices - fax, answering machines and mobiles - which have become an integral part not only of the campaign trail but of everyday commercial and personal life for an increasing number of people. From the functional viewpoint, the communication technologies included for purposes of this thesis are those providing:

- data access services (enabling people to get or exchange the information they need);

- human communication services (enabling people to communicate with each other); and

- software services (enabling people to be creative, such as computer-aided design).

Thus the holding of information in data bases - whether mailing lists for direct mail, library catalogues, news services or directories - is one large category of uses of technologies. For a relatively few 'computer literate' people these uses are available through their personal computers, modems and telephone lines. There is now access for private use through some public and specialist libraries, some community centres and peoples' place of employment for work-related information seeking. 
Human communication service technologies include the telephone and facsimile (fax), mobile phone, email, bulletin board and teleconferencing. The connection of optical fibre to the home for cable television offers the potential for interactive feedback by citizens to programs or, more relevant to this thesis, debates or voting procedures. Creative activities are possible through software applications, both for artistic and technical design purposes. The international network of networks, the Internet, provides access to both data bases and human communication services.

So the definition of what is meant by new CTs is complicated. Further the capabilities and capacities of the technologies are developing very rapidly so the definitional task will not become simpler. I use the term 'communication technologies' in preference to 'information technologies' because the former denotes more emphasis on the interactive nature of information flows underlying my premises.

Consideration of information flows in the political environment must be put in the context of the evolving information society which uses communication technologies. Perhaps the most significant innovation with which the advent of the computerised society can be compared is the invention of the printing press (Burke 1985, 112). In the same way, the evolution of the information society involves fundamental changes in social, political and economic environments. Indicators of the information economy are reflected in the number of jobs in information, in the prevalence of information technology equipment in the community and in the growth of the information industry. 'Video casette recorders are now in over 80 percent of Australian homes, personal computers in about 30 percent' (Broadband Services Expert Group [BSEG] 1994b, 3).

Politically, the new CTs have been increasingly used both in campaigning and in routine political communication. 'Traditional broadcast media and newspapers continue to dominate political communication, but candidates have learned that they ignore the new media arsenal only at their peril' 
(Abramson, Arterton and Orren 1988, xi). It has been noted that the ultimate impact has been predicted to be varied, even contradictory:

Different properties of the new media drive the electoral system towards different democratic ideals. The greater speed of the new media, which permits instant polls, instant referenda and instant voting, promotes an individualistic, plebiscitary brand of democracy. The new media's heightened potential to target messages to particular audiences strengthens pluralistic tendencies. Greater volume, interactivity and user control invite more informed and involved communitarian style of participation (Abramson, Arterton and Orren 1988, 119).

Thus, various uses of CTs are conducive to different approaches to democracy, discussed later in this chapter. However, the nature of political interaction is more complex than this quote suggests, and the impact may be mixed. By its nature, the rate of technological change makes any attempt to draw limits around the new CTs difficult. Not only do new aspects of technologies constantly emerge and evolve but the uses to which 'old' ones are put undergo adaptations. So the development of CTs can be seen to be continuing, the combined impact over time being significant.

Some of the properties characteristic of the new media which have been identified in the US are: their dramatic impact on the volume of information which can be exchanged; the increased control over messages by people receiving them; the ability of senders to target messages; the decentralising of control over mass communications; and the potential for interactive communication (Abramson, Arterton and Orren 1988, 5).

While some of these characteristics are apparent in Australia, it is necessary to differentiate the cultures of the two nations (see chapter six). 


\section{Technology Assessment}

Before considering in more detail the objectives of this study, it is necessary to place the revolution in CTs in the political process in the broader context of the challenge of the technological revolution in society in general. The issue was the subject of a seminal report in Australia in 1980 (the 'Myers' Report'). The impact of CTs on political interaction is a part of a wider need for society to adapt to an increasing rate of technological change and the problems and potential the change presents. As the Inquiry's chairman wrote:

In its consideration of the impact of technological change, the Committee has been mindful of the concern that has been expressed that the new technology could impose significant strains on the individual and on society generally (Committee of Inquiry into Technological Change in Australia 1980, 144).

The same types of concerns have been expressed with regard to the impact of CTs on the political process and the same optimistic/pessimistic predictions have been made of direct democracy or demagoguery (see chapter six). In the broader societal context, such concerns create the need for technology assessment (TA), defined as: '...a class of policy studies which systematically examine the effect on society which may occur when a technology is introduced, extended or modified. It emphasises those consequences which are unintended, indirect or delayed' (Porter, Rossini and Carpenter 1980, 5).

Careful examination of the introduction of the technology is an advantage. By identifying the likely impact and analysing its extent, TA is able (in theory) to provide decision-makers with policy options. The two key objectives are to explain the full set of interactions between the society and the technology and to provide advice which is relevant, timely, credible and communicated clearly. The question of balancing competing interests was highlighted by one commentator: 
Policies concerning science and technology once based on the assumption that technology equals progress now involve difficult social choices. Policy makers must establish appropriate research and development priorities while meeting conflicting demands from different social sectors. They must define acceptable levels of risk and weigh these risks against the benefit of new technologies in the face of diverse judgements about what constitutes a 'good society' (Nelkin 1977, 10).

The underlying assumption that technology necessarily will improve efficiency is based on a kind of technological determinism. This approach has its critics who claim, inter alia, that there is no evidence that technology per se can improve on human communication (Shulman, Penman and Sless 1990, 167). In reality, CTs affect both the opportunities for communication and the processes of communication. The availability of technology interacts with the social and political culture to produce a variety of outcomes. For this reason:

...it is necessary to study any new communication technology in and of itself, with an eye to discerning the qualities which may tilt the technology towards one form of politics over another (Abramson, Arterton and Orren 1988, 18).

TAs are carried out on the basis that it is clearly preferable to foresee possible problems and advantages before they occur and make the necessary adjustments rather than try to accommodate them after the fact. This assumption provides the rationale for this investigation, which constitutes a type of Technology Assessment.

\section{Advent and impact of Communication Technologies}

To demonstrate the importance of investigation of this topic it is necessary to outline briefly the enormous advances in CTs in the 
past 25 years and the way CTs have influenced every aspect of life, including politics. In the early 1970s, personal computers (PCs) were virtually non-existent. The following decade saw increasing numbers of PCs which progressively were linked to central macro-processors and to each other. Software tools have become much more 'user-friendly' and access to data bases through online searching or CD-ROM has vastly improved the speed and scope of information gathering. There has been an increase in the number of people connected to national and international networks to the extent that:

No longer was information technology just about computing qua computation; it was about communication as well...computers are a tool for conducting the network of conversations (Clarke and Worthington 1994, 29).

Developments in the 1990s have been mainly in the software area and there have been increases in collaborative work between individuals, both in academic and business work groups. On-line access capacities have improved from catalogues to full text and image storage and retrieval and search facilities to locate material have become more powerful.

The extent of the impact of the information age in Australia is evident in everyday life - from banks to supermarkets, from businesses to industry. People in general have adapted to and adopted the new technologies. An example is the way in which people take the use of Automatic Teller Machines (ATMs) and Electronic Funds Transfer at Point Of Sale (EFTPOS) for granted. The growth in EFTPOS terminals in operation was 25.3 percent and the number of transactions grew 62.2 percent in 1993 (Bureau of Transport and Communication Economics [BTCE] 1994b, 177). The ATM and EFTPOS growth has had repercussions for bank and building society business and has had a significant political impact on employment and industrial relations practices in the banking sector.

The use of fax machines and mobile phones has likewise increased substantially. There were 236,000 faxes in households in 
1992 and 301,000 in 1993 (BTCE 1994b, 133). Mobile phones in operation rose from 4,000 in 1987 (the year of their introduction to Australia) to an extraordinary 600,000 in 1993 . The total service revenue has risen from $\$ 2.9 \mathrm{~m}$ in 1987 to $\$ 692.9 \mathrm{~m}$ in 1993, an annual growth rate of 148.8 percent (BTCE 1994b, 128). Not surprisingly from these data, Australia is estimated to have one of the highest take-up rates of mobile phones in the world. The figures indicate the extensiveness of the influence of the new technologies in everyday life and their growing importance in economic terms. The prevalence of personal computers (PCs) provides another example. Expenditure on home computer equipment in Australia shows a huge increase. A wage and salary earner in 1984 spent on average $\$ 1.03$ per week on computers and in 1994, $\$ 6.92$ (BTCE 1994b, 42).

US surveys on PC ownership across socio-economic groups show that computers tend to be used in affluent, educated, white, urban households (Doctor 1991, 219). Australian figures also show professional people dominated in computer equipment expenditure (BTCE 1994b, 41). Interestingly, households with income in the second quintile had the biggest increase in spending - $\$ 1.47$ to $\$ 24.45$ while the lowest 20 percent income category spent more than the highest, $\$ 7.46$ compared to $\$ 4.48$, in 1994 (BTCE 1994b, 43) which may reflect the influence of computer games.

A major caveat must be placed on too great a reliance on these BTCE figures, however. As the computer market is so competitive, data on sales are regarded as commercial-inconfidence: therefore the BTCE 1993-4 figures were estimates from data provided by the Australian Bureau of Statistics (ABS) calculated as simple linear extrapolations based on growth between 1984 and 1988-9. Such calculations assume a uniform growth rate which is in truth not to be expected, given the volatile nature - and assumed exponential growth - of the computer market.

Other statistics on home ownership of personal computers (PCs) in Australia show that the penetration of PCs is second only to the 
US, indicating again that Australians are enthusiastic in their reaction to new technologies, with double the rate of the UK (Penn 1995, interview). The ABS in late 1994 collected data on household use of information technology and released it in early 1995 for the first time. Some of the main findings from their survey were:

- 23 percent of households frequently use a computer at home;

- 4.4 percent of households have a fax machine;

- $\quad 2.9$ percent of households have a CD-ROM;

- 20 percent of households have one or more desktop/PC; and

- 18 percent of households use a dedicated games machine regularly.

(ABS 1995, 1).

In households that used a computer frequently, the most common use was word processing. Training in computers had been undertaken by employees from the employer by 41 percent and by the same percentage of students at secondary schools (ABS $1995,1)$. The collection of these statistics is useful for planners and it is a little surprising that it has not been done earlier, in light of their commercial significance.

Some revealing statistics on the use of computers is contained, inadvertently, in a survey which examined mainly the sources of geoscientific information (Hill and Knowlton 1994, 9). The sector described as 'community interest' consistently demonstrated less familiarity with and use of on-line devices but wanted improved access to data. Significantly, across all the sectors questioned the issue of cost of the offered information rated of most concern followed by ease of use and confidentiality (H\&K 1994, 13). For schools, hardware availability and compatibility was a problem. 'Many schools, public, private and catholic, do not have any or appropriate terminals or Internet linkage' (H\&K 1994, 16). 
There is a commonly-held assumption that the impact of the new $\mathrm{CT}$ s has been a recent phenomenon, representing a quantum change for the functioning of society. A counter view attributed the reasons for the information society to the major economic and business upheavals of the past century. Applying steam power in the early 1800 s resulted in a dramatic rise in the speed, volume and complexity of industrial processes. To achieve the necessary control called for a corresponding growth in exploiting information in what James $R$. Beniger termed 'the control revolution'. More recent developments in such technologies as computers, telecommunications and microprocessors, he contended, do not represent a substantive change but a continuation of this control revolution (Beniger 1986, 426).

However, Beniger was writing a decade ago. The information revolution has occurred with enormous rapidity, as demonstrated by the explosion in the use of the Internet. Even bigger super computers have developed in the interim and email now enables correspondence between Australia and the US in a matter of seconds. There were no mobile phones in Australia in 1986, and improved global communications have had a profound impact on international trade in the past 10 years. The question of whether the impact of CTs results in a qualitative as well as a quantitative change is a matter of conjecture. However I will argue that the combined impact of the new CTs is sufficient to represent a substantial departure which has had and will continue to have a significant influence on political communication. I agree with the conclusion (written eight years ago) that:

...when all twenty-one volumes of the Academic American Encyclopedia can be stored on a single 4.7-inch optical disk: when fiber optics networks can transmit eight thousand telephone calls simultaneously; when communication becomes liberated from the constraints of space and time that have limited it from the beginning of recorded history - then quantitative changes carry with them qualitative changes as well (Abramson, Arterton and Orren 1988, 9-10). 
This brief outline summarises the pervasive use of CTs by different segments of the community and sets the scene for the investigation which follows. The penetration and types of users of CTs have implications for the ability of citizens to take advantage of CTs to participate in deliberation in the political process.

\section{Communication Technologies - the modern dilemmas}

The promise and the problems of the impact of CTs on the political process presents certain dilemmas. The first is whether a political party in determining policies follows public opinion as reflected in the polls, rather than formulating a philosophy and adhering to a set of objectives and consequent policy directions. In regard to strategies, as opposed to policies, it is clear that '...the campaign strategies of the parties are often determined by what their "private" public opinion polls and the "public" public opinion polls tell about their competitive situation...' (Warhurst 1991, 126). Should polls determine policies also? On the one hand, it could be argued that polls most truly reflect the wishes of the constituency and the concerns they identify should be paramount. On the other, public comprehension of complex issues can be brought into question. The issue relates to representation as against participation models of democracy which will be discussed later.

The second question - or dilemma - is whether the commercial marketing of politics and the promotion of both candidates and policies like pet food is beneficial to what Thomas E. Cronin has called 'sensible democracy' which he identified as a model incorporating values of both representative and popular democracies (Cronin 1989, 249). As in the commercial world, acceptability of the political 'product' (candidate or message) is thoroughly market researched and the optimum formulae devised. It is argued by the professional strategists that, in a society pervaded by images through the electronic media, the presentation of the political message in simplistic terms is necessary to grab the attention of the generally uninterested voter 
(see interviews with Textor and Kerrisk, chapter three). The question to be asked is whether marketing the candidate is conducive or detrimental to thoughtful deliberation and debate of complex issues.

The third important question is whether the cost of the new CTs will have the effect of further exacerbating the information rich/poor dichotomy or will on balance empower people. If access to information equates to access to power, then any tendency which limits access would result in a problem for democratic functioning. The further question is whether increased citizen participation, made possible by CTs through instant plebiscites, is desirable and, if not, what form teledemocracy should take. These questions are addressed in chapter six.

Another dilemma is presented in the cost of electronic advertising which, though judged by party organisers to be very effective, can consign parties to debt (Warhurst 1991, 131-2) and also exacerbate imbalance in exposure between the major parties and minor parties. It has been argued that expense caused by use of the electronic media could lead to the danger of corrupt practices (Warhurst 1991, 133). Finally, and in contrast to the ideal of accessible information in a democracy, the possibility of information overload, in which electors and politicians retreat into isolation to avoid the 'blizzards of information', presents another dilemma.

These are important questions to ask for several reasons. The widespread debate and concern since the 1960s regarding the effects of technology on democracy has become more intense in the 1990s. The number of books and their passionate tone reveal deepening worries over the direction of democratic practices, with references to money and influence and the dominance of political strategists (see for example Dionne 1991, Jamieson 1992, and Mathews 1994, chapter six). Both aspects are partly the consequences of the ubiquitous and costly CTs. In addition, because the rate of technological change is increasing, the subject is imbued with a greater sense of urgency. Possible answers to the ways technology can enhance rather than impoverish democracy 
need to be investigated sooner rather than later, before the momentum of the new CTs rules out guiding their use along a course more conducive to empowering rather than disenfranchising citizens.

For Australia, the questions are important because of the example of some deleterious effects of marketing politics in the US. The US also demonstrates the potential for constructive use of CTs to involve people in discussion (see chapter six). Stephen Mills argues that the 'new machine men' assume that voters are susceptible to emotional appeal:

Market research plumbs the depth of voters' fears, perceptions and enthusiasms; television, a more emotional medium than cold, hard print, perfectly projects a personality-oriented, value-laden style of campaigning (Mills 1986, 9).

The implications of the marketing of politics and the extent of the power of the new CTs to mislead are of great importance to operation of the democratic process.

\section{The objective of this study}

This thesis aims to describe and analyse the differential impacts CTs are having on communication flows in the political process for the purpose of evaluating the effect of the marketing politics and of exploring ways in which CTs could assist political participation by citizens.

The thesis makes particular reference to MPs and their constituents as individuals or members of interest groups. CTs have enabled the direct marketing of politics, akin to commercial practice, increasingly involving professionals in public relations, advertising, polling and strategic planning. CTs also have the potential to empower citizens to gain more political influence. The balance of these influences is of interest in this thesis, which draws some conclusions on the implications of these differing 
impulses of CTs for the Australian system of representative government. More broadly the thesis attempts to give definition to the longer-term impact of CTs on Australian parliamentary democracy and to discuss ways in which CTs could be used to reduce the prevailing atmosphere of cynicism towards and ignorance of things political (see Civics Expert Group's commissioned public opinion survey 1994, chapter seven).

The recurring themes of this thesis are representation and participation; equity in access to and use of CTs in terms of information as a public good; and the associated problems and positive potential of CTs in these areas. The link between the themes lies in attempts to exercise influence. MPs do so through their parties' attempt to gain votes by use of CTs in strategic, continuous campaigning which peaks before an election. Citizens' attempts to influence the political process through individual efforts or by participating in interest group activity are for the most part haphazard and relatively disorganised. Thus asymmetry exists between MPs and citizens in the relative power and influence which to date appears to have been exacerbated by the availability and use of CTs. This thesis aims to examine the potential of CTs to help citizens redress the balance to some extent.

The thesis addresses two common assertions. The first is that 'direct mail works!'. These words, written by the (then) ALP assistant national secretary (and repeated at interview), epitomise a basic belief in the efficacy of this method of political communication, which operates from a data base of names of electors. The proponents of direct mail, as the essence of direct marketing, assume that it is an effective method of communicating with electors, revealing a belief that application of this new technology gains votes. This assertion is tested in one circumstance of a by-election and seriously questioned on the basis of the findings.

The second assertion, stated simplistically, is that 'technology can save democracy' - the essence of a significant debate in the US, with its origins in teledemocracy projects. 'The capabilities of the 
new technology can be used to strengthen civic education, guarantee equal access to information and tie individuals and institutions into networks that will make real participatory discussion and debate possible across great distances' (Barber 1984, 274).

Proponents and opponents hold equally fervent views, based on the Madison versus Jefferson philosophical approaches - whether people will act in basic self interest or can be trusted to make decisions for the greater good (Cronin 1989, 18, 40). Further, the assumption that CTs can be used to increase political participation is tested by examination of US projects and analysis of the embryonic moves in Australia to involve people through technology.

As described at the beginning of this chapter, the approach of the study incorporates a stylised version of information flows, involving the information seeking of both politicians and citizens and messages exchanged. The function of CTs in facilitating or detracting from the interaction represents the new dimension in the equation. The research questions look at how MPs get the message across and how citizens participate; and considers the role of CTs in this interaction.

\section{Research questions:}

What is the influence of CTs on elected representatives' communication with citizens? The first assertion of the efficacy of marketing of politics relates to this research question.

What is the influence of CTs on citizens' participation in the democratic process? The second assertion, which looks to CTs to solve the problems, relates to this research question. 
This thesis argues that, by identifying the positive and negative aspects of the impacts of CTs in terms of campaigning and on participating, it is possible to better grasp the elements which influence outcomes. Direct mail, which uses a data base of information to target voters, has been chosen for empirical study of the use of CTs in political campaigning. While not particularly high technology, it is more suitable for investigation than are other examples of CTs as it involves interaction by MPs with the electorate, which is the essence of the thesis. The use of other CTs in campaigning in the 1993 election is examined in chapter five by describing the use of marketing strategies and by interviews with key party strategists. The non-election use of CTs in electorate offices is surveyed and analysed. The method of investigation is by:

- considering briefly the implications of CTs in political interaction and looking to studies conducted on political communication of MPs and citizens and the media role in this interaction;

- surveying attitudes of electors to direct mail and reviewing other political surveys, interviewing key officials and MPs of the major political parties and analysing and comparing their expectations of direct mail;

- investigating the use of CTs by interest groups;

- reviewing the use of CTs in the 1993 Federal election campaign, analysing electoral success in relation to the use or non-use of direct mail and surveying the use of CTs in electoral offices in a non-election period;

- reporting on the current situation in the US particularly in terms of both the perceived failure of the democratic system and initiatives to respond to this challenge by increasing participation through CTs;

- reviewing current projects in regard to political use of CTs in Australia; and 
- answering the research questions and drawing conclusions.

Chapters one and two set the parameters; chapters three, four and five present the original empirical data and analysis of the thesis; chapters six and seven compare and contrast the US and Australian experiences; and chapter eight answers the research questions and outlines possible policy options.

The study encompasses the major parties in Australia, the Australian Labor Party (Labor) and the Liberal and National Parties (in Coalition). For the purpose of this thesis the minor parties are less important in their use of CTs, mainly because cost rules out widespread use by these groups (though this in itself may be important). The focus is on the federal parliament though many of the observations apply to state parliaments and local government authorities also in a less pronounced way.

The 1994 Fremantle by-election was chosen for the direct mail survey because it was current during the research phase. Though a fairly safe Labor seat, the Fremantle by-election engendered added interest through the high profile Labor candidate (a former state Premier and a woman) in the context of the federal Labor government's particular unpopularity in Western Australia over the Mabo Aboriginal Lands Rights issue and financial scandals associated with the state Labor government. The 1993 federal election was the most recent general election at the time of researching and the use of CT-assisted strategies by the major parties illustrates modern campaigning methods. US examples are used to examine issues as they illustrate both the advantages and disadvantages of the more widespread application of new CTs in the political process.

This chapter is structured to introduce the definitional parameters, comes to focus here on the research issues, then broadens to put the discussion in terms of relationship with participatory theory. The tone of many of the quotes is influenced by their origin, being often current newspaper and journal articles, because these are in many cases the most relevant 
sources in the quickly-changing democracy/CTs debate. In addition, in the case of volumes, the authors are often ardent about the issues and tend to express them in polemical terms. While one volume from 1835 is quoted, mostly only volumes from 1990-1991 onwards are particularly relevant. Future researchers will quote emails and web sites as a matter of course. With regard to the interviews with MPs and interest groups, and comments by electorate staff, the responses are reported verbatim to give an accurate appreciation of their opinions.

Understanding the political environment has been facilitated by my practical experience in politics: as an endorsed candidate for one of the two main parties, state policy committee chair, delegate to councils and conferences and the wife of a federal MP for more than 20 years.

Finally, the approach is interdisciplinary. As politics and communication technology interplay are central, so considerations of economics, sociology, psychology and communication studies are relevant. Analysing the cross-sectoral impacts can lead to understanding the current reality and future opportunity. This diversity is a strength in attempting to describe and evaluate such a rapidly-developing arena.

\section{Theories of representation and participation}

...democracy is best understood as an implied condition and natural consequence of philosophical and political pluralism (Keane 1991, 535).

Having considered the broad parameters of the advent of CTs in political communication, it is relevant to look to how this relates to theories of representation and participation. The notion introduced earlier that political participation in a democracy requires an informed citizenry with access to information is challenged by a paradox: at a time of unprecedented availability of new CTs, which theoretically makes access to information quicker 
and easier, it appears that citizens are feeling increasingly alienated from the political process (see chapter seven).

With the advances in CTs, obtaining and analysing information provides the potential to extend individual capacities. However, 'Technology is necessary but it is not enough' (Shubik 1971, 364). Citizens need to be able to take advantage of the opportunities CTs offer, and (as has been pointed out) have the necessary time, money, interest and ability. Citizens are not equally capable, and significant imbalance exists between people in being able to take advantage of the potential advantages offered by CTs.

As the whole concept of participation in representative democracy and the potential for the new CTs to facilitate more involvement by citizens recurs as a theme throughout the thesis, it is discussed at some length here. In representative democracy voters choose substitutes to make decisions on their behalf. The theory behind participatory democracy is that more decisions should be made directly by the people themselves. To argue against participation, according to its advocates, is to express greater confidence in representatives and by implication a misgiving towards the capacities and interests of ordinary people.

The differences in approach at their core turn on whether the judgement of citizens can be expected, most of the time, to decide in the interests of the greater good (given the constraints outlined below).

Political representation is the essence of modern democratic systems. By contrast, in ancient Athens the general assembly consisted of 'all' citizens (ie, males over 21 years, excluding slaves, foreign residents and women) which met to discuss policy, legislate and choose implementors (Ranney 1971, 382). Such a gathering was possible because of the relatively small number of citizens involved and the free time available to them. Conventional wisdom holds that in modern industrial societies, which are more complex and demanding, the Athenian ideal of democracy is unworkable and thus representation is necessary. 
In fact the need for representation was observed 160 years ago by a British theorist:

In a large empire, direct participation even in counsel is impossible to the great body of the community. To meet in deliberation would be scarcely practicable, even with the most skilful arrangements, on account of the immense numbers to be assembled; it would likewise absorb that time and attention which the multitude must, in every country, bestow on providing the means of subsistence; and were these difficulties surmounted, such assemblies would be utterly incapable, from their magnitude, of legislating wisely for their own good. Everyone who has had anything to do with large collections of people, must be aware, that for cool and patient deliberation, such as ought to be given to public enactments, they are the most incompetent instruments that can be devised (Bailey 1835, 69-70).

It is appropriate to look at representation and participation because such considerations lie at the heart of the debates about direct versus representative democracy described in later chapters and are one of the themes of this thesis. There are five approaches to the fundamental role of the representative:

- a duty to the nation as a whole;

- a delegate of the majority of the constituents;

- a trustee acting in the interests of the electorate but not necessarily in accordance with the 'will' of the electorate;

- a position bound by the program of the party he or she represents; and

- a position determined by the faction of the party the MP belongs to.

(adapted from Klugman R. 1993, 73).

In fact most MPs fill all the above roles at different times. The political opinions of elected representatives are influenced by 
their life experiences, by the opinions of their electors and by their party's expectations. Further it is recognised that there are some matters which are beyond party politics, the so-called 'conscience' issues, on which the MP is entitled to follow his or her own beliefs, such as the issue of abortion.

Research has shown wide discrepancies between the views of candidates and voters on a range of social issues (the death penalty, taxes to reduce poverty, and censorship), the candidates being far more liberal in their attitudes than the voters (Social Science Data Archives 1993). While candidates for election represent an elite and surveys have shown that elite attitudes differ from the general population (Bean 1995, interview), such variations have implications for direct democracy.

The responsibilities of the MP was summarised by Edmund Burke in his famous speech to the electors of Bristol in 1774:

It ought to be the happiness and glory of a representative to live in the strictest union, the closest correspondence, and the most unreserved communication with his constituents. Their wishes ought to have great weight with him; their opinions huge respect; their business unremitting attention...[but]...Your representative owes you, not his industry alone, but his judgement; and he betrays instead of serving you if he sacrifices it to your opinion (Bogart 1972, 47).

In fact, the role alters with the circumstance: 'The representative is, typically, both special pleader and judge, an agent for his locality as well as a governor of the nation. His duty is to pursue both local and national interest, the one because he is representative, the other because his job as representative is governing the nation. That dual task is difficult, but it is neither practically nor theoretically impossible' (Pitkin 1967, 218).

With regard to citizen participation, it is ironic that when the idea of increased participation was growing in popularity with some sections of the community towards the end of the 1960s, it held 
minimal importance in the theorising of political scientists who stressed the dangers of widespread participation. These people were aware of the rise of popular fascist movements in Europe and empirical studies which showed the lower socio-economic classes were both authoritarian in temperament and anti-political in inclination (Pateman 1970, 3).

Another factor influencing the rejection of early theories which valued participation was that such theories were normative in contrast to modern, 'value-free' theories. In an influential book, Joseph A. Schumpeter had pointed to the need to revise classical theory. He postulated that democracy is a method, not a distinctive ideal, which operates under particular social conditions and he offered a definition of the democratic method as 'That institutional arrangement for arriving at political decisions in which individuals acquire the power to decide by means of a competitive struggle for the people's vote' (Schumpeter 1943, 269). He transposed an economic model to politics, comparing voters to consumers choosing between political 'products' offered by competing political parties. In this aspect, he foreshadowed the position adopted by the public choice theorists' interpretation of the political processes. His analyses influenced later political scientists who agreed that early classical theorists' belief in the desirability of widespread participation was in error. These theorists adopted what Carol Pateman called the 'contemporary theory of democracy' - in which 'democracy' refers to a set of institutional arrangements at a national level involving the competition of leaders (elites) for the votes of people at periodic free elections (Pateman 1970, 14).

The 'contemporary' theory incorporates the notion of pressure on leaders by interest groups with equal opportunity to persuade and contends that participation lies solely in the choice of leaders. 'As Bachrach has noted, such a model of democracy can be seen as one where the majority (non-elites) gain maximum output (policy decisions) from leaders with minimal input (participation) on their part' (Pateman 1970, 14). However, Pateman stated that early theorists have been misinterpreted. Rejecting the conventional 
political theorists' current wisdom, and citing her own research investigations, Pateman stated:

...we have seen that the evidence supports the arguments of Rousseau, Mill and Cole that we do learn to participate by participating and that feelings of political efficacy are more likely to be developed in a participatory environment (Pateman 1970, 105) (emphasis added).

She concluded that the ideal of a participatory society had become lost from consideration by contemporary democratic theorists: '...neither the demands for more participation, nor the theory of participatory democracy itself, are based, as is so frequently claimed, on dangerous illusions or on outmoded and unrealistic theoretical foundation. We can still have a modern, viable theory of democracy which retains the notion of participation at heart' (Pateman 1970,111). She was writing when the subsequent reach of the new CTs throughout advanced nations of the world was unforeseen. Proponents of teledemocracy argue that, with the new CTs, the implementation of the participatory ideal becomes more practical (see chapter six).

One political scientist has noted that the popularity of the concept of participation in the early 1970s seems to have diminished under the influence of economic rationalist type approaches and the drive to improve efficiency. 'The delays, costs and risks of public participation, rather than its benefits as an end in itself or as a management strategy, seem to be the predominant considerations' (Painter 1992, 21). In a cyclical way, the renewed calls in the US from the early 1990s for increased citizen participation have coincided with increasing use of CTs in politics. Criticising the philosophy underpinning liberal democracy and the failure of representative democracy Benjamin Barber, one of the early proponents of direct participation through technology, asserted that only by taking a participatory form would democracy survive (Barber 1984, xiv).

In more recent theoretical writings general disagreement continues about the contribution of political participation to 
democratic stability (McAllister 1992, 72). An assumption of proponents of participation is that citizens will have the opportunity to participate equally and that this will assist democratic deliberation. The contrary argument is that too much participation by voters leads to political instability and therefore can be counter-productive. Thus it is concluded by these people that democracy is mostikely to thrive when there is a balance between citizens' preparedness to allow representatives to speak for them and their own direct participation (see Sowell below).

Continuing the 'contemporary theory of democracy' approach questioned by Pateman, another political analyst made the point that individuals who have the time, the education and the inclination to participate are very unrepresentative of the electorate at large. In a critical appraisal he stated: 'In practice, participatory democracy means that broadly elected representatives are to share power with self-appointed representatives of narrow vocal constituencies' (Sowell 1980, 121). He concluded that the voters' right to determine who the elected representatives are is replaced by non-elected individuals or groups who become influential in the policy-making process. While it is true that the majority of people are uninterested generally in participating, the evidence appears to be that most will get involved if the issues are sufficiently important to them (see survey findings in US study View From Main Street, chapter six). More recently, one theorist has identified three broad types of democracy and specifically linked them to different aspects of CTs.

- Competitive democracy is a concept based on recognition of merit, which incorporates competing interests to gain influence. The success of elites often depends upon their access to information through the new CTs. The citizens are passive consumers of messages from the powerful interests;

- Participatory democracy is a theory based on the assumption that all groups' claims should be fairly represented and that participation should be as broadly based as possible; and 
- Discourse or dialogue democracy theory asserts an expectation of citizens to debate issues, in which neither access to information nor voting alone is sufficient for successful democracy in the absence of citizen deliberation and discussion (Lievrouw 1994, 351).

Most importantly for this thesis, the three types are associated with different information/communication environments (as Abramson et al have identified). The competitive type is associated with mass communication which directs and controls information flows with minimal involvement by citizens in an environment where gatekeepers are the dominant influence. '...citizens have been encouraged to be receivers, to "consume" information as they would any other product' (Lievrouw 1994, 351). The participatory and discourse types involve interaction with the information and communication environment which can be facilitated by CTs, including by interactive television and the Internet. So the potential exists from informing to involving citizens in the information environment. 'New technologies allow an unprecedented level of individual interaction and response, even to network television and radio programs, via telephone, electronic mail, fax, and other means' (Lievrouw 1995, 353). Political campaigning has used 'town meetings', email and bulletin boards, as well as direct satellite feeds to local television and radio stations.

The political implications of the 'informing' environment is towards stability and the maintenance of elites. Most information is distributed en masse to the public and individuals seeking alternate information sources must expend time, money and effort to secure it (Lievrouw 1995, 355). In contrast, the effect of the 'involving' information may tend towards change as new groups organise and share information, in contradiction to the prevailing mass media. However, it seems inevitable that the established interests will resist fundamental political and economic change:

In short, while the technical potential exists for a shift away from informative to discursive information resources, 
there are clear indications that the information/communications industry and policy interests are reluctant to let go of the economic advantages and structures of the mass media...The very information resources that might support a renewal of democratic participation are being organised, financed, and configured to resemble and 'deliver' the same kind of media 'products' as conventional mass media (Lievrouw 1995, 355-6) (emphasis in original).

While there are indications that CTs can be used constructively to promote political discussion, it is probable that the information rich/poor dichotomy may be exacerbated in the short term. Rising expectations will result in a demand for equity of information sources, which will become a social justice issue.

Another theorist has differentiated between teledemocracy and deliberative democracy (London 1995, 33-34). 'The rationale for teledemocracy is consistent with an approach to political theory variously termed "rational choice", "negative liberalism", or " the logic of collective action" by scholars. It is founded on a market place conception of the political world in which interests conflict and compete. By contrast, deliberative democracy is rooted in the ideal of self-governance in which political truths emerge...from reasoned discussion about issues involving the common good. In the academic literature, this model falls under the rubric of "collective rationality", "unitary democracy" or simply "deliberative democracy"'(London 1995, 33-34).

Scott London argued philosophers throughout the ages have stressed the importance of public discourse, but that the new CTs have radically changed the nature of public discourse, and that this has accompanied '...a persuasive discontent with the current state of American politics' (London 1995, 36). London identified the arguments of the advocates of teledemocracy as: fostering participation, linking citizens across time and space, linking citizens to government, lobbying, providing information and educating (London 1995, 38). 
Critics of teledemocracy point to the potential risks, of which London identified a number of major concerns - amongst which were that plebiscitary devices leave no time for reasoned debate, that technology atomises people, consultation is time-consuming for representatives, people do not wish to be engaged in policymaking, the issues are too complex, most experiments in teledemocracy have had low levels of participation, electronic discourse is based on survival of the wittiest, and finally that the costs are prohibitively high (London 1995, 38-40). He concluded that 'The two models differ not only in their democratic orientation but also in their basic approach to political talk' (47).

However, I believe that London misses the point. He confines electronic democracy to plebiscites, whereas some researchers have shown that CTs can promote deliberation and discussion prior to a vote. This is discussed further in chapter seven.

At the heart of this debate is the question of participation and what the optimum level of participation should be. The answer may be to involve some of the people all of the time - preferably different people at different times. People participate in the widely-defined political process to influence decisions which affect their lives. Making a commitment in terms of time and effort to become involved tends to reinforce cohesion in the society (Putnam 1995). The new CTs have made direct, participatory politics possible with less time and less effort. Advocates like Benjamin Barber believed the new CTs can overcome the problems of time, size and distance which made representative democracy necessary. These issues and Citizen Initiated Referenda will be discussed further in chapter seven.

In summary, it is apparent that more recent theories of representation have sought to incorporate CTs and predict ways in which different technologies will have different influences on different styles of democracy. It is in the arena of discourse before the decision that CTs can play a valuable role. While the potential exists to enhance the discursive or communitarian style with increased citizen participation, the consensus is that in terms 
of political reality it is likely that powerful entrenched interests will maintain their dominant position.

\section{Barriers to participation}

Having discussed the various theories of participation in relation to CTs, it is relevant to consider factors which militate against citizen participation in the political process. In Australia, a significant factor is lack of proficiency in English - either to speak it or to read and write it. This disadvantage affects both people from non-English speaking backgrounds and people from English-speaking backgrounds who are functionally illiterate. These people are effectively excluded from involvement in political discourse, or at least from the written aspects of it (apart from the ethnic press). Extending this line of thought, it is probable that in 20 years lack of ability to use the new technologies - particularly computers - will be as great a barrier as inability to speak, read and write English is today.

Another effective barrier is cost, not only in terms of money but in available time to participate. Again with reference to the new CTs, cost of access is a major factor. An argument can be made that equity demands as much access to the new CTs as to all basic services - water, telephone, post or transport. Time available to participate is a factor in families with two parents working, and rural and remote families must make more effort than city dwellers in becoming politically active. The advantage of the new CTs to country people could be substantial. Ironically, it is country telephone exchanges which are often inadequate to deal with new demands, with the result that country people frequently cannot realise the advantages that new CTs should provide, even if they can afford a computer and modem. A summary of the factors influencing inequity of access to the information infrastructure has been presented as follows:

- corporate versus small business versus domestic use;

- the socio-economic level of individuals; 
- geographical region of use; and

- minorities (language and disabled people)

(Clarke and Worthington 1994, 15).

In line with computer ownership surveys (see earlier) it is clear that, in the absence of regulation to the contrary, the people advantaged will be the present information-rich and that, conversely, the present groups at a disadvantage (the poor, many rural people, some migrants and some people with disabilities) will become information-poorer. By identifying the areas of disadvantage, particularly with regard to new information networks, it is possible for policy makers to devise programs to overcome or minimise the disadvantage, given the political will.

\section{Conclusion}

The essential role played by information in a democracy is being highlighted by the increasing use of sophisticated CTs as questions of access and equity arise. The danger of increasing asymmetry and exacerbating the information rich/poor divide is highlighted with more urgency. From the political science viewpoint, critical examination of the impact of the new CTs on the information interchange between MPs and their constituents is an important issue to examine. What will the long-term effects be?

Some observers are worried, fearing the CTs' potentially adverse impact on society and political institutions, while others greet the increasing use of CTs with enthusiasm, seeing through them ways of solving the problems of modern democracies. Both cite examples to support their arguments. The following chapters describe, analyse and discuss both the problems and the promise of the new CTs in the functioning of a democracy. However, there is a major caveat to reliance on the new CTs to solve the problems of electors' cynicism and reduced citizen participation in the political process. The impassioned statement by Rudolf Klein is just as relevant now as it was more than 20 years ago: 
It is desperately important that complex problems should not be reduced to the simple symmetry required of systems analysis. That is, if anything, the final surrender to technology - to adjust our vision of our problems to the technical necessities of feeding them into a computer. For the inevitable result is to produce an equally simple answer, whose simplicity makes it unfit as a guide to action. To the extent that the complex interaction of economic, ecological, social and political factors make prediction hazardous, the best prophets are those who allow for uncertainty; who do not sell the future like a patent medicine but persuade mankind to make continual running adjustments to what, after all, is a continually changing future (Klein 1972, 44). 


\section{Consequences and studies of}

\section{Communication Technologies}

The fact of change is clear, the direction is not. As a democratic society, our choices are finite and few. We can move in the direction of laissez-faire policies; or we can take a proactive position, recognising that some directions of change are more desirable than others. We can try to shape policies that will move us towards a more equitable and democratic future (Doctor 1991, 218).

Technology and its societal context are inseparable. In the information age society is facing a revolution caused by rapid changes in computer, information and communication technologies which influence all aspects of life, the extent of which was outlined in chapter one. The increasing importance of the information sector in national economies is now widely accepted. The information sector grows as it services the information production, processing and distribution needs of other sectors as well as in its own right. Australia's information industry is a major exporter, earning more than $\$ 2.6$ billion a year (Cook 1995, 2).

The implications of the information-intensive society extend to the political realm. Following the approach outlined in chapter one, this chapter will consider the studies, the surveys, parliamentary committee reports, government enquiries and legislation concerning political communication, mainly in Australia. However, prior to these considerations, it is useful to consider some American political scientists' predictions of the consequences of what they term 'the new media' on campaigning. 
Table 2.01

Generic Properties

of the New Media

\section{Likely Consequences}

Volume

- an electorate that is less informed

Speed

- further advantage to incumbents

- risk of candidate mistakes increased

- fewer opportunities for debate

Receiver control

- smaller inadvertent audience

- greater attention to local politics

- less press control in campaigns

- less political information

Decentralisation

- declining influence of major networks

- election coverage less routine

- more national issues given local spin

- trend to focus on local candidates

Targeting

Interactivity

- increased attention to local politics

- increased use of television

- more effective advertising

- more power to consultants, declining influence of parties

- shrinking pool of com mon knowledge

- greater emphasis on ideological politics

- public opinion in group terms

- more overt opinion in news

- use of electronic plebiscite, instant referenda, voting from home

(adapted from Abramson, Arterton and Orren, 1988, 109).

While it is probable that some aspects may occur in Australia, many could be dissimilar in extent at least, such as the decline in party influence (while happening in Australia, the decline does not appear to be as pronounced). Although Australian political strategists have followed the US example of marketing politics, for the purposes of this thesis one of the foremost possible consequences is that of increased political participation involving 
deliberation and discussion through CTs (noted above as 'interactivity'). Other aspects of the above table warrant comment, and many will be covered in subsequent discussion. Some consequences are already apparent - such as more power to political consultants and further advantage to incumbents. Both these factors are related to increasing use of CTs in campaigning. To elaborate on a few of the points made above in the table of consequences, some aspects are examined further.

In terms of volume and speed, the new CTs have enabled much faster communication between Ministers, the bureaucracy and the media. There are both positive and negative implications of this increased speed. On the positive side it allows for wider consultation. Mobile phones and faxes in particular have become mandatory tools in the daily lives of Ministers (and many tradespeople). An expectation has grown that computing and communication facilities are available as a matter of course. The negative aspect may be that there is a danger of information overload and policy being made 'on the run' with pressure for instant answers allowing no time for consultation, deliberation and discussion. The impact of increased speed of communication on political decision-making depends on individual circumstances. Whether the speed of information transmission has assisted the quality of the decision-making process or has made only for faster administration is dependent on the competency of the personnel. In reality, while computerised information provides the data, the processes of political decision making are far more complex.

Receiver control may result in less political information if people choose not to tune in and are no longer an inadvertent audience. Allied to this, decentralisation may tend to fragment the community, with decreased national coverage of political issues. With regard to targeting, as the discussion on direct mail will show (chapter three), ideological politics have become more apparent in the US. The increasing trend to localise issues and give national issues a local relevance are other features of Australian campaigning. 
The issue of decentralisation/centralisation is an instance where the use of CTs can have contradictory effects. While the issues become localised, campaigning organising and strategic planning becomes more centralised.

The table devised by Abramson et al is focused on consequences for campaigning. Another fundamental concern voiced by critics of the influence of CTs in the political process are the issues of campaign costs and of privacy, which will be mentioned here.

Increasing campaign costs are a result of the new campaigning methods, including extensive use of polling and television advertising as well as direct mail. The result may be to limit the range of people who could consider standing for parliament. An account of campaign costs for the parties themselves is covered later. The costs can put the independent or minor party candidates at an even greater disadvantage than they traditionally have been, continuing to rely upon coverage by mass media and their individual local efforts to gain recognition and support.

Privacy issues have been brought to the forefront because of the new CTs. With the growth in complexity and capabilities of the modern CTs, the potential for invasion of privacy in the holding of personal information on data bases has become a matter for increasing debate. One of the key elements in a democratic society is privacy (Abramson, Arterton and Orren 1988, 19), which is linked inextricably with individual freedom. A prime objective of an undemocratic society is to control its citizens by keeping information on them about their activities. 'The capacities and features of these technologies have placed personal privacy at risk in ways previously unknown or unachievable' (Privacy Commissioner 1992, iii).

The question arises as to whether some of the methods used in the marketing of politics can intrude on personal privacy. One commentator has stressed the right not to be communicated with, citing the proliferation of junk mail (Young 1990, 21). Defenders of political direct mail contend that a data base is built up from public documents or by information contributed knowingly (a 
signature on a petition, a letter to the MP) and therefore does not constitute an invasion of privacy. Further, a 'valued goal' may be the opening up of channels of communication between citizens and their representatives. However, initiation of the dialogue is one-sided, without choice.

Changes to telecommunications with the introduction of competition have challenged the regulations and led to inquiries by the Australian Telecommunications Authority (AUSTEL) and a Senate Select Committee which covered, among other things, privacy issues. In an address to the Australian Telecommunications Users Group, the Privacy Commissioner reported that:

Over 90 percent of the people surveyed during research $m y$ office commissioned last year into public attitudes to privacy considered the confidentiality of personal information 'important' or 'quite important'. And 58 percent said that consumers have lost control over how their personal information is circulated and used by companies (O'Connor 1994, interview).

As a result of the convergence of telecommunications and computing technologies, privacy issues arise which transcend individual industries and state and national boundaries and which are not adequately protected by existing policies. The Privacy Commissioner advocated a national, co-ordinated approach to privacy protection issues to produce a policy '...that is clear, relevant, and able to encompass the new technologies as they arise. We have been getting by with a limited, piecemeal approach, but we can no longer do so' (O'Connor 1994, 3).

As mentioned, many of the other issues raised by Abramson et al will be covered in following chapters, particularly relating to marketing of politics and citizen participation. 


\section{US studies of information technology and democracy}

With the increasing rate of technological change, the issue of the beneficial or harmful impact on democracy is a matter of current debate. However, the questions are not new: the potential effects of technology on democracies have been discussed over many years. Some scholars have emphasised the potential advantages of the information age in political, economic and social conditions while some have regarded technology as dangerous and invasive, particularly of privacy. People from different perspectives agree however on the crucial importance of the impact of CTs on society.

An early and important study of the impact of information technology on a democracy was undertaken in the late 1960s by Alan F. Westin in collaboration with a group through the Harvard Program on Technology and Society. The resulting volumes revealed a broad range of approaches from different disciplines on US government use of information technology. Westin put the contributions in the context of the (then) recent history of adoption of technology. Between 1950 and 1970 the electronic age began to revolutionise the handling of information. These developments were interpreted in different ways. Optimists saw in the capacity of the computer the opportunity to solve society's problems, while pessimists expressed alarm, particularly at the threat to privacy posed by data banks and to democracy by technological elites (Westin 1971, 1-2). Science fiction novels and movies postulated a take-over by computer systems:

Commentary on technology and democracy during the 1960s mirrored almost exactly the transition of American social thought from the liberal confidence and optimism of the early Kennedy era to the deep political cleavages and national confrontations of 1968-70 (Westin 1971, 149).

As is the case in the mid 1990s, opinions on the ultimate benefit or disadvantage of technologies varied. There were three distinct 
groups involved in the debate in the early 1960s: the technically minded, who emphasised the benefits and potential of the electronic age (Robert O. Macbride, Harold Sackman); moderate intellectuals who analysed both positive and negative consequences (Emmanuel Mesthene); and the critics of technology (Lewis Mumford, Erich Fromm and Robert StrauszHupe), as described by Westin (Westin 1971, 150). Towards the end of the 1960s, reformist liberals such as Arthur Mendel criticised the 'technotronic determinism' assumptions of government and the New Left attacked technology as a tool used by the industrial-military complex to tighten control over powerless people (Westin 1971, 151). An analysis by Harold D. Lasswell of policy problems of a data-rich civilisation focused on the implications for world security, individuality (particularly privacy) and the functioning of democracy. Pointing to an inbuilt bias towards monopoly, regimentation and centralised electronic information, he concluded that 'Shared data means shared power; a monopoly on data means a monopoly on power' (Lasswell 1971, 197).

The debate on the ultimate impact of technology continues in the mid 1990s, though the level of interest has fluctuated in the intervening years. The differences between the 1970s and mid1990s can be illustrated in the table summarised earlier, which shows in general terms an increasing tendency to decentralisation and fragmentation, even atomisation, of the society. While the concerns expressed by Westin et al related to increased centralisation through the use of mainframe computers associated with increased political control, the concerns of the 1990s have been influenced by technological developments in a different way. More interactivity through the Internet has meant that people can 'hack' into confidential material in a way not possible 25 years ago, raising valid security concerns, as it is very difficult to prevent a determined and experienced hacker accessing confidential material. More information can be disseminated more rapidly, with the result that government regulation has been introduced by the US Senate in 1996 to control such material as child pornography by placing responsibility on the owners of the service (Braidwood 1996, 
interview). On the positive side, the interactive nature of the Internet has empowered those people with access, challenging centralised control by the state (see chapter six), the major preoccupation of Westin et al.

In regard to the impact of CTs on political communication and campaigning, US commentators have asserted that: 'Changes in the feasibility of sending and receiving political information have fundamentally changed the relationship between citizens and elected representatives' (Crain and Goff 1988, 1). Their viewing study indicated, for example, that televised legislatures had affected election outcomes by making it easier for voters to gather political information which influenced voting decisions and hence election outcomes. They found that the exact nature of the impact of legislative television on election outcomes depended upon the diversity of the constituency. Incumbents from homogeneous constituencies were advantaged by television and those from heterogeneous constituencies were disadvantaged (Crain and Goff 1988, 4), because it is simpler to 'script' a message to a homogeneous constituency. It would be interesting to see whether studies in Australia support the contention that televised legislatures can effect election outcomes.

\section{Surveys of the impact of CTs in Australia}

It is important to consider how many of the issues raised by Abramson et al have been studied in Australia. In view of the profound consequences envisaged by the American political scientists, it is apparent that, in fact, very few studies have been done, apart from some on MPs' information needs. A literature review demonstrates that research in Australia on MPs' needs for information clearly overshadows analysis of electors' needs for political information. In a parliamentary democracy, it is the interchange of information which is important, so that investigation of both aspects of the equation is necessary. To date, to my knowledge, there has been no substantial study in Australia of the use by voters of the new CTs to participate in parliamentary democracy. 
The review which follows considers the surveys, commentaries and studies done in Australia, by political scientists, academics from other disciplines, journalists, consultants and by government inquiries and reports. The very variety of people who have conducted some investigation into the impact of CTs on the political communication process indicates both the multidisciplinary and complex nature of the questions. The studies are categorised as outlined earlier: MPs, citizens and the news media. For MPs, investigation of ways of acquiring information and conveying the messages are considered: for citizens, the ways of acquiring information and participating: and for the media, the influence it holds and the challenge it faces from the new CTs. The imbalance apparent earlier in chapter one between elected representatives' and citizens' access to CTs is repeated in the studies that have been conducted.

As to CTs and campaigning, numerous studies have been conducted in the US on the impact of the new marketing strategies (which are based on the capacity of new CTs to deliver more targeted campaigning). Apart from Mills' book (The New Machine Men, mentioned under 'media' below) little has been written in Australia specifically on the new CTs in campaigning. It is surprising that no mention of the new campaigning strategies is made in journal articles on the 1993 Federal elections. A recent publication has been valuable in examining the role of the media in political communication (Ward 1995). Ian Ward examined such questions as distinctive features of the information society, equity issues of information rich/poor, whether the new media will benefit or damage democracy and the implications of the new media for mass media theory (Ward 1995, 278-280). In general, however, this appears to be a field that has been largely neglected by political scientists. It is this lack of research to date which gives more impetus to the empirical work which follows.

\section{Studies of MPs' information sources}

The most common and obvious source of information for MPs are television news and print media. MPs tend to be keen 
watchers of news and avid newspaper readers, both to monitor current events and as a way of preparing to project a message. For example, the then Leader of the Opposition, John Howard, had the nightly TV news broadcasts of all five free-to-air channels recorded for him each evening during the 1996 election campaign so he could watch the political coverage personally in his hotel room at the end of the day's campaigning commitments (Rowlings 1996, interview).

A number of studies to evaluate the performance of parliamentary libraries have been undertaken in recent years on the assumption that an effective library is of critical importance to the proper functioning of parliament. These studies are important because libraries have generally been early adopters of CTs and parliamentary libraries are a primary source of information for MPs. Three studies were carried out on the NSW parliamentary library, in 1975, 1987 and 1990. In 1988 the deputy librarian of the Commonwealth parliamentary library reviewed the Tasmanian parliamentary library and recommended development of a research capability. A further review of the support services available to Members of the Tasmanian parliament was made in February 1991 (Cornish 1991, 7).

A multi-disciplinary team from the (then entitled) University of New England Northern Rivers Campus, headed by Ed Parr, has conducted research on information needs of MPs. They undertook three studies: in 1986 commissioned by the Commonwealth parliamentary library; in 1990 commissioned by the NSW parliamentary library (as mentioned) and in 1991 another study for the Commonwealth library. These studies, which concentrated on assessing how well the information needs of parliamentarians were being met, included reference to the new CTs and will be described in some detail. The Information Marriage, a report to the Commonwealth parliamentary librarian produced in June 1986, was the first substantive report on 'how MPs get the information they need'. Its terms of reference were broadly to determine the information needs of legislative assistants 'noting the close relationship these will bear to the information needs of Senators and Members' (Parr and Ransome 
$1986,1)$. The single most important finding of this study was that '...the Library is pre-eminent among the information sources available to staffers' (Parr and Ransome 1986, 112). They identified two major problems; the heavy workload on librarians and their consequent frustration, and the need to educate staffers in the most efficient use of the library's resources. The report made 13 recommendations. Of particular relevance to this thesis was recommendation four:

That the Library should consider ways in which it can improve, through training and/or the preparation of a suitable manual, the design, maintenance and indexing for retrieval of office-based information files including computer-based systems (Parr and Ransome 1986, 116).

Electronic access to information was viewed by staffers generally as a desirable and inevitable development which would come with a move to the new Parliament House (in 1988), but most believed human resources were far more important than technological ones (Parr and Ransome 1986, 62). Parr's next report was commissioned by the NSW parliamentary library and titled Timely, Relevant and Comprehensive. It aimed:

...to discover what kinds of information are needed by Members and others who serve Parliament; the extent to which the Parliamentary Library currently meets those needs; what might it do to provide for needs presently unmet; and what arrangements it might propose for other agencies to assist in meeting information needs (Parr 1990, 2).

Reference was made to the information explosion and the need to evaluate the library's effectiveness in the current environment.

Chapter five focused on computer-based information services. The study revealed the great majority of electorate office staff and house personnel were accustomed to using micro-computers and interested in training in the use of the library's databases and others available commercially. Members were not nearly as 
acquainted with using micro-computers as their staff, though some (31 percent) reported regular use of a micro-computer or terminal and 74 percent expressed interest in training in the use of the library's data bases (Parr 1990,59). The report did not make specific recommendations but identified and rated the information sources used by Members. It pointed out a need to develop research capabilities among library staff and the extension to individual Members of computer-based data systems, including on-line and CD-ROM information retrieval.

When Parr and associates published their most recent report on information needs of federal MPs, titled Pathways To Information (1991), the topic of information technology had its own chapter, reflecting the growing recognition of its importance. The report revealed the sources used by MPs and how each was evaluated. Significantly for this thesis, the researchers noted:

There has been a massive increase in the use of information technology in the service of Parliament and by parliamentarians in the last decade (Parr, Ransome, Davies and Warhurst 1991, 99).

By this time every parliamentarian could access databases from parliamentary offices and transmit documents to any point connected to the parliamentary telecommunications system. In the survey an overwhelming majority of parliamentarians and their personal staff said they would like to have on-line access to the parliament's databases from the electorate office. Parr et al recommended each electorate office be connected to the parliament office in a way that would allow for the secure transfer of formatted text and data and access to on-line information services of the parliament (Parr, Ransome, Davies and Warhurst 1991, 101). These connections were completed in March 1992. As was reported in the previous study, staff were more likely to be familiar with and use microcomputers than were MPs ( 94 percent compared to 30 percent). In the summary to the chapter on information technology, Parr et al wrote: 
In the legislative and policy arena the revolution in information technology has provided legislators with more information. Ultimately, however, the quality of the decisions made depends on the structure of our political system and the integrity of our politicians and their advisers. Technology is neutral, it simply allows them to be more informed in carrying out their duties (Parr, Ransome, Davies and Warhurst 1991, 116).

However it may be useful to differentiate between technology used in information seeking and technology used in information dissemination. The former could be judged to be neutral but the latter can shape the substance of the message, as the short 'bites' of political advertising to suit television demonstrate, discussed later. The report observed in conclusion that:

...the move to the New Parliament House and the introduction by the Parliament of new electronic information technologies overlap... The new Parliament House offers greatly improved electronic facilities. A parliamentarian's office offers a veritable smorgasbord of machines and electronic opportunities. At the same time the offices are beguilingly comfortable and in most cases a long way from the Library. The Library is also not as proximate to the Chambers of the two Houses as it was in the old House. For both reasons, that is the new technologies and physical location, parliamentarians are driven to use their staff much more in the informationgathering and policy analysis process (Parr, Ransome, Davies and Warhurst 1991, 121).

The observations are significant in regard to the influence of the physical environment on the way people work and interact. While the concentration in this thesis is on CTs, it is important that any new technology must be physically as well as mentally comfortable for people to use. In this context, the comment had been made earlier that: 
On the face of it the new Parliament House is a monument to the technological age. However, in practice there are severe limitations on the successful application of this new technology to meeting the information, policy analysis and advisory needs of parliamentarians. The limitations are human rather than technical. The human factor involves both those who manage the new technology, and those who use it - parliamentarians and their staff. As a consequence the great potential which exists is not yet being tapped to its fullest extent. Parliamentarians are largely of the paper generation (Parr, Ransome, Davies and Warhurst 1991, 2-3).

However this 'paper generation' of MPs is evidently changing. 'There is anecdotal evidence that many of the new Members arriving in the Commonwealth Parliament following the 1993 election were already sophisticated IT users, some of whom access the Internet independently' (Parr 1994, 13).

Although dated in terms of information technology, Can Ministers Cope? by an academic and a political journalist (Weller and Grattan 1981) provides a realistic and sensible appraisal of the pressures on ministers. As the authors point out, the job of a minister received little attention in Australia as a subject of empirical studies (then and now). Fifty ministers or former ministers and a number of top bureaucrats were interviewed just before the 1980 Federal election. Making extensive use of quotes from interviews, the book projects the life of a minister with immediacy and clarity. Though information needs are not stressed, the lack of time to consider matters is emphasised.

Interestingly information technology is not listed in the index and use of new technologies hardly rates a mention. This is not criticism of the book but indicates the rapidity of technological development, illustrating changes over the past 15 years.

Greater access for MPs and staff to information on data bases has greatly increased the range of sources available in researching any topic. The implication is that, at least in theory, decision-making 
is better informed. As part of the Parliamentary Information Systems Office (PISO), the parliamentary data base system provides on-line access to parliamentary publications and papers. In fact it is ironic that the technology which speeds up information gathering does not seem to have resulted in giving the decision-makers more time for contemplation of complex issues, but just the accumulation of more information of greater complexity. In the face of such an increase in the volume of information there is a danger of information overload. Members of Parliament are:

...unable to get the information they really need, cannot adequately process the information they do receive or cannot use it effectively in the course of parliamentary deliberations (House of Representatives Standing Committee on Long Term Strategies, Issues Paper 1992, 1).

The paper argued that the situation is exacerbated by executive dominance of parliamentary proceedings and the lack of time for debate. In this situation the new CTs have not assisted the MP because other organisational factors have operated against the most effective use of increased information. Despite specialising in areas of interest or knowledge, the MP is often unable to keep up with even the broad outlines of matters which come up for debate. This is not conducive to informed consideration or to maintenance of MPs' morale and 'The ever-swelling flood of information may cause confusion and despair rather than enlightenment and empowerment' (House of Representatives Standing Committee on Long Term Strategies, Issues Paper 1992, 3).

Another major study of the information needs of MPs was conducted for the Queensland Parliament by the Electoral and Administrative Review Commission (EARC). Arising from recommendations of the Fitzgerald Inquiry into Corruption in 1989, the study had a number of steps: a questionnaire to government and non-government Members on their information sources; the production of Issues Paper No 11; written submissions; a public seminar; and the report in 
December, 1991. The final EARC report's major recommendations were that guidelines should be issued for guaranteed access by Members of the Queensland Legislative Assembly to public officials and that factual information should be available to Members on request. That this had not been the case in the past indicated the need for substantial reform. As well as procedural reforms in the conduct of parliament, EARC recommended the library put in place a system for evaluating client satisfaction with the research and reference services. In summary the report called for much more open communication and accountability (EARC 1991, 139).

The studies by Parr et al and EARC in particular reported above represent a considerable body of information on the information needs of MPs. In addition, proceedings from Conferences of Parliamentary Librarians, held annually, usually discuss the changing role of the libraries, especially in regard to the new technologies and of 'value-adding' services at a time of increasing information overload. The studies appear to indicate that, to date, the potential of CTs has not been fully realised, in that the people's representatives often favour traditional information sources in decision making, especially discussions with trusted colleagues. Even when technology-based information is readily available to the privileged information-rich, there are other equally important factors operating in terms of which information sources are used.

\section{Studies of the impact of CTs on political communication}

Strategic pollsters in political campaigning use the new CTs to market their 'product'. Their role is graphically described in the only Australian book to date to specifically analyse their impact:

Strategic pollsters sit atop the crow's nests of Australia's political parties. Their job is tactical rather than theoretical: avoiding the rocks and finding the clear water. They are not passengers but part of the crew, partisan, searching for solutions as well as problems. Strategic pollsters are 
generalisers, more psychologists or sociologists rather than statisticians - indeed, scarcely a number appears in their reports. Their evidence is slippery but their advice must be hard and provoking (Mills 1986, 18).

The author gave instances of the pivotal influence on party policy which the pollsters exercise through the medium of their polling and political judgement. The role and influence of the professionals in campaigning is increasing (see chapter six).

With reference to the organisational side, and political communication through campaigning, the ALP NSW branch in 1988 commissioned a study by consultant researchers. This was occasioned by electoral defeat following a campaign in which the Labor Party was said to have experienced a 'communication problem' in 'getting the message across' to the electorate. The 'conduit' metaphor of political communication assumes that the communication process consists of a sender, a message, a medium (or conduit) and a receiver. In the opinion of the authors of the survey, both MPs and party machine campaigners widely subscribed to this simplistic view, which portrays communication as purely a mechanical process - like a ball being propelled along a tube. '(In this view) to communicate is to transmit - the two are treated as synonymous' (Rogers and Penman 1989, 8). Such a belief is misguided, they claimed, because it diminishes the role of voters to passive recipients. The authors concluded that communication needs joint interaction and that failure to recognise this fact can only be counter-productive to full citizen participation.

Concerned at the costs of campaigning using the new media, the Parliament legislated in 1983 for an electoral funding and disclosure scheme, which provided public funds for election expenses and required disclosure of donations and expenditure on advertising through the media during the formal campaign (Australian Electoral Commission 1995, 1). The legislation was amended following reports of two parliamentary committees. Recommendations from the Committees, carried on party political lines, included banning political advertising and the allocation of free time for political broadcasting on television and 
radio (Joint Standing Committee on Electoral Matters 1989, xiii). The result of increased costs, the government argued, was that political parties could be unduly influenced by individuals or organisations donating to campaign funds.

Negative reaction to a broad-ranging proposal to ban political advertising came from a wide cross-section of the community on the basis that it represented an attack on freedom of speech (Warhurst 1991, 133) and was a cynical attempt by a Labor government to avoid bankruptcy of its organisational wing. The legislation was challenged and subsequently over-ruled by the High Court. The Chief Justice stated:

The consequence (of the amendment) is that (it) severely impairs the freedoms previously enjoyed by citizens to discuss public and political affairs and to criticise federal institutions (Mason CJ, 1992, 8).

However the court upheld provisions for disclosure of campaign spending. The requirements for disclosure of campaign costs and the source of funds are designed to act as a deterrent to any overt influence of monied interests, disproportionately to the 'average' voter, over politicians and parties. However the requirements have not kept pace with CTs. For example the costs of direct mail (covered partly by a postage allowance for sitting Members) are not required to be disclosed and as a result the true costs of campaigning are hidden. With increasing proportions of spending directed towards marketing campaign strategies involving new CTs (see 1993 general election spending data, chapter five), it can reasonably be argued that these avenues need to be included in disclosure requirements for the true costs to be apparent. The costs of campaigning remain prohibitive. Even major political parties with much greater resources than independents or minor parties feel obliged to spend time and effort raising money to fund campaigns. The ALP federal secretary estimated that, over a three year cycle, the major parties spent about $\$ 100 \mathrm{~m}$ in administration and campaign costs (Gray 1995, radio interview). 


\section{Studies of citizens' information sources and political communication}

Before addressing the few actual studies that have been conducted, it is important to consider three factors influential in citizens acquiring information and communicating politically: attitudes to technology and to politics, literacy and the cost of access.

\section{Citizen attitudes}

As technology is increasingly pervasive, citizens' attitudes towards it are relevant. Survey research by consultants commissioned by (then) Telecom revealed a strong ambivalence towards the impact of science and technology: 'Australians both applaud technological progress and fear it' (Social Impacts 1989, 3). Science and technology are regarded as necessary for progress but there is a feeling that change is too fast and that there is no control over the negative side-effects. People have general anxiety over control of technology but some positive attitudes towards specific technologies, which account for the high adoption of such innovations as mobile phones. It appeared that:

The conclusion is that in each and every case of the introduction of new technology, there is a whole spectrum of resistance and acceptance involving not only the technology itself, but perceptions about who is controlling it, what it is being used for, what are its user benefits and what are the side-effects (Social Impacts 1989, 4).

The most recent academic survey data by the Australian Election Study (AES) on people's attitudes regarding their ability to influence politics showed people are almost equally divided on their potential to influence the political process. To the question; 'A person like me can't make much of a difference by joining a political party', 34 percent agreed strongly or agreed, 34 percent were non-committal and 32 percent disagreed or strongly disagreed (Social Science Data Archives 1993, 82). Perhaps the 
surprising finding is that, in view of reported cynicism and disillusionment, a third of respondents still believe they can influence a political party by joining it. Further, people were in general content with their MPs' attention to their problems. The AES found that 24 percent of people surveyed had contacted their Federal MP in the MP's office. Forty-four percent of these were very satisfied with the response of the MP and 31 percent somewhat satisfied (Social Science Data Archives 1993, 32). The National Social Science Survey (1984) findings were lower for contact with MPs, possibly because it was not an election campaign period. To a question on whether they had contacted a government official, 63 percent never had and 37 percent had (Kelley, Cushing and Keadley 1984, 171).

The consensus from interviews with politicians (see chapter three) is that membership of a political party now provides the centre of interest and involvement for many fewer people than it did in the past. Membership of both major political parties apparently fell by nearly 50 percent between 1975 and the early 1990s (Ward 1994) though party membership figures are somewhat rubbery due to the reluctance of both major parties to divulge such information. The reasons for the declining membership are obviously complex but the advent of the new CTs would appear to have been influential, both in terms of alternative entertainment and alienation of members associated with the professional input of pollsters and strategic campaigning consultants, as the Young inquiry following the Queensland election showed (see chapter five). Reduced membership limits the MPs capacity to reach people in general sympathy with the party philosophy. Party members have in the past provided a valuable sounding board of 'public opinion' on policy proposals. More immediately, an important source of labour for campaigning is no longer available (as was evident in the Wills by-election report, see chapter five).

\section{Numerate and literate?}

In debates about access by citizens to the new CTs there is often an underlying assumption of universal numeracy and literacy skills. 
Just as functionally illiterate people in Australia are ill-prepared to make a meaningful contribution to democratic debate, so those people without access to, or knowledge of, computers may be disadvantaged in future. In its submission to government, entitled Vision for a Networked Nation, the Australian Computer Society made a strong plea for definitive policies, particularly to ensure equitable access:

[A] necessary condition for public access to network services is the widespread ability to use them. Public book libraries could only be of benefit where social programs were instituted to promote literacy in the population. The notion of literacy, and the focus of literacy programs, need to reflect the new electronic environment. The whole population needs skills in order to operate computer equipment... (Clarke and Worthington 1994, 9) (emphasis in original).

\section{Cost of access}

It is relevant to consider the cost of information to the citizen, which decisively influences its use. In examining what the new role of CTs should be in relation to citizenship in complex democracies, it has been argued that policies aimed at privatising CTs undermine resources for full and effective participation because access becomes dependent upon purchasing power (Murdock and Golding 1989, 183). For example, under the heading 'Democracy at too high a price', one newspaper columnist was highly critical of the cost of government reports, citing the charge for the Royal Commission report into Aboriginal Deaths in Custody at nearly $\$ 400$. He blamed the 'senseless and undemocratic cost-recovery policy imposed on the AGPS [Australian Government Publishing Service] by the Government' (McGuinness 1991, 13). Further he pointed out that the report could be made available for $\$ 12$ on disk, which of course presupposes access to a computer, an assumption of sizeable proportions in relation to Aborigines in rural and remote communities. 
Submissions to the Role of Libraries/Information Networks inquiry by the House of Representatives Standing Committee for Long Term Strategies (1991) noted the commercialisation of information. While it was recognised that some commercial incentive is necessary to encourage information services, concern was expressed that access will be limited to those with the capacity to pay and that this will widen the gap between information rich and poor (House of Representatives Standing Committee on Long Term Strategies 1991a, 21). Many libraries are introducing charges for inter-library loans and other 'value-added' services. So it is possible that even access to traditionally free information sources - books - will in future depend on the citizen's ability to pay. Such an eventuality would run entirely counter to the recommendations of the above committee, which reported that libraries as a national resource should be available free of charge to every citizen:

This access is fundamental to the maintenance of our democracy, the transformation of our economy to that of a clever country and the delivery of social justice to all our citizens (House of Representatives Standing Committee for Long Term Strategies 1991a, vii).

On the role of public libraries in general, the committee concluded:

The most tangible achievements lie in the cooperative mechanisms that have been established to rationalise resources. Networks within regions and states, on-line catalogues and, nationally, the ABN [Australian Biographical Network] provide more extensive access to a wider range of materials. Telecommunication and information technologies will make possible the extension of services to remote areas and give individuals access to international, interstate or out of region information (House of Representatives Standing Committee for Long Term Strategies 1991a, 14). 
State governments fund the major State libraries and the Commonwealth funds tertiary institutions' libraries. Municipal libraries are funded by combined local government rates and federal grants, though the federal money is not earmarked, and support for local libraries seems to depend on the inclination of the local mayor or a keen librarian (Walsh 1995, interview). The situation also varies greatly between the States. The Tasmanian government runs all local libraries with no local government input, whereas in NSW local government dominates. There were moves under way in 1995 by the Federal Department of Housing and Regional Development to tie funds for library expenditure, to establish benchmarks to ensure standards are met and to analyse needs objectively and fund accordingly (Walsh 1995, interview). The ALP platform since the September 1994 Conference incorporates a statement on the role of libraries in ensuring access to information on social justice grounds.

In fact the Committee for Long Term Strategies was highly critical of the Commonwealth's past 'neglect and disinterest' (House of Representatives Standing Committee for Long Term Strategies 1991a, 1) towards the report, Public Libraries in Australia (the Horton Report). Basically as a result of its recommendation that the Commonwealth should share some responsibility for funding public libraries, the report was subjected to '...a dreary story of procrastination and prevarication' (House of Representatives Standing Committee for Long Term Strategies 1991a, 3).

Apart from reiterating the need to act upon many of the Horton Report recommendations, the committee also took submissions on the advantages and disadvantages of libraries filling the role of community information centres. Viewing themselves as information deliverers, some libraries are offering a range of services, including classes in literacy, outreach programs, exhibitions and cultural activities. Not surprisingly, some professional community information providers (such as the Citizens Advice Bureaus) did not regard libraries as suitable places for people with such information needs. In a Solomon-like finding, the committee concluded that, in the cities, specialist providers of information were appropriate while in country 
towns libraries may continue to be the first point of reference and therefore should be involved in a wider role (House of Representatives Standing Committee for Long Term Strategies, 1991a, 15).

Having considered factors influencing citizens' ability to acquire information and communicate politically, the traditional sources of information remain predominant, although libraries are increasingly adopting new CTs. Despite the professional information providers, public libraries remain a primary source for people seeking information. There were an estimated $8,454,000$ registered library members in $1992-50$ percent of the population - and total public library expenditure was $\$ 288.5 \mathrm{~m}$ (Bureau of Transport and Communication Economics 1994, 167). People can also access libraries in the Technical and Further Education (TAFE) sector or through university libraries. Access through Australian libraries to data bases overseas will be improved with the delivery in 1996 of the National Document and Information Service (NDIS). The Minister for Communications announced:

This project presents an exciting opportunity for the National Library and the Australian library community to exploit recent advances in technology and take advantage of the development of the Internet and related broadband services (Lee 1994, media release, April 6).

There has been discussion of the desirability of connecting the Extended Parliamentary Network (EPN) to the information infrastructure to allow access by citizens (Clarke and Worthington 1994, 21). As it is a facility paid for by public money, it was argued much wider public access was justified. Representatives from four departments of the Parliament formed a group to evaluate a trial (August 1993 to June 1995) of External Access to the Parliamentary DataBase Services (EXPDBS), a subset of the Parliamentary DataBase Service (PDBS) which includes only parliamentary material. One of the objectives of the departments was to 'address access and equity issues in relation to parliamentary information' (Evaluation Group on External 
Access to Parliamentary DataBase Services 1995, 7). The Group recommended wide provision of access by the public via the Internet, at the lowest possible cost consistent with acceptable service, using public libraries and community networks.

In summary, citizens' political communication sources have been largely neglected as a subject for academic study. Information on political communication by citizens has tended to be collected almost inadvertently as part of overall electoral/media surveys. Overwhelmingly, television coverage of political matters dominates the way in which people get information. During the 1993 election campaign the Australian Election Study found that 80 percent of respondents followed the campaign 'a good deal' or 'some' on television, compared to 68 percent in the newspapers and 54 percent on radio. A high 82 percent expressed a 'good deal' or 'some' interest in politics (Social Science Data Archives 1993, 3), which contrasts with the survey results (1995) reported in chapter seven, which show both ignorance of and apathy towards politics. These contradictory findings, though taking into account the time factor, indicate the problems in interpreting attitudinal survey findings regarding politics. Tapping into public sentiment presents difficulties in interpretation, with some aspects being positive and some negative. As is pointed out in relation to the Americans to Limit Congressional Terms movement, people can simultaneously hold views critical of the Congress, but favourable to their particular Congress representative (see chapter six).

The use of the new CTs in an interactive way with the public has hardly begun but videos and newly-emerging multimedia presentations provide an excellent method of public information dissemination. The Parliament Stack, a data base of information on CD ROM on all MPs and the characteristics of their electorates which visitors can access at Parliament House in Canberra, is of some use as an educational resource. However such a computerbased data store has the potential to provide access by the public to information (or, even, knowledge) which could include the current political issues under debate in the Parliament. In fact, for the election campaign in 1996, all major parties and some minor ones had home pages accessible through the Internet. 
More important to the policy-making process is the opportunity for people to convey their views through parliamentary committees of inquiry. Advertisements in major metropolitan newspapers regularly invite submissions from the public on a wide range of issues. Though the opportunity is provided, the number of people or organisations who make submissions or appear before the committees is very small and comprises mostly those with an interest (economic or other) in the topic under discussion. In many cases, the 'public interest' is represented by lobby groups who advocate the argument for the 'public good' as they perceive it.

The importance of parliamentary committee inquiries has increased in recent years. There are two reasons for this trend: first, because control of the Senate has been precariously poised on the votes of the minor parties and an independent; and second, partly as a result of power being balanced, because 'consultative' government has become a catchcry. It can be argued that it is the people with knowledge and also with a vested interest who take the trouble to give evidence and make submissions. The advantage is that hearings can be reported through the media and thus reach a wider audience. The Senate first established committees in June 1970. In total, 555 reports of Senate committees were submitted between 1970 and 1993. Their 'watchdog' function was stressed (by those with a 'vested interest'):

...Senate Committees will continue to provide Senators and the public with unparalleled potential to scrutinise legislative proposals, enquire into the quality of administration and examine important issues of national policy (Senate Committee Office Register 1993, v).

However, other evaluations which may be more disinterested have judged the Committee systems to be effective in a practical way, in a role of '...keeping the bastards honest... The job of the parliamentary committee...is to probe, enlighten, deter and squeeze: to make it as difficult as possible for ministerial and administrative misbehaviour, neglect or maladministration to be 
pushed under the carpet, to create a political environment in which even the most thick-skinned minister or official will feel the heat' (Evans, 1982, 83).

The committee reports deal with a wide range of topics - from Aboriginal affairs to transport. Most take evidence from the public, though proceedings tend to be formal and have a quasijudicial atmosphere. The government's response to such reports varies and it would appear (from a study of the issues reported) that it is related to how controversial the topic is - the more difficult, the slower the response.

For example, the Senate Standing Committee on Foreign Affairs, Defence and Trade had a report on Australia and the Refugee Problem tabled in December 1976 to which it had not, in 1993, responded (Senate Committee Office 1993, 23). The most powerful way in which individuals can pressure the government is through combining with others in an interest group, whether for economic or 'cause' purposes. The use made by interest groups of CTs in their lobbying and other political activities will be explored in chapter four.

\section{Teledemocracy}

While the traditional avenues for people to gather information and communicate politically remain important, the new CTs present an opportunity for increased participation. In the early 1970s in the US, the potential uses of CTs for extending people's ability to get the message across were first considered. The term given to this citizen/CT participation is 'teledemocracy' and a number of projects were evaluated by Christopher F. Arterton for the Roosevelt Center for American Policy Studies in 1983. He described how the advocates of teledemocracy believed that CTs made possible an expansion of power exercised directly by people in the policy-making process. Opponents regard such electronic plebiscites with strong misgiving, emphasising instead the value of decision-making being vested in elected representatives. In the context of teledemocracy, this again underlines the basic philosophical difference in approach, being the populist view of 
politics as opposed to the representative democratic theory. Arterton concluded that the ideal is '...a concept of teledemocracy in which CT is used to underwrite representative processes and the pluralist conception of political interest' (Arterton 1983, 204). More detail of his evaluation of the teledemocracy projects is given in chapter six.

\section{Studies of the impact of the new media}

The most definitive studies of the influence of the new CTs in the political arena have been conducted in the US, both in analysing the effects of the marketing of politics and in assessing projects aimed at increasing participation through the new CTs (see chapter six). Media influence theories have moved in a cyclical way, from concluding that mass media has an overwhelmingly influence through to the 'law of minimal consequences'. Contemporary theorising has swung back to conclude that mass media can have a decisive influence on political attitudes (Ward 1995, 69). In Australia, political scientists have pursued the agenda-setting theories which hold that mass media is not powerful in determining what people think but is influential in terms of what they think about. In fact, Ward postulated that changes in the conclusions reached by researchers about the power of mass media to influence attitudes and behaviour may be partly a function of the changing nature of technology.

Developments in satellite telecommunication technology have given television news instant global coverage. This in turn may have altered the political power of the medium, which leads to an interesting speculation on the nature of theories: 'Not only might differing theories of media effect be time bound, but the nature of media effect need not be constant over time' (Ward 1995, 69). In this context, any studies to evaluate the effect of interactive media will have to await their widespread uptake.

These theories of communication are important for the political process as they directly relate to suppositions on the impact of CTs on the democratic process. The impact on political attitudes in 
Australia of the televised parliament has yet to be assessed. However, 'brawls' in the House of Representatives at Question Time, acceptable as theatre to the audience in the public galleries, receive a less tolerant reception in short, out-of-context 'bites' on television news and may increase cynicism towards politicians in general. Who 'wins' or 'loses' in Question Time has a psychological impact on the actors involved. As one critic has observed:

Ironically, the real concerns of Australian people are never so remote from the real political process as when their supposed 'representatives' are asking questions in the parliament, supposedly on behalf of the people - political point-scoring has emasculated what is theoretically the 'people's period' in parliament (Rowlings 1994, interview).

Two studies of television news were conducted by Barbara Ann Butler for her $\mathrm{PhD}$ research: one in an election period and one in a non-election period (Butler 1994). The studies focused on the roles of sources and journalists in shaping television political issue agendas in Australia. The television news was monitored by video and sound recording. In recent times political journalists have been criticised for their lack of competence in fulfilling their function, being '...not the watchdogs of democracy but the lapdogs of politicians' (Butler 1994, 5). In other words they have become over-reliant on press statements and have not pursued investigative journalism. In summary Butler found that in the study done in non-election time, information from 'sources' dominated 90 percent of the news and journalists initiated 10 percent. In the study done in an election period, the figures were 95 percent and five percent. 'Clearly, federal government sources represented the major category of initiators of news using press releases to achieve television news coverage...' (Butler 1994, 22).

So, while sources dominate the news content, the power of the journalists lies in their ability to amplify or marginalise an issue. Butler contended that the journalists kept the Goods and Services Tax (GST) rather than unemployment on the agenda during the 
1993 election campaign which may have been an important factor in the outcome of a very close election.

With regard to the new CTs, and working in contrast to the decentralising influence identified by Abramson et al, 'The emergence of nationally networked news certainly enhanced the capacity of a handful of elite political sources to shape the framework for political debate in society' (Butler 1994, 13).

Butler's work has important implications because it sets a benchmark against which to monitor the balance in media reports in future. With self-regulation of the media, and in the absence of direct monitoring by the Australian Broadcasting Tribunal, these findings are important. Basically her research found that coverage of the major parties was reasonably well balanced. The link to CTs will be an evaluation of the way in which these developing technologies may influence balance of presentation of political news.

The importance of CTs is demonstrated in the dominant role played by the mass media in the campaign agenda. Television affords much more efficient and widespread message dissemination than traditional campaign meetings:

The needs of the media tend to dominate the campaigns of the leaders and their main deputies. It is only through the media that leaders can reach the vast bulk of the voters. The media provide the only channel of communication sometimes a two-way channel on talk-back radio, though the party faithful tend to dominate many shows (Solomon 1986, 148).

In his conclusion to a study of the news media in Australia, Rodney Tiffen described its political function in reporting and commenting on current events to a mass, diverse audience through the filter of their own sense of priorities. 'Their presence affects...most importantly, the extent of revelations about powerful groups' (Tiffen 1989, 197). While it is not valid to blame the faults of the political system on the media: 
...concern with the news media will always be central in evaluating the quality of democratic process. They are the pivot between rulers and the ruled. They will continue to disappoint reformers, to be the target for many legitimate grievances, to be dominated by pedestrian mediocrity. Despite their tame connivance in the charades and feints of dominant sources, and despite the prejudices of proprietors, reporters and audiences, the news media occasionally and erratically expand the quality of social choice and enhance the accountability of the governors to the governed (Tiffen 1989, 198).

The influence of mass communication on public opinion can be a huge topic, and has an extensive literature, outside the direct reference of this thesis. However, in an earlier seminal work, James B. Lemert posed the question in the title of his study - Does Mass Communication Change Public Opinion After All? (Lemert 1981) and answered in the affirmative. He argued that the media influence public opinion not by changing people's minds but by producing changes in participation and power relationships.

Mass communication can influence public opinion. For example, an argument is mounted that it was the role of mass communication which enabled and mobilised the dramatic disintegration of the communist countries of Eastern Europe through 1990-91, described 'as one of the greatest communicationinduced transformations in modern history' (King and Cushman 1992 , 3). The authors contended that mass communication played a central, catalytic role in the upheavals in the former Soviet Union and Eastern Europe because it occurred to people, aware of international events reported through often clandestine channels, that it was possible for governments to be displaced. Mass communication provided an information environment for change. However, the extension of this domination into the new CTs has been of concern to US and Australian academic commentators in the media arena (Keane 1991, 533 and Ward $1995,125-6)$ and to media players themselves (Stokes 1995). 


\section{Conclusion}

Literally out of nothing, a new dimension emerges: cyberspace, a place made out of bits, whose intangible nature does not prevent it from becoming a second home, or primary workplace, for masses of infonauts (Levy 1995, 15).

This chapter has outlined various surveys, studies and inquiries into the implications of the new CTs, broadly defined, for political communication by MPs, citizens and the new media. It is not possible to cover all these areas in detail. Their inclusion here is by way of defining the broad parameters. Would the prospects be more positive if set in the context of government information policy to guide and monitor the impact of new CTs in the political process? This question is addressed in chapter eight.

In summary, rather than the generally negative consequences of the 'new media' outlined by the American political scientists at the beginning of this chapter, the information revolution has the potential to result in contradictory outcomes, depending upon the use to which communication technologies are put. These have been described as:

- control versus decentralisation: that is, increased control by the powerful elite using information held on computerised data banks, as against decentralisation through empowering the individual by access to information: technologically, mainframes compared to micro-computers;

- $\quad$ surveillance versus privacy: though capable of invading privacy, technology can now protect it by cryptography, to some extent;

- censorship versus free speech: the Internet enables connections and also a single message to reach millions of people - both narrow and broadcast - regardless of the value or truth of the message; and 
- linear versus interactive: people can be receptors and/or contributors (Levy 1995, 15).

(Narrowcast is directed to a select audience and broadcast sends a message to a number of people).

As this chapter has outlined, the implications of the new CTs for political processes are complex. Research has focused on the better resourced MPs and citizens' political communication research has largely been neglected. Any attempt at predicting the future impacts of new CTs on political communication must be highly speculative. However it is important that attempts are made, in order that the optimum policies can be developed for a healthy democracy.

The following chapters explore these issues in greater detail, including by way of surveys, to try to reach a position in the final chapter where consideration about the future use of CTs in Australia can be undertaken in the context of an information policy for the nation. 


\title{
CHAPTER 3
}

\section{Surveying the impact of direct mail}

\author{
Direct mail works! We all know that! (Gray 1993, \\ interview and also ALP report). \\ We monitor (by telephone surveying) after a direct mail- \\ out-(our standing is) usually up 2-3 points. (Textor 1994, \\ interview).
}

\section{Introduction}

These are views of two top political strategists/pollsters from opposing parties on direct mail who both believe that direct mail is effective in gaining votes. To address the first research question: what is the influence of CTs on elected representatives' communication with citizens? and to test the first assertion: direct mail works! a series of interviews was conducted to constitute one of the empirical aspects of this thesis. As mentioned in chapter one, direct mail was chosen as an example of the application of CTs in political communication.

Direct mail, first used extensively in the US in the late 1960s, has been increasingly included in campaign strategies in Australia and is an important aspect of the new style of campaigning. Referring to the US, one commentator wrote in culinary terms: 'Direct mail is the meat and potatoes of computer-based politics: all other direct marketing and communication innovations are merely sauces and desserts' (Godwin 1988, 2). The adoption of commercial-style marketing techniques by political strategists is epitomised in direct mail: 
Political direct mail is the best example of the transliteration of commercial ideas to political election salesmanship...We perceive in direct mail, as with the adoption of other marketing techniques in politics elsewhere, the trend towards mechanisation and the impersonal: the illusion of personality is cast over an automated process. Direct mail is the coming mode of political involvement (O'Shaughnessy 1990, 87).

The Australian Labor Party's (ALP) Polfile and Liberal's Feedback data bases provide information for direct mail which is used most frequently during election campaigning and, to a limited extent, for fund raising. To establish the data bases, a sample of electors was contacted by phone after cross-referencing electoral rolls, telephone books and demographic census data. Both Polfile and Feedback receive monthly updates on voter registration from the Australian Electoral Commission and census data is purchased to provide information for further targeting the message. The elector is classified by voting intention and special interests where these are known. This information is entered on a data base along with information from other sources (signatories to petitions, representations made to MPs, letters to the editor) and then a letter appropriate to the individual's known needs or interests and 'personally signed' by the candidate or Member can be mailed out. Thus in theory an invalid pensioner could be advised of changes in social security entitlements or a conservationist of the latest party platform on 'green' issues. In fact, though this degree of targeting is possible, given the necessary time and effort to collate and update the data bases, it is rare that direct mail lists in Australia reach this level of specification and sophistication.

While the national offices of the major parties installed their respective centralised data bases, direct mail data bases are decentralised to electorate offices. The role of the national offices is supportive, providing texts for letters at the request of the electorate office to ensure accuracy and consistency in messaging, except in marginal electorates where more direct control is exerted. The demands of direct mail on staff time in compiling and maintaining the data bases are considerable. Their accuracy 
appears to vary widely, though generally in marginal seats one staff member may work exclusively on this. Another important factor is the time it takes to build up a sophisticated data base estimated to be two terms (i.e. more than five years) - which gives incumbents a significant advantage. An advocate of direct mail summarised its impact: 'Polfile makes a difference to the way an efficient Member can operate' (Gray 1993, interview).

In essence direct mail is a technique used to try to influence electors to change their vote in favour of a particular party. Advocates of direct mail contend it has also an educational and informational function. Nevertheless, in terms of political reality, its rationale is not altruistic but to secure votes and win elections. The statement that 'direct mail works!' reflected the belief that personally-addressed letters influence 'floating' or 'swinging' voter attitudes and voting patterns towards the party carrying out the direct mail exercise.

The rationale for direct mail is that electors are far more likely to read a personalised letter which addresses their concerns than they are a 'To the Householder' leaflet. It is considered more economical in not wasting material on voters who have no interest in the information from that party and are therefore unlikely to read it. Between elections it can be argued that it promotes good governance by establishing links between the Member and the constituent. Of course it advantages the incumbent who has facilities at hand, including postage paid by public funds. The postal allowance for MPs is currently $\$ 22,000$ per year, so over a three year term, the postal allowance costs over nine and a half million dollars.

Opinions on the effectiveness of direct mail vary widely. Briefly, advocates claim improved awareness on the part of MPs to the needs and concerns of his or her constituents (and consequently better service to them) and that it enables voters to respond and participate in political dialogue. Critics point to the invasion of privacy involved as well as to the potential for antagonising the voter with misdirected information. (A probably apocryphal story is cited of a member of a convent receiving information on single 
mother benefits). In addition the MP only conveys messages to his or her own advantage at taxpayers' expense. Another criticism is that the assumptions behind direct mail are manipulative and in practical terms counter-productive because voters are not deluded by the technique, interpreting it as just another form of advertising.

Whatever the debates for and against, the ALP took up the new technologies with alacrity, using telephone canvassing followed by direct mail in marginal electorates. Polfile and direct mail is credited by party machine people with having contributed to Labor's successful marginal seat campaigning in the federal elections in 1987, 1990 and 1993 (Gray 1993, interview). However there appears to be no objective criteria against which success or otherwise of direct mail has been judged. This research into the circumstances of the Fremantle by-election indicates party machine men may be mistaken concerning the influence of direct mail on floating voters, though it played a still-significant role.

This chapter first reports the views from personal interviews with senders of political messages: party machine people and MPs. I then record and analyse the attitudes of electors towards direct mail, gathered by telephone survey following the 1994 by-election for the federal seat of Fremantle, a suburban area of Perth, Western Australia. As will be apparent from the analysis and discussion of these interviews, opinions regarding the effectiveness and desirability of direct mail vary considerably between voters, politicians and party machine people. Opinions also vary substantially within these groups of people.

The names of people personally interviewed appears at the end of this chapter. The party operatives interviewed were the people with responsibility for direct mail for that party. MPs were chosen by a method known as 'snowballing' in which names of people known for their pro or anti direct mail views were interviewed and they were then asked to identify other appropriate people to interview. In addition, a balance between the major parties, states and rural/urban electorates was an influential factor. Coincidentally, the MPs chosen had achieved better results in their 
states than their party overall, either by gaining votes or by holding votes in a swing against their party, and their relative performances in the 1993 election is noted at the end of this chapter. Therefore their attitude to and use of direct mail may have been a factor in their success. While personal interviews were unstructured to allow for the widest-ranging exploration of the topic, the following areas were covered in interviews with both the machine people and MPs:

- $\quad$ opinion of direct mail compared with traditional ways of contacting voters;

- $\quad$ positive and negative aspects of direct mail;

- the changes it may have brought about;

- relative importance of local issues (direct mail) and national issues (mass media) in influencing the vote;

- the proportion of people who write back or make contact after direct mail; and

- $\quad$ how to judge the efficacy of direct mail.

\section{Party machine people's views}

In general party administration people are very committed to direct mail. This was apparent from the interviews and was also the observation of some MPs. As the then ALP member for Lowe, NSW, identified: 'Head office is very, very pro direct mail. Swear by it black and blue' (Easson 1993, interview). It could be observed that, in view of the substantial commitment in financial and human resources made by both parties, it would be surprising if the party machines were not strong advocates of direct mail, if only to justify the expense.

Both parties are reluctant to divulge the findings of their research on the effectiveness of different campaigning methods. Prior to the data bases being set up, telephone calls were made to voters in selected areas to identify their attitudes to being contacted. Wellreceived phone calls were usually followed up by targeted letters to reinforce the contact. However this form of data base maintenance is time-consuming and expensive to conduct in an 
on-going way. The national secretariats of the ALP and the Liberal Party conduct on-going staff training in the use of their respective data bases for direct mail.

Gary Gray, at the time of interview in charge of the use of ALP direct mail in marginal electorates, explained that the Labor Party's Polfile was introduced in 1986 following research overseas to find the best methods of political communication with the electorate. The ALP decided to adopt direct mail methods, which Gray described as a method of:

...managing the electoral contact... [direct mail gives a] new and valuable focus on how the Member works the electorate...(Gray 1993, interview).

Though use peaks during campaigns, Gray claimed that between elections direct mail encourages contact between the Member and constituent. The focus is increasingly on local rather than national issues and on 'apolitical' topics. According to Gray, 'People hate politicians'. So the letters may cover such diverse subjects as food additives, motor car fuel efficiency, or provide a pensioner kit or a school kit on the greenhouse effect. The topics chosen are arrived at following results of market research or in a more serendipitous manner. Gray would on occasion collect ideas by wandering around MPs' offices picking up publications.

Charges that direct mail may constitute an invasion of privacy were contested by another ALP administrator who argued that the data base was built up from public documents and augmented by information that the person made public (Henderson 1993, interview). If an elector complains an apology is given and the person's name is withdrawn from the data base. From the perspective of organisational people the advantages of direct mail - when used to optimum effect - were identified as its personal nature, that it deals with issues of interest to the recipient, it can localise a national issue and it opens the opportunity for two-way communication between the voter and the MP. Principally, however, it is believed to win votes. 
A universally-acknowledged problem was the form of salutation. Whether to address a woman as Ms, Miss, Mrs or by the first name is a decision (conveniently) left to the individual Member. Whatever method is chosen, some voters will object. 'Some will be genuinely angry but some will be chuffed...swings and roundabouts' (Henderson 1993, interview).

Other identified disadvantages were the unending task of maintaining the data base and the problem that the electoral roll is never completely up to date, which can result in some very counter-productive situations, such as a recently bereaved widow opening a letter from the local MP addressed to her husband. Of course in an ideal situation the death would have been noted from the newspaper notices and the data base corrected accordingly. The example demonstrates the time-consuming and meticulous task of keeping the data base current.

Labor's national office people regarded advice to electorate offices staff on the message content as their responsibility. 'If we tell them direct mail is a good thing, which we do, and ask them to use it, which we do, then they are entitled to expect back-up support' (Henderson 1993, interview). A more cynical reason for the national office to support direct mail may be that it maintains control centrally. Candidates prepared to run in vital marginal electorates may not be skilled in the political arena and hence may be prone to make mistakes on policy detail which the media could exploit. If the candidates can be occupied in telephone canvassing which is followed up with a targeted letter the strategy is consistent, contained and controlled. Henderson believed that direct mail opens two-way communication when it is used outside the election campaign period. In his view:

At the end of the day, politics is about standards of living. If you are not delivering what are you doing in the business? Direct mail is about dealing with concrete issues. It makes better local Members who are more accountable to the voters (Henderson 1993, interview). 
Liberal organiser Gavin Bailey believed the advantage of direct mail is its ability to personalise the message which, allied with telephone canvassing, can set up channels of communication (Bailey 1993, interview). A Liberal party organiser/political scientist who had worked with the party machine contended that the context in which direct mail is used is all important. Mail which follows a telephone conversation is much more likely to be read than if the letter arrives 'cold'. Other factors which influence the effectiveness of direct mail are the profile of the candidate, the volume of mail and frequency of elections, whether it is used in a campaign period or between times and the content and tone of the letter. In other words the effectiveness depends on the circumstances and, with direct mail as part of an overall campaign strategy, it is very difficult to isolate its influence. Floating voters are direct mail's target because, in a marginal electorate, the difference of a few percentage points can be crucial to success or failure (Hamilton 1994, interview).

It is interesting that attitudes of organisation people from both major parties were remarkably similar. In summary their overall opinion of the voters' ability to absorb political messages was very sceptical. Agreeing that the objective of direct mail is to influence the floating voter, the view was held that constant repetition, glossy photographs and the illusion of presenting information was necessary to get the message across. If complex themes are introduced the message is lost:

Unfortunately with these people, while they're always complaining that politicians don't provide them with enough information, they're only really worried about the form and not the substance...So much of the message is presentation...If glossy photographs of people looking as if they're doing something is going to influence them, so be it, because they're influenced more by the photos and the big bold text than the detail that is in the letter - if you look as though you're presenting information, I think that's half the battle (Kerrisk 1994, interview). 
In similar vein, a Liberal strategist demonstrated (by putting a pointed index finger to his forehead) that getting the message across was like firing the concepts into the brain. This has been described as the 'bullet' theory and was popular in the communication theory literature in the 1920s. It is now regarded by some experts as '...oversimplistic and wrong' (Ward 1995, 24). However, in the 1920s, there was not the capacity to target messages by use of data bases of information allowing personally addressed letters on topics of concern to that particular person, as is the case in the 1990s. There is no doubt in the minds of these party operatives that the targeted, bullet-type message 'works'.

All party officers interviewed believed that targeting, local issues and use outside the campaign period were the most successful ways of using direct mail. Taking each of these in turn, some inconsistencies are evident. Generally television is regarded as having the most impact but its cost is prohibitive. Direct mail is thought to be the next best option. Yet television is a mass medium and by definition cannot be targeted to the extent that direct mail can (apart from time-of-day programming to identified audiences). There is also the question of which has the greater influence - television with national issues or direct mail with local issues. In fact both play a role.

Direct mail is used to reinforce television messages but it can also capitalise on an issue of particular concern in an area of an electorate or to a segment of the community. Directed at the floating voter, it is frequently used during the campaign, yet the common view is that it is most effective outside the campaign period. Again the truth may lie in between. If a voter has received a letter relevant to her interests outside the campaign period it is possible that she is more receptive to the message during the campaign.

These contradictions in interpretation may be an example of an unwillingness on the part of the party machine people to admit the limitations of application of technology in the complex area of people's political perceptions, where there are no simplistic answers. 


\section{Views of parliamentarians}

We can establish in the public's mind that we are their representative and we listen to their views and we care about what they say (Charles 1994, interview).

An estimated three-quarters of Members of the House of Representatives use direct mail (Gray 1993, interview). Senators from both parties are generally allocated a House of Representatives' seat or seats and send out letters in support of the Representatives' candidate. Members interviewed for this study were chosen (as described) to represent balance in their reputed views on direct mail. As these MPs were not chosen by random sample the proportion using or not using direct mail, or the views expressed, cannot be taken to be a true reflection of the entire parliament.

In this group users and non-users were fairly evenly divided between parties. Of the $14 \mathrm{MPs}$ interviewed (seven Labor and seven Liberal): one was an enthusiastic user, four used it quite often, three used it occasionally, four very occasionally and two did not currently use it at all, including one who was vehemently opposed on the grounds of invasion of privacy. The other minimal-using Members were of the view that the risks of antagonising electors with incorrect titles or inappropriate letters were too great and that the allocation of the resources in terms of time and money was not justified. Even some advocates of direct mail admitted to apprehension on the night following a direct mail-out for fear of errors.

There appeared to be generational differences in politicians' attitudes to direct mail (as with attitudes to CTs in general, observed by Parr 1994, see chapter two). Older Members were generally more content to rely on the traditional methods, while younger Members tended to be more positive towards direct mail, using it as an integral part of an overall campaign strategy. Like the views of organisational people, the questions of the most effective time to use direct mail and on the relative value of direct mail and television produced contradictory responses. In general 
most MPs interviewed believed direct mail could be a useful tool, particularly in marginal seats (Reith 1994, interview). Some predicted that it would lose its impact as people become more accustomed to it or if it was used excessively. However in the experience of people interviewed, it can improve communication when it is used between elections. 'It can empower people' (Kemp 1994, interview). One Member, a keen advocate, finds 'excuses' to send out direct mail and once a year sends out 42,000 postcards inviting constituents to a public meeting. 'If only 350 turn up, of whom 250 are Liberal Party members, it doesn't matter. The whole point is to have the excuse to send out 42,000 postcards' (Wooldridge 1994, interview). Direct mail was regarded as an effective method of inviting electors to meet their representative to discuss issues of concern and for politicians to listen and respond. 'You're actually going and asking voters - well, what really worries you? And what do you think should be done? And I reckon that's terrific! That's democracy!' (Minchin, a Senator, 1994, interview).

However opponents of direct mail said this purpose can equally be served by 'To the Householder' letters which invite contact. Some MPs estimate up to 10 percent of voters can respond to an invitation to write to the MP on personal problems or policy matters... 'some marvellously thoughtful letters on an enormous range of issues' (Langmore 1994, interview). Servicing this demand is extremely time consuming but is acknowledged as essential to maintaining credibility, once the invitation is issued. For this reason it appears that Members issue such an invitation with caution. Concurrently with a mail-out there is usually an increase in general constituency work, as electors are reminded of the assistance the MP can provide. A disadvantage commonly identified even by supporters of direct mail was the cost of establishing and maintaining the data base. A typical response of non-users was:

There's a lot of resources go into setting up the data base and you've got to ask yourself - Is it worth the effort? In our view we don't think it is (O'Keefe 1994, interview). 
Many Members asserted that the risk of antagonising an older woman with the term Ms was real and impossible to overcome without far more detailed data. On one occasion when one Member was obliged by the party machine to use direct mail she noticed a couple of dozen 'Ms' at one address. It turned out to be a convent. 'And you can't call them all Sisters, because some will be Mothers' (McHugh 1994, interview).

In addition, the electoral roll is never entirely up to date, so errors are inevitable. 'No matter how good the material on a name-byname basis is, there will always be mistakes and usually hundreds of them' (Aldred 1994, interview). The ability of direct mail to target particular people or groups was generally seen as an advantage, though one Member pointed out the danger of missing out on contacting people on a topic which may be of interest to them, such as pensioners who are concerned about unemployment and education because of worries about their grand-children. Several MPs mentioned the value of direct mail in building up the profile of a new candidate and in informing themselves about the issues in their particular electorate through contact with voters. MPs commonly used direct mail to welcome new constituents to the electorate, based on information supplied by the Australian Electoral Commission.

A number of MPs stressed the importance of the quality of the letter, saying it must be genuine, presented well and have relevant content. 'You can blow up all that goodwill if you write a lousy letter' (Charles 1994, interview). The individual Member should write his or her own messages to reflect their own personality. It was generally agreed that presentation and content of the communication are at a premium, competing as it does with commercial advertising:

If you say something stupid or which doesn't ring true to people, if they think you are cynical or off-track...it is very important to be genuine about what you're doing with direct mail and not treat it as an easy campaign device because I don't think it is (Kerr 1994, interview). 
An environmental issue which involved one Member in a controversy is often quoted when the advantages or otherwise of direct mail are discussed. It is mentioned here as an example of the potential political 'dangers' of direct mail. An ABC Four Corners program screened in October 1991 focused on privacy, highlighting information storage, security and cross-matching of data bases. The Member's office was filmed as part of the story. A critical segment in effect accused the Member for Eden-Monaro, Jim Snow, of sending contradictory messages to different interests in his electorate - one message to loggers and another to the 'greenies'. His explanation was that he merely supplied party policy in each case (Snow 1994, interview). The ALP national office feared a backlash and circulated all electorate offices with instructions on how to respond to constituent enquiries. About half the MPs asked for a briefing to handle media questions. In the event there were very few enquiries from electors following the program, but the episode does explain the reluctance of some Members to be wholehearted advocates of direct mail. The experience seems to have made Snow far more cautious in using direct mail in the policy area. A commonly used alternative to direct mail is electorate newsletters, which can exploit current issues and keep the MP's presence in the mind of the voters without the risks of personally-addressed letters:

Is it that people will be enticed or flattered to have their names on the envelope? That strikes at the heart of where you can go wrong. If people are going to be flattered to see their name, they will be offended if you get it wrong (McHugh 1994, interview).

Another concern is that people will perceive direct mail as a gimmick which entrenches the perception of hypocrisy and lack of sincerity of politicians (Kelly 1994, interview). One Member identified an issue which goes to the heart of problems of the marketing of politics by professionals, which is taken up later:

The perception and to some extent the reality of increasing mechanisation of campaigning...that individuals and grass roots members don't count (Minchin 1994, interview). 
Direct mail has resulted in a redirection of resources. Where previously parties would have put a substantial proportion of the campaign budget into television and press, a greater proportion is currently put into mailings. Though the Liberal Party commissions qualitative and quantitative post-election research on direct mail, interpreting the findings is problematic:

It's difficult for voters themselves to be objective about the effect of a particular message on them. They're being bombarded with messages all the time...you've got to fly a bit on the basis of your own political judgement. You can't measure it [the effect of direct mail] simply by whether you won or lost or improved your vote (Minchin 1994, interview).

Critical decisions are the timing, content, targeting and frequency of letters. One Member, who believed rather quaintly that floating voters typically make their decision on how to vote during family discussions at the Sunday lunch before the following Saturday election, targets his final distribution by this time (Somlyay 1994, interview). While both major parties have the same technological capacities, success depends upon the skill and political 'nous' of the people making the strategic decisions. 'That often is the difference in the effectiveness of the mail. You have to back your judgement, at the end of the day' (Minchin 1994, interview). One Member believed over-use of direct mail is counter-productive (contrasting sharply with the assumption of machine people that the message has to be repeated and hammered home). Of course, it depends on how effectively it is done. He was of the opinion that:

If it is well done, it reflects well on both the Member and the community - both are listening and understanding the dynamics of the relationship. People can feel free to come to the Member's office when they have a problem and be confident that if they have a view it will be heard and responded to and it may influence the way the Member sees things. All that is important. It's a fairly intimate way of doing things (Kerr 1994, interview). 
The consensus of MPs interviewed was that professional operators and most politicians support the role of direct mail in campaigns. In essence:

It's a question of how much, to whom, when and how - the mix and how good the data base is...it's a classic marketing approach. How do we cut through, get the message to the voters who matter. Whether direct mail is used is decided on a case-by-case basis (Minchin 1994, interview).

As stated, the MPs interviewed generally achieved better returns than MPs as a whole. They appear to be hard working local Members, with a higher profile (Mackerras 1994, interview). However, no definite pattern emerged from these data to indicate that use or non-use of direct mail 'worked' in gaining votes. Some high achievers used direct mail and some did not.

\section{Surveying voters in the Fremantle by-election 1994}

Very little evaluative research has been conducted in Australia by political scientists into the impact of direct mail on voting patterns although an on-going study is under-way through the University of Queensland under the direction of Ian Ward. The absence of research is surprising in light of the large financial commitment to direct mail by both major parties. Findings of the small amount of surveying conducted specifically on this aspect of direct mail for political parties are regarded as confidential, as surveying is expensive to conduct and gives the party which commissions it a perceived advantage in planning strategic campaigning. The cost of gathering information in this instance results in a jealous guarding of survey findings.

The usefulness of party surveys in attempting to answer questions specifically on the impact of direct mail is in any case limited. The objective of their surveys has been wider, with direct mail only part of the whole advertising effort. Some surveys were qualitative, aimed at evaluating which format for literature was most effective. In addition, as the latest to which I have access was 
conducted in 1989, in the context of rapidly-changing technology it is dated. In these circumstances, it was necessary to conduct a small survey of the impact of direct mail following a campaign. In the absence of any funding, resources available to conduct the survey were very limited. A random sample of electors in Fremantle was interviewed by telephone following a by-election in 1994. The methodology employed is fully reported at the end of this chapter. The objectives were broadly to examine the influence of direct mail on information flows and people's political attitudes and behaviour. The questions were directed towards eliciting:

- $\quad$ perceptions of voters towards personally-addressed letters from the candidates;

- whether or not the letters were read and why;

- reactions to and recall of the main messages;

- $\quad$ any influence on their view of the candidate, on their vote and on contact with the candidate;

- opinions on the suitability of the amount of information provided; and

- attitudes to privacy.

\section{General observations}

Several difficulties arose in attempting to evaluate the impact of direct mail in the Fremantle by-election. As in other campaigns, it was used as a part of the overall campaign strategy so it is difficult to isolate its influence in the minds of voters from other aspects of the campaign. This is particularly true when direct mail is used, as it was, to repeat and emphasise the messages in television advertising. However peoples' attitudes to the mail itself can be inquired into taking contextual factors into account.

Further, it is recognised that influences on political behaviour are very complex and often not recognised or acknowledged by the person being interviewed. There is a plethora of messages from the mass media, the voter's personal experience, the influence of peers and family, changes in economic and social situations, all of 
which influence political attitudes and perceptions. The extent of influence of each factor obviously varies between individuals. So the task of isolating the impact of one of these influences - direct mail - is daunting. However, in light of strong claims of the effectiveness of direct mail made by its proponents, it is relevant to investigate the attitudes of citizens to this means of political communication. Modern campaign strategies are like marketing strategies in general, selling the 'product', in this case the candidate. In something akin to technological determinism, parties appear to believe that they cannot afford not to use direct mail. Direct mail gives 'party faithful' in the electorate the impression that their team is being active so, from that point of view, it may stop votes being lost. By way of illustration one respondent stated that the letter from the ALP candidate had 'brought her back to Labor'. In fact, her vote had not changed between elections, but she had obviously been thinking of changing.

Whether party faithful on either side read the mail is immaterial to the campaign machine people. Parties take it for granted that committed voters will not change because of a direct mail letter. The objective is to sway floating voters into deciding to vote a particular way, which they believe direct mail can accomplish. This belief is bought into question with the particular circumstance of the Fremantle by-election. While this was a particular instance, it appears to me that the Fremantle example is a common one, and that the real campaign, particularly in a general federal election, is usually characterised more by disorganisation and crisis control, rather than the controlled environment the party machine people would prefer.

\section{The effect of direct mail in the Fremantle by-election}

From the survey results described below, it is clear direct mail as used in the Fremantle by-election did not sway floating voters, but it appears to have reassured existing supporters of the two main parties. It may have opened up communication channels between a few voters and the candidates, but was widely held by voters to be a waste of time and money. 
It is evident that the circumstances in which direct mail is used are very important. While its use there was not optimal: in reality, direct mail is very rarely 'ideally' used in Australia, as the interviews with MPs demonstrated. Thus the Fremantle experience is far more likely to be typical than the theoretical situation favoured by machine people.

\section{Analysing the Fremantle survey}

The data reveals two fundamental characteristics of political behaviour in this by-election:

- that party identification was the strongest factor determining attitudes to direct mail; and

- that floating voters were in general unimpressed and seemingly uninfluenced by direct mail.

For the purpose of analysis, frequencies and relevant crosstabulations are presented for each question or series of questions (Note: percentages are rounded). As there were a number of direct mailings, respondents were asked to frame their answers with reference to the most recent letter received. Closer analysis of the responses of floating voters follows. The candidates in this election from the major parties were Dr Carmen Lawrence, for the Australian Labor Party, and Mr Geoff Hourn for the Liberal Party of Australia.

\section{Voter perceptions of personally-addressed letters}

One of the rationales for direct mail put forward by its advocates is that people are more likely to be pleased to receive a personally addressed letter than one 'To the Householder'. Examining first the sample as a whole, respondents were asked how they felt about a personally-addressed letter from a political candidate and alternative answers were read out.

This question was intended to tap reaction to direct mail itself, rather than content or its source. In general, the responses show that about an equal number of people were interested and 
annoyed with both letters and that the most frequent response was 'uninterested' (see table 3.01).

table 3.01

\begin{tabular}{||l|c|c||}
\hline \multicolumn{3}{||c|}{ Attitude to letter(s) from candidate - percentages } \\
\hline \multicolumn{1}{||}{ Lawrence $(\mathrm{n}=141)$} & Hourn (n=141) \\
\hline interested & 24 & 25 \\
\hline pleased & 10 & 6 \\
\hline uninterested & 36 & 44 \\
\hline annoyed & 25 & 17 \\
\hline other & 5 & 6 \\
\hline
\end{tabular}

The cross-tabulations of feelings towards direct mail with party affiliation and by vote in the by-election demonstrate that people most frequently react according to their political persuasion. Labor voters were positive to the letter from the Labor candidate and Liberal voters positive to a letter from their party candidate. It is interesting to note that about the same percentage of party identifiers were annoyed and uninterested with the letter from their own candidate. Even in the 'uninterested' category, partisan influence is apparent. Labor voters were more uninterested in the Liberal letter, and Liberal voters more uninterested in the Labor letter (see table 3.02)

table 3.02

\begin{tabular}{||l|c|c|c|c||}
\hline \hline \multicolumn{1}{||c|}{ Attitude to direct mail by party identification - percentages } \\
\hline & \multicolumn{2}{|c|}{ Lawrence $\mathrm{n}=135$} & \multicolumn{2}{c||}{ Hourn $\mathrm{n}=127$} \\
\hline & Labor & Liberal & Labor & Liberal \\
\hline interested & 33 & 16 & 20 & 35 \\
\hline pleased & 22 & 3 & 8 & 12 \\
\hline uninterested & 24 & 43 & 51 & 27 \\
\hline annoyed & 13 & 32 & 18 & 12 \\
\hline other & 7 & 5 & 4 & 13 \\
\hline
\end{tabular}

People of either party who were very strong or fairly strong identifiers tended to be interested or pleased with the letters while people who were most annoyed did not identify strongly with a 
party. Not surprisingly, it would appear that those people with an interest in politics were more likely to feel positive to letters. The relatively high number of strong identifiers who expressed 'uninterest' in the Liberal letter may have been strong Labor supporters, in the context of a high profile Labor candidate (see table 3.03).

table 3.03

\begin{tabular}{|l}
\hline \hline \begin{tabular}{l}
\hline Attitude to letter by strength of party ID (either party) - \\
percentages
\end{tabular} \\
\hline
\end{tabular}

Any belief held by party organisation people that female candidates are more likely to be popular with female voters does not appear to be supported by these data. About the same percentage of women were positive (adding interested and pleased categories) and negative to each letter. The age of respondents by categories are numbers too small for meaningful analysis but the general indications are that the older age group were more interested in direct mail. Most pleased with the Hourn letter were the 55-64 year olds and with the Lawrence letter, the 25-34 year olds. For both the most uninterested were the 18-24 year olds and the most annoyed were the $35-44$ year olds.

As the categories for employment resulted in small numbers they have been condensed into two - working (full or part-time) and not working. Working people seemed to be less interested, perhaps due to a lack of time (see table 3.04). 
table 3.04

\begin{tabular}{||l|c|c|c|c||}
\hline \hline & \multicolumn{3}{|c||}{ Attitude to letter by employment - percentages } \\
\hline & \multicolumn{2}{|c|}{ Lawrence $\mathrm{n}=135$} & \multicolumn{2}{c||}{ Hourn $\mathrm{n}=127$} \\
\hline & in work & no work & in work & no work \\
\hline interested & 14 & 10 & 11 & 14 \\
\hline pleased & 6 & 4 & 2 & 5 \\
\hline uninterested & 21 & 15 & 28 & 17 \\
\hline annoyed & 7 & 18 & 12 & 6 \\
\hline other & 1 & 4 & 3 & 2 \\
\hline \hline
\end{tabular}

Finally in this section on attitudes towards the letters, even when qualifications were reduced to two categories - none since school and some since school - this factor appears to have no substantial influence. The pattern persists that more people read the Lawrence letter than the Hourn letter.

In summary it is clear the people are selective in choosing to read what supports their leaning and political disposition. In other words, party identification helps determine voter reaction to direct mail and appears to have been the over-riding factor in deciding a person's attitude to direct mail - more than sex, age or employment status.

\section{Whether or not the letters were read and why}

Another argument used by advocates of direct mail is that people are more likely to read a personally-addressed letter. However, the data show that the cross-tabulations of reading the letter by party identification demonstrates the same association as was apparent in feelings towards the letters (see above). Given the volume of direct mail during the by-election and in recent campaigns, the number of voters who said they read the letters is quite surprising - an average of about 60 percent, with 66 percent reading the Lawrence letter and 55 percent reading the Hourn letter. With regard to the most recent letter received, more women and men read the Lawrence letter. Age appears to have had little influence - except that the 35-44 and 45-54 year old groups leaned towards reading the Lawrence letter. The tendency 
of people to read letters from their own party candidate is again evident, though more strongly for Lawrence than Hourn (see table 3.05).

table 3.05

\begin{tabular}{|l|c|c|c|c||}
\hline \multicolumn{2}{||}{ Read letter(s) by party ID - percentages } \\
\hline & \multicolumn{2}{|c|}{ Lawrence $\mathrm{n}=136$} & \multicolumn{2}{c|}{ Hourn $\mathrm{n}=125$} \\
\hline & Labor & Liberal & Labor & Liberal \\
\hline yes & 80 & 51 & 49 & 66 \\
\hline no & 20 & 49 & 51 & 34 \\
\hline
\end{tabular}

People with strong party identification are more likely to read letters than those with little commitment, again demonstrating the reinforcing character of direct mail (see table 3.06).

table 3.06

\begin{tabular}{||l|c|c|c|c|c|c||}
\hline \hline Read letter(s) by strength of party ID - percentages \\
\hline & \multicolumn{2}{|c|}{ Lawrence $\mathrm{n}=101$} & \multicolumn{3}{c||}{ Hourn $=92$} \\
\hline & very & fairly & $\begin{array}{c}\text { not } \\
\text { very }\end{array}$ & very & fairly & $\begin{array}{c}\text { not } \\
\text { very }\end{array}$ \\
\hline yes & 69 & 74 & 56 & 54 & 62 & 35 \\
\hline no & 31 & 26 & 44 & 46 & 38 & 65 \\
\hline
\end{tabular}

The overwhelming reason given for not reading direct mail was that it would not influence the citizen's decision on voting. The main 'other' category nominated was 'waste of time and/or money', though this response was not identified in the pre-survey pilot as a common reason for not reading mail. The critics' concern over privacy does not appear to be significant from this survey (see table 3.07). 
table 3.07

\begin{tabular}{||l|c|c||}
\hline \multicolumn{3}{|l|}{ Why letters not read - percentages } \\
\hline & Lawrence $\mathrm{n}=46$ & Hourn $\mathrm{n}=56$ \\
\hline generalities & 4 & 5 \\
\hline boring & 4 & 5 \\
\hline repeat of TV & 11 & 7 \\
\hline no difference to vote & 41 & 45 \\
\hline only contact at elections & 7 & 4 \\
\hline actions not words & 2 & - \\
\hline letters are stereotype & 7 & 9 \\
\hline other & 24 & 25 \\
\hline
\end{tabular}

\section{Reaction to and recall of main messages}

In the context of effective avenues of political communication, an evaluation of the success of the direct mail involves some idea of whether people remember the message, their opinion of its content and whether it has affected their behaviour. The whole question of recall is problematical.

To get some sort of objective estimate on content, the last letter from each of the two candidates was analysed by the four interviewers independently and consensus reached as to what constituted the main messages in each letter. However, people's perception of what the important ideas were obviously varies with the individual. For this reason, the recall of all or some can be amalgamated and separated from no recall at all.

Asked what the main message in each letter was, 40 percent recalled all or some correctly and 47 percent could not remember. Labor voters tended to recall correctly all or some of the Lawrence letter and Liberal voters tended to recall correctly all or some of the main Hourn message, again demonstrating the strong influence of partisan affiliation. However, it will be noted that 34 percent of Labor identifiers and 43 percent of Liberal identifiers did not recall the main message from their preferred candidate (see table 3.08). 
table 3.08

\begin{tabular}{||l|c|c|c|c||}
\hline \multirow{2}{*}{ Main message recall by party ID - percentages } \\
\hline & \multicolumn{2}{|c||}{ Lawrence $\mathrm{n}=90$} & \multicolumn{2}{c||}{ Hourn $\mathrm{n}=70$} \\
\hline & Labor & Liberal & Labor & Liberal \\
\hline correct all & 21 & 5 & 23 & 19 \\
\hline correct some & 37 & 26 & 12 & 14 \\
\hline wrong & 5 & 11 & 19 & 24 \\
\hline inappropriate & 2 & & & \\
\hline not remember & 34 & 58 & 46 & 43 \\
\hline
\end{tabular}

The difference in interest between the two letters is apparent when the categories are collapsed into generally interesting or not, and show a large difference between the candidates. The contrast in the tone and expression of the letters may have had an influence on how people reacted. The Hourn letter was abrasive in tone and negative in content, which even some Liberal voters said they disliked. The Lawrence letter was practical and positive (see table 3.09).

table 3.09

\begin{tabular}{|c|c|c|c|c|}
\hline \multicolumn{5}{|c|}{ Opinion of messages - percentages } \\
\hline & \multicolumn{2}{|c|}{ Lawrence $n=47$} & \multicolumn{2}{|c|}{ Hourn $\mathbf{n}=37$} \\
\hline very interesting & 11 & \multirow[b]{2}{*}{66} & 5 & \multirow[b]{2}{*}{ \} 37} \\
\hline quite interesting & 55 & & 32 & \\
\hline not very interesting & 19 & \multirow[b]{2}{*}{ \} 34} & 35 & \multirow[b]{2}{*}{ \} 62} \\
\hline not at all interesting & 15 & & 27 & \\
\hline
\end{tabular}

\section{Influence on view of candidate, on the vote and on contact}

Of those surveyed, none responded that they had changed their vote as a result of direct mail. For Hourn, 19 percent changed their attitude to be more favourable towards him and the same percentage changed their attitude to be less favourable. While it is acknowledged people may be unlikely to identify direct mail as the reason for a change of attitude or especially voting patterns, the above figures perhaps should cause some re-evaluation of the 
political parties' expectations of the influence of direct mail in changing voting behaviour. Eight percent of those surveyed either wrote back to or contacted Lawrence, whereas only one percent wrote back or contacted Hourn.

\section{Opinion of the amount of information}

As a central argument in favour of direct mail is that it provides information, it is interesting to look at voter reaction to the amount of information. These figures show that 38 percent of non-identifiers do not want letters. More Labor voters were satisfied with the amount of information, but more also thought there was too much.

Analysis by strength of party identification showed that people with strong identification were more inclined to think the information was the right amount compared to those without strong party identification (see table 3.10).

table 3.10

\begin{tabular}{|c|c|c|c|}
\hline \multicolumn{3}{|c|}{ Amount of information by party ID - percentages } & \multirow{2}{*}{$\begin{array}{c}(n=137) \\
\text { No party }\end{array}$} \\
\hline & Labor & Liberal & \\
\hline not enough & 9 & 14 & 8 \\
\hline right amount & 46 & 27 & 25 \\
\hline too much & 33 & 27 & 21 \\
\hline didn't want & 7 & 30 & 38 \\
\hline other & 6 & 3 & 8 \\
\hline
\end{tabular}

The data analysed by gender tend to contradict the rather chauvinistic view of some party officials that women at home welcome direct mail. In fact, theirs was the highest response in the 'too much' category (41 percent). On the occupation cross tabulation, 43 percent of people 'keeping house' responded that there was 'too much' and 24 percent did not want any. By age group the 45-54 year olds were the biggest group who thought there was too much information (44 percent) and the $65+$ age group were the largest who did not want any (32 percent). 
Peoples' attitude to candidates holding lists of voters' names and addresses for direct mail was ambivalent. Opinion on the holding of lists was almost evenly divided, with 40 percent in favour, 37 percent opposed and 23 percent unsure. People with weak party identification tend to be more opposed to lists and people with strong party commitment more in favour than against (see table 3.11).

table 3.11

\begin{tabular}{||l|c|c|c||}
\hline \hline & Opinion of lists by strength of party ID - percentages & ( $\mathrm{n}=105)$ \\
\hline & very strong & fairly strong & $\begin{array}{c}\text { not very } \\
\text { strong }\end{array}$ \\
\hline for & 65 & 43 & 15 \\
\hline against & 23 & 30 & 75 \\
\hline don't know & 13 & 26 & 10 \\
\hline
\end{tabular}

\section{Analysing floating voters more closely}

The aim of direct mail is to convince floating voters to vote for a particular party. Party strategists are not under an illusion that partisan voters will change their votes because of arguments in a letter from a party they do not normally vote for. Further, communication theory shows that people tend not to radically alter their voting attitudes by switching between the major parties (Lemert 1981, 97) though in Australia with two-party preferred vote, the direction of preferences is important.

It does appear that direct mail may reinforce party allegiance, reassuring the committed voters that their candidate is actively campaigning. When the Fremantle survey data was analysed, isolating the committed voters from the floating voters, some interesting results were found which call into question commonly-held assertions about direct mail. What motivates the floating or swinging voter? For this purpose the floating voters are taken to be all those who did not identify very strongly or fairly strongly with either of the major parties. They constituted 
48 people, or 34 percent of the sample. It can be argued that while some, even the majority, are entirely uninterested, some are discerning citizens who consider issues and decide on the merits of the contending candidates and the issues. Floating voters were generally less interested, with virtually no floaters pleased and a large number of them fairly annoyed with both letters (see table 3.12).

table 3.12

\begin{tabular}{|c|c|c|c|c|c|c|}
\hline \multicolumn{7}{|c|}{ Attitude to letter(s) by party /floating ID - percentages } \\
\hline & \multicolumn{3}{|c|}{ Lawrence $n=122$} & \multicolumn{3}{|c|}{ Hourn $n=115$} \\
\hline & Labor & floater & Lib & Labor & floater & Lib \\
\hline interested & 36 & 15 & 15 & 22 & 28 & 31 \\
\hline pleased & 26 & 2 & 4 & 9 & - & 17 \\
\hline uninterested & 19 & 54 & 41 & 51 & 48 & 31 \\
\hline annoyed & 11 & 27 & 37 & 13 & 20 & 13 \\
\hline other & 9 & 2 & 4 & 4 & 4 & 15 \\
\hline
\end{tabular}

As stated, no-one in fact responded that they changed their vote because of a letter. The main reason in the 'other' category was waste of time/money (see table 3.13).

table 3.13

\begin{tabular}{||l|c|c|c|c|c|c||}
\hline \hline & \multicolumn{3}{|c|}{ Lawrence $\mathrm{n}=41$} & \multicolumn{3}{c|}{ Hourn $\mathrm{n}=51$} \\
\hline & Labor & floater & Lib & Labor & floater & Lib \\
\hline generalities & & 11 & & & 4 & 14 \\
\hline boring & & 11 & & & 13 & \\
\hline repeat TV & & 16 & & 5 & 8 & 14 \\
\hline no diff. to vote & 57 & 26 & 60 & 70 & 29 & 43 \\
\hline only at election & & 5 & 13 & & 8 & \\
\hline actions,not words & 14 & & & & & \\
\hline stereotype & 29 & 5 & 7 & 15 & 8 & \\
\hline other & & 26 & 20 & 10 & 29 & 29 \\
\hline \hline
\end{tabular}


Floaters remembered all or some of the Lawrence and Hourn messages equally. The preportion of floaters having no recall of the letters was about the same for both candidates. It was more likely that party identifiers would remember (see table 3.14).

table 3.14

\begin{tabular}{||l|r|r|r|c|c|c||}
\hline \hline & \multicolumn{3}{|c|}{ Lawrence $\mathrm{n}=82$} & \multicolumn{3}{c||}{ Hourn $\mathrm{n}=63$} \\
\hline & Labor & floater & \multicolumn{1}{|c|}{ Lib } & Labor & floater & Lib \\
\hline & 20 & 7 & 8 & 23 & 18 & 20 \\
\hline correct all & 37 & 38 & 17 & 12 & 27 & 13 \\
\hline correct some & 5 & 7 & 8 & 19 & 9 & 27 \\
\hline wrong & 2 & 3 & & & & \\
\hline inappropriate & 37 & 45 & 66 & 46 & 46 & 40 \\
\hline not remember & 37 & & & & & \\
\hline
\end{tabular}

Floaters found the letter from Lawrence slightly more interesting than the Hourn letter but 69 percent found the Lawrence message not very or not at all interesting and 75 percent found the Hourn message the same (see table 3.15).

table 3.15

\begin{tabular}{||l|c|c|c|c|c|c||}
\hline \hline Opinion of message by party/floater - percentages \\
\hline & \multicolumn{3}{|c|}{ Lawrence } & \multicolumn{3}{c||}{ Hourn n=35 } \\
\hline & Labor & floater & Lib & Labor & floater & Lib \\
\hline very interesting & 16 & 6 & & & & 11 \\
\hline quite interesting & 72 & 25 & 75 & 21 & 25 & 67 \\
\hline not very interesting & 12 & 31 & & 36 & 50 & 22 \\
\hline not at all interesting & & 38 & 25 & 43 & 25 & \\
\hline
\end{tabular}

Gender differences were minimal in terms of floating voters' reactions. Almost none, male or female, was pleased with either letter. Interest declined with increasing age. The 35-44 age group were most annoyed with both. The pattern continues with employment categories but numbers are very small. Of the floaters, 28 people of the sample size of 48 people were in full or part-time work. More floaters were unemployed than in the general population. Of the floating voters, 19 had no 
qualifications since school and 29 had. More floaters with qualifications since school were uninterested or annoyed than were those with no qualifications since school (see table 3.16).

table 3.16

\begin{tabular}{||l|c|c|c|c||}
\hline \hline \multirow{2}{*}{ Floater attitude to letters by their qualifications -percentages } \\
\hline & \multicolumn{2}{|c|}{ Lawrence $\mathrm{n}=48$} & \multicolumn{2}{c||}{ Hourn $\mathrm{n}=46$} \\
\hline & no quals & some quals & no quals & some quals \\
\hline interested & 6 & 8 & 11 & 17 \\
\hline pleased & 2 & & & \\
\hline uninterested & 23 & 31 & 20 & 28 \\
\hline annoyed & 6 & 21 & 9 & 11 \\
\hline other & 2 & & 2 & 2 \\
\hline
\end{tabular}

More female floaters read the Lawrence letter than read the Hourn letter. Slightly more working floating voters read Lawrence than Hourn. Of floaters working full time, about half read the letters. Of floaters working part-time, there was a big party difference (favouring Labor). Retired floaters tended to read both letters, and Housekeeper floaters tended to read Lawrence more than Hourn.

\section{Contextual influences}

The following circumstances seem to influence voters' attitudes to direct mail. Whether the mail arrives in a campaign period is one critical factor: the Fremantle survey showed that some respondents were cynical of mail that came during the campaign. They perceived it to be mere vote-bidding material and tended to dismiss its sincerity. The volume of mail is also an important issue which influences whether or not it is read. A common comment from people interviewed was 'I read the first one and put the rest in the bin'. Competing as it does with advertisements from commercial companies in leaflets and also personallyaddressed letters from corporations, the 'currency' is devalued. Over 25 percent of respondents in the Fremantle survey commented that direct mail was a waste of time and money. Some were quite angry, on environmental grounds, at the 
volume of paper. In this connection, it is pertinent to remember that voters in Fremantle had been subjected to three election campaigns in the previous two and a half years, so their patience with political literature may have been wearing thin. Another important variable is whether direct mail is sent to all voters in the entire electorate on a general theme or targeted to a specific group addressing their interests and concerns. Studies in the US have shown that segmentation of the electorate increases the impact of direct mail (O'Shaughnessy 1990, 91-2).

In Fremantle, with a snap election, there was not time for political parties to develop properly-targeted lists, though the Labor Party did target geographical areas for invitations to 'Coffee with Carmen' as well as concentrating on residents of housing estates and the numerically-significant Maltese community. The Liberals' campaign was more generic. In an ideal and on-going operation, data base lists would be regularly updated and used in a targeted way during the campaign. Neither party had developed optimal lists.

Another factor which MPs believe influences the reception given to direct mail is whether the topic is of national or local interest. It appears that current, neighbourhood concerns are more likely to receive a positive reaction, indicating to the voter that the candidate has an awareness of local issues. Letters in Fremantle generally covered national topics. The content and tone of the letter are important as was demonstrated with the Fremantle survey. People appeared to react adversely to purely negative messages, in contrast to the view of some pollsters of their effectiveness (see interview with Textor, chapter five).

Finally, the expected election result has an influence on the reaction to direct mail. Marginal electorates are subject to intensive campaigning attention. Where the contest is close it could be assumed that people may take more interest in direct mail from candidates. However, Fremantle is generally regarded as a safe Labor seat, so there may have been less electorate interest, though media interest was intense. In summary, though the 
Fremantle example was not ideal for direct mail, it presents an accurate picture of the usual use of this campaigning method.

\section{Comparing Fremantle results with previous surveys}

Note: The source of the following survey is confidential and available to the examiners only.

With the caveat of contextual influences, discussed earlier, it would appear that direct mail in political campaigning may be becoming less effective. This is the instinctive feeling of many politicians (see interviews). Certainly it has not made people more favourably disposed towards politicians and has coincided with increasing disinterest and cynicism, as demonstrated in public opinion polls (see chapter seven).

Direct mail was less influential in the by-election studied than it appears to have been in previous elections in the city of Perth. The explanation may lie in the fact that it is now more commonly used in the political context and frequently used by commercial interests for marketing. Voters appeared much less impressed with personally-addressed letters from politicians in 1994 than they were five years earlier. Comparative survey results show there is an increase in the percentage who do not read direct mail, as there is in the percentage who read it but do not remember its contents.

While Fremantle survey findings are not directly comparable to those from a survey of two other Perth electorates in 1989 because of differences in wording and context, a pattern emerges. In 1994, there was a higher percentage of people generally unfavourable towards direct mail. More people did not want letters at all. The 1989 survey reported 11 percent of people said direct mail had an influence on their vote. In the Fremantle survey, the question was different, but none said that it influenced them to change their vote. Comparing the 1989 survey with the Fremantle survey on the question of recall, the 1989 survey reported that 31 percent of respondents had some recall (Fremantle, 40 percent), it was not read by 30 percent (Fremantle 42 percent) and read but not 
remembered by 39 percent (Fremantle 47 percent). In regard to the amount of information, the surveys reported as follows (see table 3.17).

table 3.17

\begin{tabular}{||l|c|c||}
\hline \hline \multirow{2}{*}{ Comparing surveys for amount of information - percentages } \\
\hline not enough & 1989 & 1994 \\
\hline right amount & 18 & 10 \\
\hline too much & 22 & 34 \\
\hline unsure & 54 & 34 \\
\hline not want any & 6 & \\
\hline \hline
\end{tabular}

Combining the too much and not any categories from the 1994 survey (53 percent) the results in this instance are similar.

If the categories of 'too much' and 'not want any' mail are combined, the majority of people in the two surveys have been negative. Over this time, people with higher education levels, who previously were more interested, have become the group most likely to be annoyed. The Fremantle result indicated that people with tertiary qualifications (30 percent) were not more likely to read direct mail letters and were in general far more negative than positive in their reactions to letters from candidates.

It is impossible to isolate positively the impact of direct mail from general social changes. Certainly, the use of the new CTs in political campaigning has accompanied a decline in membership of political parties (see chapter two). Mass media on the one hand has distanced political actors from voters but has also made voters more familiar with the more prominent political figures. The conclusions reached from this comparison of attitudes to direct mail over time are that it does not appear to have had the effect of significantly opening channels of communication between politicians and voters. The conclusion from this survey is that the technology used is largely irrelevant to the impact of the campaign and that context and content are far more important. It 
could be argued by its advocates that the way in which direct mail was used in Fremantle did not exploit its full potential. The lists were scarcely targeted.

However, on observation, this is most commonly the case. In this vein, Fremantle is an example that direct mail is frequently not used to its best advantage in Australia.

There is a trend in the US of using targeting to exclude people who are not worth contacting, so that resources are allocated to best effect. 'Voter registration, for example, is rarely considered because newly registered voters are less likely to turn out than established voters' (Ganz 1994, 104). Further, registration drives require volunteers, or costly paid workers. Segmenting the electorate to articulate narrow themes means the message is targeted to where it will have maximum impact. Thus:

Matching voter files with tapes of phone directories, ethnic surname directories, county assessor records, and voter turnout reports makes it possible to generate lists of voters individually profiled by their party affiliation, age, gender, marital status, home owning status, ethnicity and frequency of voting (Ganz 1994, 104).

The information available in the US to build up data bases to this degree of detail is not available in Australia.

\section{Conclusion}

There appears to be considerable variation between the expectations held by party machine people, the opinions of MPs and the reaction of voters to direct mail. MPs' interviews show a range of reservations amongst some members, irrespective of party, in contrast to the uniform support of the party machine people of both parties. The latter had far more faith in the influence of direct mail than is justified by the Fremantle findings. The enthusiasm of the party machine for direct mail to maintain and reinforce control in marginal electorates is 
understandable. The support among many MPs is more surprising, especially as it costs them resources and money to maintain an ever-changing data base.

In practice, support is often more in theory than in reality, as the interviews showed. MPs adapt direct mail to meet their particular electorate needs and use it in different ways. In contrast to the cynical attitude of the party machine people, MPs interviewed seemed sincere with regard to serving their constituents and certainly held much more respect for their intelligence.

The arguments in favour of direct mail are that, used in the best way, it makes the Member seem more attentive to the constituents and more aware of local issues. It is also claimed to open channels of communication. Against direct mail is the basic fact that it gives an illusion of being personal. An efficient staff builds up and maintains a comprehensive data base on electors. The Member signs the letter or it bears a facsimile of his or her signature. Contrary to the prevailing wisdom, direct mail can be used as a method of avoiding contact with voters by using a screen of technology.

The Fremantle survey data revealed that direct mail may have an impact but not the effect that its advocates believe. It appeared to reinforce party identification, with Liberal voters being more positive to the Liberal direct mail and similarly Labor voters being more favourable to Labor direct mail. This factor was overwhelmingly more important in influencing attitudes than any other. The floating voters were generally unimpressed. No respondent said they changed their vote. The most common reason for not reading the direct mail was that a letter would not influence the person's vote, which tends to underline the influence of traditional party affiliation on Australian voting behaviours.

Some people interpret direct mail as a ploy, making them inclined to dismiss it. On average about eight percent gave the response 'they're just stereotyped letters' as the reason for not reading them. Comparing data over time, the trend appears to be that 
there is a tendency for the impact of direct mail to be decreasing but much more research is needed, controlling for different variables, to establish the truth or otherwise of this.

My survey showed the gap between the rhetoric and the reality. Direct mail is rarely used to optimum effectiveness in Australia. In Fremantle, direct mail did not appear 'to work'. People were mostly uninterested, though identifiers were more positive than floaters but only towards their own party. Survey results show questionable return for the money and time invested in direct mail. In fact, taking into account the tone of the comments of voters, it may have increased cynicism to things political. The fact of the technology is much less important than the way in which it is used. Direct mail is a tool and its effectiveness depends on its contribution to an over-all campaign strategy. The real question is whether an equal result could be achieved by traditional methods of campaigning at much less cost and without the inherent dangers of antagonising people and making political parties obligated to their sources of funding.

I conclude that using direct mail appeared to have had no more advantage than a 'To the Householder' letter. Certainly being invited to meet the member or candidate is a positive influence and direct mail can help by being the 'invitation'. However the disadvantages, which are impossible to overcome, of incorrectly or inappropriately addressed letters remain substantial. It is not possible to maintain a completely accurate electoral roll - thus, letters to deceased people are inevitable. The question of invasion of privacy is another which remains a basic problem for direct mail. In summary it would appear that the effort and expense of maintaining an effective data base for direct mail is not worth doing in terms of votes gained, given the floaters of Fremantle findings.

Does 'direct mail work'? In theory, it should and might. If the data base is sufficiently comprehensive to include correct details of the concerns of the individual voter and is regularly updated: if direct mail is sent for specific communication on a current issue infrequently - and is accompanied by an invitation for comment 
from the elector, then I surmise that it may have a positive impact. It would be necessary to conduct repeated surveys on different uses of direct mail and control for all extraneous variables to reach a definitive conclusion on its influence.

To address the first research question from the survey and interviews reported in this chapter: the impact of one of the new CTs on campaigning, taking direct mail as the example, was of little consequence in gaining votes in the Fremantle by-election. Direct mail as a constituent part of the direct marketing of politics appears to have substantially altered the relationships of the players in the game. Professional pollsters, strategists and public relations consultants have increased their influence, replacing in some instances the traditional contribution of the 'grassroots'. This has had the effect of marginalising 'ordinary' members and party supporters (as Minchin pointed out) and of being a factor in the increasing disillusionment and apathy reflected in the polls. As some participation in the political process - to whatever degree is judged appropriate - is generally perceived to be important, this development could be detrimental to Australian democracy in the longer term. 


\section{Interest Groups and Communication}

\section{Technologies}

\section{Introduction}

While some argue that interest groups enhance representation and accountability by providing people a means of articulating their interests and holding public officials accountable for their actions, others claim that a political system dominated by interest groups is biased against people who, for whatever reason, cannot organise, and produces public policy distorted in favour of a few wealthy interest groups at the expense of the public interest (Mundo 1992, 3).

The aim of this chapter is to investigate the extent and effectiveness of interest groups' use of CTs, including direct mail. The current use of CTs is assessed, including whether the cost of CTs is a factor in their adoption for smaller organisations. The experience of some interest groups in the US appears to be that CTs have been very influential, in terms of internal organisation and external liaison (see Bonchek below). Personal interviews with representatives of 10 Australian interest groups provide an overview of various communication methods to allow a preliminary opinion to be formed regarding whether CTs are yet transforming political communication by such groups. Information on access to and use of CTs was gathered from a further four groups; the questionnaire used was identical to that used for electorate offices (reported in chapter five). 
Put in terms of the second research question posed in chapter one, this chapter investigates the influence of CTs on people's participation in the democratic process and also considers the second assertion - that technology can save democracy - by examining whether the use of CTs has empowered sections of the population. It represents the fourth point in the five way information flows approach - how people convey their concerns to decision-makers.To provide a framework and method of comparison, Australian interest groups were asked questions which paralleled the US study. A group from Harvard University developed the Political Participation Project (PPP), reported in a paper entitled Grassroots in Cyberspace, which said in its mission statement:

Our purpose is to understand how computer networks are affecting political participation in the United States, both traditional (campaigning and voting) and electronic (e-mail letters and online petitions) (Bonchek 1995, 1).

The effect of CTs on political participation incorporates two dimensions - both the internal operations of the group and its external functions. As part of the PPP, a study of interest groups examined the increasing use of computer networks to organise political activity in the US. The hypothesis was that computermediated communication (CMC) reduces the transaction costs associated with organising and thus assists collective political action. Seven case studies of interest groups upheld the conjecture that CMC reduced costs of communication, coordination and information and facilitated group formation, efficiency, member recruitment and retention. However, the study also found that the benefits were tempered by two factors. Inequalities in computer literacy and network access led to a partiality in political representation towards young, male, educated and affluent citizens. 'The bias introduced by CMC exacerbates existing distortions in the political system' (Bonchek $1995,19)$. In addition, because sending information is easier than processing information, the risk of information overload emerged as an increasing problem. 


\section{The role of interest groups}

As the opening quotation pointed out, participants in the debate on the centrality of interest groups in the US either applaud or decry their influence (Petracca 1992, 3). On one hand, the role of interest groups in providing representation for citizens is valued; on the other, the power that interest groups can wield is distrusted, reflecting what has been termed '...a deep and persistent ambivalence' (Ornstein and Elder, 1978, 8). Changes in attitudes towards the influence of interest group appears to be cyclical (Ornstein and Elder, 1978, 9). In any event, 'In the postwar era, American political science has been dominated, indeed defined, by the study of groups' (Petracca 1992, 4). Interest groups are an influential factor in the pluralist model which continues to dominate political theory and analysis.

However their desirability is interpreted, interest groups are part of the political environment. Further, as individuals are relatively powerless in their influence on government and bureaucratic decision making, joining an interest group provides an avenue for the citizen to promote either their economic interests or a 'cause' in which they believe. Such membership may go some way towards redressing the balance of power of political parties, the bureaucracy and corporations, all of which in general have greater access to CTs than do most individuals.

Interest groups are referred to by various terms - special interests, vested interests, pressure groups, organised interests, political groups, the lobby and public interest groups (Petracca 1992, 5). The names reflect diverse operational definitions. With Mark $P$. Petracca, I will use the term interest group as generic to refer to organisations or institutions which engage in activities to seek specific policy goals from the state (Petracca 1992, 7).

It is germane to consider theories on interest group formation, as this is one of the activities held to be influenced by CTs. A theory put forward by David Truman reflects the pluralist conception of politics and postulates that interest groups form when the usual 
state of equilibrium in society is disrupted and certain groups are adversely affected. People organise when they perceive they have a common interest and need to take political action to redress a situation (Mundo 1992, 20). This model assumes the citizens are aware of their interests, that they have information on who shares their concern and that they have the necessary resources to form an interest group and engage in political activity - conditions not often met in fact. Subsequent theories have focused on factors which influence the reasons for joining a group and have broadly identified three types; purposive/expressive (to pursue a goal or ideology), utilitarian/economic (to achieve tangible economic benefit) and solidarity (to gain camaraderie) (Mundo 1992 drawing on Clark and Wilson, 21). People may be motivated by more than one of these factors.

As well as providing an avenue for citizens to influence government policy, interest groups provide a major source of political information for their members and foster political participation to varying degrees. Pressure from interest groups tends to make government officials more accountable. Lobbying is the central thrust of activities, by way of meeting personally with influential officials, appearing before congressional or parliamentary hearings, and providing technical information on issues and networking. A strategy which has become more prevalent in the US, particularly by single issue, ideological groups, is electronically alerting grassroots membership to channel support or opposition of an issue - for example the US National Rifle Association uses its large membership to pressure members of Congress (by phone and fax) to oppose gun control legislation (Mundo 1992, 11).

\section{Participation and power}

The acceptability of political participation amongst some bureaucrat planners of the late 1960s in Australia (particularly in urban renewal) has been largely replaced by an emphasis in the 1990s on best practice management (underpinned philosophically by economic rationalism). Participation is perceived by some 
planners to jeopardise efficiency and challenge the power of policy makers.

Authorities can attempt to use consultation with the community to legitimise decisions already reached. "The "other face" of participation as an encounter between outside groups and authority structures is the "co-option" or "buying off" of opposition through taking its spokespeople on board' (Painter 1992, 25). While negotiation may require compromise, many interest groups prefer partial influence to complete exclusion from decision-making, unless there are political reasons for a 'hard-line' approach (see Wilderness Society interview below).

\section{CTs and US interest groups}

What activities do interest groups undertake to influence government policy and have their methods been influenced by the new CTs? In the US, activities such as lobbying Members of Congress or Senate and the bureaucracy, participating in election campaigns, taking legal action, raising money, mobilising grassroots support and forming coalitions with other organisations have all been affected to a greater or lesser extent by use of CTs. Petracca observed: 'What is new about interest group activity is its breadth and magnitude, enhanced by the new communication technologies' (Petracca 1992, 19). Satellites, cable, videocassette recorders and computers have transformed the way interest groups organise and mobilise members, raise money and attempt to influence government policy. Interest groups use direct marketing techniques and have become active in initiative and referenda in US state and local politics. Supporting the Mark Bonchek hypothesis that computer networks influence political participation, Petracca identified video distribution and communication through on-line data services as factors which have made group formation and maintenance easier.

In this context, the communication used by the interest group leadership is important, enabling faster and wider dissemination of information. Members, though enabled by fax and mobile 
phones, cannot in general contact leaders as easily as the leaders can communicate with them. Thus the leadership's domination of communication strategies gives them greater power. The growth in the number and financial power of Political Action Committees (PACs) in the US has been enormous. In 1976 there were 1,146 PACs, by 1982 3,722 and in 1988 nearly 5,000. Total PAC spending (all contributions and independent expenditure) rose from $\$ 103 \mathrm{~m}$ in 1982 to $\$ 364 \mathrm{~m}$ in 1988 (Petracca 1992, 20). After peaking in 1988, the number of PACs declined slightly - in the year to December 1992, there were 4,195 PACs, spending $\$ 394.1 \mathrm{~m}$ (Stanley and Niemi 1994, 178).

A criticism of interest groups has been the inordinate influence of big economic interests in influencing decisions, often using direct mail and expensive media techniques. Charges have been made that measures to improve community wellbeing have been defeated by monied interests:
A few of the measures that big money helped defeat in recent years included bills that would have raised the alcohol tax, required greater oil and gas conservation, created smoking regulations, required stricter hand gun control, promoted forest conservation, placed a surtax on oil profits and limited state salaries (Georges 1993, 42).

An academic reached the same conclusion in observing the relative power of business and community interest groups in influencing outcomes of referenda. 'Money is, other things being equal, the single most important factor determining direct legislation outcomes' (Cronin 1989, 215).

CTs have enabled more extensive mobilisation of public opinion than was practical earlier. 'Interest groups increasingly use direct mail to solicit contributions and encourage members to write to their Members of Congress to express their views on particular bills' (Mundo 1992, 29). It has been argued that CTs have empowered groups previously excluded from influence. 'The explosion of information technologies has revoked the near monopoly on access to policy makers that high-priced lobbyists 
and prestige journalists once held' (Henderson 1995, 43). Moreover, it would appear that modern technologies have made it relatively inexpensive for some individuals to form a single issue organisation.

Recent examples in the US of the speed and influence of 'cyberdemocracy' illustrate its effectiveness. A provision of the Federal Elementary and Secondary Education Act required school districts to employ certified teachers only. Parents educating their children at home feared this might force them to enrol in traditional schools, and, organising through the Internet, they protested by phone and fax to Capitol Hill, which was a factor in the success of the campaign (Henderson 1995, 44). Environmental legislation was defeated following pressure from property rights groups communicating, amongst other ways, through the Internet. In September 1994, when Congress tried to mandate that advocacy groups disclose donor sources to the Inland Revenue Service, pressure from an unlikely coalition of interest groups, alerted electronically, swamped Capitol Hill switchboards and defeated the lobbying bill. Americans for Tax Reform uses CTs to promote its anti-tax, anti-regulation messages (Henderson 1995, 45).

To gather information to use in their representations, citizens can reach the Library of Congress 'Thomas' program on the Internet and download any legislation within moments of it being filed. 'Organisations across the political spectrum form "working groups" to respond to legislation affecting areas as disparate as immigration, criminal sentencing and gun laws. A few hours after a meeting ends, thousands of activists can learn by fax or email what's happening in Washington and what they can do to assist legislative battles' (Henderson 1995, 46). The relative power of these campaigns obviously varies widely, supported financially, as some are, by business interests such as the tobacco industry.

The most definitive investigation and analysis of seven interest groups' use of CTs in the US was conducted by a group from Harvard, as described, and is on-going. Case studies were reported to illustrate the point. Chinese student organisations on campus 
communicated via the Internet and engaged in lobbying activities to pass legislation to protect them from reprisals from China. CTs were used in organising support, campaigning, creating a public forum and distributing news (Bonchek 1995, 11). The Public Electronic Network (PEN), further described in chapter six, was the first interactive public computer network and tackled the problem of homelessness. A survey of 62 PEN Action Group members found that CTs on the PEN system had improved communication, organisation and information exchange (Bonchek 1995, 12). SCARNet is a computer network run by the Smoking Control Access Research Centre, which links antismoking activists electronically, with email, news data bases and computer conferences.

Online Government Access requires the California government to provide on-line access to the public to information on current and existing legislation without charge (Bonchek 1995, 13). An Internet mailing list and email were used successfully to lobby on this issue. The Institute for Global Communication is part of a coalition to promote environmental protection, peace and human rights (Bonchek 1995, 15). Members can send and receive email, participate in conferences on-line, access data bases and distribute information. CTs do not advantage worthy causes only. The case studies also covered activities of the White Supremacist and Neo-Nazi Movements and demonstrated that low transaction costs of CTs have facilitated communication, coordination and information distribution amongst members (Bonchek 1995, 16). Finally, Bonchek analysed the Telecommunications Policy Roundtable, which aims for public involvement in debate on telecommunication policy. In conclusion, he observed that the case studies supported the hypothesis:

Computer-mediated communication offers geographically dispersed groups with a need for intra-organisational communication and information exchange an important alternative to more costly personal and broadcast media. CMC reduces communication, coordination, and information costs, facilitating collective action by making it 
easier for groups to form, improving the group's efficiency at providing collective goods, increasing the benefits from group membership and promoting group retention through more informed decision-making (Bonchek 1995, 20).

\section{Examples of US environmental interest groups}

In general, and in contrast to Australian groups interviewed, US groups were constant and proficient users of CTs, though with environmental groups the problem of the information-poor globally re-emerged. It certainly appeared that the hypothesis regarding reduced transaction costs was a significant factor operating in their organisations. In the US, direct mail has reached new levels of specialisation, facilitating 'participation' with a minimum of effort. Lobbying through computer or phone bank enables the individual to give their name and address to the interest group, the computer attaches it to a pre-written letter and sends it to Capitol Hill. 'Special interest groups and lobby groups in Washington are masters of this' (Paul 1995, interview). Computer-generated email to Members of Congress can be responded to by computer - '...humans are out of the loop' (Paul 1995, interview). As a result, electronic communication is to an extent devalued, unless it is targeted or there is a particular reason for taking note of it.

However, for the US-based 'green' interest groups, the logistic constraints in mobilising people worldwide are computer access, telephone lines, fax access and basic understanding of how to use technology. Some regions of the world which most need environmental protection do not have computers or the phone lines are not reliable enough to stand electronic communication. Information from conferences is relayed on the Internet, but some people in the field are unable to interpret it. Thus the situation internationally mirrors that of the information-rich/poor domestically. In addition there are difficulties in getting feedback from group members. For example, the Global Forestry Policy Project (a project of the National Wildlife Federation, the Sierra 
Club and the Friends of the Earth, US) distributes conference documents and reports electronically, but getting information back up the chain is often a problem. As a spokesman said: 'If that could be established we would rank (our work) as a real success' (Paul 1995, interview). Scott Paul described the Global Environmental Facility - GEF - as one of the most successful networks in getting information back up the chain. It is run by the International Union for the Conservation of Nature and has networks with one or two people in each continent or region who act as regional distribution nodes, working with volunteers. Documents from Washington are sent to five or six people and distributed to grassroots members, who can then have input.

Other problems are caused by rivalries resulting in information log-jams between regional non-government organisations (NGOs). Information sent to one regional node may not be passed on when there are political reasons for not wanting to share. Funding for international projects which is tied to environmental projects can cause jealousies from other needy causes. In certain countries, some NGOs are fronts for the government to collect money intended for development projects. To overcome these difficulties, as well as attempts at 'spying' by vested interests, requests for information are checked out by the Project personnel and their legitimacy established before information is disclosed. Closed conferences are held on the Internet for strategic discussions to ensure confidentiality. Official reports on any topic relevant to forest policy are distributed electronically. In truth, economic and trade issues are paramount and 'sustainable development' is often barely understood in countries with forest resources. Billions of dollars are at stake in investments for the multinational timber companies.

Thus although environmental groups in general seem to use CTs very effectively, the problem of the information-poor (in this case countries with inefficient communication systems) becomes glaringly obvious. It is particularly ironic that the forest environment often needs most protection where a dominant concern of the local population is food, clean water and shelter, rather than a first world concern about trees. Such countries need 
communications infrastructure to develop and attract foreign capital, but are often unable to afford the initial investment.

The Sierra Club (SC) is an example of a long-established interest group which has adopted the new CTs to good effect. The function of the 32 people in the office in Washington DC is to build relationships on Capitol Hill and to organise different national campaigns, from public lands to pollution, recycling, and energy. Many issues have legislative implications, involving bills the Club is trying to block (most frequently, with the current Republican-dominated Congress) or support. 'I spend a good deal of time getting information out to our members; though my title is lobbyist, I spend much time writing' (Mills, Steven 1995, interview). A newsletter alternates with a magazine each month with a readership of about one million (including sales through news-stands). The SC has about 560,000 members and most of the Club activists have email accounts and so can be contacted quickly. Each campaign has periodic alerts, operating through 350 entities across the country. Every state has a chapter and larger states like California have more than one. Chapter leaders pass on email messages through a phone tree or fax to alert their members to write. An alert may call on members to call an 800 number and a letter is sent on their behalf, though this is recognised to be not as effective. Usually the information is supplied and people urged to write their own letters as it is known that Congress Members disregard email letters unless they are signed, addressed and from their own constituency. Tasks are allocated according to the talents of members and issues involved.

SC has its own Bulletin board and World Wide Web page. Its spokesman claimed that it is probably the most active environmental group in the States. CTs have meant faster communication but a disadvantage is that opponents can find out $\mathrm{SC}$ tactics in mobilising on an issue. However, 'We have our folks monitoring their email traffic. It works both ways' (Mills, Steven 1995, interview). Direct mail was formerly a good method of recruiting members, but it is not used much currently because its impact is believed to have decreased. The SC now uses young people personally canvassing with petitions, with positive results. 
With the new Congress, people are seeing environmental laws come under attack and the SC attracted 50,000 new members between November 1994 and August 1995. SC members work on selected election campaigns which, its organisers claim, can have a significant influence on their outcomes. In summary, the Sierra Club, being mostly US concerned and therefore dealing with a membership who can in general afford CTs, appears to use CTs to near-optimum effect. The spokesman claimed that the Club's political influence is considerable, in that candidates seek them out for endorsement. It favours behind the scenes activities, through lobbying and legal challenges, rather than public demonstrations. It is interesting that the $\mathrm{SC}$ is moving towards using people to canvass with petitions - which may indicate the advantages of personal as against electronic communication in the situation of a community overloaded with commercial advertisements. From these examples, as well as his case studies, it appears that the Bonchek hypothesis is supported.

\section{Interest groups in Australia}

In general, use of CTs by interest groups is far less common in Australia than amongst the leading groups in the US. The hypothesis that CTs have reduced transaction costs and facilitated grass roots participation does not appear to be borne out in the Australian experience, at least at this early stage of the adoption of electronic networks. However, some features of CTs have had an impact. Media contact and organisational communication are enhanced by the mobile phone. Fax also plays an essential role in speedy transmission of messages. The most proficient $\mathrm{CT}$ adopter amongst the interest groups, not surprisingly, was the peak library body, giving weight to the US finding that CTs assist the already relatively information-rich.

The other aspect demonstrated by the Australian groups interviewed is the 'green and high tech' phenomenon. Coinciding with Bonchek's young, educated CT user, the members of environmental groups in Australia have adopted some networking technologies (to the limit of their resources) far 
more widely than say members of the forest industry. So the bias he identified, arising from differences in computer literacy and access, were apparent in the Australian responses.

Before considering the individual Australian interest groups interviewed and demonstrating that the US study hypothesis is applicable to Australian interest groups only in a limited way, it is useful to consider the similarities and differences between the US and Australian systems Lobby groups in Australia have not used direct mail to anything like the extent that they have in the US. 'Australian MPs would be stunned at the volume of mail in the US' (Farmer 1994, interview). American direct mail is often very emotive and negative (see chapter six).

The vital factor of non-compulsory voting in the US, along with the cultural and legal environment, means that lobbying styles in the two countries are different though some tactics in Australia mimic the US. Citizen-based groups in Australia in general do not have the budgets to conduct extensive lobbying campaigns and so tend more to try to be appointed to government committees and inquiries to influence decisions. The Australian style of campaigning has been mostly far less confrontational and single-issue driven than the American in the past but this appears to be changing. If the US model of the marketing of politics continues to be followed, it may be that pattern becomes the norm here.

In Australia, use of on-line searching and connections through the Internet are relatively new and rare outside universities, though expanding rapidly. Use of CTs by the interest groups interviewed varied widely with the nature and activities of the organisation. Factors governing their use are often human resources and equipment cost. Fax and mobile phones appear to have had most impact on daily operations. The literacy level of the membership is also a significant factor (see forest industry, following). Most organisations still rely on traditional methods of a printed newsletter or magazine to maintain regular contact with members. 


\section{Lobbying in Australia}

Any person or group who works to influence the outcome of government or opposition decisions is involved in lobbying. A critical appraisal of the need for lobbyists is made by one who is an Australian practitioner:

The existence of the fraternity of lobbyists is one piece of evidence in the case against governments for failing to govern, against public servants for failing to serve and against the new media for failing to impart news: but 'existence' is not a strong enough description (Sekuless 1991, 2).

However, in Australia, 'Political lobbying is a well-established and accepted part of national political life...'(Warhurst 1990, 173). In the absence of evidence of significant illegal activities, there has not been an expectation for strong regulation of lobbyists. Professional political lobbyists provide one avenue for interest groups to get assistance in making representations to government, if the organisation can meet the cost. The trend amongst national interest groups to move to Canberra has been encouraged by the ACT Government's policy of giving special leases to non-profit, although commercially operated, institutions (Lloyd 1991, 27). In response to the with increasing centralisation of administrative power in Canberra, the growing feeling is that the appropriate centre for a national body is the national capital (Lloyd 1991, 28).

Lobbying is a rapidly-growing industry in Australia. From only a handful in the 1970s, the so-called government relations industry had in 1994 more than 270 lobbyists on the general register of the Department of Administrative Services, representing 1,148 clients. Since 1984 also, peak organisations have assumed more prominence: as they are not representing clients for profit, they are not included on the register. Former government staffers using connections gained in their employment are numerous amongst the professional lobbyists, though their currency can be 
limited to the period in office of their particular contacts. In support of the activity of lobbyists, politicians may welcome the presentation of issues in a concise form (information overload is their perennial problem) and the opportunity to take account of the preoccupations of at least a sector of the electorate. Because of the cost, the employment of lobbyists to promote particular interests is generally restricted to monied organisations or companies and thus is inherently biased against organisations or individuals with limited resources:

Lobbyists do represent the organised and already wealthy rather more often than they do the poor and the unorganised. However, they are generally seen to be relatively minor political actors, when compared to business and trade union leaders and other elites (Warhurst 1990, 185).

Issues driving the lobby business are increases in regulations and the changing nature of the economic debate. Though the Keating Labor government moved towards deregulation of the economy in theory, regulation has in fact fluctuated in areas concerned with public health, safety standards, the environment, food quality and price competition (Rowlings 1995, interview). The lobbyists, known as 'bullet makers', are often economists who prepare arguments to decision-makers cast in terms of the current economic debate, rather than the 'old boy' network involving long liquid lunches (Connors 1995, c1). Their information is often provided by sophisticated data bases which they have the resources to exploit.

It is interesting in the Australian context to examine the reaction of MPs to various methods of lobbying, to evaluate the effectiveness of each. It appears that the characteristics most valued by Australian politicians in regard to lobby groups is useful information presented in a concise and timely way - in person. Information relevant to the MPs' special interest is welcome, as are issues related to the electorate (Client Solutions 1994, 4). The arrangement of the meeting may be made by fax, phone or mobile phone and the data to support the argument 
gathered with the aid of electronic data bases, but in essence the actual meeting relies on the skill of the interest group person in face-to-face representation and persuasion with the MP or departmental person. A classification of interest groups can be made in the following ways:

1. identifying aims as sectional or promotional - that is, those promoting a section of the society (ACTU) or those who promote a cause (Consumers Federation of Australia);

2. identifying source of support from a restricted group (National Farmers Federation) or from open membership (Australian Republican Movement);

3. distinguishing insider groups accepted by the establishment (Australian Conservation Foundation) from fringe groups (the Wilderness Society); and

4. dividing those concentrating on economic capital (Business Council of Australia) from those interested in social capital (Australian Library and Information Association).

The categories are not mutually exclusive, and at different times the same organisation may play different roles. However, for the sake of selection for interview in this exercise, they can very broadly be regarded as either economic or 'cause'.

\section{Interviews with Australian interest groups}

The choice of Australian interest groups to be interviewed was guided by gaining a balance along the lines defined by Mathews, that is, between those concerned with economic as against 'issue' concerns, radical and conservative, representing urban or rural interests, employer and employee, and large and small. Some of the roles overlapped, but the 10 interviewed represent the range of interest groups' use of CTs at one point of time. As will be apparent, the adoption of technology is changing their methods of administration, though at different rates. Because their 
operations vary so widely, each is reported and some generalisations drawn at the conclusion. The general caution of the interest groups towards spending the resources in human and economic terms for adopting technology is epitomised in the phase of the Business Council of Australia spokesman: 'It's a matter very much of testing the water...' (Beck 1995, interview). This caution is evident in data on use of CTs by interest groups interviewed (see table 4.01 on Page 140).

The political importance of interest groups in mobilising public opinion through publicity is demonstrated vividly in the environmental debate. The Wilderness Society (WS) spokesman claimed that some interest groups are fronts for commercial interests; for example, the Forest Protection Society calls itself a 'community based organisation', but is funded substantially by the forestry industry (Warden 1995, interview). The WS is the more radical arm of the environmental lobby which allows the Australian Conservation Foundation to appear to be the movement of compromise. The WS takes an absolutist line, as it sees danger of 'salami tactics' - conceding a little bit on each occasion and the ultimate objective being sliced away.

The cost of CTs is prohibitive to their widespread use by voluntary grassroots movements. Internet connection varies widely, the least expensive (November 1995) being through OzEmail at $\$ 25$ for connection and $\$ 5$ an hour usage (average). A permanent leased line is far more costly. WS has about 10,000 members who can be mobilised for letter campaigns. For lobbying, on-going personal contact with staffers of politicians is often very influential as they may have more time and interest in the issues than the Minister. The WS has a home page with links to other sources. However, '...the best communication is still faceto-face' (Warden 1995, interview).

The Australian Conservation Foundation (ACF) has access to the Internet through the Australian National University without charge (except for the cost of a local call) which is used for email and access to Internet. Its potential use is only just developing, with much more government information coming on line 
towards the end of 1995. Commonwealth legislation must be read on screen by the ACF staff, because their computer memory is limited. A mobile phone has proved to be invaluable (though privately owned) and enables contact out of office. 'The key to operations is communications' (Killam 1995, interview). Fax is used for communication with the Melbourne office '...who have not really got on to the information superhighway' (Killam 1995, interview). There is an Australian Conservation Foundation home page, but with few links and consisting mostly of text.

It is planned to use CTs to link up with other environmental groups and the ACF is currently working with World Heritage on developing a CD-ROM. The Foundation uses conventional mailout and its magazine to maintain contact with members. The limiting factor is cost. 'Everyone can use a public road. They can use public transport, ride their bikes on it, drive a car on it or walk on it. With the information superhighway, you very much have to pay for it. Whether this changes...if people become so dependent on it, the government may just nationalise the gates...the argument is to keep this public so the gate is always open' (Killam 1995, interview). In general, fax and mobile phones are vital for contacting political and departmental people and organising meetings. Members are mobilised to participate in write-in campaigns. There is a possible problem that digital data can be manipulated, so there is a need for software which prevents forgery. Potentially the new CTs will make it easier to gather information, though at present the ACF is mostly relying on the old technology.

In terms of communication within the Forest Protection Society, fax and telephone are the most common method used, including by members who are workers in the forestry industry. Networks are grouped into national, state and regional areas, though most information is distributed nationally. A home page on the Internet is being developed and was expected to be operational by the end of 1995. CD ROM is being considered. 'We're a bit further behind. When you're up to your behind in alligators...it's a bit tricky' (Loydell 1995, interview). At present, computers are not connected beyond the office as the principal problem is security. 
'To some degree it's like a little war' (Loydell 1995, interview). The environmental groups and the forest industry each monitor the activities of the other. The use of email was restricted 'There's a lot we don't want them to know' (Loydell 1995, interview).

The society was first formed in 1987, but took several years to begin to have any influence. Teleconferencing has been used for some time, particularly between the six state co-ordinators every Tuesday morning. If there is a controversial issue going to Cabinet, the central office uses teleconferences with the branches. Most of the members work and are volunteers, so conferring is done mostly at night or on weekends. The mobile phone is invaluable, because Society staff need to travel frequently and consequently an area which does not get a mobile signal plays havoc with the organisation. The importance of members being able to contact the organisational people is recognised. 'Whoever it is may only ring once or twice a year, and get frustrated if they cannot speak to organisers' (Loydell 1995, interview).

In regard to recruiting members, it is the judgement of the national director that about 65 percent of workers in the industry have limited literacy and numeracy skills. Therefore communication is predominantly verbal and organisers have to go to the workplaces, to involve conservative (mostly) men. The contrast is stark between the city, where a computer is commonplace, and rural areas, where computers are regarded as extraneous. 'It's the fear of technology - we really have to address that, looking at rural Australia' (Loydell 1995, interview). In general, the education levels are not high, and as that is coupled with an attitude that technology is something city people do, uptake is low. The exception is the mobile phone which, being verbal, is widely used.

The names of members are held on a data base but direct mail is not used often. Sometimes on a particular issue, co-ordinators will visit branch members and write a letter on their behalf. A newsletter with a circulation of 8,000 goes to members' families Australia wide. A skill of the organiser is in recognising the 
particular talent of the individual and using it. "The self confidence and self esteem within this industry is appallingly low. If you are told for 10 years that you are doing the wrong thing, eventually that will have an impact on you' (Loydell 1995, interview). There has been an increase in confidence among the members though the debate has often been bitter.

Personal communication is paramount and to some extent, technology has inhibited that. 'One might send a fax instead of spending the time to phone, and thus miss the seemingly trivial but essential chat. Face to face contact and time to socialise is essential in building up confidence and trust in a generally wary community. I eat so many scones!' (Loydell 1995, interview).

The Australian Chamber of Manufactures (ACM) staff use email between Melbourne and Sydney offices, but it is little used from the ACT office. Data bases with 6,500 members' names are used for sending out information on functions, seminars or the monthly bulletin. Input from members is achieved through a teleconference once a year. Regular lobbying of MPs and treasury officials at federal and state levels is carried out when particular issues arise. The national chief executive (based in Melbourne) is usually involved in the actual lobbying which can cover any proposed legislation which affects business : e.g. a 12.5 percent tax on building supplies was the target of a recent campaign. Submissions are also made during the preparation of the federal Budget. Indicators of the economy from companies' performances provide a source of information for politicians, as on occasion the ACM representative can point out unintended consequences and advocate amendments to legislation, sometimes successfully.

ACM services are organised around four key areas - human resources, training, international trade and the environment. In the six month period January to June 1995, there were 50 different education training programs. Major publications come out of the head office in Melbourne, produced on a needs basis. Fax, phone, mobile and mail are the most commonly used CTs. Internet is not used. 'If they are happy with the way they are communicating 
now - there are plenty of ways of getting through these days - why confuse the issue with CD-ROMs and the Internet?' (Taylor 1995, interview). Pagers, voice mail and answering machines are also used. 'It comes down basically to economics. Nobody would go into the new technology unless they could see a benefit in it for their business' (Taylor 1995, interview).

However, mobile phones make a difference to contacting key people for media interviews if a story is breaking and time is of the essence. The opportunity to get the message across to the community can be grasped. In relaying information to brief principals for such interviews, fax gives instant printed version in hard copy, which is an advantage over email.

The Australian Library and Information Association (ALIA) is in the forefront of using CTs. ALIA was the first association in Australia to build a World Wide Web site. 'It fits perfectly with what our Association is trying to do' (Walsh 1995, interview). There are a large number of members who can access their Web site but also a large number who cannot. So administratively this creates extra work, with the necessity of conveying the communication by two different means - email and fax. When it was established in 1994, the Web site cost $\$ 100,000$, including hardware, software, staff training and administrative costs. It has demonstrated to the 8,500 librarians that their representative body is on the cutting edge of IT and presents a favourable image through the home page to recruit new members.

A disadvantage of the Internet, according to the executive director, is that it is open to everyone (sic). Therefore there is a need for care not to replicate material from the monthly journal, for which people pay a subscription. The value of other functions of ALIA, like lobbying (which membership fees support), are not necessarily appreciated as a necessary activity by the membership, according to the executive director. Confidentiality of the Web site is not a problem as any sensitive material is not put on the home page. 
It appears that the Web pages are very successful with members and beyond, partly because of the novelty factor. However, 'If your machine doesn't have the "grunt" (for the graphics) they are hard to see' (Walsh 1995, interview). With regard to decision makers, it has been an aid for a whole range of reasons, not necessarily because of the information that is there, but because of the image, in itself a communication. The then-Australian Governor-General, having launched the Web site for ALIA, was so impressed that he wanted a home page of his own: ALIA staff organised one through the National Library.

ALIA holds seminars which aim to give members confidence in advocacy and media skills - in essence, how to develop a full blueprint for a lobbying campaign. Data bases have proved to be very useful for gathering information and the Internet has been used for contacting libraries overseas for ideas on activities and strategies. The development of mobile phones has made organisation easier, keeping in contact with staff when travelling and ensuring media contact when an issue is newsworthy.

It is necessary that care is taken to organise the vast amounts of information available. For example, email can flood the system without the usual filter of conventional mail to sort it. So appropriate management techniques are needed, such as selective dissemination of an email address and using a staff person to process email in the absence of the executive director. There is also a potential danger of confidential email being intercepted. An example of the advantages of one new CT to the executive is the portability of the Powerbook personal computer, which can plug into a hotel outlet, send faxes, retrieve office files and download on to another office computer.

With regard to public libraries, ALIA has lobbied strongly for public access to the Internet or at the very least to CD-ROMs in future, as sources like encyclopaedias will be on $C D$ or more frequently (because of storage problems) on-line. 'The best reference material will all be in the ether' (Walsh 1995, interview). 
For the Australian Republican Movement (ARM), the new CTs provide avenues for expanding activities to schools and academics through the Internet. However, the variation in access to technology between members has caused discrepancies in distribution of information, and therefore has not increased efficiency. CTs have not had an impact as yet on recruiting members and most members still phone or write. Communication with members is mail-based, and the Internet has been of little use in gathering information because there is little on it of relevance. However, communicating with decision makers and co-ordinating activities has been made much easier, with Faxstream, press releases and teleconferences. 'Without doubt the major change for a small office is being in touch when not in the office. Mobiles, email and fax make things much easier. Secondly it makes you media accessible - all the time when in phone range - for better or worse' (Ward 1995, interview).

The Australian Council of Trade Unions (ACTU), as the peak union body, has found that CTs have made the running of the organisation easier, in terms of gathering information and coordinating activities. The use of CTs by unions in general depends on the nature of the particular union: CTs have made a big difference in white collar, but not so much in blue collar, unions. Unions have in general been slow in utilising new technologies but are starting to get interested and are spending on upgrading their systems, including introducing the Internet (Bowtell 1995, interview).

With regard to organising activities, the Business Council of Australia (BCA) has found that broadcast faxing is most useful, as a number of members can be sent information at the same time. This method is also useful in setting up groups that have a common interest and in keeping them informed of developments in an issue and involved in organising meetings. For example, faced with a new policy issue like the review of the environmental assessment legislation, a cross-industry reference group can be set up and kept informed through broadcast faxing. Distribution can vary from a small working group of four or five members to a group of around 50 people on greenhouse issues. 
BCA members are the 90 largest companies operating in Australia, across all sectors. It has been in existence for 10 years and initially had a small office in Canberra. Like many interest groups it has expanded its Canberra operation. Though the BCA head office and the head offices of many member companies are in Melbourne, a presence in the national capital is considered important. Lobbying and consultation involves about 70 percent of the office time. There is a mailout to members particularly related to Council meeting business every two months. 'I don't think we are at the forefront of communication technology...you may find it surprising that big business tends not to be...'(Beck 1995, interview).

The reasons for this reluctance include cost to member companies of the hardware and software, concerns about security and the feeling that to be in the forefront is more trouble than it is worth. It is generally thought to be more prudent (unless there is a pressing need for the new technology) to wait until it is fully developed and can be implemented in a trouble-free way. It appears that the system connecting BCA offices itself is not functioning as it should, which may be a discouragement.

The monthly BCA bulletin is used to keep members interested and informed. Most of the communication from members is by mail. Contact with decision makers is 'old-fashioned' - by letter, either fax or mail, depending on its urgency - followed up by personal meetings. Teleconferencing is rare even between businesses. Information is exchanged between industry groups and often gathered from research agencies within universities. Research is sometimes commissioned, e.g. evaluation of the impact of reforms to the transport policy, in terms of access to inner city areas and congestion. Information on United Nations' covenants and treaties on environmental matters is accessed through the Internet, though only recently (September 1995). Some information exchange with overseas bodies is starting, through Web sites and email. The BCA may develop its own Web site in future, to allow members and others to get information on the Council, though few members at present have the capacity to access the Internet. A link between mail and 
a phone call is provided by email, and in that sense complements present communication methods. The use by executives of laptop computers gives them the capacity to connect with the office from any location. Mobile phones are invaluable to travelling executives, both for routine contacts and media accessibility.

The Consumers' Federation of Australia Inc (CFA) (recently renamed from The Australian Federation of Consumer Organisations) uses fax constantly. Email was only made available in July, 1995, so its impact was hard to estimate at the time of interview. It will allow contact with councillors, scattered throughout Australia, and with members' groups and consumers representatives who have email (Cresswell 1995, interview). There are data base lists of magazine subscribers, of consumer representatives who may serve on industry and government panels. The CFA has representatives on some influential bodies, such as the telecommunications advisory committee, for the purpose of putting the consumers' interest in debates. Calls for membership of committees are made in membership mailouts.

There are 80 member groups, representing two million consumers. Coalitions are formed according to the issues. Lobbying is carried out on priority areas - such as access to justice, food technology, public transport and financial services. Fax and phone are used for liaison with other organisations on topical issues and mobile phones are particularly useful for media contact. The Internet is new and 'No-one has really got into using it yet. We are talking about getting our own Web site' (Cresswell 1995, interview).

The magazine Consumer Action is delivered to members, politicians and to all media boxes in federal Parliament House. The secretariat comprises only eight people but, joined in alliances, becomes more influential. Impact on the Prices Surveillance Authority has been significant, for example, on banking charges. Recently the Federation in cooperation with legal centres formulated a Consumers' Justice Charter. Another example of cooperative effort was the CFA's provision of assistance and support for a submission to government by 
National Shelter, the peak body for housing organisations. Campaigns are demand driven by members but can be influenced by which direction membership drives take. A recent issue was superannuation and at the time of writing housing issues were coming to the fore.

Publications and newspaper articles are sources of finding potential interest in membership, the advantages of which are a lobbying presence, access to a huge network of groups and a voice for their interests. In 1995 there were 15 training sessions on superannuation, held in each capital city, with the cooperation of state governments and industry. Members are not charged to attend. People quite often retain membership after the particular issue for which they joined is past, evidently approving of the objectives or being interested in consumer matters in general. Membership fees are reasonable, on a sliding scale $\$ 3$ to $\$ 125$, depending on ability to pay. The secretariat aims to have a staff member visit each state each year, combining technology with personal contact. A manual covering such issues as writing and funding strategies was part funded by state governments. Communication with decision makers is made through phone, fax, letters and personal representation. In the future, activities with other groups, including information gathering, may be better co-ordinated through the Internet. For example, the Australian Consumers' Association recently provided the Federation with material for a speech from their data base. On occasions a consultant is hired for a specific piece of research, though resources limit this.

In general, CTs have complemented old ways. The network will be upgraded when funds become available, to allow email and the Internet. However, 'That presupposes that people we want to talk to use the Internet... Grassroots groups usually do not have the funds for computers. And I think it will remain that way for many years. I don't see that changing' (Cresswell 1995, interview).

For the National Farmers Federation (NFF), the fax has made contacting members easier. The members of the Federation are the 28 state groups which represent the entire farm sector. 
Recently a method was adopted to overcome information overload - distributing a one-page dot point summary of recent initiatives. Groups can request further details if the topic is of interest to them. This formula has been well received and adopted by some member bodies. A similar format is used in releases to newspapers considered sympathetic to NFF objectives.

Email started in September 1995, but there were only a couple of terminals operating in the office. Internet connection from the Canberra office is made through the Australian National University but it has not been adopted by many of the state branches. Mobile phones have helped efficient functioning. Information is gathered from a variety of sources, depending on the issue. A special project may be let to a consultant. A selection of government material is obtained daily for a fee from the Political Reference Service and a summary faxed to member bodies (e.g. the balance of payment figures). 'We pay big dollars for it, but it gives immediate information without the hassles' (Austin 1995, interview). This is an example of value-adding in information provision, the providers employing CTs extensively.

As an added incentive for farmers to join the state bodies, the Federation has entered an agreement with Telstra to give discounts on telephone accounts and may expand this to other telecommunications technologies - '...if we can educate our members. In the farming community, use of technology is pretty basic' (Austin 1995, interview). The NFF estimated 30 percent of farm families use PCs for business reasons.

Teleconferencing is used to communicate with member bodies for executive or sub-committee meetings. The Chief Executive Officer uses it fortnightly to talk with other CEOs on current issues. Communication with policy makers is by telephone and personal contact, relying considerably on networking.

A current controversial issue is the Native (Aboriginal and Torres Strait Islander) Title legislation - this and other and environmental matters in general take up an enormous proportion of resources. In influencing longer term strategies the 
NFF has participated in debates through conventional means to address the problem of rural decline over the past 10 years.

\section{Grassroots in Cyberspace?}

Following the US model, each of the factors is applied to Australian interest group operations. It will be apparent from the following observations that, in general, the impact of CTs on the operations of interest groups has not been as profound as either the Bonchek study or my US interviews revealed. However, if Australia follows the US example, they may become more influential in future.

\section{Influence of CTs on:}

\section{forming a group or expanding activities...}

The influence does not appear to be significant, except perhaps with The Australian Library Information Association (ALIA) through their new home page. It appears that the Web pages are very successful with members and beyond, partly because of the novelty factor (ALIA). In some cases, use of computer networks to expand activities is a non-issue, because of limited literacy and computer access (forest industry). However, the mobile phone, using verbal communication, has been adopted by forestry and rural workers.

In the case of the Consumers Federation of Australia (CFA), letters to the editor are followed up for prospective members and the names added to the data base. The new CTs provide new avenues to schools and academics through the Net for expanding activities of the Australian Republican Movement (ARM).

\section{efficient functioning...}

Generally, the technologies which have had most impact across all the interest groups interviewed were mobile phones and fax. The Australian Chamber of Manufactures (ACM) and Forest 
Protection Society (FPS) use teleconferencing between offices. ALIA's executive director takes her Powerbook travelling and accesses files at the office, sends faxes and email as necessary. ALIA has found data bases very useful for gathering information and contacting libraries overseas for their activities and strategies.

The organisations interviewed all held data base lists of members which they used for sending out information on functions, seminars, or the newsletter. All found that the development of mobile phones has made organisation easier, to keep in contact with staff when travelling and to keep media contact when an issue is current. Email is used by the ARM, the ACM, the ACF and ALIA. The Wilderness Society (WS) and ALIA have a home page.

\section{recruiting members...}

CTs have not had an impact as yet on recruiting members, and the traditional methods of people joining - requests by phone or letter - remain paramount. Of the groups interviewed, most were peak bodies and the active recruitment of grassroots members rested with their member organisations. In regard to recruiting members, about 65 percent of workers in the forestry industry do not have adequate literacy and numeracy skills so the technology is irrelevant.

\section{keeping members interested...}

A number of people mentioned the importance of personal communication. Even the spokesperson from the relatively high- tech WS expressed the view that personal communication is most effective. People quite often retain membership after the particular issue for which they joined is past, evidently approving of the objectives (CFA).

On occasions, incentives such as discount telephone charges are offered to members (NFF). In general terms, the traditional methods predominate. 
The effect of CTs on:

communicating with members...

Most interest groups use their newsletter, magazine or circular to communicate with members. Broadcast fax provides fast transmission of information, though to limited numbers (BCA). Only ALIA regularly used email to members.

Cost is a prohibitive factor in widespread adoption of electronic communication, though teleconferencing is used between offices by the ACM, the FPS, the NFF and the ARM. Even relatively 'rich' Business Council of Australia (BCA) members were apparently reluctant to be in the forefront, preferring to wait until the systems were trouble-free.

On the other hand, there is a distinct feeling of many organisations being on the brink of fairly extensive adoption of the new technology - and a barely expressed theme that they feel they are expected to adopt technology. The image of being progressive is a definite aspect with ALIA's use of CTs. A disadvantage is that the very grassroots people with whom the organisations wish to communicate at this stage generally do not have the technology.

\section{communicating with decision-makers...}

The personal communication through face-to-face meetings and networking remain the predominant ways in which interest groups seek to influence policy. Most interest groups on occasion mobilise members to write to their MP.

co-ordinating activities...

Several organisations conduct training courses. The ACM provides members with a wide range of training and education opportunities, as does the CFA. ALIA runs courses in strategic lobbying and media skills for library members. 


\section{gathering information...}

Few organisations use the data bases available through Internet as yet, though some expect to do so in future. Several mentioned ways of overcoming information overload - by administrative reorganisation (ALIA) or by dot-point summaries of relevant information for members (NFF). Several groups (aside from the green ones) made the point that various environmental issues are becoming an important aspect of their work - the ACM, the $\mathrm{BCA}$ and the ACTU.

Observing similarities and differences between the groups in general, it appears from this small sample that the rural-urban differences are the most evident, as far as access to and competence in computer technology is concerned. If the cost of setting up a home page is around $\$ 100,000$ (including hardware, installation and training) and on-going cost about $\$ 50,000$ per year, as ALIA says, it would seem to be beyond the reach of all but substantial companies or interest groups. As noted, however, BCA member companies were reluctant to invest until the worth of the technology was proven. ACM members had the same reservations. In conclusion, the interest groups interviewed appear to have adopted the technology which suits their operations best. Fax and mobile phone dominate. Many are obviously poised on the brink of committing human and financial resources to the Internet.

As the number of interest groups personally interviewed was necessarily small, it is not valid to draw firm conclusions from the percentages. However, as the interest groups were selected to represent a broad cross-section, economic and 'cause', as well as urban/rural, large and small, it is legitimate to look at patterns in broad terms. To gauge the penetration of CTs in the offices of interest groups, 14 (including those personally interviewed) were asked how many of each technology was available to them - the numbers and use of various CTs. The questions were:

1. In your office, could you record the number of computers? faxes? mobile phones? 
2. Do you use modems for communicating (mail, Internet)?

3. Has the electronic network largely replaced paperwork, or added to it?

It appears, not surprisingly, that the number and use of CTs is related to the size and influence of the interest group (see table 4.01). In this context, 'transit' indicates the organisation is changing over to CTs.

Table 4.01

\begin{tabular}{|l|c|c|c|c|c|}
\hline \multicolumn{6}{|c|}{ Use of CTs by Interest Groups - numbers of items of equipment } \\
\hline Organisation & Computers & $\begin{array}{c}\text { Fax } \\
\text { machines }\end{array}$ & $\begin{array}{c}\text { Mobile } \\
\text { phones }\end{array}$ & Modem & Replaced? \\
\hline ACF & 2 & 1 & 1 & yes & no impact \\
\hline ACM & 2 & 1 & 1 & yes & added \\
\hline ACTU & 8 & 2 & 3 & yes & use both \\
\hline ALIA & 22 & 1 & 2 & yes & use both \\
\hline APA & 20 & 2 & 3 & no & added \\
\hline ARM & 2 & 1 & 1 & yes & added \\
\hline BCA & 6 & 1 & 2 & yes & slightly \\
\hline CCL & 2 & 1 & 0 & no & added \\
\hline CFA & 8 & 1 & 1 & yes & added \\
\hline COT & 4 & 1 & 2 & no & no impact \\
\hline Evatt & 8 & 1 & 1 & yes & replaced \\
\hline FPS & 3 & 1 & 1 & yes & added \\
\hline NFF & 20 & 2 & 4 & yes & added \\
\hline WEL & 2 & 1 & 0 & no & added \\
\hline
\end{tabular}

$\mathrm{ACF}$

$\mathrm{ACM}$

ACTU

ALIA

APA

ARM

BCA

CCL

CFA

COT

Evatt

FPS

NFF

WEL
Australian Conservation Foundation

Australian Chamber of Manufactures

Australian Council of Trade Unions

Australian Library and Information Association

Australian Physiotherapy Association

Australian Republican Movement

Business Council of Australia

Council for Civil Liberties

Consumers Federation of Australia

Casualties of Telecom

The Evatt Foundation

Forest Protection Society

National Farmers Federation

Womens Electoral Lobby 


\begin{tabular}{|c|c|c|c|c|c|c|c|c|c|c|c|c|c|c|c|c|c|c|c|c|c|c|}
\hline Group: & & & & & & & & & & & & & & & & & & & & & & \\
\hline \multirow{2}{*}{\multicolumn{23}{|c|}{ section 1}} \\
\hline & & & & & & & & & & & & & & & & & & & & & & \\
\hline & \multicolumn{2}{|c|}{ Never } & \multicolumn{2}{|c|}{ Rarely } & \multicolumn{2}{|c|}{ Sev Mth } & \multicolumn{2}{|c|}{ Sev Wk } & \multicolumn{2}{|c|}{ Sev Day } & \multicolumn{2}{|c|}{ Constant } & \multicolumn{2}{|c|}{ Rank 1} & \multicolumn{2}{|c|}{ Rank 2} & \multicolumn{2}{|c|}{ Rank 3} & \multicolumn{2}{|c|}{ Rank 4} & & \\
\hline Mobile Phone & 1 & $8 \%$ & 0 & $0 \%$ & 2 & $17 \%$ & 3 & $25 \%$ & 2 & $17 \%$ & 4 & $33 \%$ & 4 & $33 \%$ & 5 & $42 \%$ & 2 & $17 \%$ & 1 & $8 \%$ & $73.61 \%$ & $75.00 \%$ \\
\hline Telephone & 0 & $0 \%$ & 0 & $0 \%$ & 0 & $0 \%$ & 0 & $0 \%$ & 0 & $0 \%$ & 12 & $100 \%$ & 12 & $100 \%$ & 0 & $0 \%$ & 0 & $0 \%$ & 0 & $0 \%$ & $100.00 \%$ & $100.00 \%$ \\
\hline Teleconference & 3 & $25 \%$ & 5 & $42 \%$ & 3 & $25 \%$ & 2 & $17 \%$ & 0 & $0 \%$ & 0 & $0 \%$ & 1 & $8 \%$ & 3 & $25 \%$ & 3 & $25 \%$ & 4 & $33 \%$ & $38.46 \%$ & $52.27 \%$ \\
\hline Videoconference & 10 & $83 \%$ & 1 & $8 \%$ & 0 & $0 \%$ & 0 & $0 \%$ & 0 & $0 \%$ & 0 & $0 \%$ & 0 & $0 \%$ & 1 & $8 \%$ & 1 & $8 \%$ & 10 & $83 \%$ & $18.18 \%$ & $31.25 \%$ \\
\hline Mail & 0 & $0 \%$ & 0 & $0 \%$ & 0 & $0 \%$ & 1 & $8 \%$ & 1 & $8 \%$ & 10 & $83 \%$ & 12 & $100 \%$ & 0 & $0 \%$ & 0 & $0 \%$ & 0 & $0 \%$ & $95.83 \%$ & $100.00 \%$ \\
\hline Direct mail & 2 & $17 \%$ & 3 & $25 \%$ & 3 & $25 \%$ & 0 & $0 \%$ & 0 & $0 \%$ & 2 & $17 \%$ & 3 & $25 \%$ & 2 & $17 \%$ & 1 & $8 \%$ & 4 & $33 \%$ & $48.33 \%$ & $60.00 \%$ \\
\hline Data bases & 2 & $17 \%$ & 1 & $8 \%$ & 0 & $0 \%$ & 6 & $50 \%$ & 0 & $0 \%$ & 3 & $25 \%$ & 4 & $33 \%$ & 4 & $33 \%$ & 1 & $8 \%$ & 3 & $25 \%$ & $63.89 \%$ & $68.75 \%$ \\
\hline Fax & 0 & $0 \%$ & 0 & $0 \%$ & 0 & $0 \%$ & 0 & $0 \%$ & 1 & $8 \%$ & 11 & $92 \%$ & 12 & $100 \%$ & 0 & $0 \%$ & 0 & $0 \%$ & 0 & $0 \%$ & $98.61 \%$ & $100.00 \%$ \\
\hline Internet & 4 & $33 \%$ & 2 & $17 \%$ & 1 & $8 \%$ & 5 & $42 \%$ & 0 & $0 \%$ & 0 & $0 \%$ & 0 & $0 \%$ & 5 & $42 \%$ & 3 & $25 \%$ & 4 & $33 \%$ & $43.06 \%$ & $52.08 \%$ \\
\hline Email & 5 & $42 \%$ & 0 & $0 \%$ & 1 & $8 \%$ & 3 & $25 \%$ & 1 & $8 \%$ & 2 & $17 \%$ & 2 & $17 \%$ & 4 & $33 \%$ & 2 & $17 \%$ & 4 & $33 \%$ & $51.39 \%$ & $58.33 \%$ \\
\hline Face to face meetings & 0 & $0 \%$ & 0 & $0 \%$ & 2 & $17 \%$ & 2 & $17 \%$ & 4 & $33 \%$ & 4 & $33 \%$ & 8 & $67 \%$ & 3 & $25 \%$ & 0 & $0 \%$ & 0 & $0 \%$ & $80.56 \%$ & $93.18 \%$ \\
\hline Media - newspaper & 0 & $0 \%$ & 0 & $0 \%$ & 3 & $25 \%$ & 2 & $17 \%$ & 2 & $17 \%$ & 5 & $42 \%$ & 6 & $50 \%$ & 3 & $25 \%$ & 2 & $17 \%$ & 0 & $0 \%$ & $79.17 \%$ & $84.09 \%$ \\
\hline Media - radio & 0 & $0 \%$ & 4 & $33 \%$ & 2 & $17 \%$ & 2 & $17 \%$ & 0 & $0 \%$ & 4 & $33 \%$ & 5 & $42 \%$ & 2 & $17 \%$ & 2 & $17 \%$ & 2 & $17 \%$ & $63.89 \%$ & $72.73 \%$ \\
\hline Media - television & 0 & $0 \%$ & 4 & $33 \%$ & 2 & $17 \%$ & 2 & $17 \%$ & 0 & $0 \%$ & 4 & $33 \%$ & 5 & $42 \%$ & 3 & $25 \%$ & $\overline{1}$ & $8 \%$ & 2 & $17 \%$ & $63.89 \%$ & $75.00 \%$ \\
\hline Other & 0 & $0 \%$ & 0 & $0 \%$ & 0 & $0 \%$ & 0 & $0 \%$ & 0 & $0 \%$ & 0 & $0 \%$ & 0 & $0 \%$ & 0 & $0 \%$ & 0 & $0 \%$ & 0 & $0 \%$ & $0.00 \%$ & $0.00 \%$ \\
\hline
\end{tabular}

4.02 Weighted ranking by interest groups of their use of CTs 


\section{Conclusion}

CTs have had an impact, to varying degrees, on both the communication within the interest groups, and in their representations to government. Further, the leadership has more access to CTs in general than do the members. It appears that many interest groups in Australia are poised to take up various CTs, but that traditional communication methods will continue to be the most commonly used in the immediate future.

In answer to the second research question - the influence of CTs on people's participation in the democratic process - some aspects seem to have facilitated faster communication and improved group efficiency (the fax and the mobile phone). However, although some interest groups appear to have adopted the new CTs with enthusiasm, the great advantages found in the Grassroots in Cyberspace study in the US are not borne out in Australia. As to whether 'technology can save democracy ' and the use of CTs can empower interest groups as representatives of people, the interviews show some enabling characteristics, but the adoption of technology in Australia by interest groups is still in its infancy and predictions are precarious. 


\title{
The impact of Communication
}

\section{Technologies on campaigning}

\begin{abstract}
It's the biggest game in town. It's a mixture of retail advertising, image advertising and scare-mongering and gives us a chance to use all our skills in the ultimate oneday sale (Singleton quoted in Shoebridge 1993, 27).
\end{abstract}

Responding to why his company was involved in election campaigning (given the usually precarious financial state of the major parties), the revealing answer of this hired professional epitomises the ethos of the market research-driven strategies which employ the new CTs in current election campaigning in Australia. To ALP campaign advertising agent John Singleton, election day is perceived as the ultimate one-day sale. The statement demonstrates the commercial influence of marketing the (political) product which gives little credence to any philosophical commitment of rank and file party members, although the new machine men, like traditional apparatchiks, would argue that the ends justify the means. (The title of an autobiography of a recently retired Senator renowned for his party machinations was 'Whatever It Takes', see Richardson 1995).

Against the predictions of most political commentators and journalists and the private view of many politicians, the incumbent Australian Labor Party won the 1993 federal election with a national swing of 1.5 percent in two-party preferred terms (Bean 1994, 2). What role did the new CTs play in the campaign of 1993 and other recent campaigns? 
This chapter examines different aspects to evaluate whether using various CTs changed the nature of the campaign and electorate office operations fundamentally or whether they only enabled faster, more efficient communication. Such a judgement is influenced by the particular electorate, the personalities involved, whether the seat was marginal, urban or rural and local circumstances. However, some generalisations can be made.

In further exploring the first research question - what is the impact of CTs on elected representatives' communication with citizens - the conduct of the 1993 federal election exemplifies a period of intense campaigning activity which highlights the use of CTs and enables scrutiny of their impact. The use of CTs in a by-election in Wills (Victoria) and in the Northern Territory election adds to understanding of the use of CTs during campaigns.

To achieve balance, the routine use of CTs in a non-election period by a number of electorate offices was monitored by a questionnaire circulated through the Department of Administrative Services (DAS). The co-operation of DAS was very helpful and, as a side benefit to them, the responses to the questionnaire on the routine use of CTs in a non-election period could provide a benchmark for DAS to evaluate the changing demand for CTs in electorate offices.

In chapter three, interviews with MPs and other key players revealed their attitudes to direct mail and a survey of voters in Fremantle reported and discussed their varied reactions to personally-addressed letters. A sample of interest groups' use of communication methods has been described and analysed. This chapter examines and discusses the influence of CTs in a campaign context under 10 main sections, with CTs being the common factor influencing campaigning in significant ways.

CTs enable marketing techniques to be applied to political campaigning, and alter in a fundamental way the role of the traditional players in the game. What does this mean for representation and participation? 
I will contend that the characteristics overall in the 1993 federal election and other recent campaigns were sufficiently distinctive from previous campaigns to indicate a qualitative difference and that this was associated with the new CTs. To illustrate these statements, characteristics of the application of new CTs in the 1993 federal election, relating first to parties then to people, are outlined as follows:

\section{Parties:}

- $\quad$ increased use of direct mail.

- costs of campaigning;

- $\quad$ increased influence of a small 'elite' team;

- improved public opinion polling;

- central role of lobbyists;

- increasing importance of television; and

- incumbents further advantaged.

\section{People:}

- $\quad$ impact on party members;

- new techniques for electors to follow the campaign; and

- $\quad$ role of the Canberra Press Gallery.

\section{Parties:}

\section{- $\quad$ increased use of direct mail}

With a reduced volume of media advertising, both parties used what pollster Rod Cameron called 'the hidden campaign' - direct mail, the essence of which is targeting. As he remarked, possibly facetiously:

If Labor, for example, could determine that a man in a tight marginal seat plays football, smokes and works in a car factory they would want to send him a letter highlighting Fightback! changes to cigarette prices (up), car tariffs (down) 
and sporting club costs (allegedly up). His neighbour next door, a single mother thinking of voting for the Greens, would get a very different letter (Walker 1993, 10).

The Joint Select Committee on Electoral Matters (JSCEM) has reported on each election since the establishment of the Australian Electoral Commission (AEC) in 1984. Gathering evidence from electors, MPs, political parties and organisations, the committee has recommended legislative or administrative changes when considered necessary. Relevant to direct mail, submissions from several individuals and MPs expressed dissatisfaction with the number of letters returned to sender which they asserted showed a high level of inaccuracies in the electoral roll. The AEC denied this and pointed out that, on investigation, MPs had been using outdated rolls. With a relatively high level of residential turnover, the AEC stressed the importance of MPs' using only the most current rolls as '...failure to do so can give rise to unfounded allegations of inaccuracies in the rolls' (JSCEM 1994, 73). In fact, though the AEC was fairly defensive on this question, the electoral roll relies mainly on individual voters to advise change of circumstance, though spot checks are carried out by AEC staff. In this situation there are bound to be inaccuracies and the concerns of MPs with regard to returned direct mail are probably well founded.

In a special issue the Australian Journal of Political Science (1994) reported analysis by political scientists on various aspects of the 1993 Federal election. The targeting by Labor of strategic groups was identified as a significant factor in its success (Jupp and Sawer 1994, 10). Though it is not mentioned, this targeting was often achieved by direct mail. The rate of technological change, though the underlying cause of much structural unemployment, was not a matter for debate during the campaign.

\section{The Northern Territory campaign}

During the 1994 election campaign in the Northern Territory, the Liberal's direct mail expert devised a campaign to capitalise on sentiment against the federal Labor Government, Three direct 
mails were sent out reinforcing television advertisements. Direct mailings funnelled the messages and were timed to overcome the electronic media blackout on advertising (which operates for three days prior to the election). The aim of the Liberals was to neutralise the Labor campaign material and to target a specific message from each candidate. Reaction to direct mail was tracked every night after it was delivered, showing an increase of two to three percentage points in the conservative vote (Textor 1994, interview). The campaign was extremely negative but was defended on the grounds that it was merely reflecting and reinforcing attitudes against Labor that were already present in the minds of the electors.

Contrary to predictions of the pundits, the conservatives won a resounding victory. While there were obviously a number of factors which bought about this result, not the least of which was an 11th hour land claim by a group of Aborigines to parts of the capital, Darwin, direct mail appears to have been influential in this instance, although Richardson claimed that the ALP never expected to win (Richardson 1995, interview).

\section{- $\quad$ costs of campaigning}

The two major parties spent an estimated $\$ 22 \mathrm{~m}$ on election advertising from February 9 to March 121993 with an emphasis on television and direct mail. Spending on television advertising reached $\$ 5.1 \mathrm{~m}$ (46 percent of the budget) by Labor and $\$ 4.5 \mathrm{~m}$ by the Liberals ( 41 percent). Spending by both parties appeared to be reduced, falling from a combined outlay of $\$ 26.8 \mathrm{~m}$ in 1990 to $\$ 22 \mathrm{~m}$ (Shoebridge 1993, 26). However these figures do not account for elements of campaign spending which do not have to be reported, such as direct mail (exact spending on direct mail was not available from either major party). Declining outlays on reportable spending suggest strongly an increasing importance of direct mail in political campaigning. Public funding, based on the number of primary votes polled, recouped $\$ 7.1 \mathrm{~m}$ to the ALP, $\$ 5.7 \mathrm{~m}$ to the Liberal Party and $\$ 2.1 \mathrm{~m}$ to the National Party. The Australian Democrats received $\$ 450,000$ (Dodd 1994, 32). 


\section{- $\quad$ increased influence of a small 'elite' team}

The new CTs are vital to this political management and effectively increase central control. This is the theatre where the 'new machine men' exercise great influence. Campaign planning by both political parties begins in detail at least about three months from election day with polling guiding day-to-day decisions on the targeting of messages through different media.

\section{The Australian Labor Party}

The campaign planning group, comprising representatives from the leader's (for 1993, the Labor Prime Minister's) office and the national secretary's office as well as two state party secretaries, meets every two months between campaigns and concentrates on longer-term planning. Three months before the election is likely, all state secretaries meet to discuss the main issues in broad terms.

In the 1993 Federal election campaign the main theme was developed by Labor's national office, the advertising agency and the leader. The principal people involved were party secretary Bob Hogg, advertising executive John Singleton and Prime Minister Paul Keating. During the campaign this core group conferred as necessary with state secretaries through telephone hook-ups. Guided by the most recent research data, they agreed on an approach and the agency created an advertising concept. 'There were tensions...Keating never gets on with national secretaries. But it didn't matter. It all just flowed on anyway' (Richardson 1994, interview).

The influence of the national campaign on marginal seats was 'considerable' (Hogg 1995, interview). There were regular meetings in Canberra of incumbents and candidates in marginal seats to ensure efficient running of their electorates and/or their campaigns, significantly including training in use of direct mail. These meetings enabled exchange of information and instruction in media strategies and were a means of the national office maintaining control and momentum. "The danger is not in 
providing too little information but too much' (Hogg 1995, interview).

\section{The Liberal Party/ National Party (in Coalition)}

While the National Party concentrates on campaigning in rural and provincial centres, the Liberals take the dominant role in national campaigning. The Liberal campaign team was the leader John Hewson and the campaign director Andrew Robb. The advertising team involved Robb, advertising expert Geoffrey Cousins, marketing consultant Noel Delbridge and John King from another advertising company, Stokes King DDB Needham (Textor interview, 1994).

Hogg's opinion of Liberal campaign management was critical: 'They campaigned by a committee of disparate people - hopeless driven by a belief, ideology...' (Hogg 1995, interview) which by inference Labor was not.

From the standpoint of Liberal party operatives, the 1993 federal election campaign was abnormal. The need to argue the advantages of the Liberal Fightback! package dominated their agenda. In the opinion of one leading Liberal pollster, the campaign was significantly different because the Coalition was obliged to:

... 'sell' a policy and fit the politics of the day into this.. There were opportunity costs...while fighting for Fightback! we were not attacking the government on its vulnerable points, such as unemployment. Our surveys showed a 30 percent awareness of Fightback! but everyone knew about the GST (Textor 1995, interview).

Finally, the implementation of market strategies in the campaign devised from research polling relied very heavily on other technologies - mobile phones, faxes and teleconferencing - for communication with campaigners in the marginal electorates. 


\section{- improved public opinion polling}

The research on which campaign strategies rely is usually conducted in marginal electorates in the electorally significant states. Surveys show which segments to target with direct mail. The ways the new CTs are used in devising national campaign strategies are perceived by the political operatives to be critical to a party's electoral success. Public opinion polling and focus group discussions highlight issues important to voters - the 'tracking' of the electorate. Guided by this data, which is generated by sophisticated polling techniques, campaign strategies are devised. Decisions are made by the elite campaign teams (see later references) regarding the most effective mix of direct mail, television, radio and print advertising and the appearances of leaders (whether in television debates, at rallies or in advertisements) to reach a targeted audience or a general one.

In January 1993 the ALP commissioned a private company to research in the marginal electorates of Adelaide, South Australia; Corinella, Victoria; and Macarthur, New South Wales (Australian Community Research 1993,4$)$. While regional factors had some influence, general conclusions from these surveys were as follows: electors who had switched their intended vote away from Labor had done so because of the changes John Hewson (then Opposition Leader) had made to the proposed controversial Goods and Services Tax (GST) which softened its impact; dissatisfaction with Labor's performance; unemployment; the economy; and the perceived need for a change of government. Electors who had switched their intended votes towards Labor had done so because of continued concern over the GST; reaction against Liberal Victorian Premier Jeff Kennett's industrial relations actions; some positive regard for Labor's performance; and general distrust of Liberal policies. Overall 38 percent of electors said the federal (Labor) government should have another term in office and 49 percent said that the Coalition was ready for government. In summary the consultants advised Labor Party operatives that a positive plan to address unemployment and long-term economic problems be projected and attacks be 
maintained on the Liberal agenda, to be portrayed by Labor as one to raise taxes and lower wages by way of the GST and individual work contracts (Australian Community Research 1993, 6).

Through the campaign the ALP ran a minimum of three minor surveys a week, alternating between telephone interviews and focus group discussions. These were organised through the Singleton advertising agency and carried out by a separate research company. The frequency of commissioned surveys depended upon the budget '... which was pretty tight last time' (Hogg 1995, interview). Although polling techniques are now more sophisticated than 10 years ago, their interpretation is crucial and here experience and intuition both play a part. However the overwhelming issue was the GST:

...we just flogged that one issue, which we didn't need research to tell us. Going into the campaign, we had one thing going for us and that was the consumption tax...the GST was the overwhelming issue. It was a campaign less reliant on research than any I've ever been in. It was the only campaign where there was only one issue. Research confirmed fears about the consumption tax. We all knew that (Richardson 1994, interview).

Thus the tendency of a seasoned campaigner was to trust instinct before research findings. In fact, although surveys identified the GST as a major issue worrying to electors it was some time before '...we finally managed to get across to (Prime Minister) Keating that it was the issue' (Hogg 1995, interview). The messages were generally targeted as surveys showed regional differences on secondary issues. Advertising took different approaches in different regions more than in previous campaigns.

Contrary to the reported Liberal surveys (below), ALP polling did not predict a Labor win. In a reference to comments by Graham Richardson that he could smell success (see later), Bob Hogg remarked drily 'No-one went home on Friday night very confident...there is a lot of revisionism after the event' (Hogg 1995, interview). 
Extensive polling by the Liberals, which clearly indicated the difficulty of finding a way of 'selling' the party manifesto, Fightback! and its core, the GST, was evidently ignored by a party leadership bent on pursuing a philosophically-driven agenda (Textor interview, 1994).

So the most advanced CTs (Computer Assisted Telephone Interviewing or CATI) used in strategic polling are of limited value if the evidence they provide is not heeded or is misinterpreted. Operating CATI, interviewers enter responses from voters directly onto the data base, which allows very rapid processing of aggregated results.

I believe that refusal to take heed of polls before and during the election campaign was influential in costing the Coalition office. The proposed tax concessions in the package were difficult to explain, varying with individual circumstances, whereas the GST represented a tax increase that applied to everyone. The Liberals commissioned research over two years, testing various ways of presenting Fightback! which was launched on November 211991 to almost universal media acclaim. However subsequent Liberal surveys showed that the promised tax cuts were simply not believed. A revised version, which dropped the tax on food and abandoned plans to cease unemployment benefits after nine months, was launched on December 191992 to an also generally favourable media reception.

A point which has not to my knowledge been reported or commented on to date is that, according to their main party pollster, at no stage did the Liberal public opinion surveys show that the Coalition would win the 1993 federal election (Textor 1995, interview). That is, in the vital marginal seats, the Liberals were not confident that the Coalition would gain sufficient votes. This is curious and indicates the complex nature of public opinion polling and the difficulties of its interpretation.

In the opinion of Labor's then national secretary, the Liberals conducted too many surveys. 'They were doing in-house stuff every day which leads to the danger of shadow-boxing. By the 
time you analyse one you have another' (Hogg 1995, interview). The ALP research findings led to advertisements attacking the GST and the Coalition's health care policy proposals. The Coalition's CATI telephone surveys identified concerns with unemployment, the economy and the need for a change of government.

Public polls predicting which party will be successful in the election are an influential factor in a campaign. The timing of their taking and release is a crucial issue and publication in major newspapers ensures a high profile and 'legitimacy' for a research company. 'In a highly competitive industry, to have regular access to the press and a large measure of control over how one's poll gets to be reported is a decided advantage' (Goot 1994, 5).

While politicians tend to brush off unfavourable poll reports ('The only poll that matters is the one on election day...' is a favourite response of politicians questioned by journalists), polls influence the morale of campaigners in subtle ways. Because of the attention paid to them by the political actors they are also influential in perceptions of the capabilities of leaders, both inside and outside election campaign periods.

Continuing speculation on the relative popularity of leaders has had a very destabilising effect. With rivals waiting for the next downturn, 'Consistent policy-making will be difficult to achieve and principles hard to adhere to' (The Australian 1995, 3).

Well-known pollster Irving Saulwick believed the polls and the media feed off each other and create self-fulfilling prophecies. He pointed to:

... a danger that the media, and particularly the electronic media, have trivialised the political debate, and polls are an easy way to do that. I think the media should treat polls with caution and not be carried away by the opportunity to make news from them (The Sunday Herald-Sun 1994, 5). 
While large polling companies remain tied to major newspapers, this seems unlikely to happen. It is interesting to consider the rationale of polls from one of the people who introduced polling to Australia. Roy Morgan believed measuring the opinions of people is important:

- to stop people making sweeping claims about what the public wants, without any systematic research to support their claims;

- to state the core of a problem as a question, thus confronting people with the issue. By publishing the results, opinion polls ensure that everyone knows not just the issue but the public's attitudes, expressed as a quantifiable figure, towards it. This forces political leaders to recognise the issues; and

- to create a continuous 'election atmosphere', rather than a phoney atmosphere at the bidding of political leaders and the media, by publishing regular and reasonably accurate percentages of voting intentions (The Bulletin 1995, 15).

For the Liberal Party the Morgan research company conduct polling by CATI which, though cost and time effective, can be more error prone than face-to-face interviewing, as adjustment must be made for homes without telephones, as the Morgan pollster explained (Scales 1995, interview). Telephone surveys conducted on week-day evenings are compared to door interviews on weekends, the latter giving a more reliable response, being less rushed and less influenced by the immediate news on television. 'CATI is easier and quicker, but there are traps to be aware of' (Scales 1995, interview).

Clients of the research company can now log on through their modems, leave an account number and data from the surveys can be downloaded to their computers. John Scales made the point that sections of marginal electorates can be identified to gain 'most votes for dollars spent'. A basic questionnaire to test awareness of 
the candidate and the chances of success of winning an electorate costs $\$ 4,000$ to $\$ 5,000$ (Scales 1995 , interview). He estimated late deciders as five percent on polling day, and 20-30 percent two to three days before the poll. He concluded that some floaters critically monitor the campaign, some are undecided and some do not care - the proportions being hard to gauge.

Turning to the 1993 campaign, commentators just before the election declared it too close to call (Steketee, Wright and Lagan, 1993, 4). A uniform swing of just under one percent and the gaining of six seats would have given victory to the Coalition. However, according to one journalist, 'Normal polling techniques have failed to get past a wall of swinging voter resistance to telling political pollsters anything' (Kitney 1993, 5).

The final polls, taken in the 24-48 hours before the election day, were in fact accurate predictors of the vote and far closer than the predictions of most political commentators. Richardson was derogatory in his opinion of the polls which he described as 'horseshit'. Two weeks before the election he was convinced that the government would be returned and '...a week out, I started putting the money on' (Richardson 1994, interview). On the campaign trail he observed a change in peoples' attitudes. 'You could just smell what was happening...' (Richardson 1994, interview).

A practice known in the US as 'negative calling' has occasionally been employed in Australia where it is called 'push polling'. It uses telephone survey calls to spread rumours against the character of candidates by asking whether the voter would be less likely to vote for the candidate if they knew some unsavoury 'fact' about them. However the likelihood of such calls reaching a voter opposed to such practices or of the other party persuasion is fairly high and instances have been leaked to the press (Lamberton 1995, 1-2). The Minister for Administrative Services instigated an inquiry by the Joint Standing Committee on Electoral Matters into the practice, following reports it was used by the Liberal party in the Canberra by-election in 1995 (The House 
Magazine 1995, 19). At the time of writing, the JSCEM had not bought down a finding.

In general, public opinion in Australia would appear to be more negative to such practices, if the newspaper commentaries are to be believed, so it may be that 'push polling' may be less widespread in Australia than is the case in the US. In addition, the defamation laws are more stringent in Australia than in the US, which may deter such occurrences.

\section{- central role of lobbyists}

During the 1993 campaign various peak bodies became involved in private campaigns in promoting the government's or opposition's policies. Such campaigns were regarded as very important in the face of decreased donations to party funds in general.

Targeting marginal seats, such groups as the Australian Private Hospitals Association, the Australian Health Insurance Industry Association, the Housing Industry Association and the National Farmers' Federation spent millions of dollars on advertising, direct mail and private polling in the interests of the Coalition (Hewett 1993, 7).

In the Labor government's interest, the ACTU devised a $\$ 1.3$ million campaign in support of its re-election and the Doctors' Reform Society campaigned in favour of retaining Medicare (important in the Lowe electorate against the incumbent Liberal, Dr Woods, who was associated with a threat to Medicare). The support for Labor by the trade union movement in direct mail and surveying was substantial, the most committed Hogg has ever known, and was 'a critical factor' in returning the government (Hogg 1995, interview).

Speaking in 1996, the National Secretary of the ALP pointed out the imbalance in contributions from corporations to the major political parties. Over the last three year political cycle, the Coalition spent around $\$ 88 \mathrm{~m}$ and the ALP around $\$ 67 \mathrm{~m}$ (Gray 
1996, 2). Quoting Professor Rolf Gerritsen's research, Gray said that the Coalition parties received over $\$ 21 \mathrm{~m}$ more in donations from the corporate sector than the ALP in the three financial years from 1992-1993 to 1994-1995 (Gray 1996, 4). The donation system was necessary, he believed, because public funding provided only one third of the running costs of the ALP. Urging an evenhanded approach to funding both sides of politics, Gray said: 'Donations to political parties are, above all, a donation to the system and the processes we have evolved in Australia. They contribute to stability and predictability. They help to maintain both parties near the centre of the political spectrum, in the mainstream, because they ensure that neither can become dependent on or captive to narrow sectional interests. In the end, all that translates into good government' (Gray 1996, 10). Not surprisingly, he saw little value in donations to minor parties. 'The fringe parties and the one-issue lobby groups masquerading as political parties still see themselves as gifted amateurs, donating their superior wisdom to the less enlightened of our society...' (Gray 1996, 7).

The high and increasing costs of campaigning have arisen principally as a result of campaigning methods using the new technologies in the marketing of politics, of which Gray is a strong advocate.

\section{- increasing importance of television}

In general, the influence of television on political communication is considerable. 'It is ingrained in the very way in which parties and governments operate, form policy and appeal to voters. It is, for voters, their principal window on the world of politics' (Ward 1995, 227). Television news is regarded as a reliable and factual source of information by a majority of Australians (Ward 1995, 71). In the 1993 campaign television news played a distinctive role. Extensive, regular coverage of high unemployment elsewhere in the world put Australia's unemployment 'in perspective' (between the 1990 and 1993 election campaigns, television networks, particularly the $A B C$, had opened a large number of new offices overseas) (Butler 1995, 
interview). The effect was to diminish unemployment's primacy as an issue which could be 'solved' by government intervention.

\section{Television advertising}

The concentration on television produced simple advertising themes. Both parties used small teams of professional consultants to run their campaigns through the media and by direct mail. The style of the election campaign changed in several ways from earlier elections in that songs and slogans were abandoned and both major parties concentrated on attacking the opponent's policies. Leaders appeared in news clips but barely at all in media advertising. Labor's Medicare campaign, and other television election advertisements from both sides, were more emotional and negative than in previous elections - tending to follow the American example (Adams 1994, 47). The dominance of brief television advertisements conveying negative impressions was particularly suited to an essentially emotive federal campaign mounted by both major parties in 1993.

The battle was waged through television advertising of alarmist images and extreme allegations made by both sides. For example, a Labor television advertisement featured a cash register relentlessly adding 15 percent tax to every-day items and a Liberal advertisement showed voters dropping through Labor's unemployment trapdoor. In Richardson's view, Labor's most successful advertisement depicted a dishevelled woman and three children worrying about health care costs under the proposed Coalition program. 'She [the dishevelled woman] was a real human being [sic], a former actress living on the [Blue] Mountains [NSW] who felt strongly and volunteered her services - a powerful weapon' (Richardson 1994, interview).

The election campaign television advertising thus centred around negatives - unemployment, health and the GST. While it was generally conceded that the jobless presented a long term and difficult problem, the issue affected (only) 11 percent of workers, whereas the GST 'threatened' everyone and was within the power of the voter to avoid, as were health changes. Attacking 
these tactics post-election, Coalition frontbenchers blamed lies and propaganda for the election loss. Keating's campaign was accused of being dangerous, ruthless and a deliberate attempt to frighten people. The Opposition consumer affairs spokeswoman said that Keating had campaigned '...viciously and with menace. It was terrible and appalling' (Magazanik 1993, 9).

An effect of negative television advertising may be to increase cynical attitudes amongst voters towards things political. With television being used increasingly, this could have important long-term consequences. '...it is possible that television political advertising in general fuels voter disillusionment and is inimical to the health of democracy itself' (Ward 1995, 191). As television advertising can use images and sound emotively, it is not obliged to present reasoned argument, so:

...in using television ads to persuade, politicians and parties are able to escape the rules of logic which apply to conventional political speech and argument (Ward 1995, 199).

It did appear in the 1993 election campaign that television advertising was influential in setting the agenda and determining issues for debate. Government 'research' - as opposed to Labor Party 'polling' - was used to mount a highly-targeted television, print, poster and community campaign on the benefits of Medicare, aimed at women voters particularly, in the four weeks before the election was called officially. This particular campaign, which may have been crucial to the outcome of an election where a tiny margin counted and where subsequent polling revealed health as the issue of major importance to many voters, especially females, has gone virtually unremarked.

\section{Television debates}

The debate on the GST was a contest in scaremongering by the Government and reassurance by the Coalition. It became a battle of lists of items which would be taxed, against lists of 'hidden' taxes. Whether the GST would be beneficial to the economy or to 
individuals in the longer term was never seriously debated, such substantive issues being lost in the rhetoric. Doorstop interviews which characterised the leaders' media exchanges are not conducive to detailed questions and answers on policy issues.

During the campaign there were three televised debates between Paul Keating and John Hewson, the major party leaders. In the first the demeanour of both men was constrained and somewhat wooden. In subsequent debates the better-known, aggressive Keating style surfaced as he vigorously attacked the Coalition's policies and rebutted criticism of the government's record. Reports on the second debate alleged bias on the part of moderator Kerry O'Brien for concentrating on Coalition policies rather than Labor's record. Advice to both leaders from their campaign consultants to avoid technically complex economics was heeded and resulted in a more comprehensible debate (Dobson and Gray 1993,5). The main issue hammered by Keating was predictably the GST and threats to Medicare while Hewson counter-attacked on the government's unemployment record:

Thanks largely to the poor performance by Dr Hewson, $\mathrm{Mr}$ Keating clearly 'won' last night's debate. For a Prime Minister who is entering the last week of the campaign behind in the public opinion polls, that is an enormous boost to morale. However, if Dr Hewson seemed nervous and unconvincing in his handling of questions on the GST and Medicare, Mr Keating was equally unconvincing in his attempts to persuade voters that the worst was behind them...Frankly, it is hard to see swinging voters being drawn in their droves towards either $\mathrm{Mr}$ Keating or $\mathrm{Dr}$ Hewson as a result of last night's performance (The Financial Review 1993, 12).

Keating was judged by one commentator to have lost the first two debates but to have won the final one (Oakes 1993, 16). The television debates are indicative of the degree to which the 'performance' of the leaders is important in Australia's increasingly 'US-style' campaigns. The psychological battle between the leaders has also been described by theatrical allusions. 
Following the debacle of whether the GST would apply to a birthday cake '...Hewson went into stage-fright - it unnerved him' (Richardson 1994, interview).

In addition the capacity for Liberals to explain the complexities of the GST was severely limited by the quick 'bites' demanded by television interviewers. The implications of the GST was far too complex to be adequately explained through this medium. The Coalition decision to feature Hewson in large and noisy public rallies was also counter-productive. A much larger television audience that night would see dissension and confrontation among the rally audience, a picture that Keating could capitalise on as evidence of a divided society which would result if the Coalition parties gained office.

\section{- incumbents further advantaged}

Coordination of the campaigns was made easier and more efficient through use of CTs linking electorate offices with Parliament House and with each other. There appears to be a 'one election gap' between introduction and availability of new CTs and their exploitation efficiently by political parties. Thus, mobile phones were introduced to Australia in 1987 but came into widespread use only during the 1990 election campaign.

Hogg believed that the essential elements of campaigning have not changed but that mobile phones and faxes have made communication quicker and easier. He described several occasions during the 1993 campaign when calls on mobile phones were crucial in solving problems. For example, one Sunday morning a call from the Western Australian state secretary alerted the national secretary to the Democrats' intention to give their preferences to the Greens. 'A solution was agreed by the end of the call and it was sorted out by Tuesday' (Hogg 1995, interview). This improvement in speed and efficiency in communication is particularly significant given the vast distances involved in campaigning across Australia. Like the US, telecommunications systems in Australia span the country, enabling more efficient and faster political communication. In 
Australia, however, with much sparser populations, these vital links have helped to overcome what has been termed 'the tyranny of distance' (Blainey 1966).

In rural seats, Members often operate mobile offices covering great distances to improve citizens access. The 'caravans' are linked to the electorate office by mobile phones and faxes and constituent problems can often be dealt with immediately. Thus the MP in a rural constituency overcomes distance by traversing it, using CTs to manage and organise electorate office work (Sharp 1995, interview with staff). The areas involved can be geographically vast, and this is an instance where the new CTs have been particularly conducive to political communication in both election or in non-election periods.

\section{People:}

\section{- impact on party members}

Although there is no formal research to support this contention definitively as to cause and effect, the indications are that CTs' use in local campaigning is related to declining branch members' commitment, demonstrated on the Labor side by the report on the Wills by-election in March 1992 and by the Young Inquiry into the Queensland State election in 1995, and on the Liberal Party side by comments by a Liberal Senator (see interview with Nick Minchin, chapter three).

Extensive research by the ALP in Wills on political attitudes identified key issues which were then addressed in campaigning, including through direct mail. One-third of the campaign budget was used on research (Gray 1992,1). The surveys showed that the mood of the electorate reflected feelings of desertion by the local MP, Bob Hawke (retiring Prime Minister), anger at the perceived self-seeking barrage of attention from politicians, frustration of electors who knew their vote could not change the government and refusal to be 'taken for granted'. This led to a Labor strategy 
which focused on the theme - Local Who Listens. This approach was chosen because:

The theme symbolised a campaign which tried to repair the damage created by the 'desertion' charge which local community leaders, local media and the Liberals were levelling at us. We sought to give local residents a representative living locally responding to local issues. To do this we combined low cost direct voter contact activity with direct mail, targeted campaigning, local endorsement and lots of letter box pamphlets. We localised our campaign literature to the greatest possible degree (Gray 1992, 3).

The analysis of the campaign by its director was a thorough review of positive and negative aspects. He identified declining participation by branch members as a significant factor, which was both linked to a centralised CT campaign and necessitated it. Lack of local commitment adversely influenced the available people resources, to the extent that the whole Victorian state branch was needed to work on the campaign as local members lacked enthusiasm. The problem he identified as a general one:

As I have stated, grass roots political participation is at a low ebb in the ALP. In Wills, additional factors made it worse. Without reflecting on Left or Right factions when pre-selection is determined by 'branch stackers', an illusion of large branch membership is created. Low levels of political participation are a growing problem for us (Gray 1992, 4).

The importance of image in modern campaigning became a predominant feature:

On the down side, 'Bill the Greek' (the Labor candidate) was not attractive to the electronic media. His accent and difficult manner were emphasised on radio and TV... This was unfair in many respects because Bill's real quality and 
capacity could not be demonstrated. In a general election Bill would have survived the campaign (Gray 1992, 4).

The ALP spent about $\$ 250,000$ on the campaign and had support from unions in terms of direct mail, money and personnel. Ironically, in successfully attacking the Liberal's GST Labor damaged the Liberal vote in favour of the independent candidate Phil Cleary (who also opposed the GST), resulting in his ultimate success. The tactic rebounded when it was too successful, leading to Labor losing a traditionally very safe Labor seat:

It should be remembered that on Day 1 of the campaign, the Liberals were going to win. We were able to get ourselves into a winnable position but the Liberal vote collapsed. Had the Liberal vote not collapsed by 6\%, Cleary's vote would have peaked at about $28 \%$, leaving Labor with a 58$60 \%$ two-Party-preferred vote! Such a result would have made heroes of us all (Gray 1992, 11).

Significantly, post-election research showed that about one-third of voters decided their vote on election day, showing the same pattern as some surveys of the 1993 general election. The Wills by-election indicated that decreased local commitment had a rebounding and reinforcing effect. While the locals believed that head office did not listen, and that they relied too much on professionals (using new campaigning techniques), the head office believed that the locals were in general disinterested and therefore placed heavier reliance on the application of the new CTs to campaigning.

Post Script: The Labor candidate, Kelvin Thomson, reclaimed Wills in the 1996 federal election with a primary swing of 4.95 percent (The Australian, March 4, 1996, 8).

A more recent inquiry pinpointed lack of consultation of the central campaign committee with rank and file members as the key problem. Following the July 1995 state election, in which the Labor majority in the Queensland parliament was reduced from 19 to one, a Committee of Inquiry was established, chaired by 
former National ALP President and former federal Minister Mick Young. A total of over 1,000 ALP members contributed to 55 hours of discussion and 270 people made oral and written submissions.

The findings in the light of the association of the use of CTs with party disenchantment were revealing. The Inquiry made a series of recommendations, including requirements for better consultation and communication by head office with grassroots members. 'The Inquiry found the widespread view that the group making decisions in the campaign was too small and unrepresentative' (The Young Inquiry 1995, 13).

The use of new CTs in campaigning was identified as a problem, in that it was believed by branch members that pollsters' activities should be confined to polling, and the actions which follow should be controlled by party people. 'Many submissions focused on the alienation from the central campaign felt by many local campaigns' (The Young Inquiry 1995, 14). The reason for this may lie in the faith the central organisers hold in the technologies, believing in strategists and pollsters, rather than listening to the grass-roots opinion.

In fact, it appeared that faith held by the central campaign people in the new campaigning techniques had repercussions at the local level. 'There was a strong desire expressed by members and branches to play an active role in the party - in policy development and providing timely, honest feedback to the Party about its status in the community - but they were frustrated because the Party office appeared not to be listening to such advice or feedback' (The Young Inquiry 1995, 19).

The chairman spoke to me of 'the mad conflict between head office and the branches' (Young 1996, interview) in which material was imposed on branches which was not relevant to the electorate and which many refused to use. Young agreed that the use of new campaigning techniques and the professionals had added to the feelings of alienation (Young 1996, interview). 


\section{- new techniques for electors to follow the campaign}

The Nine television network in the program 60 Minutes screened the reaction to the debate of a studio audience of swinging voters by use of the electronic 'worm', a rising and falling graph across the screen which registered audience approval or disapproval of the performances of the leaders in the campaign (Boylen 1993, 5). This was the first time the perception monitor technique (the 'worm') had been used in a live assessment of political debate but it has been used in the commercial advertising world for more than 30 years.

Not surprisingly for floating voters, for most of the debate a third to a half of the dial twiddlers chose to stay in neutral, indicating a lack of involvement (Souter 1993, 18). It could be argued that credence to the 'worm' has the potential to result in misinterpretation and policy dictated by emotive reaction rather than by rational analysis. However, one party operative observed:

None of us take it [the 'worm' technology] as gospel. It is part of a mix - same with all research - we use gut feeling, our own experiences, how the media will react, how colleagues will react, what the Labor Party might say...we balance all this. It doesn't just rely on dial twiddling - It's a mixture of common sense, history, basic values and what you think you can get away. with - research is only part (Morris 1994, interview).

This comment demonstrates the common-sense approach to the use of CTs in campaigning, in contrast to the universal endorsement afforded to direct mail by many party machine people. But, as suggested earlier, the apparatchiks' motives may be organisational rather than technological. The control over campaigns evidenced by direct mail 'advice' is an important aspect of the professional, controlled, CT-centred campaign. 


\section{- $\quad$ role of the Canberra press gallery}

It was indicative of the extent to which the Canberra press gallery was out of touch with the people that they were so much in error in predicting the election result. Instead of gauging the mood of the electorate by making on-the-ground assessments, a critical commentator surmised:

....reporters were either cocooned in the back of the VIP [Boeing] 707's traipsing after the leaders or in the head office in Sydney, reading transcripts and watching prime TV regurgitate the facile images of pie shops and early morning jogs. This lead to the ultimate absurdity of day-today and week-to-week scoring of who won the tactical battle to gain the best television grabs and newspaper headlines substituting for real reporting of how the community was reacting to the major parties (Burton 1993, 5).

To a degree the very accessibility of the new CTs has led the political journalist to believe that grassroots appraisal of the electorate's mood is unnecessary. Even when late polling, conducted by CATI, indicated a swing back to Labor the Canberrabased journalists continued to believe in the conventional opinion that a government with a million people unemployed could not win. Thus the mind-set of the journalists contradicted the evidence the polls were providing.

However the media did report sustained attacks by Labor as the campaign progressed, which forced the Coalition on the defensive, attempting to explain their complex policies rather than being in a position to attack the perceived government failures. Labor picked away at the detail and, when specifics were unclear or poorly explained, was able to discredit the entire Fightback! package through the negative television advertisements, mentioned earlier.

One conservative commentator was scathing in his assessment of the competence and balance of media coverage of the campaign. 
'...Nobody with any sense of fairness can conclude that, over the past five weeks, our media has even tried to probe the issues confronting Australia in the years ahead' (Stone 1993, 6). Another influential aspect of the campaign was the failure of the Canberra Press Gallery to analyse in any depth the implications of the Coalition's proposed tax changes:

At no stage did the Canberra-based journalists subject either version of Fightback! to a detailed and critical scrutiny. Had they done so, then it is likely that at least some would have come to realise that the policy package on which John Hewson had decided to fight the election was seriously flawed (Media Watch 1993, 3).

Journalists who, during the 1980s, appeared to be hold an advantage in the technology race with the introduction of sophisticated, computerised production facilities were comparitively less benefited, as use of CTs in general become more widespread.

\section{Electoral consequences of the new CTs in future}

In the opinion of pollster Rod Cameron, general advertising will become less important in election campaigns:

Very rarely do you get blockbuster ads that are going to change campaigns. They help reinforce on-going themes but future campaigns will depend less and less on big money advertising and more on messages that are delivered not only by personally addressed pamphlets and letters but also organised word-of-mouth campaigns... (Boylen 1993,30).

Further he believed that: "The views and the interests and the prejudices of the very cynical and the very uninterested in politics are still the key to the election' (Dixon, 1993, 3). While broad electronic appeal is important, success lies in identifying and targeting specific groups within specific seats. He held that 90 
percent of television advertising, particularly negative attacks which repel uncommitted voters, are counter-productive. Yet in the instance of the 1993 election, negative advertising appears to have been very influential, even decisive, to the result.

A seasoned election observer, David Butler, drew attention to evolutions in campaigning over the years. Several developments have relevance to the new CTs. Whereas contradictions between spokespeople in different parts of the country were common in the past, faxes and mobile phones have made communication quicker and have led to better co-ordination. 'Modern communication technology has done much to nationalise (campaign) electioneering' (Butler D. 1993, 5). The other major development he commented on was the increased importance of direct mail because it allows campaigners to target specific audiences.

Speculation on the future impact of CTs on campaigns is fraught with difficulties. However, one possible outcome of pay television may be that the electorate may actually become less informed. A proliferation of channels and more individual choice could result in people choosing to avoid election news, something difficult to do in 1993.

The advantage held by the incumbent will be increased as elected Members utilise the new CTs (as they are introduced) to target their constituents. With public funding of campaigns in Australia, major party and incumbent advantage are entrenched. Campaign costs will continue to increase due mainly to expensive television advertising, polling and direct mail.

The immediacy of election news transmission will increase, coupled with the likelihood that targeting by parties will result in increased localisation of issues, though the campaign organisation has become more national. National issues becoming displaced by local ones is a counter to the centralising influence of CTs in general. Further, an increase in the number of narrowly-defined interest groups catered for by a multitude of pay TV channels (and the Internet) may be detrimental to national cohesion. In contrast 
to national broadcasters (private and public) previously encouraging a common civic culture, the new media may divide and segment the community. The targeting of messages through a video clip attached to email may provide a more effective - or at least a viable alternative - avenue of political advertising than the present system of television advertising.

\section{Conclusion - the use of CTs in campaigning}

Probably the most memorable phrase of the 1993 campaign was that of the Prime Minister in claiming victory for the 'true believers'. In the face of the scaremongering campaign, driven by market strategists and put into place by a small team of professionals, it is hard to see where Labor stalwarts, the 'true believers', fitted in. Given the small margin in the 1993 election result and the very high number of 'floating' voters, however defined, it appears that the marketing of politics will operate in an increasingly volatile environment.

The impact of CTs on representation and participation were considerable. In my judgement the extent of CT influences was such as to constitute a qualitative difference in the conduct of the campaign in 1993. Each individual new CT has altered campaigning and elections slightly, but collectively have forced a substantial change on the way campaigns are conducted. The extent of the impact and acceptance of the new CTs in the Australian community generally can be measured by how little comment was made on the new, CT-driven sophistication during the 1993 election campaign. In the end, victory came down not to using new CTs in a sophisticated way, though that was important, but to holding confidence and belief right to the end. In this context, Keating's 'true believers' comment is much more apposite than people have given him credit for. His purview of 'true believers' did not embrace the Labor Party faithful as people have supposed but rather the elite few, the hard-core professionals who ran the Labor campaign and refused to give in or give up in what even they mostly believed were the dark, final days before the 1993 election. 


\section{Use of CTs in electorate offices in a non-campaign period}

An election period represents an intensified activity, when campaigning brings into action all possible means of communication, including the new CTs. It is therefore relevant to consider use of CTs in 'normal' periods, though the 'continuous campaign' cited by Stephen Mills has meant a general rise in activity, as some of the comments by electorate office staff to the questionnaire reported below noted.

\section{Methodology}

A questionnaire, devised and pre-tested by the researcher, was circulated in December 1995 by Faxstream through the Department of Administrative Services (DAS), for the purpose of monitoring use of CTs in electorate offices in a non-campaign period. It was surmised that the response rate might be higher if offices were approached through DAS (who supply the electorate offices' computer advice and services). In the event, after an initial ban by the ALP head office on Labor offices' responding was rescinded following consultation by the researcher with Labor head office, a total of 104 responses was received from a possible 223 (65 from non-Labor and 39 from Labor), representing a response rate of 46.63 percent. Thus the ban appears to have adversely affected the response rate from Labor offices (though only five of those who responded did not answer the direct mail question, as head office had decreed).

NOTE: The ostensible reason for the ban was the confidential nature of the Labor Party's use of direct mail. The episode is an interesting example of the extreme reluctance of either major party (especially Labor) to reveal anything it judges might possibly be used against it, and general distrust of researchers. It again demonstrates a jealous guarding of information. 


\section{Findings}

(Detailed tables are attached in the appendix)

As stated, use of CTs peaks during election times, with the general increase in activities. For routine administration in electorate offices, the mail, phone and fax are constantly used, with mobiles becoming more frequent. Face to face meetings are valued, both in campaigning and in routine times. Use by the whole sample is reported below.

Mobile phones, though used 'constantly' by only 19 percent and several times a day by 26 percent, were used never or rarely by 31 percent. Mobile phones are supplied by DAS to Members, but not staff. However the mobile was rated 1 (indispensable) by 39 percent of respondents and rated 2 (very important) by a further 20 percent. The telephone was overwhelmingly the most important communication medium, with 100 percent using it constantly and 98 percent rating it indispensable. Teleconferencing was used rarely by 50 percent and rated 3 important - 30 percent, and 4 - unimportant - by 55 percent. Videoconferencing was never used by 90 percent and generally rated unimportant ( 80 percent).

Mail was the second most common communication medium for electorate offices, with 94 percent scoring constantly and 94 percent rating it 1 . Direct mail was used several times a month by 52 percent and constantly by 19 percent. About a third of respondents rated it 1 or 2. EPN (Extended Parliamentary Network) mail was accessed several times a week by 43 percent, several times a day by 24 percent and constantly by only six percent. It was rated 1 by 24 percent and 2 by 37 percent. Fax was used constantly by 88 percent and judged to rate 1 by 95 percent. The least it was used was several times a week (four percent).

The Internet was never used by 87 percent and rarely by seven percent. One office responded 'constantly' (this was checked by a telephone call to the Member's office and found to be accurate, 
access to the Internet being provided on the staff's initiative). The rating in importance, reflecting actual use, was commensurately low: unimportant by 49 percent and important by only 17 percent, though six percent rated it indispensable, presumably predicting that it would be important in future. The EPN database was used quite consistently: 28 percent several times a day, 28 percent several times a week and 19 percent constantly. It was rated 1 by 45 percent and 2 by 26 percent. Face to face meetings were held constantly by 39 percent and several times a day for 22 percent. This form of communication was rated 1 by 57 percent and 2 by 26 percent.

Of the media as an information source, newspapers scored most highly (constantly 51 percent and several times a day 26 percent), and rated indispensable by 80 percent. Radio was monitored less frequently - 33 percent constantly and 22 percent several times a day. Radio was rated 1 by 52 percent and 2 by 27 percent. Television was apparently the least influential within electorate offices with constantly only 16 percent and several times a day 15 percent. Its rating was consistently lower than other media, which contrasts with survey findings of the population which rate television highly as a political information source. However, television does feature the leaders rather than ordinary Members, which may explain its relatively low status.

For analysis, the responses were segmented into rural/non rural, Labor and non Labor and Senate and House of Representatives to evaluate any large differences. Senate Labor represented 12 responses, Senate non-Labor 28, rural Labor seven, rural nonLabor 19, urban Labor 20 and urban non-Labor 18.

\section{Non-urban/urban}

Not surprisingly, non-urban ofices tended to make greater use of mobile phones. Urban offices tended to use more teleconferencing - but still not commonly. Videoconferencing was used rarely or never by non-urban and urban offices, so it appears that the new CTs have not as yet overcome distance disadvantages. Mail was used extensively by both and highly 
rated, and the use of direct mail was similar. Urban Members made slightly more use of EPN mail. Fax was used slightly more by non-urban, but both used it extensively and rated it indispensable. The Internet is currently not rated highly by either non-urban or urban electorate offices' staff. Ratings for EPN were generally similar, though urban use appears to be higher. Over half of both groups deemed it to be indispensable and about half to be quite important. Meetings face-to-face were judged to be important and frequent by both groups. Non-urban made slightly more use of newspapers (presumably the local press) and less use of radio and television.

\section{Labor and non-Labor}

Mobile phone responses were very similar, as was overwhelming use of telephone and low importance of teleconferencing and videoconferencing. Mail was important to both, as was direct mail, when the categories of frequencies are added. Both accessed EPN about the same amount and fax was used extensively by both and highly rated. The Internet was used never by 95 percent of Labor and 82 percent of non- Labor, and rarely by 5 percent and 8 percent respectively. The incidence of meetings and their rating were similar, as was the monitoring of the media.

\section{Senate/House of Representatives responses}

Senators tended to use all three mass media more, possibly because their constituency is less immediate and less time is taken up with individual problem solution. Members of the House of Representatives tended to have more face-to-face meetings, otherwise the patterns were similar.

Section 2 of the questionnaire to electorate offices was intended to convey the ways in which the constituents and/or lobby groups contacted the electorate office. In general terms, it reflected the staff perception of constituent use. The responses to the pattern of use of CTs showed the asymmetry discussed earlier between the access of Members and Senators as compared with constituents (for example, use of the EPN). 
However the pattern which emerges shows the predominant importance of the telephone, while teleconferencing and videoconferencing were very rarely used. Mail was used constantly by 69 percent and rated indispensable for 74 percent. Direct mail from lobby groups arrived several times a month for 26 percent but was not generally rated highly. Email was almost never used by constituents, but fax was used constantly by 30 percent and several times a day by 18 percent and rated highly by 45 percent of staff for constituents contacting the office.

Thus it is apparent that at the time of writing the traditional methods of communication dominate, though the electorate office staff are increasingly taking advantage of data bases and some would welcome Internet connection. Many respondents predicted more widespread use of the Internet, but were concerned that cost would be prohibitive to rural people. For the constituents, and even the lobby groups that represent them, phone, mail and fax are predominant.

Section three of the questionnaire, which incorporated open ended questions on CTs' current and future use, enabled an expression of opinion that most respondents took advantage of. One even wrote that he/she welcomed the opportunity to participate.

In general terms, the flavour of responses in this 'open' section did not vary between Labor and non-Labor, so it appears that reaction to CTs is not party political but a common experience. There was more difference between the rural and urban responses (of either party) in that rural offices made the point of the cost of STD charges and also that CTs bridged distance in large rural electorates.

To the question whether the new CTs (defined) had made a difference to communication, one respondent wrote 'Is the Pope a Catholic?' Multiple responses were entered, the most frequent being that the new CTs made communication easier and quicker (52). More efficient was cited 38 times, improved constituent contact mentioned 16 times, and problems of increased pressure 
and stress nominated by 15 respondents. Other responses were that CTs were an aid to research (nine) and that they added diversity to communication channels (three).

Seventy-four people responded that the new CTs had complemented traditional communication methods, and 38 responded that they had substituted for them. A number of people said 'both', in that fax has tended to replace letters to some extent while data bases have added a new avenue. Questioned as to the most useful CTs in future, 42 people nominated the Internet, 39 email, 24 mobile phones and 13 direct mail. Phone was assumed to be of continuing importance by eight people, laptops by six, as was video-conferencing and use of the EPN. Further access to data bases was mentioned by four people.

Under 'Other comments', seven people specified that they would welcome Internet connection, though two would not, for security reasons. Three people stated that they would like DAS to supply mobile phones to staff members as well as to MPs.

Other people commented on the increase in public expectation through use of new CTs, the danger of viruses, and the potential for increased work away from the office. Several people made the point that email was less than satisfactory and that older staff were less computer-comfortable.

\section{Some typical comments were:}

Hopefully email will cut down on paper use, but I have my doubts. Computers were supposed to...provide us with the paper-less office. Instead we use even more paper re-doing many times what used to by done accurately the first time. The amount of information that passes through an electorate office is impossible to assimilate - thought should be given to 'need to know' status of much of the information. Too much means very little is absorbed and is therefore a waste of time, resources and energy (office of Jim Snow, Labor, Eden-Monaro, New South Wales). 
We often need an extra staff member to cope with the sheer volume of work which comes through our office - the whole pace is so fast most of the time and we often feel quite stressed (office of Christopher Miles, Liberal, Braddon, Tasmania).

I think the role of computer-generated communications is over-stated. For immediate response people will continue to use FAX and TELEPHONE...Email is not fool-proof - has all sorts of systemic problems (office of Senator Robert Bell, Australian Democrat, Tasmania) (emphasis in original).

DON'T UPDATE ANY MORE FOR A WHILE - GIVE US TIME TO LEARN WHAT WE HAVE NOW! (office of Senator John Panizza, Liberal, West Australia) (emphasis in original).

Still believe the personal touch is the best and technology which frees people to give more time to personal contact is very helpful (office of Alan Cadman, Liberal, Mitchell, New South Wales).

\section{As to the future of CTs, respondents wrote:}

Fax and video conferencing. But who can guess what the future holds in communication (office of Neil Andrew, Liberal, Wakefield, South Australia).

I believe the present phone and computer communication methods will eventually be merged to provide one service. It will then make the home and office computer systems a one-stop shop (office of Senator Sue West, Labor, New South Wales).

Email, Internet, mobile phones, laptop computers will be essential for both politicians and staff. Portability of equipment will be crucial. Security of the systems and privacy will be a big issue associated with the use of technology (office of Senator Eric Abetz, Liberal, Tasmania). 
Internet which we would love to have as constituents are constantly asking when we will get it (office of Clyde Holding, Labor, Melbourne Ports, Victoria).

It is difficult to foresee changes, as the current rate of change is so rapid. Dreams are coming true quicker than many expect (office of Senator John Watson, Liberal, Tasmania).

\section{Comparisons}

It is interesting to compare the use of CTs by MPs' electorate offices with that of Australian interest groups. As to frequency of various communication methods, some interest groups interviewed appeared to be adopting new CTs at a greater rate than many politicians' offices, particularly in reference to teleconferencing, videoconferencing, email and the Internet.

The particularly outstanding features include use of mobile phones, where the proportion of use by interest groups was much higher; as it was with teleconferencing. MPs tended to use direct mail substantially more, whereas the interest groups surveyed tended to make greater use of data bases.

Interest groups used the Internet to a much greater extent, though as noted, this is not supplied to electorate office staff by DAS and some electorate offices are keen to be connected.

Email was not used at all by most interest groups, and tended to be by electorate offices, though those interest groups who did use it did so constantly. The pattern of media sources and face-to-face meetings was apparently similar. Both groups used telephone, fax and mail extensively.

At the time of writing very few MPs accessed the Internet compared to some people in interest groups who did. However, the MPs used email relatively more than interest groups. MPs tended to follow newspapers more closely, while radio and 
television monitoring were similar. Thus it appears that interest groups make greater use of mobiles, data bases and the Internet, while MPs offices make greater use of direct mail and email.

The following charts, based on a survey of electorate office staff, give a pictorial representation of relative use/importance of the new CTs. Figure one shows the use of various communication methods by electorate offices (outgoing) and the rating given by staff of their importance. Figure two shows the pattern of use by constituents, as reported by the electorate office staff (incoming) and how important they are perceived to be. Figures three to six differentiate all results by urban, non-urban, Senate and House. The patterns of use are similar. 


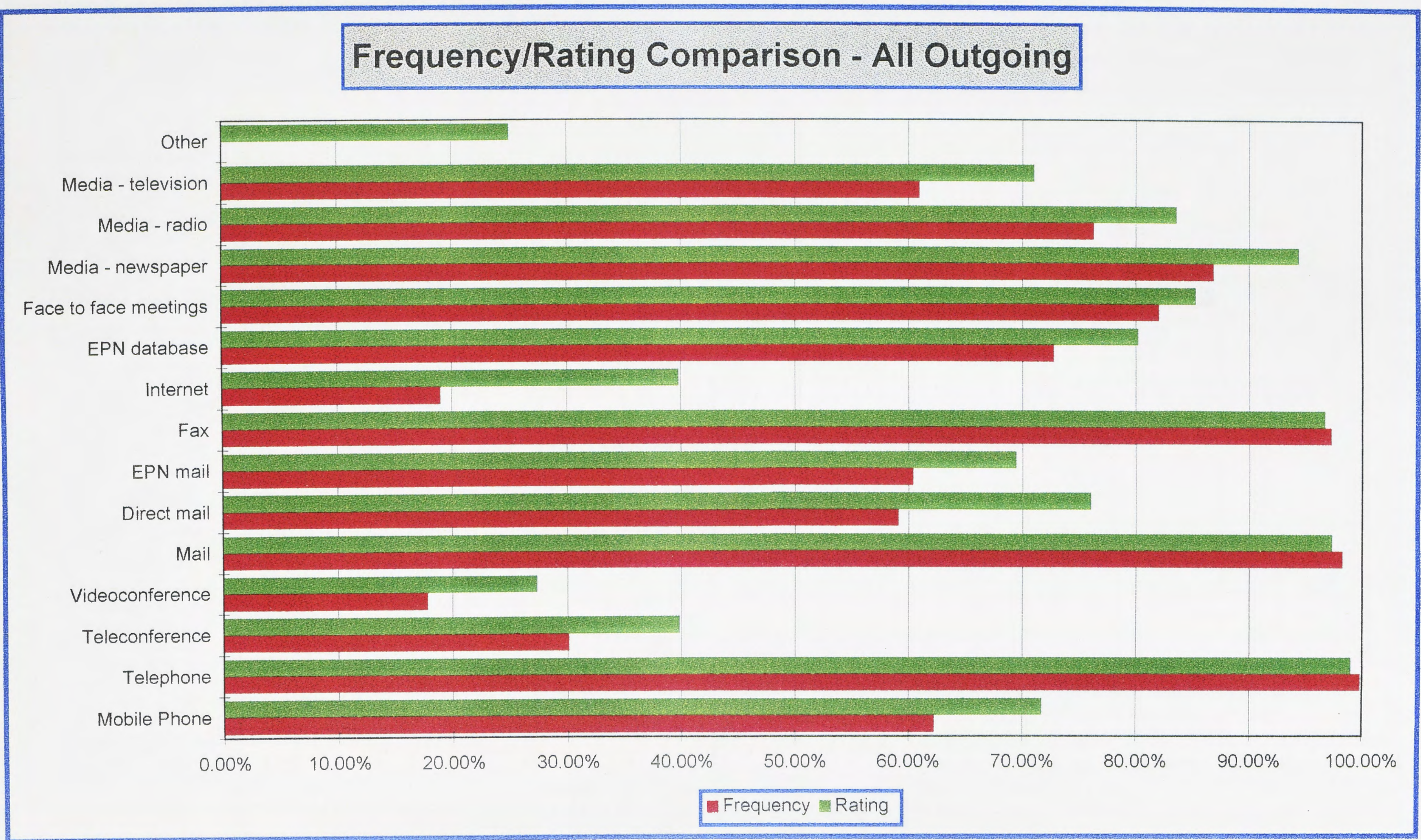

Figure 5.01: Use of various communication methods (outgoing) by electorate offices and staff rating of relative importance. 


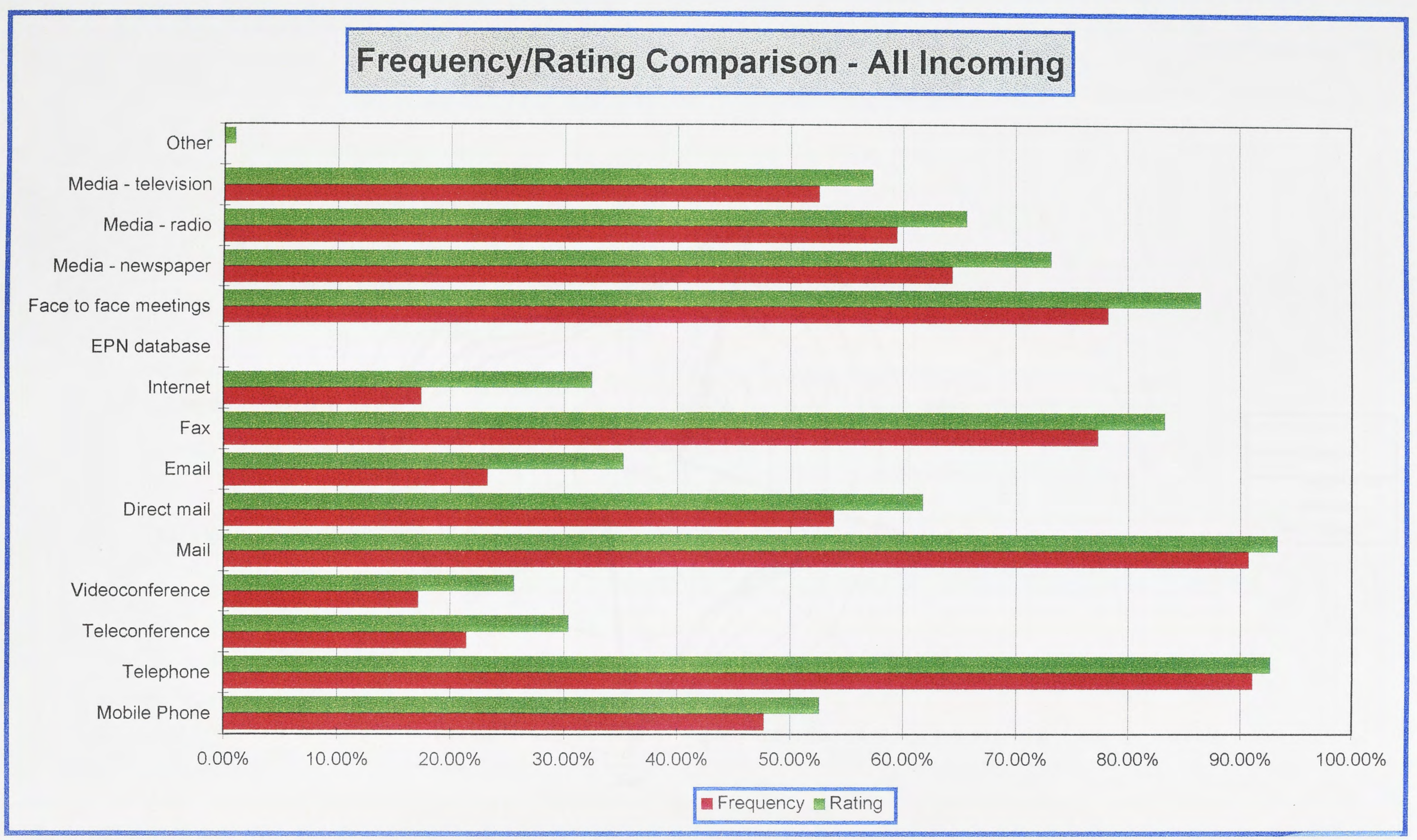

Figure 5.02: Pattern of use of various communication methods by constituents as reported by electorate office staff (incoming). 


\section{Electorate Office Use of Communication Technologies}

\section{Usage Frequencies - Outgoing}
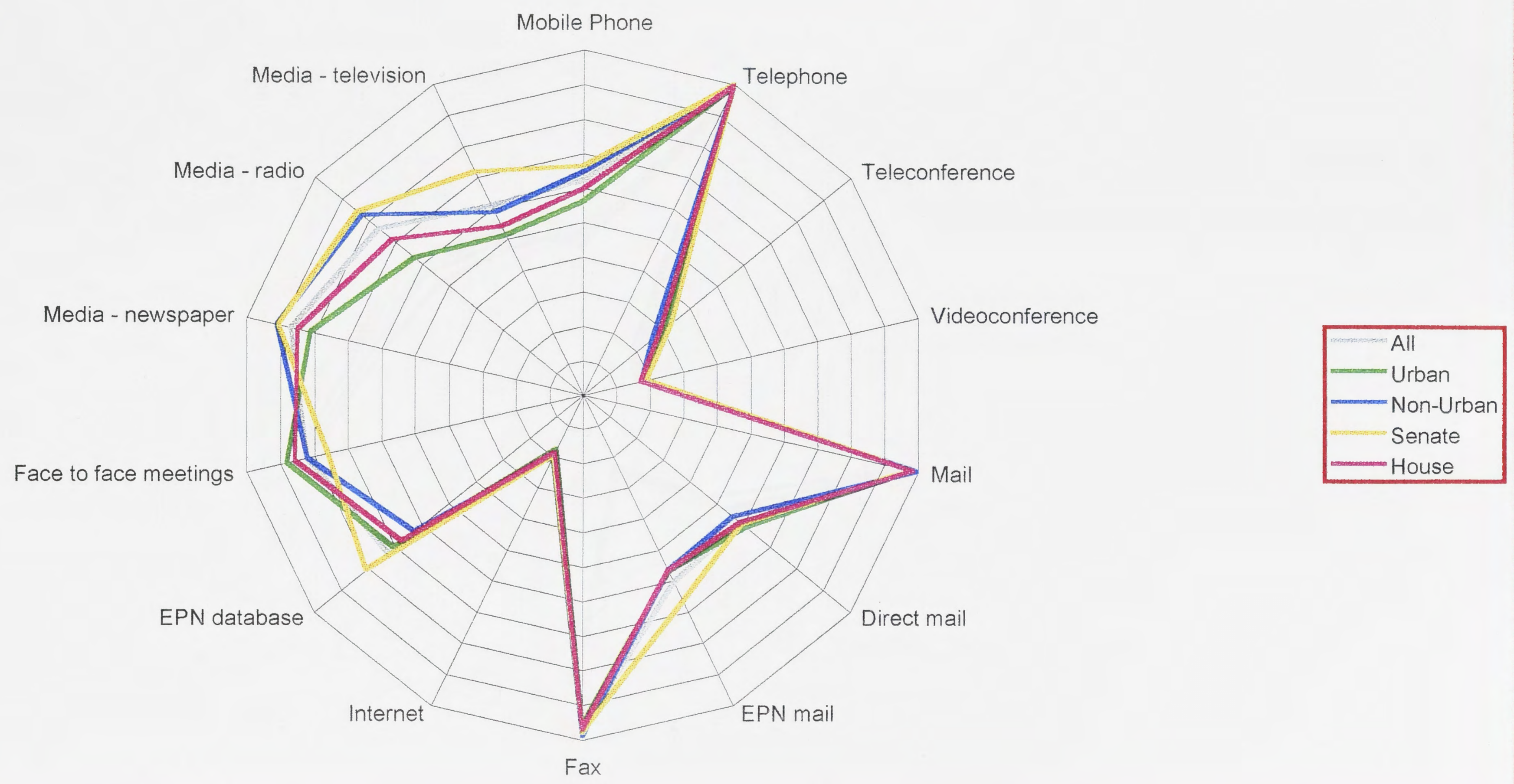

$\overrightarrow{8}$ 
Constituent Use of Communication Technologies

\section{Usage Frequencies - Incoming}

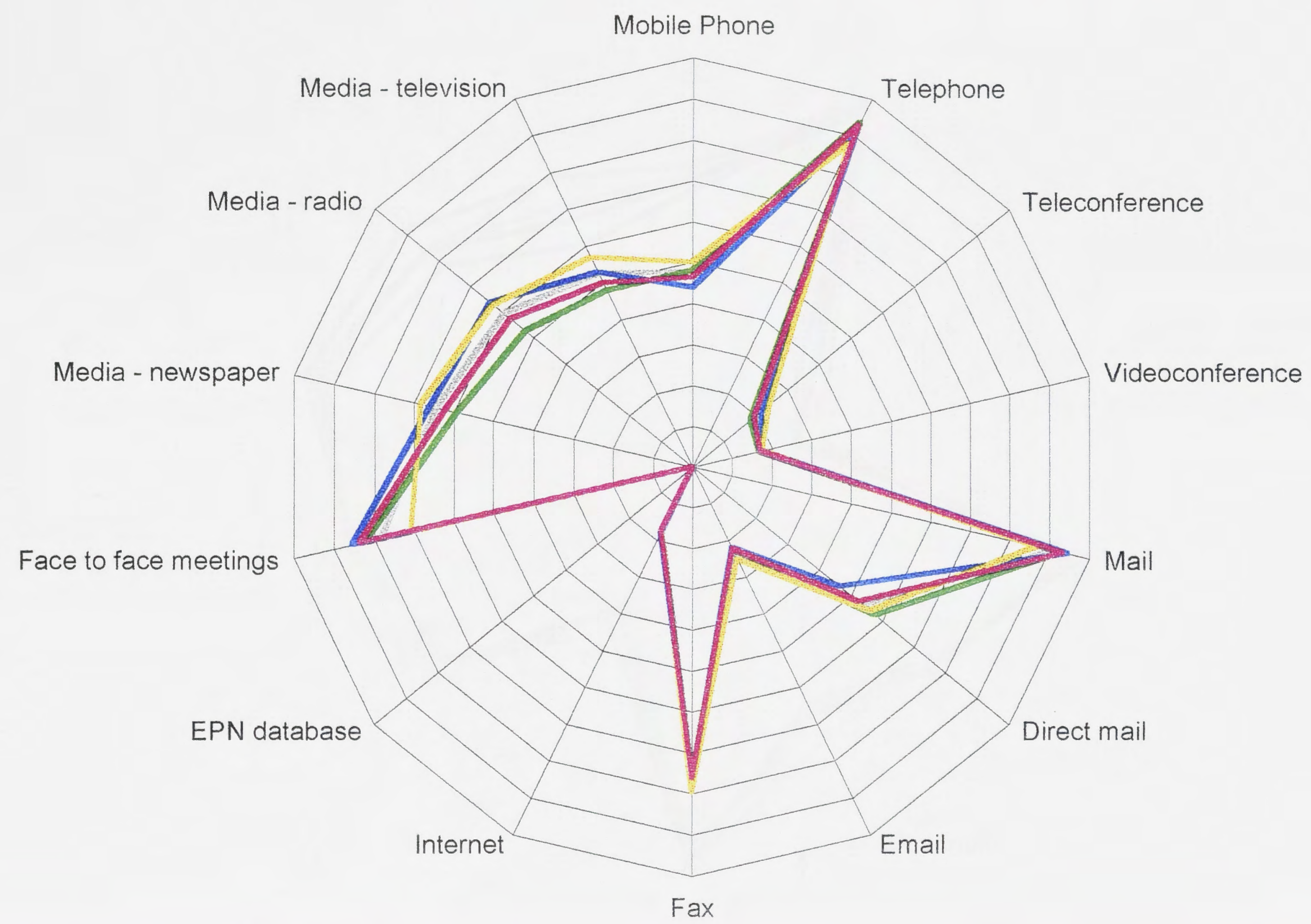




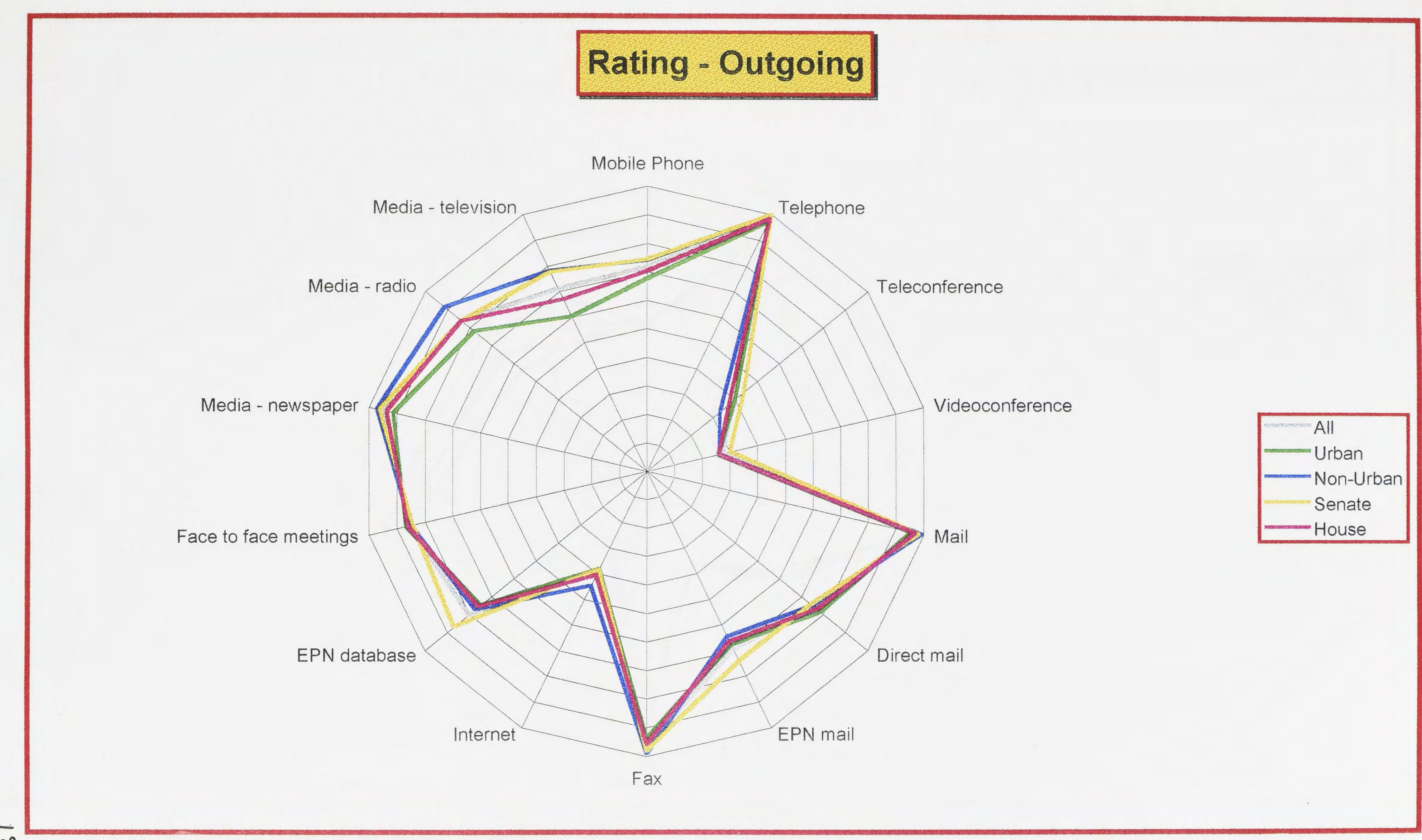




\section{Constituent Use of Communication Technologies}

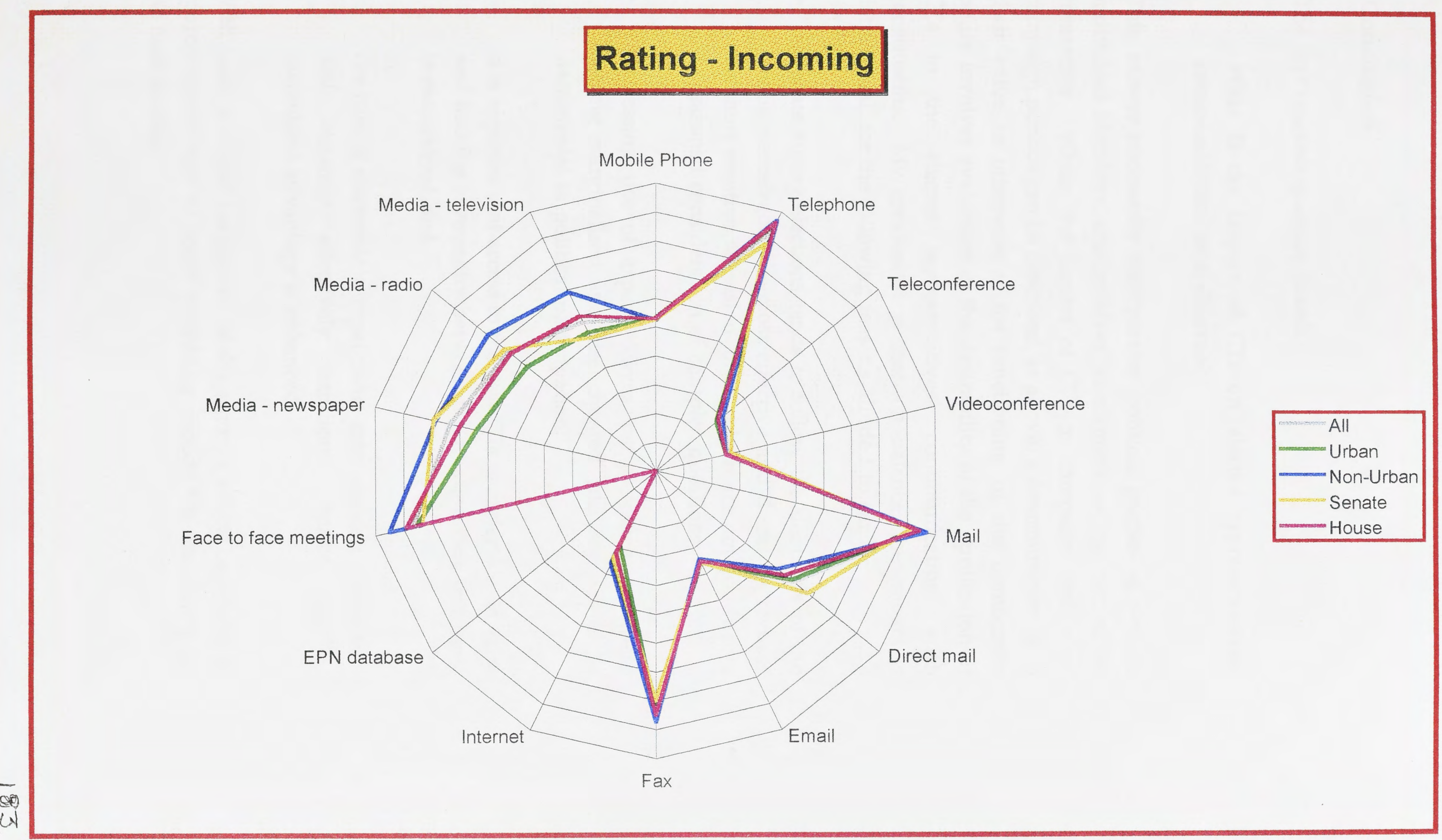

Figure 5.06:

Constituent use of communication methods, rated by electorate office staff (incoming). 


\section{Conclusion}

The first research question asked:

What is the impact of CTs on elected representatives' communication with citizens?

This answer necessarily incorporates political parties as well as individual Members, and involves assessment on the part of the researcher. While the impact of CTs in campaign and noncampaign periods can be described, as above, a determination as to their value or otherwise to the functioning of the democratic polity involves evaluation of the desirability of the application of CTs to the elected representatives' communication with constituents. My conclusion is that, on balance, the impact is detrimental, for the following reasons alluded to earlier:

- debate during elections tends to follow the demands of the media perceived to be most effective and therefore focuses on short emotive television 'bites' which are not conducive to reasoned consideration of complex questions;

- increasing use of experts leaves party branch members feeling marginalised and disenchanted and appears to be detrimental to political participation;

- it is apparent that access to the new CTs is easier for an elite and that the asymmetry between information rich and poor is exacerbated; and

- the cost of electronic campaigning may exclude candidates and certainly effectively handicaps minor parties; incumbent advantage is enhanced.

With such a critical judgement of the adverse affects of CTs, it is appropriate to look to some promising aspects for democracy in the next chapter. 
CHAPTER 6

\section{The experience of the new}

\section{Communication Technologies}

\section{in the United States}

The biggest problem is that direct democracy leaves no room for amendment, compromise and all of the other human elements that eventually lead to consensus and movement. Technology helps democracy by eroding secrecy, but technology hurts democracy by eroding reflection and time. Yes, the people do generally know what's best. It just takes a little longer than the push of a button to figure it out (Alter 1995, 25).

\section{Introduction}

The previous chapters addressed the first research question - what is the influence of CTs on elected representatives' communication with citizens? - by looking at the impact of direct mail in a particular circumstance and comparing and contrasting the attitudes of various players. The use of CTs by interest groups was examined. Direct marketing in the 1993 campaign, the performance of direct mail user and non-user MPs and observation of use of CTs during a non-election period put their role in a broader context.

The findings brought into question the first assertion that 'direct mail works!' and the implicit endorsement of CTs in political communication which this suggests. 
This and the next chapter address the second research question what is the influence of CTs on citizen participation in the democratic process? - by evaluating the seemingly detrimental impact of the direct marketing of politics and by examining the promise of various 'teledemocracy' projects in the US. Some Australian initiatives to use CTs to increase participation are considered in chapter seven. A conditional finding on the second assertion that 'technology can save democracy' is made.

CTs have made the 'marketing' of politics more possible. I conclude on balance that the impact to the well-being of the polity is negative. CTs have also made 'teledemocracy' possible. The effects have generally been promising for increased citizen participation. This chapter looks firstly at the topic of democracy under challenge, substantially as a consequence of the application of CTs, and then at the responses to this challenge by concerned citizens, some methods involving CTs. I will review various projects categorised according to their objectives and evaluate their impact.

\section{Democracy under challenge?}

The problems identified in the US political system range from a deep belief that it is in crisis to less extreme concerns about the need to improve the political processes. The CT-related worries focus on two basic factors - the professionalisation of politics and direct marketing of politics, both of which generate increasing dependence on fund-raising sources. Co-incidentally, decreased participation in politics accompanies deep cynicism, as various surveys and books reviewed later demonstrate. There is an irony in this situation. Many aspects of the American democratic dream appear to an Australian to be naive, with resulting high expectations leading to commensurate disappointment and disillusionment in the face of reality. An added paradox lies in the phenomenon of unprecedented amounts of political information on the Internet (Kohoe 1996, 4) at a time of unparalleled cynicism and apathy towards the US presidential campaign (Waldmier 1996, 3). 
The political CT concerns are part of a much wider social malaise, which appears to be affecting the community in the US. Worries that are not specific to CTs, such as urban crime, race tensions, apparently declining education and health care standards and increasing poverty, also have political repercussions (see, for example, Dionne 1996). In the US the mood of political disenchantment appears to be pervasive, according to journal articles and recent titles (see Dionne, Jamieson and Mathews, below). The government is perceived to have failed and, as a consequence, people appear to have lost faith in the practice of politics. 'Given the inability of the government in the United States to protect citizens from even the most basic forms of insecurity is there not a danger that democracy in America will wither into insignificance, as citizens retreat from any form of civic engagement?' (Gray, J. 1995, 25).

Three recent studies of the theory and practice of democratic government reviewed by John Gray point to the dangers of citizens retreating from civic participation. According to one, rights-based individualism has replaced communal relationships of a civil society (Elshtain 1994). Another scholar blamed elites economic and academic - for abdicating responsibility for the community and contributing to a decline in public discourse (Lasch 1995). The third study (on regional government in Italy) considers the factors which contribute to stability and effectiveness of democratic institutions and identifies civic engagement as the crucial feature (Putnam 1993). The common feature of these studies is the identified need for citizens to participate in democratic deliberation.

In recent years there has been a plethora of popular books, articles and media discussion emanating from the US regarding the crisis state of democracy (see, for example, Phillips 1993). Widespread disquiet has been expressed by political commentators at the increasing cynicism and disillusionment of voters, apathy towards the democratic process and decreasing participation rates. US current affairs television commentator Bill Moyers summed up the situation in polemical terms: 
We're listening to America tonight on Capitol Hill in Washington DC. There's a bunker mentality here these days. The city is under a political state of siege. You don't need to follow the polls or even read the papers to know that the gap between citizens and politicians could hardly be wider. Confidence in Congress is at an all-time low. The presidency and the executive branch are widely scorned as well. Politicians I've known a long time say they have never had to endure such a vitriolic, ugly and dehumanising atmosphere as the one which prevails now in Washington (Moyers 1992, 2).

The context of this circumstance was that there had been increasing public dissatisfaction with the conduct of Congress, culminating in the House Bank Scandal, first reported in September 1991 and finally admitted by Congress in April 1992. The names of 303 Members and Senators who had written fraudulent cheques against their accounts in the House of Representatives' Bank were disclosed. But the implications were interpreted to be wider by one group:

The issue was never just a question of a little perk for a few Members, but now it had become a dramatic symbol of the degree of Congressional arrogance and corruption. The public isn't stupid. The American public knew what was going on. Members were writing checks to get interest-free loans that saved them thousands of dollars (Americans to Limit Congressional Terms 1992, 79).

In this atmosphere public anger was exceptional when Moyers went to air in May. The House Bank scandal, which became a catalyst for calls for drastic reform of the political system, has been one factor which has given impetus to various efforts to restore democracy, described below. During the Moyers' television show one guest described an incident which demonstrated public dissatisfaction with the trivialisation of politics by the media. When television interviewer Phil Donahue repeatedly questioned President Clinton about Gennifer Flower's allegations of sexual associations: 
... a woman in the audience stood up and said to Donahue 'There's education to deal with, environment to deal with. Why are you giving us this instead?' 'I don't even support Bill Clinton' said another member of the audience 'but I' $m$ fed up with this. I'd like to know what the guy stands for.' The same day, Bill Clinton delivered a major, important foreign policy address. Most of what got through the media filter wasn't that important policy address, it was Gennifer Flowers (Jamieson in Moyers 1992, 3).

This guest on the Moyers show was Kathleen Jamieson, Dean of The Annenburg School for Communication, and a strong critic of the current state of democracy in the US. Her views are further quoted later. The paradox of American democracy is the contrast between rhetoric and reality. An early advocate of teledemocracy pointed out:

Millions of immigrants vote annually with their feet to come to a land where nearly half of us don't bother to vote at all. A paragon of democracy abroad, Americans often seem to be ruled by apathy and privatism at home. People die around the world in a struggle to acquire freedoms we sometimes don't seem to notice we have. They struggle to establish political parties while we abandon ours in the search for candidates untainted by party or politics (Barber 1992, 3).

Public opinion polls indicate dissatisfaction resulting in apathy towards and alienation from the way the political system currently operates. A majority of 80 percent of people surveyed early in 1993 for a Washington Post/ABC News Poll responded that 'the country needs to make major changes in the way government works' (Georges 1993, 38).

In a book entitled Why Americans Hate Politics the author postulated that both liberals and conservatives have misread the US electorate, offering approaches and policies inappropriate to people's real concerns. Americans believe that both parties have failed to represent their interests and have lost touch. It is 
contended that voters prefer compromise to continual confrontation. 'There are more ideas that unite us than divide us, but politics doesn't reflect that' (Dionne 1991, 11). Further, the presentation of issues in terms of dichotomies prevents the nation from resolving problems and makes consensus difficult. The fundamental problem was that:

When government was seen to fail on the basics educating children, delivering health care, building roads and mass transport, fighting crime - the broad American middle gave up on government. This message was misread by conservatives as a demand for less government, when in fact it was a demand for better government (Dionne 1991, 346).

Dionne blamed the pernicious influence of professionals skilled in fund-raising, polling, media relations and advertising who have excluded ordinary citizens with the result that public discussion and participation have been minimalised. I will contend that the same trend is evident in Australian politics, with examples of decreased party membership and participation (see chapter seven). The author warned of the implications of the situation, believing that: 'A nation that hates politics will not long survive as a democracy' (Dionne 1991, 355). It is again demonstrated that the cost of campaigning using marketing techniques involving new technologies has resulted in fundraising assuming such importance. The author gave no consideration to the role technology may play in helping to overcome this antipathy and increase participation. There is no mention in the index of teledemocracy, electronic town meetings or even technology.

Many current books of this genre argue that the mass media is mainly responsible for the deterioration in the credibility of political communication (see Patterson 1993, 202-203). With its powerful ability to attract attention, television news particularly defines the political agenda and attracts criticism. 
Another current observer of the American political scene, whose comments on media trivia were quoted earlier, argued for accurate, engaged campaign discourse by candidates willing to take responsibility for their statements (Jamieson 1992, 11). She blamed the influence of mass media for turning politics into a spectator sport rather than a participatory activity. While reporters refuse to accept the assurances of candidates at face value public cynicism is reinforced:

Refusing to take candidates' words and actions as anything other than crass ploys to influence voters invites public cynicism...To appeal to an increasingly alienated electorate, candidates and their political consultants have adopted a cynical stance which, they believe with good reason, plays to popular cynicism about politics and wins them votes (Jamieson 1992, 186).

Jamieson welcomed the emergence of the 'talk show' which provides callers with direct access to candidates and invites participation. However the format was not considered likely to elicit a high quality of political discussion, as callers are often not skilled in managing the media and the professionalism of moderators varies greatly (Jamieson 1992, 266). Again, quite surprisingly for a book published relatively recently, there is no index reference to technology, electronic town meetings, citizens' action groups, participatory democracy or teledemocracy. Another view which blamed television entirely for decreased citizen participation in politics asserted that it isolates people from communicating with each other and that this tendency will be exacerbated by cable television. It is alleged that television monopolises leisure time and biases the news, undermines critical analysis of issues and increases cynicism. Finally television advertising distorted political campaigns:

Because these ads are in the form of emotive images, they cannot be responded to rationally, but must be responded to in kind, resulting in an escalating arms race of ads that pollute the airwaves and drive people from the political process (Gans 1993, 28). 
While television advertising does not encourage rational analysis, the world news coverage has become substantially wider with the new television technologies, effectively 'Bringing the news back home' [Special Broadcasting Service (SBS Australia) promotional theme]. While the scenes may be much more of despair rather than hope, it is now possible for the whole television-watching international community to be aware of world events, as they happen. The impact of this phenomenon is no doubt various, and yet to be fully evaluated.

Taking up the question of people's involvement in politics, another commentator concluded that it is the nature not the substance of involvement which has changed. 'Participation in traditional partisan political activities has declined in the past two decades. Yet overall participation in politics has increased' (Godwin 1988,43). He cited the examples of citizens engaged in such activities as organising to prevent unwanted nuclear reactors being built, demanding a say in local planning decisions, lobbying Senators and Congress representatives and contributing to, and becoming members of, public interest groups.

This observation that people are involved in issues they regard as important is reinforced in the following survey findings. Yet the suspicion remains that only a very small percentage of people want to attend political meetings (see Arterton below).

The question of the changing nature of participation can be interpreted in two ways. Decline in peoples' participation in party politics can lead to a weakening in majoritarian politics and arguably affect stable democratic structures. On the other hand, multiple interest groups acting and agitating politically could be positive in a vibrant democracy. I am ambivalent and suspect the ideal lies in between, not in the extremes. Political parties exerting a stranglehold on political processes is not conducive to thoughtful participation, but atomistic, disparate political discourse could lead to fragmentation and no sense of a commonweal. 


\section{Surveys of citizens' political attitudes}

The general feelings of public unease with the operation of representative democracy were highlighted in a study conducted by The Harwood Group (a Washington-based private research company) for the Kettering Foundation in 1991 which found:

... a widespread public reaction against the political system. This reaction is more than the familiar attacks on individual politicians, incumbents, big government, party politics and corruption. It is a reaction against a political system which is perceived as so autonomous that the public is no longer able to control and direct it. People talk as though our political system had been taken over by alien beings (The Harwood Group 1991, iv).

Americans interviewed did not believe the average citizen has any influence on political activity and thought that the system is run by a professional political class and controlled by money. Further, they had no expectations that the system was capable of solving pressing problems of society. Rejecting 'political' activities, people became involved in voluntary community activities. 'Many people did not want to be associated in any way with "politics". Politics is like leprosy; people do not want to be around it' (The Harwood Group 1991, iv).

The study reported people believe that two factors have corrupted democracy: the replacement of representatives by lobbyists as the primary political actors and the influence of campaign contributors on political outcomes.

The first factor is associated with the professionalisation of politics using the new CTs and the second factor is the result of the expense of electronic campaigning. The study concluded that public dialogue is pivotal to enable participation in deliberations on matters of community concern. The most significant finding of the study postulated an erosion of the political system's basic legitimacy (The Harwood Group 1991, vi). 
However, a substantial caveat should be placed on relying solely on the findings of The Harwood Group. Their qualitative methodology used small focus groups and, by their own admission, should not be mistaken for findings from a random sample survey. A total of 10 focus groups of 12 people each were conducted in different centres across the US in 1990 and 1991. Each group meeting lasted about two hours and was led by a trained moderator and recorded. That is, 120 people were involved in group discussions in a population of about 250 million - highlighting the danger of small, non-random samples setting the political agenda.

The use of focus groups has also been criticised as superficial. Christopher F. Arterton was of the view that such studies are not particularly helpful because they do not force the participants to consider the trade-offs which may be necessary. 'It is very easy to dismiss politics and politicians as being nothing but a corruption of the public dialogue or the commonwealth without understanding or facing the difficult problems facing those in public policy' (Arterton 1995, interview).

In fact, there is a substantial literature, involving random surveys and studies, pointing to increasing public scepticism towards political parties, which supports the Harwood findings. Allied with the books mentioned above, the general conclusion is that such attitudes pose a severe threat to the parties (Patterson 1993, 226) and even to traditional democratic process.

The contradiction between political activism in interest groups and the public's negative attitude to parties is influenced by the critical portrayal of parties in the media and the modern style of campaigning which emphasises the individual candidate's relationship with the voter through direct mailings (Patterson 1993, 227).

It would be cynical to conclude that The Harwood Group had a vested interest in the findings of the study. However they were the consultants chosen on the basis of the study just cited (Citizens and Politics: A View from Main Street America) to 
organise The Portland Agenda - Principles and Practices for Reconnecting Citizens and the Political Process. The resulting report of the subsequently-formed National Commission for the Renewal of American Democracy, was entitled Project Democracy (reported later).

The report provided material for a book by the president of the Kettering Foundation, David Mathews. Elaborating on the findings, Mathews pointed to the use of referenda (in those states which have a referendum system) as evidence that representative government has failed. He reported the 'enormous' response to the $A$ View From Main Street study with nearly 1,000 articles, editorials, letters to the editor and television shows in the US and other countries commenting on the study. The currency of the debate is apparent in the first printing of 20,000 copies of the report being sold out and a second printing ordered. Over 1,000 inquiries about the report came from a wide range of groups and individuals (Mathews 1994, 13). Posing the question - Can people measure up to the demands of democratic citizenship? - Mathews asserts that on balance:

People can overcome the barriers to active citizenship... Many citizens are willing to deliberate with their fellow citizens and, if that deliberation has proceeded long enough, people can really know what they are talking about. Deliberation can give purpose to citizen action and broad direction to government policy (Mathews 1994, 188).

A manifestation of the dissatisfaction of many Americans in the political system is seen in calls to limit the terms of elected representatives. The argument is that the communication revolution has led to a new breed of representative, the professional. The electronic media has dramatically changed the political environment:

Elections are won today by 30-second negative television ads and blizzards of computerised political junk mail. The voter is manipulated with 'scientifically tested' messages produced by an army of specialists and PR consultants. No 
wonder he feels alienated by the whole political process. No wonder a revolution is at hand (Americans to Limit Congressional Terms, 1992, 11-12).

Pointing out that, in the 1990 US Congressional election, 97 percent of incumbents were re-elected (actually, 96.3 percent Ornstein and Elder 1994, 58), the Americans to Limit Congressional Terms (ALCT) concluded that the high re-election rate results in representatives losing touch with their constituents and becoming arrogant and corrupt. Citing the use of direct mail at taxpayers' expense as an example of the abuse of privileges of incumbency, they stated that the average Member of Congress sends out 12,000 pieces of mail for every one he receives, costing in total \$200 million on 'junk mail' a year (ALCT 1992, 26).

There is a paradox in the ALCT stance. While the movement was highly critical of the Congress itself, the opinion from surveys of individual Congress representatives' performance is generally favourable (Hart 1996, interview). This is possibly a consequence of the local representative's capacity to deliver subsidies and other advantages to the local constituency.

In summary the term limits movement was important because it represented an example of some citizens trying to re-exert control over elected officials. It reflected the perception that the political elite class no longer sees itself as part of the citizenry and that the system should be changed to make the elite more accountable.

The term limits movement's current status, however, is '...basically dead' (Hart interview, 1996). When a Supreme Court challenge in May, 1995 as to the right of states to limit terms was upheld on a five-to-four decision, and the judgement made that such action was unconstitutional (Biskupic 1995, A1, A6), the issue lost momentum. Subsequently, the Republican impetus was removed when they gained control of both the Senate and Congress, as the Republicans had begun to despair of ever gaining power. Having gained it, their emphasis changed. 


\section{The new electronic campaign and the professionals}

The new CTs have transformed the way in which American political campaigns are conducted. Even eight years ago, it was pointed out that:

By 1988, it was standard procedure in most campaigns to share data files between laptop and portable computers in the field and headquarters hard-disks. Campaigns transmitted speech texts and memos to candidates on the road, advance staff raced ahead with data disks to load remarks electronically into teleprompters, and press secretaries utilised portable printers to distribute speeches to the press well in advance of deadlines. Personal computers also sorted and organised lists of supporters, press contacts, fundraisers and friends - while researchers arranged data on the opposition for instant retrieval... (McCurry 1989, 26).

The uptake of CTs in political communication has increased substantially since. Communications satellites broadcast debates and press conferences across the country and candidates rent space to target advertisements, speeches or interactive conferences to audiences of chosen size and location. The use of cable television and videotapes has allowed campaigners to bypass the traditional media to some extent, and where the traditional media is involved, the timing of their access is controlled carefully.

An example was apparent in early campaigning for the 1996 Presidential election. Lamar Alexander used his Powerbook from home to $\log$ on to an American Online Forum and converse with electors, the first Presidential candidate ever to do so (Fineman $1995,20)$. He belongs to a new type of political campaigner who uses cyberspace. Interest groups such as the gun lobby, environmentalists and both sides of the abortion debate are regular users. Despite the fact that only 13 percent of Americans say they have ever gone on-line and four percent have explored the World Wide Web, these numbers are still powerful, equalling viewership of many cable television networks. Like other 
surveys, a Newsweek poll found that users of computer technology are younger, more educated and more affluent than the general population (Fineman 1995, 22). Paradoxically, cyberspace will force candidates to interact with citizens for oldfashioned reasons - concerned with answering immediate constituency needs. The increased expectations of voters will demand that these increased needs are met (see survey into electorate offices in Australia, chapter five).

Technological innovation produces experts who provide access to the new tools, usually for a substantial fee. Without the intermediary of strong political parties (as is the case in Australia), candidates in the US tend to make arrangements directly with consultants. Running for office has become an entrepreneurial exercise and the voluntary campaign manager with party commitment has been largely replaced by the paid professional consultant (Ganz 1994, 103). Further, these consultants have enormous control over setting issues and determining tactics, the only essential factor being to win votes by creating, exploiting or reflecting public opinion polls:

Consultants have thus come to play multiple roles: campaign manager, press agent, party and even candidate. But for most political consultants, the motivation to get out the vote is private, not public, gain. It is a business in which market principles apply and there is one criteria of success - winning. From the consultant's perspective, winning does not depend upon who is right, who is the better candidate, or what is in the best interest of the community (Ganz 1994, 104).

The above view is reinforced by Margolis (see later). The situation arises as a direct result of applying marketplace economic theory to American politics - an influence also evident in Australian campaigns. The marketing of politics has resulted in a huge growth in various firms hired by candidates. Public opinion polling, focus group discussions, advertising, direct mail, public relations and fund raising are functions undertaken by often a collection of loosely-associated firms. 
An example in Washington DC is the company of Greer, Margolis, Mitchell, Burns and Associates (GMMB\&A) which runs one of the five major political consulting firms used by the Democrats. (Republicans employ about the same number). Described as 'a Clinton agency', the firm covers about 17 statewide elections a year, mostly for Governors and Senators, organising television, radio and print advertising strategies, often in collaboration with a selected research polling firm.

There are various specialist departments within the firm itself, with tasks of buying advertising time, designing graphics and media relations. A specific population can be identified and targeted - for example, 25-year-old women who watch certain television programs. Likewise, the message can be devised for (say) labour, blacks, gays, or Asians, with direct mail appeals appropriate to their concerns which are identified by public opinion surveys (Margolis 1994, interview).

GMMB\&A uses focus groups to test the presentation of advertisements. As Australian strategists have found, although a negative message may not be approved of by the participants, it is remembered and deemed to be generally effective advertising. The words are monitored for audience reaction by the 'worm', an electronic monitor which records audience reactions to various expressions, which are then used in often emotive direct mail or television advertisements. Margolis expressed some concern that many policies are becoming driven by the findings of public opinion research and that leaders are increasingly reluctant to take decisions based on principle - in essence, failing to lead. In fact, as Graeme Morris pointed out (chapter five, P. 164), the 'worm' is only one technique used to gauge public reaction.

\section{Direct marketing of politics}

As much of the criticism of the current operations of the political system is directed to the campaigning methods which employ the new CTs and the money needed to run campaigns, it is pertinent to look to analysis which has been conducted of these 
determinants. Direct marketing is the most apparent aspect of the new CTs in politics, as mentioned in chapter one. Direct mail, allied with television direct marketing and direct marketing by telephone, is employed in the US in four main ways. It is used to advertise issues, programs and candidates; to mobilise public pressure on decision-makers; to raise money; and to recruit new members to citizens' action groups. Direct mail is part of campaigns using sophisticated marketing techniques and is now an important part of most major campaigns. The critics have identified such techniques as sinister. However, it has been suggested that the marketing of politics merely feeds back to people what they want to hear and therefore is not inherently manipulative:

...if marketing as a concept is rooted in the search for what people actually want, in a sense people manipulate themselves; the ethical problem here is that, however superficially manipulative political marketing appears, it is really their own desires that people have bizarrely reflected back at them - a self-parody (O'Shaughnessy 1990, 156).

An American political scientist undertook an extensive investigation of the impact of direct marketing on the American political process. His hypotheses were:

- direct marketing encourages political equity by recruiting people who have different demographic and socio-economic characteristics from people who become active through traditional social network channels;

- direct marketing encourages alienated, distrustful and aggressive political attitudes and behaviours; and

- people recruited through direct marketing techniques know less, care less and do less for their citizens' action groups than persons who joined in response to social network invitations (Godwin, 1988, 50). 
Kenneth R. Godwin used three major sets of data to examine how pressure groups, political action committees (PACs) and political parties use direct marketing to achieve their political objectives. He took a sample of 150 political direct mailings, conducted a survey of over 3,000 members of citizen action groups by mailed questionnaire and interviewed leaders of political parties.

He found that the fears of direct marketing's opponents were not realised. Direct marketing does not fragment political parties or replace democratic participation. It does not significantly increase extremism. Nor have the hopes been realised. Direct marketing has not led to greater participation by the underprivileged and in fact seems to have increased the difference in political involvement between rich and poor.

Godwin compared the attitudes of people who became involved with citizens' action committees through direct marketing with those who became involved through social contacts. He found that direct marketing has affected mass political behaviour. The direct marketing respondents were less committed to the organisation than those recruited to the citizens' action committees through social ties and were less knowledgeable, less tolerant, more alienated and more aggressive. However the difference was not large and tended to lessen over time.

Direct mailing's effect on political tactics is to promote extremist language, 'insinnuendo' and half truths. The tone in letters in the US is often emotive, even hysterical, and there is little accountability for the truth of the allegations.

These campaigning techniques have changed the strength and influence of the parties because the Republicans in general raise more money than the Democrats. As a result, Godwin argued, Democrats have been forced to seek funds from special interest groups and support their demands to the detriment of their traditional support for the underprivileged.

In fact, this may have more to do with the shifting nature of American politics towards the centre and the fact that Republicans 
are now the incumbents, than PAC donations. Godwin concluded that direct marketing fosters economic inefficiencies. Special interest groups do not become more profitable through productivity but continue to rely on favourable government policies and subsidies. Their members are alerted through direct mail to make representations to Congress.

Despite the characteristics identified above, Godwin also identified some advantages. Direct marketing raises moral issues for public debate, improves general knowledge and increases participation in political deliberation. He recommended measures to increase the positive and decrease the negative effects by severely penalising false statements and obliging all political action committees to produce financial statements for the source of their contributions. Further to reduce the influence of organised groups, all PACs should pay their own costs rather than have them paid by the parent organisation. Such measures would appear to overcome undue influence of monied interests, or at least open them to public scrutiny.

\section{Responses to the challenge}

A common characteristic underlying the philosophy of many supporters of the use of CTs in the democratic process is a belief that they can empower people, and that this is advantageous. Some of the assertions and expectations appear utopian, ignoring the inevitable influence of people with vested interests in an outcome.

Further, the potential of the new CTs to facilitate democratic participation is hindered by lack of access and capability and interest in using them. Resources exist for those who want to be politically connected, and have the time and money, including local computer bulletin boards, electronic discussion groups, mailing lists, live on-line forums and talk lines and electronic publishing centres. For the relatively few who can take advantage of them: 
Each of the major commercial on-line information services maintains an extensive political data base and forums where one can study and debate the issues of the day. Because they confer the ability to send and receive electronic mail, these electronic services hold the promise of putting constituents in more immediate touch with government (Lewis 1995, 28).

The projects or mechanisms which use CTs in the political process are described below, under categories according to their aims. First, however, the general conclusions from researchers of the use of CTs in the democratic process are identified.

\section{Direct democracy should support representative democracy, not replace it}

\section{Electronic Town Meetings (ETMs)}

Amitai Etzioni described experiments he conducted more than 20 years ago with electronic town meetings for the US National Science Foundation. In theory, ETMs provide an opportunity for citizens to debate and discuss, interacting with each other and with their representatives and officials, thus overcoming the problems of geographical distance and increasing participation by using CTs. However, rather than advocating a radical departure from the present arrangements, the team led by Etzioni started from the principle that '...it would be undemocratic to replace elected representatives and legislatures with computerised voting or any kind of electronic wizardry' (Etzioni 1992, 35). The reason for this is described as the Edmund Burke argument - that large groups need layers of representation rather than direct representation to work out consensus-based public policies. Representatives must be allowed to engage in deliberation to find shared decisions on policy, which involves time and due consideration to reach consensus (which is a fairly idealistic interpretation of the way modern party politics operates). If it is conducted solely as push button plebiscite: 
...direct democracy produces few if any opportunities to work out compromises that most people can feel comfortable ratifying. For this reason, telepolling should be used to supplement the existing representative system (Etzioni 1992, 35).

Etzioni identified the main problem as special interest groups being the major source of the huge funds needed for election campaigns and the consequent influence these groups wield over policy. Therefore:

Until this unholy alliance is severed, teledemocracy's primary contribution might well be to make it even clearer to the public that legislators often do not respond to the public will (Etzioni 1992, 39).

One way of using the new technologies to meet the requirements for discussion and proper representation could be by taking a statistically selected sample of voters who could hold discussions on the issues. If some consensus on an issue was reached, the voters could take part in nationally-televised question and answer sessions with party leaders.

As the choice of participants would vary randomly from issue to issue, there would be less danger of domination by vested interests or of the duties being too onerous or time consuming for the individual. Ideally, if the opportunity to participate was explained properly, citizens may possibly welcome the occasion.

Decision of the people through referenda

Referenda are used in the US, Switzerland, Australia, New Zealand, France, Scandinavia and to a lesser extent in Ireland and the UK. In the US context, the initiative allows voters to propose legislation through the collection of signatures; the referendum puts a proposal to the vote; and the recall empowers voters to remove public officials (Cronin 1989, 2). In an examination of the actual outcomes of initiative, referenda and recall in the US, Thomas E. Cronin concluded there are both advantages and 
disadvantages. Direct democracy has possibly been influential in increasing government responsiveness and accountability. Few of the states with the three provisions are known for corruption but it is hard to argue that initiative, referendum and recall are the sole reasons for this. He found that the processes do appear to provide an effective safety valve when legislators are too compliant to special interest groups. The very circulation of petitions may force reconsideration of an issue. Direct democracy appears to be one of many influences in shifting power from party bases towards organised interests groups. But it has not brought about rule by the common people, as has been predicted:

Government by the people has been a dream of many, but most Americans want their legislators and other elected officials to represent them as best they can and to make the vast bulk of the public policy decisions. Direct democracy devices occasionally permit those who are motivated and interested in public policy issues to have a direct personal input by recording their vote, but this is a long way from claiming that direct democracy gives a significant voice to ordinary citizens on a regular basis. That early claim was considerably overstated (Cronin 1989, 225).

Cronin found that initiative, referendum and recall have not undermined representative democracy. Even where they are used, 98 percent of the laws remain the responsibility of the legislators. Nor is there evidence that direct democracy results in unsound policies. Unwise proposals are put forward but usually rejected. Where defective legislation has been passed, it has often been successfully contested in the courts and either modified or rejected. In addition, the fear for minority rights has not been realised. When compared to the legislatures, the outcomes of initiative and referenda campaigns are equally tolerant or intolerant of minority rights. The charge from opponents that the typical voter would be uninformed on the complexities of issues is conceded by advocates of the provisions:

Survey data confirm that as many as one third to the majority of those voting acknowledge that they feel 
uncomfortable about voting because they needed more information or more time to discuss the issue or to read the voter pamphlet more carefully, or found that the statement was too hard to comprehend. However, most of the perceived flaws of direct democracy are also flaws of democracy in general (Cronin 1989, 230).

Cronin's report on the contradictory attitudes towards the benefits and defects of the initiative (Cronin 1989, 233) demonstrates the crucial importance of the question wording and the extent to which people can hold opposing views simultaneously. A danger of plebiscite democracy is that the answer depends on the question. 'Even subtle differences in question-wording can have profound consequences for the answers people give' (Schudson 1992, 44).

In conclusion, Cronin offers suggestions to safeguard initiative and referenda. These included a requirement for, amongst other things, 'reasonable' signature requirements, stiff penalties for deceptive petitioning, voter information pamphlets and mandatory financial disclosure of contributions to campaigns (Cronin 1989, 234 - 240). While 'voter information pamphlets' are listed as one of many conditions, it could be argued that the new CTs could play a role in providing information for citizens to deliberate on issues prior to voting, through public libraries.

Finally a guarded conclusion from Cronin as to whether the people can be trusted to make political decisions - repeating the old Jefferson/Madison debate. He favoured properly safeguarded initiatives and referenda in states and communities, but opposed the adoption of a national initiative and referenda (Cronin 1989, 215) as apparently foreign policy issues may be too sensitive and complex (or too internecine) for popular consideration.

While this may be a compromise position, I agree that some safeguards are necessary in international relations. However, the evidence seems to be that teledemocracy has been widely accepted in the US states in which it operates. 
Neither extreme pro- nor anti-claims of CTs' impact are valid

Teledemocracy

One of the earliest and most impassioned advocates for using technology to strengthen democracy was Benjamin Barber, who believed electronic communications can be used to enhance democratic participation (Barber 1984, 274). Answering the charge that the successful and industrious would not participate because they are too busy and the poor and victimised not participate because they are too apathetic, Barber asserted:

...people refuse to participate only where politics does not count...They are apathetic because they are powerless, not powerless because they are apathetic. There is no evidence to suggest that, once empowered, a people will refuse to participate (Barber 1984, 272).

This belief is not supported by many political scientists (see Arterton below and the direct democracy debate in Cronin). In the face of Congress being content to let market forces shape the future course of telecommunications, Barber contended that a strong program for regional and national electronic town meetings requires that a Civic Communications Cooperative should be established. This organisation would pioneer innovative forms of civic broadcasting, develop guidelines for regional and national town meetings, ensure public access and organise electronic voting. A Civic Videotex Service should be introduced to meet the public need for equal access to civic information and provide a nationwide interactive and free service of regular news and discussion of issues (Barber 1984, 279). Barber conceded that the dangers of elite manipulation in mass society are real but :

...it is foolish to think that a nation can be rescued from the manipulation of elites by reducing the potentially manipulable public's input to the democratic process. One might as well combat crime in the subways by keeping the public at home (Barber 1984, 282). 
Another early advocate of teledemocracy, Ted Becker, anticipated in 1981 that electronic town meetings would help educate citizens on issues, encourage discussion, register opinions and facilitate voting directly on public policy. 'My prediction was that advances in inter-active electronic communication technologies would empower the American citizenry and lead to much stronger democracy at the national, regional, state and local levels' (Becker 1993, 14). Writing in 1993, his belief had been reinforced by the examples of electronic communication strengthening the political system at all levels (Becker 1993, 14). 'Teledemocracy and ETMs continue advances and improvements in technologies, techniques and applications at all levels of government. Despite occasional lapses, mistakes and problems, the level of citizen satisfaction with each experiment has been high, the amount of citizen participation has far exceeded that in conventional processes, and the quality of citizen input has been impressive' (Becker, 1993, 19). Less committed observers have had some reservations.

An examination of the competing claims between the proponents and opponents regarding the role of technology in democracies has been conducted by Christopher F. Arterton. In a well-balanced appraisal, Arterton evaluated the actual operations of 13 'teledemocracy' projects. As he stated succinctly:

Citizen participation facilitated by technology is the central thread of the teledemocracy argument (Arterton 1983, 15).

The advocates of teledemocracy (see Becker, above) assert that the emerging CTs will transform politics, giving people the opportunity to have a direct say through electronic interaction. They see the technologies strengthening democracy and providing the solutions to decreased participation rates and cynical and alienated attitudes to politics. Beyond voting, the new technologies can be used by citizens to communicate with elected officials and each other. 'Communication, dialogue and information exchange are, after all, the cornerstone of the informed body politic' (Arterton 1983, 22). 
The critics of teledemocracy argue it would be unworkable. Plebiscites can be manipulated and control by extreme special interest groups would be a danger, as would citizens' lack of interest in and knowledge of issues. Conversely plebiscites have the potential to be divisive if citizens become very intense about an issue, to the extent that, as I. de S. Pool pointed out:

...If citizens are brought, by effective personal participation, to a point of caring very deeply about political outcomes, then there had better not be too many important political decisions, for every time one is made there will be losers as well as winners (Arterton 1983, 22).

Arterton pointed to the fact that neither side in the debate has much systematic evidence to support the conflicting contentions. Research has focused on individuals, with the societal context in which participation occurs being given little attention. Therefore:

I set out to investigate systematically a number of teledemocracy projects, in which communications media have actually been used to encourage citizen involvement. I wanted to find out how the media had been used and what the consequences have been (Arterton 1983, 25).

Looking specifically at the political participation projects Arterton found that, since the interactive media were not yet widely available, the program organisers adapted various existing channels of communication - televised call-in formats, mail back ballots, interactive cable television, teleconferencing and videoconferencing, computer conferencing and electronic mail and videotex.

The projects were divided along different conceptual lines. The first distinction was that some aimed to enable citizens to lobby elected officials to influence public policy while others emphasised public education. The second difference in assumptions was between those programs which encouraged dialogues and those which staged plebiscites. Having monitored 13 projects, Arterton concluded that: 
...the largest differences in the nature, the role and the effectiveness of political participation were rooted not in the technical capacity but in the models of participation that project initiators carried in their heads (Arterton 1983, 26).

In other words the political application of technologies depends upon the social, cultural and economic environment in which they are used. Arterton concluded that philosophical approaches were more influential than the actual technologies. Answering the question he posed in the title of the book Can Technology Protect Democracy?, Arterton wrote:

Can telecommunication technologies be used to improve the quality and quantity of citizen participation in politics? Yes. Can these uses also mitigate the inequalities now found in the rates of participation of different social groups? Yes. Do these projects collectively point towards one technology that best facilitates participation? No. Does this research suggest that technological change will produce an inevitable transition towards direct democracy? No. Can teledemocracy contribute to the functioning of America's political institutions? It depends what you mean by 'teledemocracy' (Arterton 1983, 184-5).

The differences in philosophy of the projects cited earlier reflect alternative attitudes towards participation which are deeply rooted in American history and are apparent in the Republican or Democrat premises - though not only in a party political sense.

The Republican approach asserts the value of representation with leaders making judgements on behalf of citizens. The Democrats have challenged this view, promoting more popular involvement:

The modern version of the Jefferson versus Madison argument surrounding the discussion of teledemocracy pits the popularist vision of politics against the pluralist theories of political interest (Arterton 1983, 196). 
Arterton found little support for the argument that technology could make representative democracy obsolete by involving all voters in political decision-making. Citizens do not have the time, inclination or interest to sustain near universal participation. 'Most citizens, probably around two-thirds, will not participate' (Arterton 1983, 197). He cited as evidence that in statewide referenda, where real issues are at stake, the number voting is frequently smaller than for candidate elections.

Arterton concluded that the second problem of controlling elites was a severe one for plebiscite democracy advocates. Agenda setting in the projects he evaluated was entirely controlled by the organisers, who showed little appreciation that political disputes often involve passionate defence of self-interest with no regard for the 'common good'. However it appeared that public officials initially sceptical about the projects came to see the value in input from citizens, even if only to defuse contentious issues and signal danger areas. So 'Technology can make teledemocracy, in the sense of pluralist dialogues, possible' (Arterton 1983, 200).

Where the communications media were used to facilitate communication between citizens and elected officials, the results were positive. More people who were better informed participated and public officials were influenced. In summary, agreeing with the general findings reached by Cronin, Arterton concluded that the projects showed:

...greater support for a conception of teledemocracy in which technology is used to underwrite representative processes and a pluralist conception of political interest (Arterton 1983, 204).

It is in the discursive and deliberative phase that CTs can be of most value to democracy. I would conclude with Arterton that CTs are best used to support participation rather than to conduct instant plebiscites. To my knowledge, there have not been any more recent evaluations of teledemocracy projects conducted. 


\section{Objectives of various projects using technology}

The literature sources for the following projects are somewhat limited, as many are in their early stages and it may be some time before comprehensive, objective assessment is conducted. An exception is PEN, the subject of three different investigations (see below). The operatives tend to be enthusiastic in their efforts and fairly uncritical in their evaluation of the success of their projects.

I will discuss the various projects under the particular focus of their use:

- to improve community welfare through Civic Networks;

- to improve involvement and participation;

- $\quad$ to consult;

- $\quad$ to inform and educate:

- by interest groups in communication projects;

- by Representatives/candidates to by-pass traditional media; and

- by the Administration, in terms of National Information Infrastructure.

\section{Used to improve community welfare through Civic Networks}

There are an increasing number of 'civic networks' which have the objective of using 'network technology to serve public interests and increase public access to information' (Anderson, Bikson, Law and Mitchell 1995, 120). The Public Electronic Network (PEN) project, Santa Monica, is a computer-based, interactive communication system which is available free to residents and was one of the projects evaluated by Mark Bonchek (see chapter four). Launched in February 1989, PEN was the first free, local government-sponsored, interactive communication system in the US and is probably the best known, and will therefore be explained in some detail. It was designed to: 
- provide access to public information;

- assist in the delivery of city services;

- provide additional forms of communication to residents;

- provide electronic forums that would increase the sense of community;

- diffuse knowledge of, and access to, communication technologies;

- improve computer literacy; and

- provide more equitable distribution of communication technologies to the socially disadvantaged (Rogers, CollinsJarvis, Schimtz 1994, 402).

The pattern of widening gaps between the information rich and poor has been apparent in the past 10 years in the uptake of cable television, VCRs, home computers and videotext. In attempting to minimise this, PEN organisers (three academics from different universities) encouraged wide access by socially disadvantaged groups, such as the homeless and unemployed. The network can be accessed through home or office computers and modems or via 18 public terminals sited in libraries and recreational and neighbourhood support centres (Rogers, Collins-Jarvis, Schimtz 1994, 402). This range of access points encouraged differing views:

Because of this capacity for widespread participation, PEN served as a means for the exchange of diverse perspectives. These perspectives were exchanged in interactive computer conferences that addressed pressing political issues such as homelessness and gender equity. In certain cases, the dialogue exchanged within these computer conferences led to the formation of political action groups and support networks that included people who had been disenfranchised from the political sphere (Rogers, CollinsJarvis, Schmitz 1994, 402).

While PEN users still tended to be male, more highly educated and more politically active than the general population, the availability of public access terminals meant residents without computers were not necessarily excluded. Of the quarter of a million accesses to PEN between 1989 and 1992, 23 percent were 
public terminal log-ins. As of June 1992, one third lacked other access to a computer (Rogers, Collins-Jarvis, Schmitz 1994, 404). One outcome was an action group for homeless people who persuaded council to grant $\$ 150,000$ for showers and lockers in the SHWASHLOCK program to help overcome the jobless/homeless trap. Reflecting an underlying utopian philosophy:

...the PEN system in Santa Monica illuminates how an interactive communication like PEN helps us recapture the participatory democracy once found in the small rural community of the past (Rogers, Collins-Jarvis, Schmitz 1994, 409).

Thus the organisers, not surprisingly, have a rather altruistic view of the potential value of such projects. It is interesting to note the conditions under which PEN originated and the factors which are influential in its relative success (as outlined by Rogers et al, Bonchek and Anderson et al). It appears the generally liberal, democratic culture of the community coincided with a governing elite which favoured political involvement by citizens. Influential individuals at city council level appear also to have been a crucial factor (Rogers, Collins-Jarvis, Schmitz 1994, 404). Not coincidentally, financial support for equipment valued at $\$ 350,000$ was supplied by the private sector.

The PEN project was also one of five civic networks chosen for indepth study by a group from the Center for Information Revolution Analysis (RAND, see below). To briefly describe some other civic networks they investigated: the Seattle Community Network, Seattle, founded in 1994, was designed to provide a forum for the exchange of ideas to promote community building and give a venue for activities and events (Anderson, Bikson, Law and Mitchell 1995, 126). The Blacksburg Electronic Village (BEV), Blacksburg, aimed to create a 'virtual community' where all activities (politics, business and social interaction) could be conducted via an on-line network. Both LatinoNet, San Francisco, and The Playing to Win Network, Boston, promote interaction amongst organisations with similar objectives. 
These civic networks were chosen by the team from RAND to illustrate the way in which civic networks use communication technology to achieve their goals. The objectives were to understand how different civic networks used technology to accomplish their goals (the types of services they establish, and their relative success) and to find the strategies the networks used to ensure access by targeted clients (Anderson, Bikson, Law and Mitchell 1995, 125).

By use of statistical analysis, the researchers found that 'interconnectivity' (ie, electronic communication) was a more powerful predictor of democracy than any of the traditional correlates, such as GDP (Anderson, Bikson, Law and Mitchell 1995, 168). Four main categories of benefits were identified. Network access afforded more effective communication, were an important information resource, assisted organisational functioning, and enabled education and participation. 'We find that use of electronic mail is valuable for individuals, for communities, for the practice and spread of democracy, and for the general development of a viable information infrastructure. Consequently, the nation should support universal access to email through appropriate public and private policies' (Anderson, Bikson, Law and Mitchell 1995, 169).

This finding gives credence to the premise stated in chapter one that communication/information are essential elements of a properly functioning democracy.

\section{Used to improve involvement and participation}

\section{Project Democracy}

A comprehensive effort to increase involvement of citizens with the political process in the US started in early 1992 with a movement called Project Democracy. Prompted by the findings of the survey of voter attitudes in Citizens and Politics: A View From Main Street America (discussed earlier), the National Association of Secretaries of State created the National 
Commission for the Renewal of American Democracy - also known as Project Democracy. During 1992 members of the commission travelled the country talking to hundreds of citizens about their ideas for reconnecting citizens to the political process.

They found that citizens were looking for meaningful ways to participate in the whole political process, seeking a sense of community, and needed a political process which can reflect the complexity and diversity of society and restore confidence of spirit (The National Commission for the Renewal of American Democracy 1993, 2). The mission of Project Democracy was to draw upon the experience, knowledge and ideas of people already working on projects to engage people in the political process.

Stage I of Project Democracy outlined three strategic areas for action:

- reconnecting people with government by building a culture of participation;

- educating for effective citizenship; and

- using technology to connect people.

In addition they advocated that urgent action should be taken by authorities to remove structural barriers in the electoral processes and to address the problem of the influence of money in politics (The National Commission for the Renewal of American Democracy 1993, 5). A set of principles and practices was outlined for each strategic area to form the cornerstone for development of Stage II of Project Democracy.

Work in Stage II planned to use the knowledge gained through surveys of local initiatives to develop a community resources workbook, to be used as a guide for organisations to develop projects to strengthen participation in government decisionmaking. 
While the objectives of reconnecting people with government and with each other through participation and education for citizenship are essential components in an overall approach, the use of technology is more relevant to this thesis and will be explored in more detail. The commission group found that:

In our travels across America, we heard about how different technologies are being used to bring people together in public dialogue, to provide education and training to citizens in distant areas, and to offer potential voters more choice for when and where they can register to cast their ballots (The National Commission for the Renewal of American Democracy 1993, 22).

However, the possibility that people can become disconnected by technology was identified as a real danger. The need to draw people out into the political arena, not to isolate them further in front of computers or television sets, was recognised. Six principles identified to design innovative initiatives in Stage $\Pi$ of Project Democracy under use of technology were:

- interaction must be the goal;

- technology must provide ongoing ways to participate;

- technology must be accessible;

- information must be relevant;

- citizens must hear and learn a wide variety of viewpoints; and

- privacy and integrity must be maintained (The National Commission for the Renewal of American Democracy 1993, 23).

In practice, the most appropriate technology rather than the latest should be identified and used. Access must be convenient, comprehensible and 'user friendly'. Finally, in competing for attention with sophisticated entertainment, information about 
participating in the political process must be equally professional. Examples of the use of CTs in the political process, found through the research phase, included:

- interactive television programs to provide people with the opportunity to talk with public officials and other citizens;

- electronic town meetings;

- increased choice in voter registration through a computer network; and

- multimedia programs linking young people to political discussions.

In summary, Project Democracy appeared to have the potential to link projects with the common broad aim of re-involving people in the political process. The belief was that the principal objectives of increasing participation and improving civic education could be assisted by appropriate use of technology as a tool to achieve a goal - and not as an end in itself.

Its current status has not fulfilled the expectations outlined above. Due to lack of financial support from foundations and corporations, the Project (as of October 1995) was effectively in abeyance. Reasons for this included the downturn in the economic situation and a consequent re-evaluation by funding sources of the value of their 'investments'. As a small aspect of Project Democracy, The Harwood group are currently preparing workbooks '...to help people work out what it takes to effectively engage people in the political process' (Creighton 1995, interview). Marketed to leaders of organisations, these educational materials aim to reach citizens in the memberships. The information will also go on a World Wide Web site.

There appears to be increasing citizen disenchantment, following raised expectations for involvement, with the election of President Clinton - '...but there has been no change. It's more of the same. People who took the chance and came out of their 
private homes to participate found it didn't pay off' (Creighton 1995, interview). The implications of this for political use of CTs may be that it is only one factor influencing the process of participation but that it can still be a tool, used to facilitate education and discussion, in a conducive environment.

The Harwood Group spokesman was of the view that efforts to increase participation have failed because political rhetoric has appealed to self-interest, rather than looking for common aspirations in the community. Reflecting E.J. Dionne's view, he commented 'We emphasise what divides people' (Creighton 1995, interview). Too often grandiose promises have been made and not fulfilled, which has had the effect of increasing frustration with politics, '...so the irony is the harder we try to get people involved, the further we push them away' (Creighton 1995, interview). John Creighton believed that people do get involved in their community, but they are drawing a circle beyond which they will not get involved. 'That circle is becoming closer...even though involved, it is in a very individual way as opposed to what we would call the public realm...so the community is further fragmented' (Creighton 1995, interview). He saw the solution in building civic capital - networks between people and organisations which have little to do with technology as such. 'The technological aspects will work themselves out. The principles of what it takes to engage people don't change just because the technology changes' (Creighton 1995, interview).

A recent initiative aims to improve Minnesota's democracy through use of information networks. Its primary goal is the creation of an information network to increase citizens' political participation. 'It seeks to increase citizen participation in elections and public discourse through on-line civic forums and collections of important information' (Clift 1996, email). The 1996 focus will be on providing information to voters on candidates and issues. 'Detailed non-partisan campaign information will be compiled and be presented to help citizens get involved in campaigns and the election process' (Clift 1996, email). Thus it is again apparent that the field of use of electronic networks to help participatory democracy is a rapidly developing one. 


\section{Used to Consult}

\section{Discussing The Conversation}

In a practical way, the Governor of Oregon, Barbara Roberts, used electronic technology to consult directly with the people of her state. The exercise, known as 'The Conversation', took place in the winter of 1991-2, and aimed to find out how Oregonians felt about 'some unpleasant choices like fewer services, higher taxes and other forms of political suicide' (Becker 1993, 18).

The two reasons for undertaking The Conversation were to build up voter trust and sense of involvement and to convey a better understanding of budget deficit issues:

I felt that if they had my information, they would reach $m y$ conclusions (Prowse 1992, 8).

Through 500 electronic meetings the Governor was able to consult directly with 10,000 people selected randomly from voter registration lists. Roberts addressed citizens by one-way video and they could interact by two-way audio. She claimed The Conversation reached a clear conclusion - people were willing to pay for essential services through increased taxes but only on condition that the state government first demonstrated greater efficiency (Prowse 1992, 8). Advocates of electronic conversations believe they can educate people on complex issues while providing direct feedback to politicians (Becker 1993, 18).

\section{Used to inform and educate}

The most important nation-wide development in providing political information to electors has come through C-SPAN (Cable-Satellite Public Affairs Network). Since the late 1970s, coverage of the House of Representatives and the Senate sessions has brought their activities to over 57 million American homes, making it the eighth largest cable programming network. 
'C-SPAN is an anomaly: in the competitive world of television, the cable industry chose to band together to create a public service' (Abramson, Arterton and Orren 1988, 142). It remains a not-forprofit co-operative and in non-session times brings viewers committee hearings, significant political events, ring-in segments and meetings of interest groups. The value of such a service depends on its audience numbers. In a survey 38 percent of people watched it at least once a month (Abramson, Arterton and Orren 1988, 143). Not surprisingly, viewers tended to participate in politics more than non-viewers.

Public access to cable television varies widely in the US, reliant on the interest and commitment of local authorities who can impose conditions on granting franchises to cable companies. Supporters of public access such as advocacy groups claim it has increased citizen involvement in local council deliberations and has made councillors both more visible and more accountable. In contrast to Santa Monica (home of the PEN project), whose council meetings are covered, the city of Washington DC did not impose public access conditions and now citizen groups are struggling for funds (Radio National Australia 1995, June).

\section{National Issues Forums}

Another approach to democracy stresses education and civic involvement, with or without CTs, as the response to the challenge of declining interest. As a method of involving citizens in deliberation on political issues, National Issue Forums (NIF) began in 1981 when groups of civic and educational organisations already holding forums on different topics decided to co-ordinate their discussions. Each year three topics of widespread national concern are selected by the organisations. The issues are considered and policy options debated to reach consensus outcomes. Like the Civics Expert Group in Australia:

The objective of the forums is to help people become a public, to develop the skills needed for public politics, to speak in a public voice, and to contribute towards defining the public interest (Mathews 1994, 108). 
Throughout the US, thousands of organisations have joined NIFs. Members of the NIF have access to the Internet to exchange mail, data and information services (Connections 1993, 8). Starting as a pilot project, the experience was used to connect other NIF affiliates as groups of citizens take the opportunities to use CTs for information exchange.

As a result of NIF there is increasing interest in developing public discussion materials. The Kettering Foundation has run issueframing workshops since 1990 aiming to train groups. The underlying philosophy is expressed by Mathews, repeating the sentiment of Woodrow Wilson:

...we have to hold counsel with one another...There are certain responsibilities we can't delegate to our government; making up our mind is one of them (Mathews 1993, 6-7).

Thus some commentators see the solution to a perceived crisis in democracy lying not in increased participation through the new CTs but through education in citizenship. Following on the plea for strong democracy in 1984 which saw a role for ETMs, Barber's latest book made little reference to the new technologies. He took as a premise that education and democracy are inextricably linked and that in a free society the link is severed only at our peril. 'Education must be both public and democratic if we wish to preserve our democracy's public spaces' (Barber 1992, 9).

Stressing the interrelated nature of liberty, education for citizenship and democracy, he stated: "There is only one road to democracy: education. And in a democracy, there is only one essential task for the educator: teaching liberty' (Barber 1992, 15). In this view he is in accord with the Australian Civics Expert Group (see chapter seven). 


\section{Used by interest groups in communication projects}

The positive potential of the new technologies for grassroots political movements has been demonstrated in the US (outlined in detail in Bonchek 1995, chapter four). Groups concerned with labour issues, ecology, feminism, peace, civil rights and homelessness have run projects using computers. An American academic, D.H. Downing, has described two computer communication projects, one devoted to peace issues and the other to making government information more broadly available:

They offer a way out of political atomisation but also present an instance of autonomous political action. They are in the business of constructing an alternative public realm, a space in which political movements can exchange and refine new perspectives and information in the light of practical projects (Downing 1989, 156).

PeaceNet 11 is available to users in all American states and over 70 countries. It incorporates mainly conferencing and electronic mail and user organisations have a range of interests. The Public Data Access (PDA) aims to make government information available to people who need it. Started in 1986, PDA concentrated initially on two issues - the environment (especially toxic waste dumping) and identifying the source of political donations to Members of Congress and political action committees. PDA made over a million pages of files on these topics, re-processing data from computer information prepared by public agencies (Downing 1989, 162). The potential for grassroots teledemocracy exists through computer communication projects. These enable gathering and analysis of data on sensitive issues which would not otherwise be known, and the inter-connection of citizens in a common cause to exert political pressure. As well, agendas for political action can be developed and, by linking people internationally, computer communication projects can allow people to address problems common to all humanity (Downing 1989, 162). The somewhat idealistic philosophy is again apparent. 


\section{Used by Representatives/candidates to by-pass traditional media}

It is relevant to consider the impact of increased participation in political discussion, which may help to explain the popularity of the appearances of Ross Perot, Bill Clinton and George Bush on television and in radio call-in sessions. This trend to personalise the main actors has shown that one effect of the new CTs can be to reduce the interpretive function of the media.

In the 1992 campaign, Clinton appeared on cable television nationally. The President has also adopted a policy of meeting with citizens directly to discuss such issues as the economy. Through television hook-ups he has answered questions from studio audiences across the country (Patterson 1993, 235).

Predictably the press complained that they were being by-passed but such forums have become part of a trend to integrate politics and the information age. With the traditional media commentators' role somewhat reduced, the potential for more direct and immediate contact between representative and represented appears set to change the nature of political interaction.

Furthermore the candidate Ross Perot, with no party but unlimited funds, sensed the possibilities of the new CTs. By avoiding the tough questions of professional political reporters he presented a folksy style on cable television interviews and purchased hours of advertising time.

He vowed that if elected he would introduce frequent electronic town meetings. With Perot and selected Congress leaders having described remedies to national problems, voters would register a vote by a push button on their television sets, by telephone or by postcard (Perry 1992, A-16). But as Perot's electronic town meetings would be neither representative of the majority, being self-selected, nor come to decisions by a deliberative process, the danger of extremist outcomes was significant (Perry 1992, A16). 
A national information infrastructure can provide a seamless web of interconnected, interoperable information networks, computers, data-bases, and consumer electronics that will eventually link homes, work-places, and public institutions together. It can embrace virtually all forms of information generation, transport and use. The potential benefits can be glimpsed in the experiences to date of the research and education communities, where access through the Internet to high-speed networks has begun to radically change the way researchers work, educators teach and students learn (National Research Council 1994, 1).

Finally, on the administration side, an initiative by the Democrats led by Vice-President Al Gore aims to create a network whereby Americans can communicate via the computer. An advisory committee to the White House comprises influential people from private and public sectors. An indication of the importance attached to this issue is the increase in the budget allocation from US $\$ 26 \mathrm{~m}$ to US $\$ 100 \mathrm{~m}$ to connect schools, libraries and other nonprofit organisations to existing computer networks. 'The crucial focus for the Internet is the use to which it is put' ( $\mathrm{O}^{\prime}$ Connors 1994, 159). The National Research Council saw the government role in realising the information future as:

- $\quad$ providing leadership and vision;

- balancing interests and airing competing perspectives; and

- influencing the shape of the information superstructure

(National Research Council 1994, 10).

The network enables reliable, rapid information exchange over great geographical distances (Law and Keltner 1995, 119). Acknowledging that the federal government role in the information infrastructure is far less powerful than private sector investment, the council recommended that the federal government focus its own investment to gain maximum 
leverage and ensure a balancing of interests to protect the public welfare. The power of the government lies in its ability to control standards, procurement regulations and research and development activities.

Vice-President Gore regarded access to the 'superhighway' as crucial in light of its educational potential. These moves by the US Administration signal a recognition of the importance of access in terms of the functioning of American democracy. The Administration's goal of connecting every American school to the Internet by the year 2000 seems unrealistic when many schools cannot afford computers. The distribution of government information over the Internet, through the new Library of Congress data base, aims to increase access. However, access does not ensure that legislation will be comprehensible:
Anyone who has tried to read the arcane language of Congressional bills may be in for a shock, or perhaps enlightenment as to why Congress often seems so gridlocked (Lewis 1995, 28).

This is an example where provision of the information as such may not lead to an informed citizenry if the cost of gaining it (in terms of money or time) is too high or the form in which it is presented is incomprehensible.

\section{Conclusion}

What is the influence of CTs on citizen participation in the democratic process? Returning to the direct democracy debate, it is clear that in reality counting the votes is not as important as the processes of information exchange leading up to the voting. Many issues are contentious and the 'correct' decision is far from clear. The reasons for disagreement stem as much from mechanical uncertainties about outcomes as from philosophical conflicts of interest. Despite the difficulties of some instances described above, it appears that the discourse can be facilitated by the new CTs, mechanistics explained and philosophies explored. 


\section{Can technology save democracy?}

While the new CTs can be used to empower people, economies of scale give advantage to the political influence of big business and substantial interest groups. The use by grassroots organisations in Australia is minimal compared with use by vested interests. Yet it represents a beginning. Only citizens can 'save democracy'...or help it to grow into new forms and ways cohabiting with the new technologies. The citizens may use CTs - the US experience demonstrates the potential for CTs to facilitate participation.

However, as Arterton concluded, CTs alone are not sufficient. It is the context in which they are used and the mind-set of the operatives which determines whether teledemocracy projects are successful. Further, rather than being used for instant plebiscites, the consensus view is that CTs can be most fruitfully employed in supporting representation, through education, not replacing it.

In summary, the U.S. experience reveals pitfalls and possibilities for Australia. The pitfalls appear to lie in allowing new elites, particularly political consultants, to dominate political debate through the intensive use of CTs and mould it in a manipulative fashion. Further empowering such consultancy processes in the political debate during elections appears to result in candidates being largely shielded from public and media scrutiny by comparison with previous decades, despite the proliferation of new and enhanced media and communication channels over that period. Candidates can 'hide' - or, more accurately, be hidden from the traditional media and the public by carefully contrived 'appearances' which limit the opportunity for questioning and retorts: this has happened in the U.S. for the past two Presidential elections and, certainly, in Australia in the 1996 federal election.

For Australia, there is a salutary example in these comments - the Liberal Party's successful 1996 federal election campaign has been much praised for the degree of media control achieved and for the avoidance of public interaction - 'ruthless, manipulative of the media, controlled, contrived' according to one commentator involved on the Liberal side (Rowlings 1996, email). 
Overall, the 'consultisation' of U.S. politics has led to more oneway propaganda and less of the important, two-way educational communication and participation that researchers have found is the cornerstone of democracy at local, state and federal level. Whether the apparent result, a detrimental outcome for democracy, can be reversed is problematical: its roots lie in business and societal trends to greater economic rationalism and the concomitant rise of 'market forces' and marketing machinery as drivers of political processes. Apart from questions of control being realistically possible, whether any attempt at control is reasonable is another important question.

On the positive side, the U.S. experience points to the possibilities of CTs for involving more citizens more often, for reaching and embracing the 'exiled' homeless/jobless and for educating the polity more widely on civics. Relatively small pilot projects have shown the way CTs could be used, and the U.S. government is attempting to show leadership by developing a national information policy, with a strong emphasis on voters of the future, school children. Building on these foundations is the U.S. challenge: leap-frogging them is the Australian opportunity.

For Australia, there are lessons that the extent and quality of national leadership in utilising and adapting CTs to our unique needs may be an important determinant of how clever and civicminded a community Australia is in the 21st century. Australia's greater tyranny of distance (relative to the larger population and more even geographic spread of the U.S.) and the special difficulties of two-way communication with rural and remote people, particularly Aborigines and Torres Strait Islanders, would appear to increase the relative importance of harnessing the new CTs to Australia's national needs. 


\section{What the new Communication}

\section{Technologies mean for}

\section{Australian participation}

\section{Australia and the US - comparative experiences}

The previous chapter considered the US experience of CTs in relation to political processes. In comparing the American and Australian political environments, there has been discussion of the Americanisation of Australian politics (see Bean 1995, 43-45, Ward 1995, 222-4). But there are also significant differences. Prime Ministers are not directly elected, but must gain support through leading the party which wins a majority of seats in the House of Representatives. US electoral politics is based on competition between would-be party candidates in primary elections raising funds to support their campaigns outside the party organisation, and hiring consultants in advertising and polling. In Australia, parties control candidate preselection and party machines maintain much more dominance over campaigns. Though external advertising and opinion polling consultants are hired by major parties in both countries, in Australia the party elites (working with consultants) generally maintain control of the messages conveyed (Ward 1995, 224).

However, the single biggest difference in relation to campaigning lies in compulsory voting, which has a profound influence on campaigning styles. Time and money are necessary in the US to convince people to vote and the size of the turnout is variable, whereas in Australia campaigns are not reliant on costly motivation-to-vote advertising and turnout is predictable. 
Chapter five examined the marketing of politics in the 1993 general election and other recent elections in Australia. This chapter examines the implications of the new CTs for future democratic participation in Australia. Drawing lessons from the US experience, Australian policy-makers have the opportunity to develop strategies which can use the new CTs to optimum benefit and attempt to avoid detrimental effects. To set the scene for considering the question inherent in the title of the chapter, it is helpful to examine two particular aspects - the control of the media and the way CTs impact on political processes are regarded in economic rationalist terms.

\section{The control of media}

The rhetoric of private market competition has been apparent in debates about the role of media (increasingly influenced by new CTs) in democracies. Policy discussions about the press and particularly broadcasting are increasingly shaped by considerations of deregulation and market competition (Ward 1995, 136-7). Protected media are charged with being costly, inefficient and burdened by restrictive practices. In the opinion of the free marketers, the perception of public broadcasters as community trustees should be replaced by broadcasters as marketplace participants (Keane 1991,525). They maintain that regulations on the allocation of frequencies, licences and advertising should be abolished and the media should become more competitive and cost efficient. The political repercussions of this position are that the economic rationalist viewpoint are transposed into the political arena, as the media decisively influence politics. As has been pointed out, direct mail represents the most direct transliteration of the market economy to politics (see O'Shaughnessy 1987, chapter three).

Opponents of market liberalism assert that deregulation will lead to local culture succumbing to American imports; multi-channel choice will in fact mean broadcasting focused on low-cost, mediocre productions and public service broadcasting will be destroyed. There will be no protection of the beyond-profit 
'community interest' in the survival of local culture. The range of program choice for consumers in Australia may in fact be quite limited as broadcasters jostle for the safe middle ground with mass-appeal programs:

The overall point to be made about the market liberal fetish of 'deregulation' is this: the time has long passed when it could be assumed credibly that market competition guarantees freedom of communication... market economic imperatives are the prevailing models of development in the private information sector (Keane 1991, 528).

The political implications of this may be a political debate which is fragmented and localised to the extent that national, let alone international, issues programs are in the main not watched. The private information sector may be concerned more with profits than the community interest. The solution lies, it is argued by opponents of market liberalism, not in unrestricted market competition nor in unnecessary bureaucratic restrictions, but in the establishment of regulatory bodies to deal with broad questions of operation and conditions of network access. In essence national identity and integrity need to be protected by government policy and actions. The cause has been taken up by the Member for Werriwa, John Latham, who wrote: 'It is essential for the government to set a policy framework - with safety net provisions of access and affordability - which anticipates the corporate plans of the big players, especially Murdoch and Packer. The convergence of technology and ownership could give enormous public power to a handful of unelected, unaccountable giants. Information really is power' (Latham 1994b, 6). I concur with this judgement as I outline in the concluding chapter.

\section{Viewing the new CTs in economic rationalist terms}

The economic rationalist influence on government policy has been important, particularly as regards the new CTs. Reluctance to interfere in the operation of free market competition has in the past militated against the government taking a leading role in 
guiding the way in which technology should be introduced and used. Speaking polemically to emphasise the point, Kerry Stokes (Boyer lecturer 1994 and media owner) was of the view that 'Open markets are the current love children of the free market economists who believe all ills can be cured by unrestrained competition. I believe they are wrong' (Stokes 1994 21). In fact, many market economists in fact do not hold such simplistic views but in essence Stokes was sceptical of the current wisdom which endorses free market premises.

With the economic rationalist philosophy has come widespread moves to privatisation on the grounds of increasing efficiency. The supposed benefits of privatising government enterprises have however been questioned. The criticism is levelled by one academic that there has been no attempt to evaluate the longer term impact of the sale of Government Business Enterprises (GBEs) on the budget deficit of the government. In addition no account is taken of the loss of profits from GBEs to the public sector. 'As long as the present uncritical attitude to privatisation is maintained we can expect the continuing disposal of valuable public assets for inadequate returns. The long-term result will inevitably be higher taxes and reduced services' (Quiggin 1994, 9). Particularly relevant for this thesis is the proposal to sell part of the major telecommunications carrier, Telstra, and complete deregulation of the telecommunication industry by 1997 (see Beyond the Duopoly, below).

In Australia, the public broadcaster has come under increasing criticism from advocates of market liberalism in the federal departments, who charge it with inefficiency and have demonstrated reluctance to fund it (Ward 1995, 145). The Dix Committee, commissioned by the conservative government in 1979, recommended that the $\mathrm{ABC}$ be restructured along corporate lines and that it become more entrepreneurial in its operation. While this has happened, the special regard held for the ABC by influential sections of the community, particularly for impartial, authoritative news coverage, has meant that debate on its privatisation has largely lapsed (Ward 1995, 145). 
Politicians and electors alike are obliged to act in the inevitable circumstance of incomplete information. One economist questioned whether market forces were sufficient to overcome the difficulties created by incomplete information and concluded that some intervention by government was necessary to protect consumers. It has been argued that, as firms and people generally act in their own economic self-interest, government has an obligation to act in the interests of the greater good (Inman 1987, 661). It is noteworthy that all the government inquiries into different aspects of the impact of CTs, reported later, have concluded that there is a strong and positive role for government to play. It would appear that towards the end of 1995, these suggestions were heeded by the then government with the announcement of various methods of influencing the impact of CTs, to some degree (see Government Responses, below).

\section{Research questions:}

- What is the influence of CTs on elected representatives' communication with citizens? and

What is the influence of CTs on citizens' participation in the democratic process?

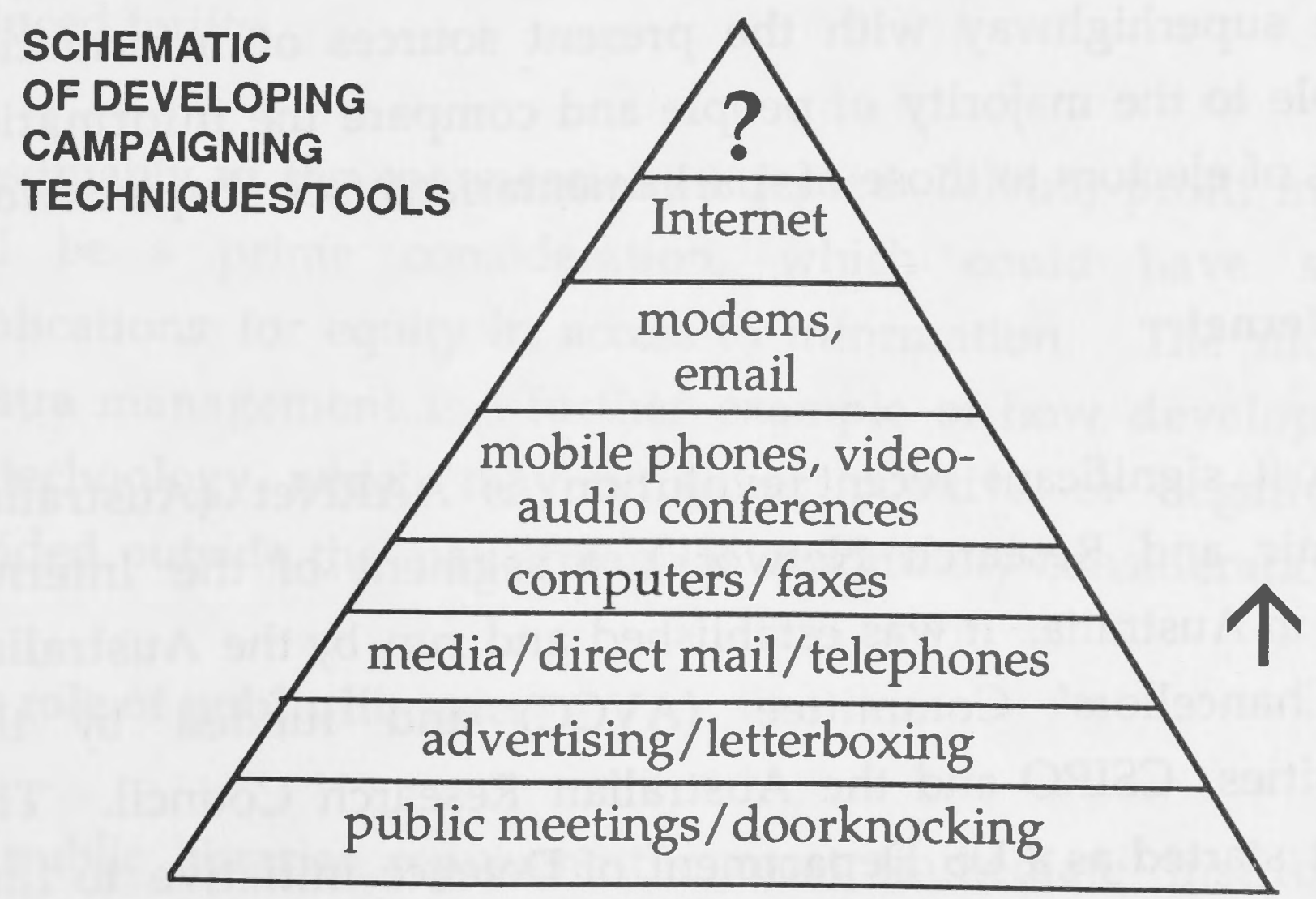


In a chronological development of CTs, it appears that their application to the contact between representatives and constituents has been to make communication progressively less personal, until the 'full circle' of candidate/voter communication through CTs is realised (see chapter six). This has coincided with increasing voter disenchantment, as demonstrated by surveys (Saulwick 1992, 76), falling branch membership in the two main political parties in Australia and increased cynicism in the community in general (see report of the Civics Expert Group, Whereas the people...Civics and Citizenship Education, Summary of the Report of the Civics Expert Group, below).

Thus to answer research question one, the impact has in general been negative. On the other hand, various political participation projects, most evident in the US and embryonic only in Australia, have indicated the potential to use CTs to increase citizen participation, so in answer to research question two, the outlook is positive. The impact of the new CTs for Australian democracy could be conducive to increased participation, awareness and deliberation, and act as some deterrent to the widespread cynicism now evident.

\section{People's information sources}

It is pertinent to compare the potential of the networked nation on the superhighway with the present sources of information available to the majority of people and compare the information sources of electors to those of parliamentarians (see chapter two).

The Internet

The most significant recent evolution is AARNet (Australian Academic and Research Network), a segment of the Internet located in Australia. It was established and run by the Australian Vice Chancellors' Committee (AVCC) and funded by the universities, CSIRO and the Australian Research Council. The Internet started as a US Department of Defence initiative to link researchers but has since expanded, particularly through 
universities worldwide, and is used to some extent by business, government and community organisations.

Users of the Internet can access vast amounts of information on any topic, communicate around the world by email, exchange computer files and connect to other computer systems. The number of users is hard to gauge, but is thought to be about 40 million people world-wide and more than 500,000 in Australia (Innovate Australia 1995a, 7).

A high proportion of users are young and well-educated, and a third are female. Fifty-nine percent of use is in education, followed by business ( 21 percent), government (14 percent) and individuals (Innovate Australia 1995a, 7). It is now routine for organisations to advertise their home page and email addresses. It has been estimated that there will be over four million Internet users in Australia by 1998 (ASTEC 1995 43).

In 1995, the AVCC announced that it had transferred management responsibility of AARNet to Telstra (formerly Telecom Australia) (AVCC 1995). The reason given was a huge growth in demand for access to the Internet with which the AVCC could not cope. Telstra will restructure the AARNet tariffs, introduce round-the-clock customer service and increase transmission speed internationally. Customers will supposedly benefit through Telstra's extra capacity, higher quality service and reduced tariffs.

Presumably in the commercially-oriented Telstra, profit margins will be a prime consideration, which could have serious implications for equity in access to information. The move to Telstra management is a further example of how developments in technology which may be either positive or negative are decided outside the mainstream of community consideration.

\section{The role of public libraries}

As public libraries represent the most immediate institutional source of information for citizens it is pertinent to note the 
minimal role of the Commonwealth government has taken in the past in fostering this aspect of the 'clever country'. State governments have adopted differing levels of financial support for municipal libraries. New South Wales provides only 15 percent of public library funding while Victoria, Queensland and South Australia provide about 40 percent (ALIA 1995, 3).

As a resource, the value of public libraries is enormous. Four in 10 Australians use libraries, involving 100 million loans and 10 million requests for information each year. One government MP has championed repeatedly the cause of public libraries in terms of social justice, maintaining that:

The availability and quality of library services remains a significant gap in Australia's commitment to a just society. The Federal Government has an equity role to play in closing the gap between municipal responsibility and municipal finances for libraries, particularly in the disadvantaged local government areas. This can only be achieved by correcting one of the fiscal imbalances of federalism (Latham 1994a, 2).

In relation to public access through public libraries, the issue of availability is a recurring one. 'One set of equity issues arises from the socio-economic effects inherent in the diffusion process for the new technology-based products' (BTCE paper 3, 1994c, 101). In plainer terms, what will they cost? As discussed earlier, people who adopt the new technologies tend to be better educated, more comfortable with technology and wealthier than the population at large. The provision of public access points through libraries would ensure that people were not excluded on the basis of economic cost.

Latham, the Member for Werriwa, is following the example set by Barry Jones, also a Labor MP, in raising issues related to the new CTs (Latham, 1994b, 4468). Mark Latham asked the relevant ministers questions on notice on the provision of public access points for the distribution of electronic information in regional, district or urban centres around Australia and whether 
consideration had been given to using Australia's extensive network of municipal libraries to house the devices and foster public access to the information superhighway (Latham, 1994b, 4468).

He called for federal funding for municipal libraries in areas of greatest need. While agreeing with the access points principle, the opposition accused Labor of attempting to extend central control and pointed to dissension on funding public libraries within government ranks. One government speaker conceded that the Jones' committee's recommendations of 1991 (The Role of Libraries/Information Networks, discussed in chapter two) had received no response from the government.

In fact it took four years, to December 1995, before a decision to fund electronic aspects of library services was made, in the Innovate Australia statement. The provision of $\$ 11.4$ million for equipping Australia's 1,400 public libraries with the capability to provide community access to on-line information (Innovate Australia 1995b, 44) has been greeted enthusiastically by library groups. 'The government should be congratulated for demonstrating its support for the role of public libraries in providing access to all modes of information' (Walsh 1995, press release). Whether the incoming (1996) Coalition government will proceed with this undertaking is a matter of speculation.

\section{Access to government information}

There have been various moves by government departments to improve access to the information they hold (reported collectively in Hansard of the House of Representatives 1994, 2724-2729). In summary, with the exception of the Department of Social Security which aims to initiate the Community Information Network (CIN) (see later discussion), the technology is used by government departments basically for administrative purposes to perform their current functions more quickly and efficiently - although there is a fast-growing trend to making information available through departmental Web sites. 


\section{The People Speak}

Citizens Initiated Referendum (CIR) is a way in which wishes of voters can be conveyed to governments. It is discussed here as a democratic device which could use the new CTs in the dissemination of information on an issue prior to the vote.

The debates over the advantages or disadvantages of CIR mirror those of direct or representative democracy, and have increased in recent years in Australia. In fact, referenda have been conducted at a national level on proposals to amend the Australian constitution on 42 occasions since the first in 1906 (Dean 1992, 87). The Australian states have used referenda for various reasons, though much less commonly. The stringent conditions governing referenda proposals have been a factor in their lack of success - only eight have been approved by voters federally in 90 years.

$\mathrm{CIR}$ can be defined as the expression of opinion by voters by way of a referendum upon a petition of a specified number of people (Walker G. de Q. 1992, 39). Such petitions could call for constitutional change, to change or veto legislation, to propose new legislation or to recall (censure and/or dismiss) government officials. The method may be direct, to require a referendum to be held on a citizens' initiated petition without the participation of parliament, or indirect, when such a petition could be required to be considered by parliament (Walker G. de Q. 1992, 39). A number of questions arise in considering CIRs, including the number of signatures required, the allowable period for collection of signatures and the permissible spending in promoting the proposal.

The first CIR in Australia was introduced in the North Sydney Council in 1983 through the efforts of the Mayor, Ted Mack (who as an MHR in 1990 sought to have similar legislation introduced into the federal parliament). 
More recently the then shadow Attorney-General, a strong advocate of CIR, foresaw that the new technologies could be useful in collecting the 350,000 signatures required for a petition, in that people could lodge their signature electronically. It could foster a two-way communication system and help fulfil the constitutional requirement to disseminate information to households prior to holding referenda (Reith 1994, interview).

Advocates claim that CIR gives citizens a direct voice, encourages them to be involved, reduces alienation and encourages public discussion of policy issues rather than personalities. Critics say that CIR lacks the deliberative process of representative democracy, is open to manipulation by special interest groups and presents some issues too complex for the average voter to express a view (Legislative Assembly of Northern Territory's Sessional Committee on Constitutional Development 1991, 17-18).

CIR has been endorsed by most of the branches of the Liberal Party and the Queensland National Party and public opinion polls have shown strong support of 70 to 80 percent. Peter Reith saw CIR as a supplement to the present representative political system to increase participation. Further, the charge that CIR would allow control by special interest groups was in reality:

...the ultimate coward's answer...what they are saying is that...Australians lack a sense of liberal values. It's just an insult! This is one of the most liberal societies on earth. Outrageously paternalistic...If you are to be free then you have to be free to make mistakes. All the arguments against it [CIR] are arguments against the idea of democracy. The entrenched interests of the present political elite are against it. It is such a powerful idea that it brings forth powerful responses (Reith 1994, interview).

An example of the powerful response was seen in the move by a committee of the ACT Legislative Assembly to defer CIR while giving lip service to widespread community consultation. CIR in the ACT continues to be the subject of intense debate. One commentator was of the view that CIR may operate in the 
interests of incumbents. 'Far from dismissing CIR because it erodes their power, Government MLAs should realise that CIR could occasionally save them from their own folly and thus increase their chances of staying in power' (Hull 1994, 11). A motion advocating CIR by an Assembly Member was defeated (December 1995) with the Greens, Labor and the independents opposed.

However, this proposal contained no constraints on spending and thus ignored the lessons of initiative, referenda and recall in the US. If more attention to the safeguards had been given, it is possible that it may have been passed (Hart 1995, interview). As an aside, there was a salutary lesson in Peter Cook and David Frost's satirical film of over 20 years ago, The Rise and Rise of Michael Rimmer. Rimmer, on being elected to Prime Minister, fulfilled his electoral promise of holding a referendum on every issue. The red light on the television set would call for yet another vote, until the final referendum was carried - that there would be no more referenda. The link between the new CTs and Australian democracy - as reflected in CIR - lies in the public consultation that CTs make possible. If public libraries and community centres have Internet access (as many have) then it is possible to conceive of these sites being used in referenda discussion, in the same way as Australia Consults envisages (see chapter eight).

\section{Votagram}

The people's answer to direct mail from their elected Member could arguably be the Votagram which provides an interesting example of the use of technology to 'get the message across' to politicians. Started in March 1986 by a company called Votalobby, the aim was to use the dynamics of parliament to increase attention on issues (Bloomfield 1994, interview). Like a telegram, the Votagram can deliver a personally-addressed message to all federal, state or local government representatives from names held on a data base. 
The alleged advantage is that, with all Members receiving the message, it is more likely that the issue will be referred to the responsible minister, have questions asked about it in the parliament and generally be discussed between Members. The company spokesman claimed the response had been overwhelming and gave examples of the success of Votagram as drought relief, removal of the excise on low alcohol beer, the handling by banks of farmers' debts, the payment by the Department of Community Services of the homeless allowance to runaway children and various environmental issues (Bloomfield 1994, interview).

However, in trying to evaluate the influence of various pressures in the decision-making process, it is dubious to attribute success to just one source. In addition, Votagram differs from direct mail in not being targeted to the MPs' special interest in the way letters from MPs to electors can be. To this extent Votagram is not the people's answer to direct mail though, with increasing sophistication of data bases on MPs' interests (all on the public record), there is no reason why Votagram could not fulfil the function in future.

The views of the politicians on Votagram stand in direct contrast to the expectations held by the people who operate it. The same Members interviewed on direct mail were asked the following questions on Votagram: how many were received a week or month; whether they were from their own constituents or also other electorates; whether this influenced the action taken; what sort of groups/people send them; and the subjects of the letters (see details at the end of this chapter).

The MPs were then asked whether they thought Votagram was an effective method of communication compared to others and examples of their success or otherwise. The reactions of MPs to Votagrams showed that all were negative and the majority were hostile. Some typical responses were: ...They're not effective at all! They go in the bin! (Kelly,
Labor). 
I consider Votagrams to be low in importance in comparison to usual methods of contact...I generally read and destroy [them] (Somlyay, Liberal).

They're used by educated middle class people...they are not indicative of public opinion...their effectiveness is poor (O'Keefe, Labor).

[They are]... a complete waste of time...if someone cannot be bothered writing to me and signing the letter I am not going to waste my time answering it (Wooldridge, Liberal).

They are not an effective way of communicating with a politician. Quite often the senders of Votagrams also tend to have unreasonable/impractical demands (Minchin, Liberal).

(Interviews are sourced in chapter three).

Thus it appears that the claims of the company spokesman that Votagram opens up communication with MPs and is an effective lobbying method are not substantiated. This negative attitude to Votagram by MPs of different parties is ironic in view of the belief by many MPs that direct mail is well received by the voter. It is interesting to speculate what their reaction would be to letters targeted to their particular areas of interest.

\section{The people's understanding}

A comprehensive survey by ANOP, commissioned by the Civics Expert Group (CEG) for their report Whereas the People... showed a generally high level of ignorance of the democratic system. The survey reported that the concept of citizenship itself was poorly understood. Only a third of respondents claimed to have knowledge of the rights and responsibilities of citizenship. Most Australians had little knowledge of the constitutions of the Commonwealth, States and Territories. They were not familiar with the principles of responsible government, of the division of powers and the relationship between legislature, executive and 
judiciary. The federal system was poorly understood. There were other aspects of the findings which gave the CEG cause for grave concern for the future functioning of Australian democracy:

More significant than this low level of formal knowledge are the attitudes the study revealed. Lack of knowledge and understanding is linked closely to feelings of cynicism, estrangement and resentment of our system of government. The emphasis of the media on political conflict results in highly critical comments on Parliamentary proceedings (Civics Expert Group 1994, 21).

The CEG recommended a program of civics education for schools and the wider community which it outlined in detail for implementation as soon as possible (discussed further in chapter eight). The consultation process is using the Internet to report back, linking the new CTs in an important way to political discussion in Australia. The ways in which CTs could be used to facilitate political participation and deliberation are covered later, as is discussion of proposals to improve civic involvement (see Australia Consults, below and chapter eight).

Various other polls have revealed suspicion about politics and politicians. A June 1991 poll included questions on the perceived honesty of politicians - 40 percent believed that politicians could rarely or never be trusted to tell the truth (Saulwick 1992, 76). Interestingly the scores for the honesty of the media were very similar. With regard to confidence in the political system, the survey showed responses of: a great deal: three percent; a fair amount: 33 percent; not much: 49 percent; none: 13 percent; and don't know: two percent (Saulwick 1992, 77). A majority of voters in marginal seats believed politicians make promises during campaigns that they do not intend to keep and half the voters said the main parties had failed to offer solutions to Australia's problems (Saulwick 1992, 16).

An experienced pollster observed that there is an increasing cynicism in the electorate over the past 20 years (Saulwick 1995, on Radio National). He believed that people are more distrustful 
of politics, disbelieve politicians whom they perceive are out of touch, and have low expectations of the political process. A social commentator attributed erosion of traditional support for both parties, particularly Labor, to the 'clever campaigning' using new CTs (Mackay 1995, on Radio National), though he gave no evidence. He argued that focus of campaigning efforts on marginal seats and swinging votes has decreased the level of commitment amongst normally stalwart voters.

Recent polls have shown the pattern of distrust and dissatisfaction. A Bulletin (magazine) Morgan (research company) poll on voter attitudes to federal politics revealed deep cynicism, with 91 percent believing that politicians twist the truth to suit their arguments, and 95 percent agreeing that 'Federal politicians should stop arguing with each other and concentrate more on running the country' (Walsh and Richardson 1995, 14). Fifty-six percent said they had lost faith in the political system, yet only 33 percent agreed that they voted only because it was compulsory. Further, a national survey showed that most 17year-olds were poorly informed on political matters. Only nine percent could name two federal government ministers excluding the Prime Minister and most could not distinguish between the Labor and Liberal Parties (Jones 1994, 1). This would seem to indicate that students within a year of being obliged to vote do not consider politics to be worthy of attention. Another study of school students' attitudes reported a low level of interest in politics. Only eight percent of respondents professed to having 'a great deal of interest' in Australian politics, whilst nearly half of the sample responded that they had 'not much' or 'no' interest in politics (Vromen 1995, 80).

Drawing conclusions from these surveys for the implications for democracy in Australia and for the quality of communication flows between MPs and electors, it appears citizens distrust politicians and most do not have much confidence in a system, of which they have inadequate knowledge. It seems probable that, if voting were not compulsory in Australia, turnout to vote may decrease from around 97 percent to the UK and Canada figures of 70-80 percent. However, given the low level of knowledge and 
the high level of cynicism in Australia, it may be closer to 67 percent as indicated above (those who would vote even if it were not compulsory). Although it is not valid to compare surveys without identically-worded questions, the general tenor would appear to be that distrust in politics is increasing and this has coincided with an increase in the marketing of politics and increasing use of CTs by political elites, a trend identified by Mick Young in his report on the Queensland election. More research would be needed to find a definitive association, but the indications are that a correlation may exist. The hypothesis could be that high use of CTs by party machines has occurred because of their belief that the electorate is in general ignorant and disinterested. The electorate has in turn shown increased political disenchantment, perceiving the political process to be too influenced by professionals and money, both of which accompany the marketing of politics with the new CTs. Whatever the judgement, the CEG signalled that a grave situation existed in the Australian polity:

When the lack of knowledge of how government institutions work and the uncertainty of what the civic ethos means is coupled with mistrust of politics, a danger arises. Our system of government relies for its efficacy and legitimacy on an informed citizenry; without active, knowledgeable citizens the forms of democratic representation remain empty; without vigilant, informed citizens there is no check to potential tyranny (Civics Expert Group 1994, 6).

\section{Recent examples of the use of technology in projects}

While there are no projects in Australia with the objective of using CTs to increase political participation as such, as there are in the US, there are an increasing number of instances where use of CTs in the community is being piloted. On the premise that access to information is an essential element in a democracy, these projects are worthy of consideration and are reported briefly here to give an indication of the range of current projects. 
In essence, these projects indicate the increasing use of new CTs to improve public access to information. The community access projects have a common aim of empowering people to improve their living or working information, knowledge and circumstances. As the US example has shown, such projects can be used to involve people politically.

A difficulty arises in attempting to assess the success or effectiveness of these projects. Understandably, the people running them are enthusiastic and committed, and as they are recent, no systematic evaluation has been carried out. In any case, as many aim to improve 'quality of life' standards, proving their impact is either positive or negative would be very difficult. The use of the new CTs to enhance Australian democracy is still in its infancy. Education in CIR issues could provide an example, as does Australia Consults, described in chapter eight.

The Ipswich Global Info-Links project: With its traditional industries of agriculture, coal mining and engineering stagnating, Ipswich Council in December 1992 '...took an enormously brave decision...the only way was to hot-foot it onto the information superhighway' (Walsh 1994, interview). The council spent $\$ 13.0 \mathrm{~m}$. on a new library to form the hub of a network using modems, fibre optics and digital links (Global Info-Links Information booklet 1995, 5). User groups would be 10 secondary and 28 primary schools, a TAFE (Tertiary And Further Education) College and proposed University, suppliers and users of government information and business and community groups. The challenge was to ensure the network was accessible, both through being user-friendly and being affordable. By making global links available, the assumption was that better-informed businesses would be more profitable, attracting employment and helping economic recovery (Global Info-Links Information booklet 1995, 6). Global Info-Links opened in December 1994 and to date no formal evaluation of its impact has been done.

The Newcastle Community Access project is one which involves different sectors - public, university and school libraries. Managed jointly by the University of Newcastle library, the Macquarie 
School library and the Newcastle City library, it provides links through AARNet to the Internet, thus giving public library users access to that great range of data bases. Access is available for researchers to the earthquake data base, for which the area is well known (Walsh 1994, interview).

The ACT Education Information Network - ACTEIN - is a joint project by all four ACT universities (including the Australian Defence Force Academy) and 16 public and private schools. The purpose is to provide links for school students and, ultimately, (through the public library network), for the community to global information. The underlying philosophy is that today's children must be given the opportunity to master the new CTs to open up a new world of computer literacy (Banks 1995, interview).

Various other projects in the education field have used technology to link isolated rural students to central courses, to establish state-wide open learning systems for higher education and to investigate technology-based education and training centres (Horner and Reeve 1991, 74). The projects use combinations of equipment - micro-computers with modems and printers, loudspeaker telephones, answering machines, photocopiers, faxes and videocassette recorders.

Open Learning provides distance education using the new information technologies. Open Learning aimed to enable students who missed the opportunity to attend university to enrol in courses, regardless of their educational background. Having picked up sufficient units they could then enter mainstream tertiary institutions. The second stage was the new Electronic Support Service. "This service will enable students to communicate with tutors and other students through electronic mail, to search library catalogues and to access course and administrative information...Access points will be established in community-based centres around Australia to ensure that all students have access to the service' (Keating 1994, 4). 
The Pilbara video conferencing project (LIVENET) is a joint industry-government initiative which aims to evaluate the effectiveness of videoconferencing to deliver courses to remote towns, whether it could be used by state government agencies and whether a market exists in the business sector or with community groups for video conferencing (Horner and Reeve 1991, 78).

The Department of Social Security (DSS) has initiated the Community Research Project (mentioned earlier) which aimed to use communication technology to enable people on low incomes to take action to improve their standard of living. There are two key aspects to the project:

- a computer-based Community Information Network (CIN) to provide information on DSS payments and on services available locally, and to provide a means for communication and the exchange of ideas; and

- Action Research Projects to define ways of improving living standards by such means as organising child care, forming food co-operatives, engaging in educational activities or setting up an accommodation register

(Department of Social Security 1994, information pack).

Launched by the Minister for Social Security in June 1995, CIN aimed to provide free access to government and community information and some access to the Internet through 300 entry points located in libraries, social security offices and community centres. News groups would be able to exchange information on subjects of special interest. Over $\$ 4$ million was committed to establishing CIN, which would also provide advice on training in computer software and seek to build social networks and support groups. The Minister explained the rationale:

In a world where access to information is rapidly becoming a social and economic necessity, it is important to ensure that all Australians have the protection of an information 'safety net' (Baldwin 1995, 1). 
Similar in philosophy to the PEN project in Santa Monica (described in chapter six), the Community Research Project is rooted in the concept that people can be empowered through sharing information. An added benefit could be to give unemployed people the ability and confidence to use the new technologies. The pilot scheme ran in the ACT through the end of 1994 to trial the computer system and to gauge the degree of interest amongst DSS clients. Submissions from groups interested in forming Action Research Projects were called for and the response rate was high. The department awarded grants of up to $\$ 20,000$ and provided a computer and modem at no cost, to be housed in a community centre or library. The first projects were set up in suburbs in Adelaide and Brisbane and in several centres in Tasmania (Department of Social Security 1994, information pack). It was extended in December 1995. The scheme is planned to run through to mid-1996 and will be monitored and evaluated.

\section{The Information Superhighway}

The various projects outlined above should be put in the context of what has been termed the information superhighway. Questions regarding proposed plans for a networked nation, although complex, must be addressed by decision makers. '...the very fact that they are so difficult to answer should be cause for genuine reflection and caution as we progress in the decisionmaking process' (Stokes 1994, 3).

An underlying concern of this Boyer lecturer and media owner was '...that the direction of Australia's communications and information industries is being driven by technology and those that manufacture it to the exclusion of broad social goals that would be in Australia's national interest' (Stokes 1994, 5). He argued that the common-weal would be served best by ensuring that there was a public lane on the information superhighway.

Technology convergence is resulting in different technologies being used to deliver the same services (broadcast and cable television) while service convergence is merging traditional 
services and creating new ones (Electronic Data Interchange [EDI]). These convergences of technologies and services have resulted in firms in the traditionally distinct spheres of telecommunications, radio communications, broadcasting, post, the media, publishing, computing and entertainment positioning themselves to take advantage of new market opportunities by investing in new sectors or in forming new alliances. Stokes contended that the need for fibre optics to the home in Australia was highly questionable and that communication services could be adequately handled by the present technology without incurring the enormous costs of linking every home to the superhighway:

To return to the analogy of the road traffic system, it is like replacing each and every suburban street with four multilane freeways each capable of transporting semi-trailers and bicycles alike (Stokes 1994, 10).

Further, he argued there had been no sound investment basis for the costs; there was no consumer demand evident and there was no clear social or political objective. The economic implications of introducing the information superhighway were considerable and consumer interests had been overlooked:

The situation is a disturbing one, where profit is in the driving seat and the Australian consumer, to continue the analogy, is a blindfolded back-seat passenger without a seat belt (Stokes 1994, 13).

Criticism of the role played by government has come from other quarters. The government has been accused of incompetence in handling the introduction of cable with its failure to auction local cable franchises losing Treasury billions of dollars in franchise fees and local community groups being denied services. 'The government auctioned the second long-distance carrier, the competing mobile phone operators as well as Multi-point Distribution Services (MDS) and satellite and yet has given away the most valuable entertainment and telecommunications asset in Australia for free' (Cox 1994, 12). 
I believe the point on community access is important, as examples in the US show the benefit where successful bidders were obliged in many cities to offer community television studios for covering local politics, council meetings, public affairs, news and current affairs (Radio National Australia 1995, June). None of these services to local communities has to be provided in Australia, where:

The current free-for-all will allow cable operators to provide services to the more densely populated or perceived high value added telephone subscribers. This could lead to an information-rich versus information-poor society which would seem highly undesirable for a Labor government. A licence system would ensure operators also provided services to the outer, provincial, rural, remote and lower socio-economic areas (Cox 1994, 12).

Government inaction has had other repercussions. Foreign control of sectors of the information industry has resulted in important policy decisions affecting the well-being of the Australian community being taken overseas. I agree that: 'In short, the informatisation of Australian society is driven by the business (and even political) imperatives of a relatively few transnational corporations with headquarters beyond its borders in the United States, Japan or Europe' (Ward 1995, 283). I argue in the conclusion for the need to protect Australia's national identity (see chapter eight).

Interactive communication (which could include political discussion) through optical fibre to the home, previously thought to be imminent, now looks problematical on economic grounds. Following glowing predictions of the possibilities of optic fibre, the consensus of opinion overseas is now that fibre to the home or to the kerb is too expensive at present and that hybrid fibrecopper (HFC) can provide most of the capacity at lower cost but still with good quality (BTCE 1994a, 6).

In any case the goal of equality of access is unlikely to be achieved. 'Based on...the BTCE's estimate, the cost in 1994 of the analogue 
network is around $\$ 610$ per household passed in inner urban areas plus a further $\$ 650$ to connect those who subscribe' (BTCE 1994a, 11). Digital interactive services allowing people to communicate with a central point but not with each other would involve a number of costs. The image of eliminating rural isolation through use of the new technologies seems very hazy, for the reasons that:

The costs of cabling rural and remote areas with HFC is shown to be particularly high, being about $\$ 18$ billion for a distributive system only, even if started around the end of the decade. However, in reality it is highly unlikely that many remote households will receive a HFC service (BTCE $1994 a, 43)$.

The BTCE did not attempt to estimate a definitive cost of fibre to the home for a interactive broadband network for Australia. However based on Japanese estimates the cost for Australia would be about $\$ 70$ billion or higher, because of the lower population density (BTCE 1994a, 44). The BTCE released its final report of the Communications Futures Project in May, 1995. The economics of residential networks and the implications for suppliers were modelled and the expense of providing universal service obligations for the new technologies were identified. It found that interactive broadband services were unlikely to be widely available until the end of the decade, so cable would remain primarily entertainment based.

\section{Government responses to the superhighway challenge}

While these initiatives are not overtly political, in a broader sense they should empower people and therefore have political implications. It is clear from the US experience that grass-roots organisations can take the initiative and organise. The use by interest groups of email in lobbying and researching via the Internet is still not significant in Australia. The traditional ways are used and seem to work. However, as chapter four discussed, many interest groups in Australia seem to be poised on the edge 
of employing CTs more widely in political lobbying and in organising. In the two years to the end of 1995, a number of government-initiated investigations were undertaken. It has been argued the large number of inquiries, rather than enlightening, might be counter-productive:

My political concerns relate to the numerous inquiries currently under way that will send confused signals to government, thereby affecting the decision-making process for the current and future regulatory framework within which the communications industries will operate (Stokes 1994, 4).

In fact, no themes emerge from these reports, which appear to have been commissioned almost independently, though by the same government. I believe that the point Stokes made is valid. The cognisance given to these reports by the incoming Coalition government (March 1996) has yet to be evaluated.

By the second half of 1994 reference to the information superhighway was beginning to appear with great regularity in speeches by the Prime Minister and other senior ministers. The establishment of the Broadband Services Expert Group (BSEG) is quoted by government spokespeople as the answer to charges of lack of concerted planning by government to meet the challenges of the networked nation. Although the terms of reference for the BSEG make no reference to access or equity, these aspects are in fact covered in the interim and final reports.

Indicating an market-focused mindset of the government, the terms required BSEG to '...examine the technical, economic and commercial preconditions for the widespread delivery of broadband services to homes, businesses and schools in Australia...' (BSEG 1994a, 89). Only one of six following matters for investigation in the terms of reference specifically refers to the potential benefits and social impact on the Australian community. 
The BSEG was set up in December 1993 and held consultations with people with an interest and expertise in the topic. They received about 100 submissions from individuals and groups. The interim report covered a description of the current status of broadband services, market opportunities, access, delivery techniques and risks for investors. Concluding that the communications environment will change vastly in the next 10 years, the BSEG's interim report stated:

There is a degree of uncertainty about the demand for broadband services and this is reflected in the caution potential investors are exhibiting in committing funds to new projects. The current flurry of infrastructure investment activity in Australia is largely being driven by opportunities presented by deregulation of the pay television industry... But it is essential that Australia goes beyond one-way video services. Most of the benefits of a broadband network will come from interactive services (BSEG 1994a, 82).

The BSEG advocated that the government should take a leading role in using and promoting broadband services by informing the community of their potential and by using them to benefit rural and remote health and education services. The interim report had its critics. One communications commentator pointed to the paradoxical difficulty he experienced in obtaining a copy:

I want to contrast the technophoria in your report with the technofailure of its delivery. There is such a wide gap between, on the one hand your enthusiastic canvassing based on new untried technology and, on the other your incapacity to deliver information with the old technology of print that I cannot resist pointing out the differences between your future dreams and current realities (Ives 1994, 17).

It is interesting to note that the final report also encompasses a broader agenda than the narrow terms of reference by advocating an approach 'based on developing a new, user-orientated strategy 
for communications'. Dealing with the profound changes in new CTs which lie ahead would require a comprehensive platform:

...to promote social interaction, enrich education, improve health services, enhance the delivery of government services and improve competitiveness for business and the economy. We also need to manage change sensitively (BSEG 1994b, iv).

Fundamentally, the Group recommended that a National Strategy for New Communication Networks be implemented based on three key elements: education and community access, industry development and the role of government (BSEG 1994b, x).

It also advocated the establishment of a National Information Services Council, chaired by the Prime Minister, which would comprise representatives from industry, carriers, service providers, consumers and researchers. The role of the Council would be consultation and policy advice to government and industry. Its establishment is described later.

A long-awaited, and several times delayed, Commonwealth cultural policy Creative Nation was produced in October 1994. It included the extravagant observation that 'Information technology, and all that it now offers, has crossed the technical rubicon into the realm of consciousness, to the realm of culture' (Department of Communication and the Arts 1994, 55). The merging of the Communications and Arts portfolios in January 1994 was to reflect the convergence of telecommunications, broadcasting, computing and creative industries and technologies:

Australia has the opportunity to become a world leader in the new services environment through the creation of content - an essential element in multi-media and broadband services (Department of Communication and the Arts 1994, 56). 
Principles of access and equity in ensuring people are able to use the networked information services were acknowledged but there were no specific proposals how this might be achieved.

Yet another discussion paper, Beyond the Duopoly, was produced by the Department of Communications and the Arts. It concentrated on issues with regard to regulatory matters which will arise after complete telecommunications deregulation in 1997 and called for submissions on a broad range of matters. The guiding principles include Australians having access to a full range of communications infrastructures and services and being able to utilise services to meet their communication requirements. Theoretically:
It envisages Australians being empowered, not disenfranchised, by communications technologies, with telecommunications promoting the development of other sectors of the Australian economy. Integral to such a vision is the government's commitment to building a strong and fairer democracy. The challenge is to minimise current and future disparities among groups in society attributable to telecommunications change (Department of Communication and the Arts 1994, 21-22).

The Australian Science and Technology Council (ASTEC) produced another report for government, The Networked Nation. Its terms of reference were more research oriented:

- to examine Australia's requirements for national research data networks, including their use in universities, government research organisations, education and industry;

- to examine the role of research data services for the wider community and the means of providing services; and

- to recommend appropriate action that could be taken by the Commonwealth Government. 
The principal recommendations were that, through AARNet, the benefits of the Internet be extended for use by industry and government and that a national co-ordinated approach be adopted. In addition a non-profit consortium should be established involving government, telecommunication carriers, industry and the research and higher education organisations to provide a national information network for the entire nation. The consortium would operate a national information network with international links and interface with state, territory and regional operators. A group of representatives of user communities would advise on user needs and network requirements.

The ASTEC report also recommended the establishment of a Commonwealth Government Information Services Task Force to develop a pilot program for delivering government information electronically, to develop an Internet-based directory of government information, to investigate options for extending community access to networked information and to encourage links with non-government organisations.

ASTEC is conducting an on-going research project entitled Matching Science and Technology to Future Needs: 2010. In this project a number of 'partnerships' are created on such topics as environment, health and information and communication technologies with the aim of providing the government and industry with a basis for planning and investment decisionmaking into the next century. This partnership principle is an example of the government tapping into private industry and also seeking input from researchers (ASTEC 1994).

The partnership on Information and Communications Technology which predicted alternative futures for full service networks in Australia was produced in December 1995 and is discussed in more detail under the futures section (see later). 


\section{National Information Services Council and Innovate Australia}

The Labor government's response to the challenge of new CTs can be seen in the establishment of a National Information Services Council, as recommended by the BSEG. Holding its inaugural meeting in August 1995, and chaired by the then Prime Minister, it aimed to:

- examine and discuss important socio-economic issues associated with the growth and widespread adoption of information and communication services and technologies;

- provide Government with access to expert views on opportunities and marketplace developments and their importance and potential for Australia; and

- enhance awareness in Government and in the community of current market developments by emphasising their relevance to broader economic and social objectives

(Office of the Chief Scientist 1995, iv).

The Government's strategy for promoting information services aimed to encourage Australia's worldwide communications network, to ensure access to new services for all Australians and to establish an appropriate regulatory framework for information services. It would encourage Australian content and use of Australian material in education. In economic terms, it would foster development of an internationally competitive technology and telecommunications sector, improve business practice and promote effective government use of new information services (Innovate Australia 1995b, 37).

However, these proposals have been dismissed, as far as access is concerned, by prominent Labor MP Barry Jones (mentioned earlier) as 'plumbing...more to do with compatibility of bandwidths than equity' (Jones 1996, interview) and by a communications journalist as 'superficial light-weight crap' (Fist 1996, interview). 
Fist contended that a far more comprehensive policy was needed and that Australia was in a unique position to create a base information industry:

'Instead of Telstra acting as the main highway, they want to supply the roadside stalls, run the garages and control the trucking firms, because they know that is where the profits will lie in future. And the government has had no guts...' (Fist 1996, interview).

It certainly appears from the general tenor of the terms of reference of these reports that the government has been more concerned with the economic aspects of the development and use of the new CTs than with social justice and equity issues.

In the education field, Commonwealth, States and Territories agreed to co-operate in the establishment of a national education network, EdNA, which would link for the first time the vocational education and training sector, further education, universities and private education and training providers across Australia and internationally in interactive communication. With a budget allocation of $\$ 1.5 \mathrm{~m}$ in seed funding in 1995-6, it was expected to become operational in early 1996. 'Every school, TAFE, university and education provider in Australia will be linked electronically and have access to high quality education products by 1999' (Crean 1995, 1). Touch screens were to be installed in over 320 CES offices throughout Australia in the first months of 1996, providing jobseekers with access to national databases.

A range of initiatives designed to increase citizen access to new information services were announced, including $\$ 18 \mathrm{~m}$ to fund Accessing Australia through public libraries, and expanding the DSS Community Information Network (CIN), both described earlier. In addition, $\$ 3.5 \mathrm{~m}$ was assigned to fund the National Indigenous Communications Network to link communities in remote areas (Lee 1995, news release). Australia's major national cultural and heritage institutions' collections is planned to go online through a $\$ 10 \mathrm{~m}$ program entitled Australia's Story: Our 
National Collections Online. It has yet to be seen how the incoming Coalition government will deal with these proposals.

\section{How should the networked nation be planned for?}

Over 10 years ago, consideration was given to the need for an information policy. The House of Representatives Standing Committee for Long Term Strategies was established in May 1985. Its wide-ranging and ambitious charter was to inquire into and report on economic, social and cultural issues relevant to the welfare of Australians. The committee identified three immediate issues for investigation: the implications of the information society, the implications of an aging population and the problems of the cities.

Under Barry Jones' chairmanship, the committee has been active in producing reports and in raising public debate of these issues. In the first inquiry, the committee addressed the central term of reference - the desirability of the adoption of a National Information Policy. The title of the report, Grasping New Paradigms, aptly reflects the scope of the task. The committee by May 1991 had received 121 submissions and held public hearings in the major capital cities.

Issues to be addressed in a National Information Policy were identified as the growing disparity between the information-rich and the information-poor, whether information should be regarded as a free good, the political implications of information distribution, the economic significance of information and the balance between protection of individual privacy and access to information. The submissions to the committee by no means unanimously supported a National Information Policy. Predictably, most critical were those government departments with vested interests which they perceived may be threatened and most supportive were government agencies lower in status or organisations which provide information. The former Department of Transport and Communications submitted that: 
...the concept of a general policy for information is really quite amorphous...an attempt at policy integration of any one of a number of information issues into a single strategic framework would seem somewhat illconceived...it could run the risk of over-simplification of complex and diverse issues (House of Representatives Standing Committee on Long Term Strategies 1991b, 35).

The committee recommended that the various issues involved should be presented to the Australian parliament for debate and adoption of a National Information Policy, 'setting out appropriate guides for access to information in a period of rapid technological change' (House of Representatives Standing Committee on Long Term Strategies 1991b, 39).

However the very problem identified in the report fragmentation in analysis and policy - has militated against proper consideration of its recommendations. Because its focus is conceptual, long term and strategic rather than specific and immediate, the committee's recommendations have not been appreciated by the bureaucrats whose task it was to comment on them, according to the committee's chairman (Jones 1996, interview). In fact, the recommendations were not of the type readily appreciated by bureaucrats, in that they tended to be waffly and non-specific. In essence, the committee's work was marginalised.

There have been other calls for government intervention. A draft policy statement by Australian Computer Society members advocated the creation of an 'architecture' for the networked nation - an optimal way of organising the network services. Arguing for the public interest, the authors submitted that equity of access was an essential element. A necessary condition is an ability to use the network - i.e. 'The notion of literacy, and the focus of literacy programs, need to reflect the new electronic environment' (Clarke and Worthington 1994, 10). Just as it was assumed since the second world war that access to telephones was fundamental, so '...equitable, universal access to a much wider range of networking services is at least as critical to the cohesion 
of our information-based society [as were telephone links then]' (Clarke and Worthington 1994, 10). Rights of communication must also be incorporated in the design of the information superhighway. The question of whether the new information infrastructure will be supply-driven or interactive is an important one, the preferred model being one in which consumers have the ability to provide feedback. Politically the argument for access is irrefutable because:

Genuine democracy, if it is indeed an aim of Australian society rather than a mere slogan, demands that information infrastructure comprise democratic structures, provide access to information to the population as a whole, and deny large protected spaces within which narrow interests can arrange resource allocation and public policy to suit their own interests (Clarke and Worthington 1994, 11).

Accordingly, access should also be protected by keeping entry costs to the public very low. For most mainstream users, usage costs (as distinct from the initial set-up cost for hardware and software) should be little or nothing, though user-pays for full or partial cost recovery may be appropriate for specialist services. Summarising their comprehensive policy statement, the authors stated that the responsibility of government lies in its roles as:

- leader;

- stimulator;

- co-ordinator;

- facilitator of infrastructure where markets fail; and

- $\quad$ regulator of key aspects when self-regulation is not successful

(Clarke and Worthington 1994, 24).

These comments on the government's responsibilities in regard to the information superhighway point to the desirability of policy-makers taking a more pro-active role in the interests of the common-weal, which is evident in the recommendations of Innovate Australia and Australia Consults reports. 
In considering the responsibility of the government to take the lead in determining long-term policy guidelines for important issues, it is relevant to consider the significant changes in the balance of influence. The inclusion of extra-parliamentary bodies in national decision-making (such as the trade union movement through the Accord since 1983), the increased influence of lobby groups and the dominant influence of the executive arm of government have had enormous impact. 'In short, the parliament and the citizen are undermined by economic changes, political pressures and organisational developments. Lawmaking is shaped by flexible, informal processes which are not regularised by constitutional processes' (Warden 1994, 12). Though obviously law-making must be made in legislation through the parliament, the rise in power and influence of influential groups on the formulation of policy before it is enacted makes even more important pro-active government intervention in the common interest.

Australia Consults was described as 'an innovative project in community democracy which will hold forums to encourage greater participation by Australians in debate on key issues such as constitutional reform, the republic and reconciliation with indigenous people' (National Australia Day Council 1995). It was scheduled to take place on the Australia Day long weekends in January of 1996, 1997 and 1998, and represents the first initiative to involve citizens in future planning through the Internet. With the support of Telstra, the National Australia Day Council has established an Internet site to connect the discussion of local government-based forums. The forums would not make decisions but would focus initially on providing information on the key issues. Small groups would hold discussions and report back to a greater forum, with the reports to be entered on the Internet.

The initial Australia Day consultation saw 140 of the total 700 local government councils registered, with an estimated 3,000 people participating. The minutes of the 1996 meetings of 70 councils are posted on the Internet (Singleton 1996, interview) and it is expected that participation will increase in subsequent 
years. The project has the support of all major political parties. It is further discussed in chapter eight.

\section{Possible Futures}

The ASTEC report, SURF'S UP, identified the uptake of new CTs as a crucial factor in the way they impact on society and politically, which has a direct correlation to their cost. In addition, the need for positive government policy to avoid pitfalls and ensure a cohesive regulatory environment was emphasised. Four possible scenarios were outlined in imaginative terms uncommon in reports to government.

Riding The Wild Surf sees a scenario in which business and industry have taken up broadband and narrowband interactive services. In a highly competitive environment, there have been winners and losers. ISDN pricing played a significant part in stimulating development of on-line services, and government is a medium density user. Household demand for pay television has grown slowly but steadily. On the negative side, uptake is far lower in the non-lucrative rural and remote areas (which continue to be disadvantaged) (ASTEC 1995, 1-2).

Navigating The High Seas foresees high uptake of broadband interactive services in all main sectors - business, industry, government and residential. In an internationally-competitive telecommunications sector, government endorsement of standards has reduced consumer frustration. Government programs have encouraged community use of on-line services and social organisation has adapted significantly.

Drifting in the Doldrums depicts a slow take-up of most services in all sectors, with missed opportunities as Australia falls behind. In the absence of any government regulation the multitude of standards has contributed to consumer dissatisfaction and the initial growth in the Internet has diminished because of congestion of lines. ISDN prices have remained high and slow economic growth has exacerbated slow uptake of services. 
Shipwrecked portrays a disaster scenario, due to the low demand for services, fraud with electronic cash transfers, 'cyberterrorists' and incompatible technology. In conclusion, ASTEC endorsed an attempt to anticipate future situations and gain the optimum outcome: 'Foresight is a process which deals with a range of possible futures and attempts to examine them impartially. However, the process also suggests ways in which preferred futures can be realised...' (ASTEC 1995, 3).

\section{National identity}

One of the greatest challenges of the emerging global technologies will be in the area of national identity - though impact is difficult to predict with the lack of evidence of the emerging patterns of demand:

'The characteristics of demand are likely to be critical, since with the newer forms of access (presumed to be first multichannel, CD and on-line, later broadband) consumers will be better able to follow their preferences and will potentially gain greater exposure to not only our own culture but others as well' (BTCE 1994c, 116).

With consumers free to choose foreign rather than Australian material, there may be a danger of the Australian identity being overwhelmed.

In contrary argument the success of various Australian television 'soapies' and movies overseas indicates that, in terms of culture exchange, the traffic may be two-way as far as Australia is concerned. Economies-of-scale outputs with appeal to a mass market could be countered by specialist segments to appeal to sections of the global community but here may lie another danger. If segments of the society - differing ethnically, racially, geographically, socio-economically - are all consuming news, entertainment and sports peculiar to themselves, Australian society could become more fragmented than it is at present. 
However any attempts to control program distribution are likely to be ineffective. 'In an open society like Australia's, it is difficult to restrict the transmission of cultural forms at the best of times. In an increasingly multi-channelled, digitised, networked world the task of controlling distribution channels is likely to become increasingly difficult. As users gain extensive choice, they are likely to respond to interesting programming that attracts their attention' (BTCE 1994c, 117).

\section{What are the implications of the new CTs for future democratic processes in Australia?}

The marketing of politics, American style, is one path Australian campaign organisers may continue to pursue, though fraught with the problems identified in the US and in evidence here. On the other hand, the possibility exists for increased participation and renewed civic cohesion through CTs. There are indications in such projects as the Community Information Network and Australia Consults for new CTs to be used in a way which is conducive to increased participation. Further, the civics and citizenship education program will aim to ensure that Australians become informed and involved. For this objective to be realised there is a need for a national strategy to introduce broadband services in a way that will at least keep government departments 'on track' in acquisition and use of CTs as recommended by the BSEG and endorsed by cabinet in April, 1995 (Lee 1995, 1).

The government reports cited all call for a co-ordinated national approach, which presumably goes beyond effective management of CTs. The challenge is to achieve order and equity without threatening cohesion and democracy. The very amorphous and enveloping nature of information policy makes it extremely hard to integrate. CTs touch every aspect of social and economic life, each department, each business, each household.

A conclusion to be drawn is that, without a consistent, cohesive government policy, there is a danger to both pluralism and 
participation. Pluralism is challenged by the predominant influence of the huge media empires which could swamp smaller interests, and participation is threatened by the marketing of politics. The currency of debate surrounding CTs and the widespread nature of the implications have led to almost daily developments in some relevant aspect or other. This chapter has demonstrated some of the problems and potential for Australia in a rapidly-changing environment and has given some indicators as to the role CTs may play in future in increasing participation and involvement of citizens in the democratic processs. 


\section{Votagram}

On average a Member or Senator may receive between five and 10 a week. When an issue is topical, the volume increases. They are 'sent' from throughout Australia and generally the Member would answer only those from his or her constituents because the task of answering all would be too great and the primary responsibility is to his or her own electors. The subjects range widely - migration, drought relief, homosexual laws, censorship. The belief of all MPs interviewed was that Votagrams were not nearly so successful a method of bringing an issue to the attention of the MP as was the personal letter. Contrary to the claims of the Votagram advocate, none of the interviewed parliamentarians discussed the requests in Votagrams with colleagues. 


\section{CHAPTER 8}

\section{Advance Australia Where?*}

* Title of Stokes' Boyer Lecture, 1994

The advanced telecommunications networks being built today could increase civic participation - or they could encourage sound bites and demagoguery. They could support the electronic equivalent of public spaces, where people come together as informed citizens - or they could provide only electronic malls, where people are targeted as spectators and consumers. At stake here are the workings of democracy (Benton Foundation 1995, 1).

The impact of the new CTs (of which the advanced telecommunications networks, cited above, are the foundation, at present) on democratic processes depends upon the particular technologies and the way people relate them to the political environment. Even such a seeming truism would be contested by the technological enthusiasts and the sceptical. Rather than adopting either extreme position, a better understanding can be gained by looking at the CTs singly and collectively in their particular context and judging their relative impacts. This is done in this chapter by again addressing the research questions in turn.

First, however, some general points need to be highlighted. Democracy in Australia incorporates political pluralism and tolerance. By comparison with many other countries, Australia is a very peaceful nation. The military does not threaten civilian rule and changes of government happen through elections and are accepted without violence. There is a jury system and the presumption of innocence. Though there is no bill of rights, civil 
liberties are reasonably well protected through various political and legal instrumentalities and by the general community ethos.

However, the Civics Expert Group (CEG, 1994) concluded from commissioned research that Australian democracy was threatened internally by the ignorance and cynicism of electors towards party politics.

Calls for action by government and citizens to address these problems have come from many quarters. As chapter seven described, the CEG recommended far-reaching education in 'civics' - awareness of politics expanded into knowledge of democratic systems and processes - both for school students and the wider community. The Australia Consults project, reported through the Internet, aims to involve citizens in debates which affect Australia's future, though its impact has yet to be fully evaluated.

The effects of CTs are extremely wide-ranging, covering every aspect of life. The implications for democracy in general and for politicians, citizens, campaigning and the media in particular make an inter-related mosaic of influences which, almost unnoticed, have pervaded community consciousness. Australians have been among the earliest in the world to adopt new CTs over many decades (television, VCRs, faxes, mobile phones) (Innovate Australia 1995a, information package), often without conscious examination of their future impact. Where individual technology developments are concerned, it could be argued that examination of marketplace uptake is evidence enough of their usefulness and judged worth to society. However, when the CTs are described and combined in one volume, such as here, and the compounding effects of one on the other considered, it is obvious the political consequences may well be more far-reaching than a simple question of which CTs are used in campaigning. The communication and information revolution is long-term in its effects, increasing in its impact and growing more diverse in its pervasive reach throughout society. 
We draw on history when considering 'revolutions' for a basis of comparison. The industrial revolution, however, was different in kind and scope to the CT revolution. Then, machine power replaced human and animal power as the main force of industry, commerce ceased being local and became state-wide or even interstate between the 'advanced' countries, and nations rose or fell on the basis of how well they adapted to change. Nation states used their new-found power to redress old grievances and claim, or reclaim, territory; wars were, if not a direct result of technology change, a concomitant outcome. Yet the industrial revolution fundamentally involved mainly machines, not minds. This unfolding CT revolution embraces information, knowledge, thought and perhaps even reality - 'virtual reality' is no longer only a science fiction term. Politically, the new CTs offer the chance to re-define and re-create how democracy will be lived in the 21st century. For the first time, it is practical to conceive - if not yet practical to achieve - a plebiscite of all human kind, electronically.

These are long-term issues. An immediate challenge for Australia lies in adapting CTs to provide optimum benefit for the functioning of democracy. This thesis has looked to the US experience for lessons on both the problems and the positive potential. While there have been substantial developments in the European Community in political strategic campaigning, and in the use by the European parliaments of CTs (Hjortdal, 1991, 134), it is to the US that Australian machine people from both major parties have looked for practical experience. However, the differences between the Australian and US political environments are significant. Although both positive and negative aspects of the effects of application of the new CTs can be observed in the US, it is not valid to assume that the influence operates identically here. In Australia compulsory voting, the different operation of the party systems, the more stringent requirements to disclose campaign finances and public funding, as well as a particular cultural ethos, combine to create a distinctive environment. However there are enough similarities in actual and potential application of CTs to make judgements on preferred directions to take the opportunities and avoid the pitfalls. 
As outlined in chapter two, the information needs of MPs have been researched by a small group of academics but those of citizens have received scant attention. The relationship between people and CTs in political interaction has not attracted the research attention it warrants. Because of the pivotal role that CTs can play and are playing, through direct mail data bases, Computer Assisted Telephone Interviews (CATI), mobile phones, and email as well as the Extended Parliamentary Network, it was surprising to discover how little academic research attention has been given in Australia to the impact of the new CTs on political processes. This absence gave added impetus to this thesis. However, because the issue is very important for Australian democracy, it is hoped it will not prove such an isolated experience for future researchers.

Some comments on the limits of this work are appropriate. The survey research was as comprehensive as possible within resource constraints. It was not possible to cover all the extraordinarily diverse aspects of this topic, which provides many further promising areas for research. The currency of the subject has meant almost daily media reporting of important issues relevant to the thesis - I should record here that the cut-off point for new material was December 15 1995, apart from the odd postscript.

Further, and ironically, I found the most current information on inquiries and projects using the new CTs was not retrieved from electronic data bases but by word of mouth from interviews with librarians, politicians, academics, public servants, journalists and party machine people. The field is changing so fast that much information is not yet even 'in the ether'.

The use of direct mail and representatives' use of CTs were taken as practical examples of the application of new CTs to politics that could be evaluated by surveying. The polling and marketing strategies employed by the major parties are harder to measure, intertwined as they are with various other factors, and detailed information is usually for 'insiders' only. However, interviews with key strategists revealed a pattern in the modern marketing of politics in Australia. To draw conclusions in this chapter, the 
research questions are addressed, then the answers are considered in the context of future policy making.

\section{Addressing the research questions}

- What is the influence of CTs on elected representatives' communication with citizens?

- What is the influence of CTs on citizens' participation in the democratic process?

As stated, the impact of the new CTs depends both on which CTs are under consideration and the context in which they are used. Certain aspects of CTs in certain applications are, to my mind, conducive to the optimum functioning of democracy, and some are not.

Looking first at research question one, which covers the marketing of politics during campaigns, as well as the routine MP contact with the constituency, the CTs of most note are those tracking through polling (CATI) and targeting through direct mail. In addition, the use of home pages and email are becoming important. The new CTs appear to be increasing the pace of centralising power to an elite who are the experts in the use of electronic media. As organisational power is more controlled, reliance on expensive advertising is resulting in increased costs; this in turn increases cynicism amongst the citizens, who perceive politics being controlled by monied interests, as US surveys illustrate (see chapter six). The Australian Electoral Study found that 36 percent of people thought that the federal government is run by a few big interests and 56 percent believed that the Federal government could be trusted only some of the time (Australian Electoral Study 1993, 90). These findings would appear to indicate a downward spiral for democracy.

Thus there seems to be significant potential problems if CTs continue to dominate political campaigning. The disillusionment of ordinary party members, feeling ineffectual 
against the influence of high-tech, strategic marketing consultants, is also a very important negative influence for participation in a democracy. It affects involvement by the people who would otherwise have been most committed, as the report on the Wills by-election demonstrated (see chapter five). In any case, the apparently decreasing impact of direct mail may no longer justify its economic and administrative cost, certainly in terms of increasing the vote: in fact, it may be alienating the very swinging voters it aims to convince even while reinforcing a party's loosely-committed voters. 'There is some evidence that (the) pattern of (party) partisanship may be weakening, if only at the margins' (Jaensch 1994, 36). Further, the increasing numbers of voters deciding late how they will vote may reflect growing apathy and cynicism amongst some of these people, as they consistently rated a range of issues as less important than did stable voters (see Bean 1994b, 145). It is doubtful that the late deciders could be convinced by glossy pamphlets or personallyaddressed letters using direct mail data bases. The Fremantle evidence is that they were not.

The marketing of politics through direct mail has been most extensively studied in the US and my conclusion on its impact in that country (from their research findings) is generally negative, in that it uses emotion rather than factual debate, increases reliance on and obligation to contributors and encourages economic inefficiencies through subsidies and log-rolling. Interest groups alert their members of the importance of a particular issue, and the members then lobby their representative to take a course of action. Direct mail also has the effect of taking issues out of the scrutiny of the public arena. It employs direct contact between the candidate and the voter and, as it is dispersed throughout an electorate, it is not subjected to evaluation or criticism by commentators, except by accidental discovery or publicity via a disgruntled voter (as with push polling). On some occasions, as Fremantle showed, it had the effect of opening up dialogue between the MP and the constituent, though it is doubtful whether direct mail has really improved on traditional methods of electorate contact. 
Summarising the findings of the direct mail surveys, in the particular instance of the Fremantle by-election, direct mail was not effective. It did reinforce the strong party identifiers, but did not influence the floating voters who appeared to be less interested than the party identifiers in hearing from their MP or candidate. Comparison of the attitudes of MPs and machine people revealed that, while the latter were interested solely in gaining votes by direct mail, the MPs interviewed appeared to be genuinely attempting to improve communications with their constituents. In this context, the widely reported public cynicism towards politicians seems a little unjust, though these MPs in the sample were high achievers, in that they achieved better swings or resisted adverse swings better than their party's average.

Further, significant differences between the views of the voters, the MPs and the party machine people seem to indicate that judging the impact of this particular application of CTs is highly subjective. While information held on the data bases of voters' individual characteristics and concerns is more comprehensive in the US, it appears that Australians may be more sceptical than US voters about personal letters. Also, while the potential of 'personal' letters to enable more communication between MPs and electors exists, this result has not in general been realised. The significant danger of targeting excessively is evident in the US experience, where the vital swinging voter is very closely identified and sectors deemed to be unproductive in terms of votes receive little or no information from the candidate.

The almost technological determinism which sees citizens as consumers in the marketplace and information as a commodity is reflected in the political arena. Politics here is a subset of a wider phenomenon which is influencing the whole society. Economic rationalism and public choice theories, which are generally assumed to be the natural province of the conservative parties, have been enthusiastically embraced by Labor governments. When information is regarded as a commodity and commercialin-confidence factors are applied, such strictures are counterproductive to information being available to policy planners, as such 'resources' are jealously guarded. 
In summary, I judge that the impact of using the new CTs during political campaigning to increasingly introduce commercial marketing techniques has, on balance, been counter-productive to the democratic process, in terms of trust in the political system, rational political discussion and belief that the individual citizen can have an influence. Outside campaign periods, Australia's elected representatives have yet to use the more sophisticated CTs at their disposal to make any meaningful difference in their communication with citizens. As the negative points are apparent, it is appropriate to evaluate how the new CTs can be used to advantage. 'Now is the time to raise fundamental questions about how a democracy may best profit from the marvels of electronic communication' (Abramson, Arterton and Orren 1988, 295).

Turning to the second research question, which covers peoples' participation, experiments with Electronic Town Meetings have demonstrated the potential to increase involvement in the US, as have projects like PEN (the Public Electronic Network). Bonchek has shown that interest groups can harness CTs to reduce their organisational costs, facilitate group formation, efficiency, member recruitment and retention and thus assist collective political action. However, inequalities in computer literacy and network access led to a partiality in political representation towards young, male, educated and affluent citizens. The new CTs could be used to speed up democracy, with instant plebiscites, or they could be used to educate, deliberate on and debate issues, increasing participation and decreasing currently cynical attitudes as citizens become more involved in making the decisions that affect their lives. In reality, virtually none of these things has yet happened in Australia - and the active use of the new CTs by grassroots organisations is minimal. While holding the potential in theory of increased participation in the democratic processes:

In practice, non-profit, civic uses of computer and video power are dwarfed by the commercial market in electronic information services...This gap between civic and commercial access to the new media, between candidate use 
and citizen use, is a vexing problem for democracy in the new electronic age (Ward 1995, xii).

Ward made the point that the manufacturers/marketers of the new CTs are not acting altruistically. It is the unplanned use to which the new CTs are put which has enabled people to play a more involved role, as teledemocracy projects described in chapter seven demonstrate:

For the new technologies which are the hallmark of the emerging information society in Australia and elsewhere have not been introduced with the aim of empowering ordinary citizens. The 'mass consumerisation' of high-tech information hardware and services is primarily driven by the global marketing strategies of a relatively few large transnational corporations. It is clearly not being motivated by citizens demanding 'teledemocracy' (Ward 1995, 288).

The new CTs encompass the possibility for both use and abuse. 'If electronic town meetings and computerised plebiscites have the potential to encourage widespread, informed political participation, then they also have the capacity unobtrusively to collect information from, and about, citizens taking part in them' (Ward 1995, 301). This issue of privacy is a crucial one and protection of civil liberties fundamental in considering the introduction of new CTs, as discussed in chapter two.

\section{Addressing the two assertions:}

\section{Direct mail works! Technology can save democracy}

Direct mail, in the Fremantle by election circumstance, worked in a way other than that of the party machine people's expectations. It reinforced existing party affiliation but apparently had little influence on floating voters, its primary target. The wholehearted adoption of direct mail by the party machines appears to be as 
related to expanding central control as to any other issue. On the evidence, it is questionable that direct mail is worth the cost and effort, and it seems that its negative potential is considerable.

Whether technology can save democracy is also problematic. Technology has been demonstrated in the US to have been a useful tool in increasing (a very limited number of) people's participation in the political process - but again, the most definitive study showed that it is people's perceptions and mindsets which are more influential than the technology used (see Arterton, chapter six).

\section{The influence of CTs on political interaction in future}

The increasingly sophisticated tools at the disposal of the MP may improve communication with electors, if the MP uses them adroitly. With small margins in voting between success and defeat, it still appears that attention to the electorate through personal communication will remain an important aspect. The positive reaction of voters of Fremantle to have 'Coffee with Carmen' is an example.

Contrary to the conventional wisdom, research has shown the importance of the personal vote, the potential effect being up to three percent (see Bean 1990). 'The personal vote is a significant factor in federal lower house elections, even when numerous other variables known to influence voting behaviour are controlled for' (Bean 1990, 253). While the influence is less pronounced in marginal seats (Bean 1990, 268), even a percentage point often determines the election outcome. Such a finding may have important repercussions for the localised campaign using direct mail, used wisely.

The influence to date in Australia, as far as positively engaging citizens in political discourse, has been minor. But the US experience demonstrates the potential, and the recentlyannounced (late 1995) Australia Consults program may provide an avenue. However, as stated, the new CTs appear to have been 
detrimental to people's participation because CTs have been taken over mostly by the political marketeers. This factor has not to date been counter-balanced by increased involvement and participation by citizens through electronic means in Australia.

It is useful to look at different areas in which CTs may be influential in political communication: that is, broadly under two headings of political organisation, and impact on people. In chapter one, I outlined the present situation in regard to these areas of concern. Here, I take the 'courageous' (in Yes, Minister terms) step of predicting what the impact may be in future.

\section{Organisational terms}

In organisational terms, the new technologies will continue to encourage centralisation by parties in order to achieve economies of scale and control, because this is inherent in the nature of the operation of new CTs. Central control is necessary to run a modern 'mistake-free' election campaign with strategic advertising making uniform the colours, slogans and messages, consistent with a theme. The parties take up a corporate image, as in the commercial world, with marketing strategies modelled on private enterprise and driven by market research. Despite the tendency above, the ability to devise and run national campaign strategies appears to have been more competently achieved to date by the Labor Party than by the Liberals, who are traditionally more inclined towards autonomy in state divisions. However, analysis of the 1996 federal election result appears to show the Coalition regained an advantage in strategic campaigning (Williams 1996), principally by stringent centralised control.

Campaigning techniques will continue to be heavily influenced by trends in the US. As chapter five on the 1993 Australian election demonstrated, small teams of key people work directly with the party advertising agency and other 'insiders' to organise and direct campaigns. Party officials are used to implement the decisions reached by this team, rather than having influence in directional terms (see the Young Inquiry report, 1995). As for branch members (as the Wills by-election report, 1992, pointed 
out), even when invited they are reluctant to participate, and appear to be becoming more reluctant. This tendency will be exacerbated unless the major parties take positive steps to involve existing members more closely and seek new constituents. Key campaigners will continue to use faxes, modems and mobile telephones to integrate and co-ordinate campaign activities. Major parties already have their Web home pages.

The overwhelming result of the dominance of television advertising has been to limit debate because visual images, often with few or no words, are not answerable in rational terms. It is probable that the dominating trend of advertising will continue because of its ability to mould emotions...the most vivid example being the US anti-Goldwater advertisements, with daisy petals being picked off by a child, counting, before the screen erupts with the image of a nuclear explosion (Adams 1994, 46). The 1993 and 1996 Australian federal election campaigns saw similar (though not as extreme) advertisements run by both parties, instilling fear and distrust. The negative nature of television advertisements will continue to be well suited to that medium, particularly when a change of government in Australia is portrayed principally in terms of a choice between two leaders. In the same style as television, the increasing use of glossy pamphlet-letters in direct mail also follows the US example, but the effect of them is questionable, certainly in light of the Fremantle survey results.

In the case of surveying, CATI technologies enable frequent public opinion polling which will remain very influential in determining campaign programs. Focus groups are used for qualitative assessment of strategies. The 1993 election campaign saw extensive use of polling by both parties, though the implications of the findings were not always recognised. As stated earlier, information per se is useless - it is the way in which the machine men or others interpret and apply the information which is significant. Private polling and research may tap the mood of the electorate at any particular time, yet there appear to be large discrepancies in how the survey results are interpreted. The comment by Mark Textor, Liberal pollster/strategist, that at no time did their research show the Liberals winning crucial 
marginal seats during the 1993 election campaign stands in contradiction to ALP survey findings. So the actual success of continuous polling - and direct mail based on it - would seem to be called into question as far as consistency is concerned. The particular characteristics of marginal electorates, which defy nation-wide polling interpretations, may provide some of the reason for this. As polling is expensive, both parties are reluctant to divulge survey results, reflecting the concept of information as a commodity and, in political terms, as a strategic asset.

Tracking of public opinion by polling and focus groups gives the parties what they perceive to be a better indication of electorate concerns. However, there is a deal of evidence which indicates that the answer depends on the question and the danger arises of party policy being entirely poll led, where a party or both major parties) stakes out the middle ground. This leaves the margins open to new and, in many cases, single-issue groupings to emerge and have disproportionate influence (such as the gun lobby in the US and very recently - from May 1996 - in Australia). In addition, the dominance of opinion polling on community attitudes may lead individual citizens to believe they could have no influence in the face of majority opinion.

In funding terms, the use of new CTs to market politics during campaigning will continue to be extremely expensive. There is public funding for election campaigns for the major parties and the postage allowance makes widespread direct mail campaigns possible for sitting Members, but it does not cover total costs. For the incumbent government, use of education campaigns to publicise government programs with public money outside election periods gives an additional advantage. Both legal and illegal 'slush' funds have been set up, as recent state-based inquiries and court cases have demonstrated (the Fitzgerald Inquiry into Corruption in Queensland and the WA Inc. Inquiry in Western Australia). However, both major parties are currently in debt and fund raising has become a priority. As discussed, there seems to be little critical analysis by political parties of the actual cost-benefit of some expensive campaigning techniques. In the US, the perception that campaign contributors unduly 
influence political outcomes has increased voter dissatisfaction. The need to rely on political contributions arises directly from the increasing cost of campaigning with the new CTs.

In terms of media coverage, the trend to simplify complex issues is likely to continue, and follow the US style of emphasis on personalities. The concentration on the proposed Goods and Services Tax (GST), using emotive television advertising, kept the issue to the forefront of the debate and may have influenced a close election result in 1993. The televised debates added to the air of theatre as the leaders performed and the reaction of swinging voters was monitored by the electronic 'worm'.

In one circumstance, the technique of the old-fashioned blockade was used, and extensively covered by television news. The huge loggers' demonstration in Canberra in 1995 blocked traffic access with their trucks and forced the MPs, including the Prime Minister, to walk the remaining distance to Parliament House. This allowed an excellent opportunity for the demonstrators and journalists to question them face-to-face, as in traditional political campaigning. A reason for the success of this demonstration, coordinated by mobile phones, may have been its unusual nature. Forest workers have not been prone to demonstrating, so their presence had more impact, like a traditional town hall meeting, as suggested by Robin Loydell of the Forest Protection Society (see interview).

\section{Impact on people}

In terms of impact on people, Australians are very adaptable, as is clear from uptake rates of new CTs, and will continue to use those CTs they find useful - both representatives and citizens. It appears that younger people will continue to be more computer literate and comfortable with CTs, provided they can afford them. As the BTCE found, predictions on the uptake of services provided by cable are particularly precarious. Any changes in media ownership regulations towards increased 'liberalising' of operations (particularly the cross-ownership rules) and the 
proposed sale of the public telecommunications company will both be issues pertinent to future political communication.

Therefore, in terms of costs and access, it has been strongly argued that equity demands public access to the information superhighway through the public library system (as finally accepted by the Labor government at the end of 1995). For the future, the extent of the current Coalition government's commitment to this principle will be crucial. The ASTEC Report Surf's Up, discussed in chapter seven, identified the cost of new CTs as a critical factor in the impact they will have on the community. The dream of every Australian household politically participating through interactive home computers is, for the foreseeable future, not feasible. Cost, capability to operate new CTs, time and interest preclude all but the wealthy and the technological elite from playing. Two-way cable and videotex promised to overcome the imbalance in access to CTs and provide citizens with an avenue to communicate with their elected representatives. However:

No promise of the new media remains more unfulfilled than the arrival of interactive television. Marketwise, twoway cable programming has been a dud (Abramson, Arterton and Orren 1988, 292).

In the US, cable now has little political content and participation is in quiz shows. However, with proper planning, cable could provide improved access to the policy-making processes of federal, state and local government, as does the C-SPAN channel (Snider 1994, 15).

In terms of the use of CTs in the consultative process, I believe that even the GST could have been explained and even possibly made acceptable to citizens in the 1993 campaign if the whole issue had been handled like the Conversation in Oregon by Gov. Barbara Roberts (see chapter six). The Conversation was an excellent example of citizens participating in discussions of the complexity of many policy decisions and of using the new CTs to facilitate discussion. In that case, the voters accepted increased 
taxes on condition the state showed fiscal restraint. However in the face of increased alienation, society may become so fragmented that faith in the system may be lost and success in finding agreed-upon common interest disappear.

In terms of the nature of political interaction, the US experience demonstrates both the problems and the positive possibilities. The generally negative impact of direct marketing of politics can be balanced by its potential to facilitate participation, as the teledemocracy projects demonstrate. It is interesting that the same disillusionment with the democratic processes as in Australia has led to similar suggested solutions. In both nations, increased education in civics is urged, as is the development of policies for national information infrastructures.

The current atmosphere of antipathy can be overcome if electors perceive that it is in their interest to participate. As the CEG in Australia and the Main Street USA surveys have shown, many people are in fact engaged in civic activity but it is not perceived to be political. Ignorance of the political system would seem to indicate that politics and civics are not thought to be relevant or important. Citizens feel alienated from the democratic process and the continual cynicism of the media reinforces this disaffection (see Jamieson, chapter seven).

Political systems as dynamic organisations need to find solutions to such problems. The negative public attitude to things political is detrimental to the functioning of democracy and conducive to an alternative of 'potential tyranny', as the CEG identified.

In considering the role of citizen involvement, debates for and against the use of CTs to increase participation often include discussion of direct democracy through electronic town meetings (ETMs). These arguments are similar to those used for and against Citizens Initiated Referenda (CIR). In favour, ETMs can allow fuller informed debate of the issues, linking people in dialogue. However, if insufficient time is given for deliberation, decisions may be made with inadequate information and consideration. Advocates say public judgement should be trusted 
on broad policy issues - critics maintain that the public does not have sufficient knowledge of issues to make proper decisions. Some arguments for ETMs are simplistic because they assume only one 'public view' and take no account of conflicts and shades of interests. Critics say that unpopular decisions have often to be made in the interests of the longer-term, greater community good. Monied interests can run disinformation campaigns, which can influence the outcome of plebiscites, as has been the case with referenda in the US, and majority views can discriminate against minorities. The consensus from the US seems to be that direct democracy should be used to supplement representative democracy, not replace it.

The proposals to introduce CIR represent an substantial change in the operation of democracy, and the advantages and disadvantages have been covered in the previous chapter. To extend the parameters of the CIR debate and perhaps make the proposal a little more acceptable to the sceptics, American commentator Benjamin Barber made the suggestion that, rather than a black and white yes/no alternative, it is important to allow people to respond in shades of grey. For example, on the contentious abortion issue, the alternatives offered may be graduated to incorporate shades of opinion - from strong support, through conditional support to degrees of opposition to total opposition (Barber 1984, 286).

While the wording can be debated, this approach to complex and emotive social policy issues would appear rational. However it may be that, on such issues, there can never be compromise between diametrically-opposed positions.

Referring to the economic rationalist approach, the yes/no alternatives are typical of market-style decisions which assume people will maximise things they value, whereas the multi-choice alternative is typical of political interactions, which require flexibility and subtlety. Analysing whether the concept of CIR could be incorporated into the Australian democratic system, one commentator concluded it has a number of valuable aspects. However, to control the influence of monied interests, he 
recommended '...stringent and strictly enforced financial disclosure laws...' (Major 1994, 75) to prevent some of the excesses apparent in the US.

CIR again raises the central philosophical question of representative or direct democracy discussed in chapter one. The answer really depends upon the perspective of the individual whether a belief is held that people can be trusted to participate in decisions which affect them. If such trust exists, then new CTs can be used to increase participation.

In reality, the optimum course lies between the two extremes, as the American academic, Thomas E. Cronin, identified. His 'sensible democracy' could realise the best attributes of both models and would retain the representative model, with elected officials making the vast majority of the laws and protecting minority rights. Referenda would be used on important public policy issues, after lengthy public discussion, and increased accountability for funding would reduce the influence of special interest groups (Cronin 1989, 249-250).

In terms of the role of interest groups as a medium of empowering individual citizens through use of CTs, this hypothesis was not supported by the interviews of peak bodies and the smaller interest groups in Australia. Even major and relatively affluent bodies (like the $\mathrm{BCA}$ ) have to date been cautious in adopting technologies such as Internet connection and a home page, while the smaller ones find the cost prohibitive. So, despite the existence of interest groups to give citizens a louder voice, evidence appears to show that asymmetry between the citizens and MPs in the use of CTs in political communication will continue to be significant in future.

\section{How could the new CTs be used more constructively?}

Given the two research findings, what are the essential elements to create an optimum process for adopting and adapting the new CTs to the common-weal in Australia? If, as I contend, the two- 
way political intercommunication between parliamentarians and citizens is made more asymmetrical by the present application of CTs, what could be done, in an ideal situation, to redress this imbalance?

The questions can be answered conditionally: the new CTs can be conducive to greater participation in Australia if their adoption and use goes hand-in-hand with:

- a National Information Policy which incorporates public access to networks for the potentially information-poor;

- $\quad$ general education in civics using CTs, as recommended by CEG; and

- forums for public discussion, as provided in Australia Consults

Thus, in my view, while the use of CTs in marketing politics has to date impacted negatively, the potential to use CTs to increase participation, within the confines of representative democracy, is positive. Almost by serendipity, the latter two of these necessary pre-conditions appear to be falling into place, while stumbling attempts have been made in implementing the first.

\section{A National Information Policy}

The most crucial element in determining the ultimate impact of new CTs for the good of a democracy must be the question of access and equity. Many of the reports cited in chapter seven have a common theme - that the interests of democracy require that all citizens who want to are able to take advantage of the new CTs. This involves not just a question of economic cost being considered, but also capability of people to recognise and utilise the opportunities. It is of no value to the citizen, even if access points to the superhighway are available at no cost through the local library, if the person does not have the time, interest or knowledge to use the information. Many of the reports also outline the need for education to ensure social justice. 
Boyer lecturer Kerry Stokes advocated a statutory authority, with strict accountability to parliament, to control use of the superhighway to ensure independence from all vested interests. It would protect the wider community interest, in that:

The regulatory authority I am proposing would put the national interest first and would allocate lanes or carrier space on this highway at prices and on terms that reflect the social and cultural interest of the nation. It is essential that capacity be reserved, for example, for educational services, community channels, special interest programs and foreign-language services. Whether free-to-air or pay, the same governing principle should apply: diversity before profit (Stokes 1994, 23).

Barry Jones MP has for many years urged the development of a national information policy (see chapter seven). These calls for recognition of the potentially crucial role of the new CTs on the democratic process have been largely unheeded. While the federal government's holding of the National Strategies Conference in November 1994 demonstrated cognisance of the need to plan nationally, there was no reference in its glossy documents or in speeches at any of the main sessions to the impact of the new CTs with regard to access and equity in a democracy. No recognition or attention was given to the impact of new CTs on the political process in any of the plenary sessions or relevant seminars.

A necessary precondition to CTs' facilitating political participation is that people have access to them, both to gain information and to communicate with other people. The only feasible way of achieving this is through a national approach, as the influence of the new CTs covers many departments and areas that have traditionally been discrete, if not disparate. An illustration is seen in the numerous investigations and reports which attempt to come to grips with the complex issues involved in the impact of the new CTs. Some elements of a national information policy should be to ensure all political candidates and interest groups have equal access to present their opinion in the political debate, 
where presently the major parties have over-riding advantage. The language used must be clear and comprehensible. Literacy in the new CTs should be actively encouraged, both in schools and in adult education. Individual privacy should be protected from threat of technology by nationwide privacy legislation. To achieve this, a co-ordinated approach is necessary, which can only come from the federal government. This requires that the policymakers depart in this instance from the economic rationalist philosophy, where market forces predominate, and intervene in a positive way to ensure access and equity to the new CTs.

The reports which have approached the issues from different perspectives, described in chapter seven, need to be drawn upon to create an overall comprehensive policy. The concern of the CEG at the level of ignorance, as well as apathy and cynicism, can be alleviated, if not overcome, by judicious use of the new CTs. Increased participation and involvement could gradually dispel the current distrust of things political which is potentially detrimental for Australian democracy. Governments call for submissions to departmental inquiries via the Internet network (and in other ways) but in fact access remains the province of an elite, mainly academics and federal and state public servants, who are able to reinforce their privileged positions virtually free of any cost (to date).

Hence the necessity for government intervention to provide public access points, at minimal or no charge, for it would be the ultimate irony if the government, by passive non-intervention, increased the wide divide between the information rich and poor. The use of public libraries, as advocated by Mark Latham MP, would appear to be the most logical first step - an initiative accepted by the then government (December 1995). The public perception of libraries is already conducive to this role, as an advocate pointed out:

Equality of access to information has become one of the most critical social justice issues of our time. The development of computerised information systems and on-line delivery of digitised data threatens to bolster an 
even greater division between the information rich and the information poor. Many libraries have already committed financial resources to developing systems that provide access to the Internet...but greater support is required if we are to ensure that all Australians have the opportunity to develop the information literacy skills that will enable them to fully participate in the working world of the immediate future (Walsh 1995b, 1).

The promise of increased public access to information faces problems of cost, privacy, data security and protection, lack of hardware and software for the public user, inconsistent data formats, a patchwork of pricing schemes and lack of expert knowledge to help the user. For these reasons, access through public libraries, with expert help on hand, seems to be the obvious solution to many of these difficulties. People do not seek information per se from government: they seek answers to solve practical problems and to take advantage of an opportunity or address a particular question. Whether electronic access fulfils its promise of better informing citizens depends on citizens' insisting that access is relevant and affordable. The greatest challenge of electronic democracy is the vast scope and scale of changes and the effect their interaction will have on the community. The most critical variable that will affect the ability to meet this challenge is whether the various levels and parts of government will coordinate activities to make electronic democracy - as well as electronic commerce - operate optimally.

Contrary to the argument that government should develop and manage an information policy, Australian economist Geoffrey Brennan pointed out that government's management in the past of IT has not been encouraging. There is a tendency for governments to suppress unpalatable information and in some cases to promote disinformation. For example, in the key area of granting media rights, the government's decision-making in the media ownership area is substantially politically driven in the expectation of a favourable press (Brennan 1994, interview). 
However, access to information through the new technologies becomes a social justice issue. Leaving the results of the information revolution to laissez-faire development and the market place will not ensure equity of access, which demands policy formation at a national level. Unfortunately, a coordinated approach has been lacking in Australia. Rather than acknowledging the inter-connected economic, social and political nature of the impacts of technology, the approaches of government departments have been fragmented. Each department has dealt largely with that aspect of technology which falls directly under its responsibility and which can benefit its operation, and inter-departmental committees are mainly concerned with preserving existing, public service interests - these dilemmas were apparent in the New Paradigms (Jones Committee) hearings. There appears to have been little interest in a co-ordinated, integrated policy focused on the community the department should serve.

The recent attempts to provide some government policy guidance in the commercial, research and scientific area (such as the Innovate Australia statement in December 1995) have been less than enthusiastically received by some CT commentators. The consensus of opinion is that it represents a technical standards approach (Jones 1996, interview; Fist 1996, interview). Again, and regardless of how well or badly the government's policy direction is perceived, commercial and technical compatibility of systems appear to have been the government's motivation for Innovate Australia. While important, these are not the fundamentals for a just society and there is a danger that the new Coalition government will continue to see the core issue of a national information policy primarily in economic terms.

The dangers for democracy are the exacerbation of the information rich/poor dichotomy, the replacement of pluralism by domination by a technocratic elite, ownership of the new media/CTs in few hands and information decisions becoming the province of the powerful, inside or (increasingly) outside government. When these dangers are added to the disenchantment of citizens, the ultimate mixture is potentially 
destructive to a government and to democracy. In addition, the reverse side of the coin to inadequate information being available to citizens is the danger of 'information blizzards'. Where previously there was a scarcity of information, now the opposite is potentially the case. A fully democratic society could produce information overload: '...the swamping of the citizens by a bewildering set of dials and electronic gadgets, scores of alternative radio and television programs, hundreds of magazines and journals, thousands of fliers, electronic leaflets and manuscripts and millions of books. There are indeed dangers...that citizens will become trapped in a never-ending blizzard of information, without adequate free time to digest or even make sense of the information flows which envelop them' (Keane 1991, 537).

\section{General Education in Civics - Whereas the People...}

Of all the relevant inquiries and initiatives, those by the Civics Expert Group and the Australia Day Council (ADC) are of particular relevance to this thesis. The CEG advocated civics education delivered through the school curricula and, to the wider community, through local government. The ADC took up the challenge through a program called Australia Consults, involving local government-based discussion and widespread reporting through the Internet.

The CEG was commissioned to provide a plan for a program of public education and information on the Australian government, citizenship and the constitution. The government believed an education program could strengthen democracy by enlivening an appreciation of it. 'It will inform all Australians of the privileges and responsibilities of Australian democracy and ensure that Australians have sufficient information about our system of government to participate fully in the decision-making process' (Keating, 1994, media release).

The title of the report, 'Whereas the People...' comprises the opening words of the Australian Constitution. The CEG was 
concerned that the diversity of Australian society has not been accompanied by an increase in civic virtues and a recognition of the value of citizenship. Significantly, an extensive quantitative poll commissioned by the CEG and conducted by ANOP found high levels of ignorance in the community of the structure and function of Australia's system of government, as discussed in chapter seven. The CEG identified the reason as the failure of the education system to provide basic information about the functioning of Australian democracy because the study of civics is no longer a formal part of the curriculum. In addition there is no inspirational declaration of nationhood, as in the American Declaration of Independence.

To deal with this situation, the CEG recommended education at both school and community levels. As they succinctly point out, many young Australians '...can list the islands of Japan and give you a detailed description of the building of the Pyramids. Few can tell you anything about Federation, or name six great Australians in the arts, science or politics' (Civics Expert Group Summary report, 1994, 13). Education in primary and secondary schools can be provided by making civics a compulsory part of the curriculum. The CEG recommended that courses for teachers should incorporate citizenship education. In regard to civics education for the wider community, the CEG recognised difficulties. The challenges are:

- to raise the community status of being an active and informed citizen and to promote participation and interest;

- $\quad$ to respond to this interest in a variety of appropriate ways and settings, recognising that there are various levels of interest as well as levels of understanding; and

- to stimulate discussion and involvement by means of appropriate resource materials

CEG 1994, 20).

The CEG recommended that interest in the centenary of Federation (2001) could be used to promote discussion of civics 
issues, through various clubs, school parent groups, church organisations, public libraries, heritage groups, historical societies and community organisations. The aim would be to generate lively discussions of immediate issues affecting the Australian system of democracy. Access to impartial and accurate information to form a basis for discussion was seen as essential. The CEG recommended the Constitutional Centenary Foundation develop and administer the program.

A further avenue suggested by the CEG for community citizenship education was a series of forums culminating in national awards. Local councils could invite people to participate in discussions of such topics as whether the powers of the state governments are appropriate, ways to streamline the justice system, whether Australia should become a republic and whether upper houses of parliaments should be abolished (CEG 1994, 22). Elected citizens could participate in similar discussions at a regional or state level, culminating in a national event with the presentation of a citizens' speaker of the year award.

The question of who would participate is a pertinent one in light of the possible domination by special interest groups. The CEG recommended that, after three months for public comment, a national forum be held electronically to discuss issues raised in the report on civics education.

\section{Australia Consults}

'You are invited to participate in a big conversation on the Australia Day weekend and have your say on the major issues facing our nation in the lead up to the Centenary of Federation. in 2001...It's about time we all spoke our minds about where we are headed as a nation. And through a unique consultation process, Australians have the opportunity to express their thoughts and ideas' (Australia Consults 1995, leaflet). 
As a response to part of the CEG recommendations, Australia's first project in community democracy aimed to discuss issues 'that will shape our nation' (National Australia Day Council 1995, information package on Australia Consults). It is a joint initiative of the National Australia Day Council and the Australian Local Government Association in co-operation with the Constitutional Centenary Foundation and is sponsored by Telstra. For those councils who do not have Internet access, schools and local libraries could be used. Local forums were hosted in town halls on the Australia Day long weekend in January 1996 and are planned for 1997 and 1998. The topics for discussion centred on three themes:

- celebrating the Centenary of Federation;

- the possibility of an Australian Republic; and

- $\quad$ reconciliation between indigenous and other Australians (National Australia Day Council 1995, information package).

The 1996 forum was concerned mainly with providing information as a basis for discussion. This non-partisan initiative presented the first opportunity for citizens to participate in discussions of key (chosen) topics by electronic means. The first series of forums, held on Australia Day 1996, resulted in 140 Councils registering (of the 700 members of the local government association). Forums were held in 80 Councils and Shires, which was deemed by organisers to be a satisfactory response for the first occasion (Singleton 1996, interview).

CTs were used in several important ways. Background papers were published on the Telstra home page, and the minutes of the forums have been entered on the Internet. The National Australia Day Council's home page has been used extensively, with 40,000 individual contacts over the Australia Day weekend in 1996 (National Australia Day Council 1996, 2). The themes which emerged from the forums covered the topics as described. Support and confidence were expressed in the underlying democratic principles which define the Australian political 
system, particularly freedom of speech. There was a wide range of views expressed on the possibility of an Australian Republic.

Community consultation was supported: 'Here was a clear indication that constitutional reform is about informed decisions and debate and not simply about referenda. Australians are keen to be involved in the whole process' (National Australia Day Council 1996, 3). However, concern was expressed that if the discursive processes were not undertaken adequately, there would be a risk of political instability.

On the topic of Aboriginal reconciliation, while many people agreed that there should be greater recognition of indigenous people, there was a belief expressed that programs which treat people specially are discriminatory (National Australia Day Council 1996, 4).

In summary, '...the one theme which flowed through all sections was a demand for more information and the support and enthusiasm for the consultative process. Australia Consults is positioned as an effective vehicle by which information regarding citizenship and civics can be disseminated' (National Australia Day Council 1996, 5).

However, it would appear that community participation will need to be more widespread if the dangers of domination by special interests are to be avoided. It will be interesting to observe whether the forums develop into representative assemblies for discussion and debate as well as education in civics, which the CEG envisaged, and how extensively they utilise the new CTs.

\section{Conclusion}

The fundamental dilemma underlying the two research questions is how democracy can benefit from the new CTs. Alternatives have been posed between 'instant' democracy by polls and plebiscites, or 'percolated' democracy with increased deliberation and discussion before decisions are taken. 'The choice between 
racing democracy and slowing democracy is ours. Only politics, not machines, can make the choice' (Abramson, Arterton and Orren 1988, 295). In analysing research data on the evidence of the effect of new CTs, value judgements come into play. It is important that consideration first be given to what the community wants to achieve through technologies. Then the most appropriate set of democratic institutions with which to harness CTs can be identified:

Merely applying technology and observing its effect will not suffice; nor can we hope to strengthen or safeguard democracy by standing by and allowing technological change to continue apace, unexamined and unfiltered by the values we hold dear. To do so would be to surrender our future to directions we may not now understand and might not accept if we did (Arterton 1983, 27).

In summary, there is an urgent need for leadership from the federal government in collaboration with active citizen participation. Access to information and the means to use it will in future be even more crucial than it is now - information itself is the 'currency' of the future. If the federal government does not take the leadership position and provide policy direction, the influence of money and magnates will pervade the community.

Future broadband services will be the network that holds the structure of society together, here in Australia and increasingly with links to other nations. For the government to leave the organisation of these services to private interests is to abandon the responsibility that goes with the perquisites of power.

In creating a policy, the fundamental premise must be that it advantages all citizens within a reasonable time frame, perhaps five to 10 years. That is, it makes Australia a more equal society and Australians have increasing equality of access to the benefits the new CTs can, or could, bring.

The national information policy should empower our 'lesser' citizens more than our 'greater'; on this basis, it would appear that 
a national information policy, coupled with at least equality of access to the new CTs, could hold some hope for our remote and rural populations - particularly Aborigines - to transcend time and space through technology for greater equality of opportunity in terms of future information and knowledge.

The national information policy of the government must also articulate clearly where we as a nation should aim to stand in the world community 10 or 15 years from now, what our 'national identity' will be, which will be decisively influenced by how effectively we utilise the new technological options of the future. To do this, a different type of leadership will be needed from that normally shown by politicians whose focus is mostly just beyond the next election, and a different type of communication service from our media people, whose future focus is typically one day or one week.

To return to the superhighway analogy, the government must provide a light on a hill overlooking the lanes to show the way, advisory (not constraining) signs and indicators to help Australians drive forward and, most importantly, a public transport lane so that the less information-rich can afford to ride. 


\section{BIBLIOGRAPHY}

\section{MONOGRAPHS}

Abramson, J. B., Arterton, C. F. and Orren, G. R., 1988, The Electronic Commonwealth: The Impact of New Media Technologies on Democratic Politics, Basic Books, Inc., New York.

Americans to Limit Congressional Terms, 1992, Kick the Bums Out! National Press Books, Washington DC.

Arterton, C. F., 1983, Teledemocracy: Can Technology Protect Democracy?, Vol.165, Sage Library of Social Research, Roosevelt Center for Policy Studies, Washington DC.

Bailey, S., 1835, The Rationale of Political Representation, R. Hunter, London.

Barber, B. R., 1984, Strong Democracy: Participatory Politics for a New Age, University of California Press, Berkeley.

-----, 1992, An Aristocracy for Everyone - The Politics of Education and the Future of America, Oxford University Press, New York.

Beniger, J. R., 1986, The Control Revolution: Technological and Economic Origins of the Information Society, Harvard University Press, Cambridge, Massachusetts.

Blainey, G., 1975, The Tyranny of Distance, How distance shaped Australia's History, Macmillan, Melbourne.

Bogart, L., 1972, Silent Politics: Polls and Awareness of Public Opinion, John Wiley, New York.

Bogdanor V, ed., 1991, Blackwell Encyclopedia of Political Science, Basil Blackwell, Oxford.

Briefs, U., 1991, Support of Parliamentary Decision Making by Computerized Information Systems in Clarke, R. and Cameron, J., Managing Information Technology's Organisational Impact, North Holland. Burke, J, 1985, The Day the Universe Changed, British Broadcasting Corporation,
London.

Cawson, A., 1994, Corporatism and Political Theory, Basil Blackwell, Oxford.

Crain, M. W. and Goff, B. L., 1988, Televised Legislatures: Political Information Technology and Public Choice, Kluwer Academic Publishers, US.

Cronin, T. E., 1989, Direct Democracy: The Politics of Initiative, Referendum and Recall, Harvard University Press, Cambridge, Massachusetts.

Dahl, R.A., 1956, Who Governs? Democracy and Power in an American City, Yale University Press, New Haven, US.

Dean, J., 1992, The Politics of Australia, Macmillan, South Melbourne.

Dionne, E.J. Jnr., 1991, Why Americans Hate Politics, Simon and Schuster, US.

-.----, 1996, They Only Look Dead: why progressives will dominate the next political era, Simon and Schuster, New York.

Downs, A., 1957, An Economic Theory of Democracy, Harper, New York. 
Elshtain, J.B., 1994, Democracy on Trial, Basic Books, New York.

Evans, G., 1982, Scrutiny of the executive by parliamentary committees, in Nethercote, J.R., Parliament and Bureaucracy, Hale and Iremonger, Sydney.

Godwin, K. R., 1988, One Billion Dollars of Influence: Direct Marketing of Politics, Chatham House Publishers Inc, New Jersey.

Jamison, K.H., 1992, Dirty Politics: Deception, Distraction and Democracy, Oxford University Press, New York.

Kedzie, C., 1995, International Implications for Global Democratization in Anderson, R.H., Bikson, T.K., Law, S.A. and Mitchell, B.M., Universal Access to E-Mail: Feasibility and Social Implications, RAND, Santa Monica.

Kelley, J., 1988, Political Ideology in Australia in Kelley, J., and Bean, C., Australian Attitudes, Allen and Unwin, Sydney.

King, S. S. and Cushman, D. P. (eds), 1992, Political Communication: Engineering Visions of Order in the Socialist World, State University of New York Press, Albany.

Laffin, M., 1989, Public policy making in Smith, R. and Watson, L., Politics in Australia, Allen and Unwin, Australia.

Lasch, C., 1995, The Revolt of the Elites and the Betrayal of Democracy, Norton and Co., New York.

Lasswell, H. D., 1971, Policy Problems of a Data-Rich Civilization in Westin, A. F., Information Technology in a Democracy, Harvard University Press, Cambridge,
Massachusetts.

Law, S.A. and Keltner, B., 1995, Civic Networks: Social Benefits of On-line Communitities, in Anderson, R.H., Bikson, T.K., Law, S.A. and Mitchell, B.M., Universal Access to E-Mail: Feasibility and Social Implications, RAND, Santa Monica.

Lemert, J.B., 1981, Does Mass Communication Change Public Opinion After All? Nelson-Hall, Chicago.

Lloyd, C., foreword in Cullen, P.,1991, No is not the answer, Lobbying for success, Allen and Unwin, Sydney.

Mathews, D., 1994, Politics for People: Finding a Responsible Public Voice, University of Illinois Press, Chicago.

McAllister, I., 1992, Political Behaviour: Citizens, Parties and Elites in Australia, Longman Cheshire, Melbourne.

Mills, Stephen, 1986, The New Machine Men: Polls and Persuasion in Australian Politics, Penguin, Australia. Mundo, P. A., 1992, Interest Groups: Cases and Characteristics, Nelson Hall Inc.,
Chicago, Illinois.

Munro-Clark, M., (ed), 1992, Citizen participation in Government, Hale and Iremonger, Sydney.

National Research Council, 1994, Realising the Information Future, National Academy Press, Washington DC. Nelkin, D., 1977, Technological Decisions and Democracy, Sage Publications,
Beverley Hills. 

O'Shaughnessy, N. J., 1990, The Phenomenon of Political Marketing, Macmillan,
London.

Painter, M., 1992, Participation and Power in Munro-Clark, M., (ed.), Citizen Participation in Government, Hale and Iremonger, Sydney.

Pateman, C., 1970, Participation and Democratic Theory, Cambridge at the University Press, London.

Patterson, T.E., 1993, Out of Order, Alfred A. Knopf, New York.

Petracca, M. P., 1992, The Politics of Interest Groups Transformed, Westview Press, Boulder, US.

Phillips, K., 1993, Boiling Point in the Democratic Republic and the Decrease of Middle-Class Prosperity, Random House, New York.

Pitkin, H.F., 1967, The Concept of Representation, University of California Press, Berkeley.

Pool, I.d.S., 1983, Technologies of Freedom, Belknap Press, Boston.

Popkin, S.L., 1991, The Reasoning Voter: Communication and Persuasion in Presidential Campaigns, University of Chicago Press, Chicago and London.

Porter, A.L., Rossini, F.A. and Carpenter, S.R., 1980, A Guidebook for Technological Assessment and Impact Analysis, New Holland Publications, New
York.

Putnam, R.D., 1993, Making Democracy Work: Civic Traditions in Modern Italy, Princeton University Press, New Jersey.

Ranney, A., 1971, The Governing of Men (3rd edition), Holt, Rinehart and Winston Inc., New York.

Richardson, G., 1995, Whatever It Takes, Batman, Victoria. Schumpeter, J.A., 1943, Capitalism, Socialism and Democracy, Allen and Unwin,
London.

Sekuless, P., 1991, Lobbying Canberra in the Nineties, Allen and Unwin, Australia.

Shubik, M., 1971, Information, Rationality and Free Choice in a Future Democratic Society in Lamberton, D.M. (ed) Economics of information and knowledge, Penguin Books, Middlesex, England.

Shulman, A.D., Penman, R. and Sless, D., 1990, Putting information technology in its place: Organisational communication and the human infrastructure in Carrol, $\mathrm{J}$. ed., Applied Social Psychology and Organisational Settings, Laurence Evlbaum, Hillsdale, New Jersey.

Solomon, D., 1986, The People's Palace: Parliament in Modern Australia, Melbourne University Press, Victoria.

Sowell, T., 1980, Knowledge and Decisions, Basic Books Inc., New York.

Tiffen, R., 1989, News and Power, Allen and Unwin, Sydney.

Walker, G. de Q., 1992, Participation by Initiative and Referendum: Could it Work in Australia? in Munro-Clark, M., Citizen Participation in Government, Hale and Iremonger, Sydney. 
Ward, I. V, 1994, Media Intrusion, Centralisation and the Changing Nature of Established Parties in Canada and Australia in Shamon, C (ed.), Parties and Federalism in Australia and Canada, Federalism Research Centre, The Australian National University, Canberra.

------, 1995, Politics of the Media, Macmillan Education Australia, Victoria.

Warhurst, J., 1991, Campaign Communication in Australian Elections in Fletcher, F. (ed) Media, Elections and Democracy, Dundurn Press.

Weller, P. and Grattan, M., 1981, Can Ministers Cope? Australian Federal Ministers at Work, Hutchinson, Australia.

Westin, A.F. (ed), 1971, Information Technology in a Democracy, Harvard University Press, Cambridge, Massachusetts.

\section{JOURNALS}

Bean, C., 1990, The Personal Vote in Australian Federal Elections, Political Studies 1990, Vol. 38, Pp. 253-268.

the 1990s, 1994a, Introduction: The 1993 Election and Australian Electoral Studies in the 1990s, Australian Journal of Political Science, Vol. 29, Special Issue, Pp. 1-9.

Vol. 29 , Special Issue, Pp. 134-157.
. 1954, Australian Journal of Political Science,

Becker, T.,1981, Teledemocracy, The Futurist, December, Pp. 6-9.

,---- 1993, Teledemocracy: Gathering Momentum in State and Local Governance,
Spectrum, Vol. 66 No. 2, Spring 1993, Pp. 14-20.

Benton Foundation, 1995, Telecommunications and Democracy, Communications
Policy Briefing $\# 4,1$.

Braman, S., 1989, Defining information, Telecommunications Policy, September,
Pp. 233-242.

Connections 1993, Internet leads NIF into Digital Data Revolution, Vol. 5, Issue 2 ,
Winter, P.8. Dervin, B., 1994, Information - Democracy, Journal of American Society for
Information Science, Vol 45 No 6, Pp. 369-385.

Doctor, R. D., 1991, Information Technologies and Social Equity: Confronting the Revolution, The Journal of the American Society for Information Science, 42 (3)
Pp. 216-228.

Downing, D.H.,1989, Computers and Political Change: PeaceNet and Public Access Data Access, Journal of Communication 39(3), Summer, Pp. 154-162. Etzioni, A., 1992, Teledemocracy, Atlantic Monthly, Vol. 270, October, Pp 34-35,
38-39.

Gans, C.,1993, Television: Political Participation's Enemy, Spectrum, Spring, Pp.
26-30.

Ganz, M., 1994, Voters at the Crosshairs, The American Perspective, No 16,
Winter, Pp. 100-109.

Henderson, R., 1995, Cyberdemocracy, Reason Vol. 26, April, 1995, Pp. 43-46. 
Inman, R. P.,1987, Markets, Governments and the 'New' Political Economy in Auerbach, A. J. and Feldstein, M., Handbook of Public Economics Vol. 2, North Holland, US.

Jupp, J., and Sawer, M., 1994, Building Coalitions: The Australian Labor Party and the 1993 General Election, Australian Journal of Political Science Vol. 29, Special Issue 1993 Federal Election, Pp. 10-27.

Keane, J., 1991, Democracy and the Media, International Social Science Journal, 129, Pp.523-540.

Klein, R., 1972, Growth and Its Enemies, Commentary, Vol. 53, No. 6, June, Pp.
44 . Klugman, R.E., 1993, The Role of the Backbencher, The Sydney Papers, Spring,
Pp. 73-80.

Lievrouw, L. A., 1994, Information Resources and Democracy: Understanding the Paradox, Journal of the American Society for Information Science, Vol. 45, No. 6, Pp. 350-357.

London, S., 1995, Interpersonal Computing and Technology: An Electronic Journal for the 21st. Century, Vol. 3, No. 2, April, Pp. 33-55 (accessed through
Netscape Excite)

McCurry, M., 1989, The New Electronic Politics, Campaigns and Elections, Vol. 9,
March/April, Media Watch 1993, The Press Gallery and the 1993 Election, No. 15, January-
March, Pp.3-11.

Murdock, G. and Golding, P., 1989, Information Poverty and Political Inequality: Citizenship in an Age of Privatised Communications, Journal of Communication 39
(3), Summer, Pp. 180-195.

O'Connor, S., 1994, Access to Information on the Superhighway, Australian Academic and Research Libraries, Vol. 25, No 3, September, Pp. 159-161.

Ornstein, N. J. and Elder, S., 1978, Interest Groups, Lobbying and Policy Making, Congressional Quarterly Press, US.

Press, US.

Perry, J. M., 1992, Expect Candidates of the Future to Tap 'Teledemocracy' and the 'New Media', The Wall Street Journal, November 4, P. A16.

Rogers, E., Collins-Jarvis, L. and Schimtz, J., 1994, The PEN Project in Santa Monica: Interactive Communication, Equality, and Political Action, Journal of the American Society for Information Science (JÁSIS), Vol. 45, No. 6. July, Pp 401 -
410 .

Schudson, M., 1992, The Limits of Teledemocracy, American Prospect, No. 11,
Fall, Pp. 41-52. Shoebridge, N., The ultimate one-day sale, Business Review Weekly, March 19, P.
26 .

Snider, J. H., 1994, Democracy On-Line, The Futurist, September-October, Pp. Stanley, H. W. and Niemi, R. G., 1994, Vital statistics in American Politics, 4th
edition, Congressional Quarterly Inc., USA. 
The House Magazine,1995, Push Pulling (sic) Under Review, June 21, P. 19.

Turner, B. S., 1995, Rorty Rights and Relativism in Citizenship and Human Rights,
Forum, No 2, P.4.

Vromen, A., 1995, Paul Keating is the Prime Minister, but Who Delivers the Mail? A Study of Political Knowledge Amongst Young People, The Australian Journal of Political Science, Vol. 30, Pp. 74-90.

Walsh, V., 1995a, Direct Line in InCite, Vol 16, No.8, August, P.11.

Ward, I., 1991, Making Television News: Political Journalists and Politicians At Work, Media Information Australia, No. 61, August, Pp. 54-62. Warhurst, J., 1990, Political lobbying in Australia, Corruption and Reform 5: Pp.
173-187.

Young, E.L., 1990, The Information Right, Bulletin of the American Society for Information Science, Vol. 16, No. 4, Pp. 21-28.

\section{GOVERNMENT REPORTS}

Adams, P., 1994, What's wrong with election advertising? in Australian Electoral Commission: The People's Say: Elections in Australia, Australian Government Publishing Service, Canberra.

Australian Bureau of Statistics, 1994, Cultural Trends in Australia, No. 1: A Statistical Overview, ABS Catalogue No. 4172.0, produced in conjunction with Department of Communication and the Arts, Commonwealth of Australia, Canberra.

Catalogue No. 8128.0, ABS, Canberra. Australian Electoral Commission, 1995, Election Funding and Financial Disclosure Report, Election 1993, Australian Government Publishing Service, Canberra.

Australian Science and Technology Council, 1994, The Networked Nation, Australian Government Publishing Service, Canberra.

Future 1995, Surf's Up: Alternative Futures for Full Service Networks in Australia, Future Needs 2010, Australian Government Publishing Service, Canberra.

Bean, C., 1995, From party to presidential campaigns? in The People's Say, Australian Electoral Commission, Canberra, Pp. 43-45. Broadband Services Expert Group 1994a, Networking Australia's Future, Interim
Report, Internal document, July.

Publishing Service, Canberra.
Pustralia's Future, Final Report, Australian Government

Bureau of Transport and Communication Economics, 1994a, Costing New Residential Networks, Communications Futures Project, Work-in-Progress Paper
No. 5, BTCE Module 7, BTCE, Canberra.

Infor 1994b, Statistical Summary of the Communications, Entertainment and Information Industries, Attachment 1 to Communications Futures Project, Work in
Progress paper xvi, BTCE, Canberra. Paper 3, BTCE, Canberra.
PTd New Media: Commercial and Cultural Implications, 
Civics Expert Group 1994, Whereas the People...Civics and Citizenship Education, Australian Government Publishing Service, Canberra.

Committee of Inquiry into Technological Change in Australia (The Myers' Report), 1980, Technological Change in Australia, Vol. 1, Technological Change and its Consequences, Australian Government Publishing Service, Canberra.

Department of Communication and the Arts 1994, Beyond the Duopoly: Australian Telecommunications Policy and Regulation, Issues Paper, November. $-1,1994$, Creative Nation: Commonwealth Cultural Policy, Commonwealth of
Australia, October.

Dodd, T., 1994, Public funding of election campaigns in The People's Say, Australian Electoral Commission, Canberra, Pp. 32-34.

Hansard of the House of Representatives Hansard, 1994, November 7, Pp. 26242729.

Horner, D. and Reve, I., 1991, Telecottages: The Potential For Rural Australia, Department of Primary Industries, Australian Government Publishing Services, Canberra.

House of Representatives Standing Committee for Long Term Strategies, 1991a, Australia as an Information Society. The Role of Libraries/Information Networks, Australian Government Publishing Service, Canberra.

1991b, Australia as an Information Society: Grasping New Paradigms, Australian Government Publishing Service, Canberra.

1992, Inquiry into Australia as an Information Society: the role of Parliament in the age of executive dominance, Issues paper, Australian Government Publishing Service, Canberra.

Innovate Australia 1995a, Department of Industry, Science and Technology, Canberra.

Jaensch, D., 1994, The role of the party in The Australian Electoral Commission, The People's Say, Elections in Australia, Australian Government Publishing Service, Canberra.

Joint Standing Committee on Electoral Matters, 1990, The 1990 Federal Election, Australian Government Publishing Service, Canberra.

Service, Canberra.
Sag

Latham, M., 1994 (b) The House of Representatives Notice Paper No 90, September 19, Questions Nos. 1358-1370, Pp. 4468.

Lee, M., 1994, Minister for Communications and the Arts, Hansard, 3829, Canberra, November 17.

Major, S., 1994, The Citizens Initiated Referendum: Direct Democracy or Irresponsible Mass Government? Western Australian Electoral Commission, Perth.

Papers on Parliament No. 21, 1993, Parliament and the Constitution: Some Issues of Interest, Department of the Senate, Canberra.

Privacy Commissioner, 1992, Austel Inquiry into the Privacy Implications of Telecommunication Services, Submission, Human Rights and Equal Opportunity Commission, Sydney. 
Senate Committee Office, 1993, Consolidated Register of Senate Committee Reports 1970-1993, Parliament of the Commonwealth of Australia, Canberra.

Warden, J., 1995, Parliament, Democracy and Political Identity in Australia, Government Publishing Service, Canberra.

\section{INTERVIEWS}

Aldred, K., 1994, Member for Deakin, Victoria, Canberra, June 1.

Arterton, C.F., 1995, political scientist, Washington DC, August 6.

Austin, J., 1995, National Farmers Federation, Canberra, September 29.

Bailey, G., 1993, Liberal Party organiser, Canberra, December 1.

Banks, D., 1995, ACT Chief Minister's Office, interview, Canberra, November 22.

Bean, C., 1995, political scientist, Canberra, July 14.

Beck, T.,1995, Business Council of Australia, Canberra, September 28.

Bloomfield, T., 1994, businessman, Canberra, June 15.

Bowtell, C., 1995, Australian Council of Trade Unions, Canberra, September 24.

Braidwood, N., 1996, Norleymac Computer Consultant, Canberra, Febuary 13.

Brennan, G., 1994, economist, Canberra, December 10.

Butler, B.A.,1995, Political science PhD candidate, Canberra, June 15.

Charles, B., 1994, Member for Latrobe, Victoria, Canberra, May 30.

Creighton, J.,1995, The Harwood Group, Washington DC, August 8. Cresswell, C., 1995, Consumers' Federation of Australia Inc., Canberra,
September 28.

Easson, M., 1994, Member for Lowe, New South Wales, Canberra, June 6.

Farmer, R., 1994, journalist/lobbyist, Canberra, June 10.

Fist, S. A., 1996, telecommunications journalist, Melbourne, March 13.

Gray, G., 1993, Labor Party Assistant National Secretary, Canberra, December 15.

-----, 1995, Labor Party National Secretary, interview on Radio National, Australian Broadcasting Corporation, October 24, 8.40am.

Hamilton, G., 1994, PhD candidate, Canberra, May 12.

Hart, J.,1995, political scientist, Canberra, December 16.

------, 1996, political scientist, Canberra, May 21.

Henderson, I., 1993, Labor Party National office, Canberra, November 25.

Hogg, R., 1995, Labor Party National office, Canberra, January 13.

Jones, B. O., 1996, Member for Lalor, Victoria, Canberra, March 18. 
Kelly, R., 1994, Member for Canberra, ACT, Canberra, October 17.

Kemp, D., 1994, Member for Goldstein, Victoria, Canberra, November 18.

Kerr, D., 1994, Member for Denison, Tasmania, Canberra, June 1.

Kerrisk, M., 1994, Australian Labor Party National office, Canberra, June 5.

Killam, G., 1995, Australian Conservation Foundation, Canberra, September 14.

Langmore, J., 1994, Member for Fraser, ACT, Canberra, August 12.

Loydell, R.,1995, Forest Protection Society, Canbera, September 22.

Mackerras, M., 1994, political scientist, Canberra, March 21.

Margolis, J., 1994, campaign consultant, Washington DC, June 14.

McHugh, J., 1994, Member for Grayndler, New South Wales, Sydney, June 2.

McKay, H., 1995, social commentator, interview on Radio National, Australian Broadcasting Corporation, October 10, 7.30am.

Mills, Steven, 1995, Sierra Club, Washington DC, August 16.

Minchin, N., 1994, Senator for South Australia, Canberra, June 2.

Morris G., 1995, Liberal Party organiser, Canberra, November 9.

O’Connor, K., 1994, Privacy Commisioner, Sydney, October 5.

O'Keefe, N., 1994, Member for Burke, Victoria, Melbourne, June 30.

Paul, S., 1995, Global Forestry Policy Project, Washington DC, August 15.

Penn, G., 1994, International Data Corporation, Sydney, July 15.

Radio National, Australian Broadcasting Corporation, 1995, June 14, 8.30am.

Reith, P., 1994, Member for Flinders, Victoria, Canberra, September 19.

Richardson, G., 1994, Senator for South Australia, Sydney, December 19.

Rowlings, W.M., 1995, PQR Public Relations Consultants, Canberra, December 15.

------, 1996, media staff of Opposition Leader, Canberra, March 1.

Saulwick, I., 1995, interview on Radio National, Australian Broadcasting Corporation, October 9, 8.45am.

Scales, J., 1995, pollster with Morgan, Melbourne, May 8.

Sharp, J., Member for Hume, NSW, 1995, interview with staff, Goulburn, May 11.

Singleton, J., 1996, National Australia Day Council, Sydney, February 19.

------, 1996, National Australia Day Council, Canberra, June 25.

Snow, J., 1994, Member for Eden-Monaro, New South Wales, Canberra, October 15.

Somlyay, A., 1994, Member for Fairfax, Queensland, Canberra, June 1. 
Taylor, P., 1995, Australian Council of Manufactures, Canberra, September 12.

Textor, M., 1994, Liberal Party pollster, Canberra, June 23.

------, 1995, Liberal Party pollster, interview, Canberra, January 18. Walsh, V., 1995, Australian Library and Information Association, Canberra, August
9.

Ward, J., 1994, political scientist, Canberra, December 1.

Ward, M., 1995, Australian Republican Movement, Sydney, September 25.

Warden, J., 1995, Wilderness Society, Canberra, July 15.

Wooldridge, M., 1994, Member for Chisholm, Victoria, Canberra, June 1.

Young, M., 1996, Sydney, January 10.

\section{SURVEYS}

Australian Community Research (ACR) 1993, Federal Callbacks Adelaide, Corinella and Macarthur, Luscombe and Associates PL, Melbourne, Confidential ALP report.

Client Solutions PL, 1994, Committee Bulletin's Guide to Politicians' Lobbying Preferences, A survey of federal members of parliament on their preferences in dealing with special interest groups, Committee Bulletin and Polbase, Canberra.

Cornish, A.M., 1991, Report of the Review of Support Services to Members of Parliament, Tasmanian Parliamentary Library, Hobart.

Electoral and Administrative Review Commission (EARC), 1991, Report on Information and Resource Needs of Non-Government Members of the Queensland Legislative Assembly, EARC, Brisbane, Queensland.

EARC, Brisbane, Queensland.
Ex

Evaluation Group on External Access to the Parliamentary DataBase Service Strategy for External Access to the Parliamentary DataBase, 1995, Report to the Information Systems User Forum, Parliament of Australia, Canberra.

Gray, G.,1992, Wills By-election, April 1992 Campaign Report, Confidental ALP document.

Hill and Knowlton, 1994, @ ngis Client Survey and Consultation Program Report on External Client Survey, Canberra, December 19.

Hjortdal, H., 1991, Report on the introduction of new technologies in parliaments, Constitutional and Parliamentary Information, No. 161, Pp 1-34.

Kelley, J., Cushing, R. G. and Keadley, B., 1984, Australian National Social Science Survey 1984, Social Science Data Archives, The Australian National University,
Canberra.

Parr, E. and Ransome, A., 1986, The Information Marriage: The Parliamentary Library and Personal Staff of Senators and Members, A Report to the Parliamentary Librarian, Lismore, NSW.

------, 1990, Timely, Relevant and Comprehensive: The Parliamentary Library and Information Needs of Members, A Report to the Joint Library Committee, NSW Parliamentary Library, Sydney. 
Davies, A., Ransome, A., and Warhurst, J., 1991, Pathways to Information: The Information, Policy Analysis and Advisory Needs of Senators and Members, Australian Government Publishing Service, Canberra. Saulwick, I., 1992, Saulwick Poll Reprints, 1990-1991, Syme Community
Newspapers, Melbourne.

Social Impacts, 1989, Public Perceptions of Science and Technology, Implications for Telecom, Executive Summary, Edgecliff, New South Wales.

Social Science Data Archives, 1990, Australian Election Study, 1990 SSDA Study No. 570, The Australian National University, Canberra.

National Universtralian Election Study, 1993 SSDA Study No. 763, The Australian ---1993, Australian Candidates Study, SSDA Study No. 764, The Australian
National University, Canberra.

The Young Inquiry, 1995, The ALP Queensland Branch Committee of Inquiry into the 1995 State Election Result, ALP document, October.

\section{NEWSPAPER and MAGAZINE ARTICLES}

Alter, J.,1995, The Couch Potato Vote, Newsweek, February 27, P. 25.

Anderson, R.H., Bikson, T.K., Law, S.A. and Mitchell, B.M., 1995, Universal Access to E-Mail: Feasibility and Social Implications, RAND, Santa Monica.

Australian Financial Review, 1996, March 4, Special Issue, P. E9. Australian Vice Chancellors' Committee, 1995, media release AARNet signs MOU
with Telecom, January 12.

Baldwin, P., 1995, The Community Information Network: Bridging the Information Gap, media release, Minister for Social Security, June. Biskupic, J., 1995, Congressional Term Limits Struck Down, The Washington Post,
May 23, A1, A6.

Boylen, 1993a, Swinging voters to watch leaders with fingers on button, The Australian Financial Review, February 12, P. 5.

March 16, P. 30 .
. 1993 spending down $30 \%$, The Australian Financial Review,

Burton, T., 1993, How the media got it so wrong, The Australian Financial Review,
March 19, P. 5 .

Butler, D., 1993, Evolutionary twists on the campaign trail, The Canberra Times, P.
14. Churbuck, D., 1995, Where's the cash in the Internet? Business Review Weekly,
February, Pp. 86-88.

Connors, T., 1995, Lobbying has changed. Long lunches are making way for bullet-makers with treasury-proof arguments, The Canberra Times, Saturday
Magazine, July 22, P.19. Cox, P.,1994, The opportunities are there, but we have to move quickly, The
Weekend Australian, October $12, \mathrm{Pp} .22-23$. 
Crean, S., 1995, Commonwealth and States Join Forces on Education and Training Superhighway, media release, May 26.

Dixon, R., 1993, Cynics are the key, says pollster, The Age, March 11, P.19.

Dodson, L., and Gray, J., 1993, Libs say debate format gave Keating the edge, The Australian Financial Review, March 8, P.2.

Fineman, H., 1995, The Brave New World of Cybertribes, Newsweek, February 27, Pp. 20- 23.

Georges, C., 1993, 'Perot and Con', The Washington Post Monthly, June 1993, Pp. 38-43.

Goot, M.,1994, Money cannot buy timely opinion polls, The Australian Financial Review, August 16, 5.

Gray, J., 1995, Does Democracy Have a Future? New York Times Book Review, January 22, Pp. 25-32. Hewett, T., 1993, Lobby groups work the marginal seats, The Sydney Morning
Herald, March 12, P.7.

Hull, C., 1994, MLAs do hatchet job on good idea, The Canberra Times, November 14, P.11. Ives, D., 1994, First master the old technologies, The Canberra Times, October 10 ,
P. 10 .

Jones, C., 1994, Our student body just not politic, The Australian, September 28 , Pp. 1,4 .

Keating, P., 1995, media release, Prime Minister, September 10.

Kitney, G., 1993, Silent majority keeping silent - to pollsters, The Australian, March 13, P. 5. Kohoe, L., 1996, Internet offers new electoral vantage point, The Financial Times,
February 22.

Lamberton, H., 1995, Lib poll uses 'lies and filth': ALP, The Canberra Times, February 27, Pp. 1-2.

Lee, M., 1995, Minister for Communication and the Arts Welcomes National Strategy of Networked Services, media release, April 6.

Levy, S., 1995, TechnoMania, Newsweek, February 27, Pp. 11-15.

Lewis, P. H., 1995, Exploring New Soapboxes for Political Animals, The New York Times, January 10, P. 28.

Magazanik, M., 1993, Frontbenchers attack Labor, The Age, March 15, P.9. McGuinness, P. P., 1991, Democracy at too high a price, The Australian, May 14,
P. 13.

National Australia Day Council 1995, Constitution, Reconciliation and Republic Addressing the Issues Through Community Democracy, media release, November 12.

Oakes, L., 1993, Last-minute lunge, The Bulletin, March 16, P. 16.

Ogden, C., 1992, Going Where The Voters Are, Time, 29 June, P. 29. 
Prowse, M.,1992, Oregon Blazes an Electronic Trail, The London Times, June 8.

Quiggin, J., 1994, Privatisation's genuine benefits far from rosy, The Canberra Times, October 3, P. 9.

Singleton, J.A., 1993, quoted in Shoebridge, N., The ultimate one-day sale, Business Review Weekly, March 19, Pp. 26-27.

Souter, F.,1993, The turn of the worm, The Bulletin, February 23, P. 18.

Stone,J., 1993, Media trivialises campaign, The Canberra Times, March 11, P. 6.

Steketee, M., Wright, T., and Lagan, B.,1993, It's too close to call, The Sydney Morning Herald, March 13, P. 5. The Australian 1995, Principle the first victim in plague of political opinion polls,
January 19, P. 7 . , 1996, Election Coverage, March 4, P. 8.

The Australian Financial Review, 1993, Keating wins the battle but not the war, March 8, P. 12.

The Bulletin, 1995, Morgan returns, January 10, P. 15.

The Sunday Herald-Sun, 1994, Polls take their toll, December 11, P. 5. Waldmier, P., 1996, America the pessimistic, The Financial Times, US, February
15.

Walker, D.,1993, Ads subtracted in political sum, The Age, March 12, P.10.

Walsh, K. and Richardson, N., 1995, Politicians: How low can they go? The Bulletin, September 12, Pp. 14-17.

Walsh, V., 1995b, Press release of the Australian Library and Information Association, February 8, P.1.

Westfield, M., 1994, Survival of the Fittest, The Weekend Australian, 19-20 November 1994, P. 27.

Williams, P., 1996, Operation Lodge: Inside the Liberals war room, The Australian Financial Review, March 5,6, and 7.

\section{BROCHURES, BOOKLETS and CONFERENCE PAPERS}

Australia Consults, 1995, Speak Up, information booklet, Sydney.

-------, 1995, information package on Australia Consults, Sydney. Forums, Sydney
Foralia Consults 1996: Report and Minutes of Local Government

Australian Library and Information Association, 1995, booklet, ALIA, Canberra.

Butler, B.A., 1994, The Roles of Journalists and Sources in Shaping Prime-Time Political News Agendas in Australia, Conference Paper to The Journalism Education Association (JEA), November, Canberra .

Clarke, R. and Worthington, T., 1994, Vision for a Networked Nation: The Public Interest in Network Services, Australian Computer Society, Canberra. 
Cook, P., 1995, Speech at the launch of the Australian Information Industry Association's Agenda for Growth, Parliament House, Canberra, February 5.

Department of Social Security 1994, Information Kit on the Community Research Project, Strategic Development Unit, Canberra.

Durack, P., 1992, Parliament and People, Senate Occasional Lecture, Parliament House, Canberra, November 23.

Global Info-Links, 1995, Information booklet, Ipswich City Council, Queensland.

Gray, G., 1996, Speech by the National Secretary, Australian Labor Party, to the Sydney Institute, Tuesday June 18, ALP document.

Jamieson, K. H., 1992, Debate in Bill Moyers' Can We Govern? Part 2, Transcript Public Affairs Television, May 12 , P. 3.

Keating, P., 1994, Transcript of the launch of the Open Learning Agency of Australia's international television production of 'The Global Economy', Parliament House, Canberra, August, P. 4.

Latham, M., 1994a, Federal Responsibilities For Libraries, Paper to Federal ALP Caucus, August.

Legislative Assembly of the Northern Territory, 1991, Committee on Constitutional Development, Discussion Paper No. 3, Citizens Initiated Referenda, August, Pp.
17-18.

Macdonald, S. and Reams, D., 1989, Selling Government Information: The Issues Overseas, Attachment B to Mandeville, T. (ed.) The Supply of Queensland Government Information, University of Queensland, unpublished UniQuest Report for CITEC (Centre for Information Technology and Communication).

Mason, C.J., 1992, High Court of Australia Transcript, Matter S5 and S6 of 1992, Judgement delivered September 30.

Moyers, B., 1992, Listening to America with Bill Moyers - Can We Govern? Part 1 Transcript, Public Affairs Television, April 28.

Office of the Chief Scientist, Department of the Prime Minister and Cabinet 1995 , National Information Services Council, Agenda papers from the first meeting of the Council, August 10.

Parr, E., 1994, 'Good' Information and Two Parliamentary Libraries, Address to Conference at the University of NSW on Government and Parliamentary Information, Kensington, NSW, July 19.

Rogers, D. and Penman, R., 1989, Communication in the Political Arena: Whither Citizenship? Occasional Paper No. 12, Communication Research Institute of Australia Incorporated, Hackett, Canberra.

Stokes, K., 1994, Advance Australia Where? 1994 Boyer Lecture, Australian Broadcasting Corporation, Sydney (the title is a play on words on the Australian national song, Advance Australia Fair).

The Harwood Group 1991, Citizens and Politics - A View From Main Street America, The Kettering Foundation, Maryland.

The National Commission for the Renewal of American Democracy, 1993, The Portland Agenda, Lawyers Cooperative Publishing, The Harwood Group, Maryland. 


\section{INTERNET}

WWW Bonchek, M., 1995, Grassroots in Cyberspace: Using Computer Networks to Facilitate Political Participation - via Netscape at

http://www.ai.mit.edu/projects/ppp/home.html

WWW Clift, S.L., 1996, Minnesota E-Democracy, email, http://freenet.msp.mn.us/govt/e-democracy

WWW Rowlings, W.M., 1996, e-mail (rowlings@ozemail.com.au) to U.S. political network, March 28. 


\section{APPENDIX A}

\section{Methodology of the Fremantle survey on direct mail}

The following methodology was employed. The Fremantle by-election on March 121994 was chosen for the survey because it was a current campaign with high profile candidate and considerable media attention in which both parties made extensive use of direct mail. The seat was regarded as marginal Labor though in normal circumstances it would be regarded as safe Labor. The Labor candidate was Dr Carmen Lawrence and the Liberal candidate was $\mathrm{Mr}$ Geoff Hourn.

A random sample of 353 names was drawn from 74,729 people on the Fremantle electoral role. Telephone interviews were concluded successfully with 141 electors of the 155 who were reached. There were 68 people who were resident at the listed phone number who could not be contacted personally within the time frame. Of the remaining 130 people, the majority were not listed in the telephone book. Other reasons for no interview were that the selected persons had moved house or were away, were not in Fremantle during the byelection or could not converse in English.

Silent unlisted numbers could indicate an attitude group was not included, but available resources precluded any way to overcome this, if one existed. The success rate once the person was contacted was satisfactory, with only 14 people refusing. The distribution of survey data on age, employment, sex and qualifications indicated no great variance in the sample to that in the wider community. It is necessary to put a caveat on generalising from small numbers in this survey, particularly from some sub-sets of responses. The results should be taken as indicative only and not necessarily true for the whole population. However, broad patterns which emerge are clear.

After consultation on the questionnaire, a small pilot was run and some question wording changed as a result. The main interviewing began on March 22 and concluded on March 27 , 1994. It was found that by this date people's recall was becoming hazy and it was decided that prolonging the time period might jeopardise validity of the responses.

After an explanatory session on the wording and intent of each question, four interviewers telephoned a nominated person at different times of the day. No substitutes were interviewed and attempts to interview the nominated person only abandoned if there was no success after at least six attempts. For analysis, the Statistical Package for the Social Sciences (SPSS) software package was used at the Political Science Department of the Australian National University. 


\section{APPENDIX B}

\section{INTEREST GROUP PEOPLE PERSONALLY INTERVIEWED:}

- Economic-based:

Australian Chamber of Manufactures: (06) 2572072

$11 / 40$ Marcus Clarke St, Canberra City (Ms Penny Taylor).

ACTU: (03) 96635266

939 Swanston St, Melbourne (Ms Cath Bowtell)

Business Council of Australia: (06) 2478202

60 Marcus Clarke St, Canberra City (Dr Tony Beck).

National Farmers Federation: (06) 2733588

14 Brisbane Ave, Barton ACT (Ms Julie Austin)

Issues-based:

Australian Conservation Foundation: (06) 2473013

Cinema Building, Bunda St. Canberra City 2601 (Mr Grant Killam)

Australian Library and Information Association: (06) 2851877

8 Napier Cl, Deakin ACT (Ms Virginia Walsh)

Australian Republican Movement: (06) 2812155

PO Box 2001, Woden ACT (Dr Michael Ward)

Wilderness Society: (06) 2498011

Bunda Street, Canberra City (Dr James Warden)

Both economic- and issues-based:

Consumers' Federation of Australia: (06) 2576311

40 Mort St, Braddon ACT (Ms Claudia Creswell)

Forest Protection Society: (06) 2853833

Shop 2, Southlands Shopping Centre, Mawson ACT (Ms Robyn Loydell)

\section{INTEREST GROUP QUESTIONNAIRE}

I am interested in the impact that some of the new communication technologies or CTs (such as fax, mobile phones, direct mail, email, computer data bases and CD-ROMs, the Internet, computerised offices and teleconferencing) may be having on the running of your organisation.

Could you give me your impression of the influence of such things on:

- forming an interest group or expanding activities?

- its efficient functioning?

- recruiting members?

- keeping members interested?

Also, what is your view of the effect of CTs on:

- communicating with members?

- communicating with decision-makers (lobbying)?

- co-ordinating activities?

- gathering information?

[Code as $1=$ easier, $2=$ same, $3=$ harder, $4=$ no difference, 5=not applicable]

Do you think CTs have substituted for the traditional ways to a significant extent, or complemented them? In what ways? 


\section{APPENDIX C}

Electorate office perceptions of their own and constituents' use of Communications

Technologies, including relative rating of usefulness: 
Groups:

ALL

Total: 104

Section 1 of 3 (outgoing)

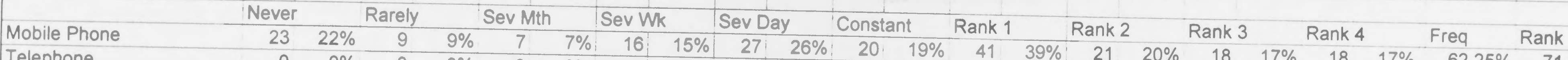

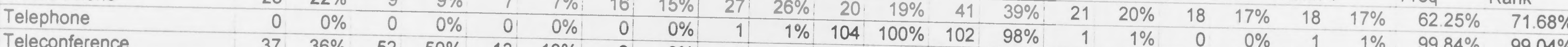

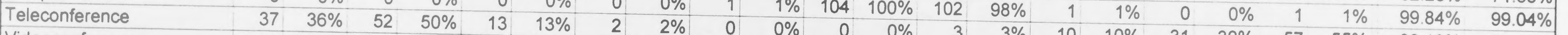

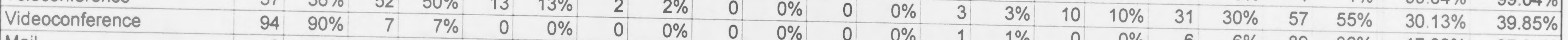

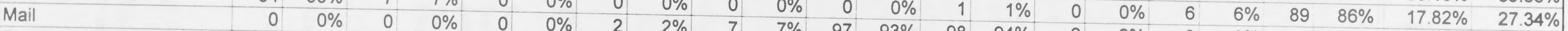

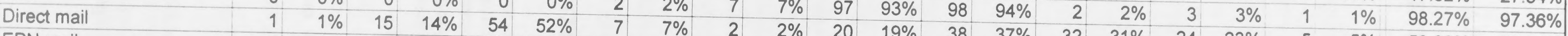

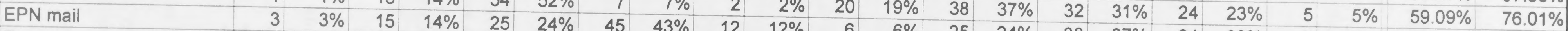

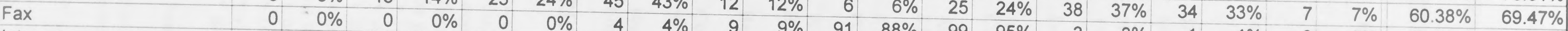

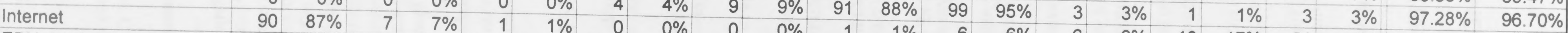

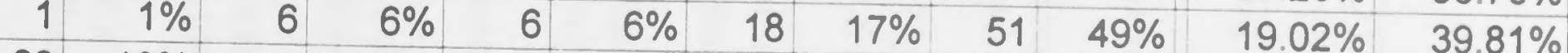

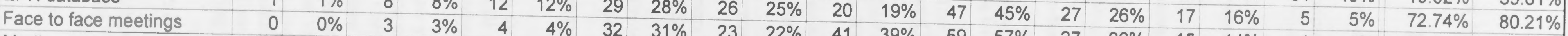

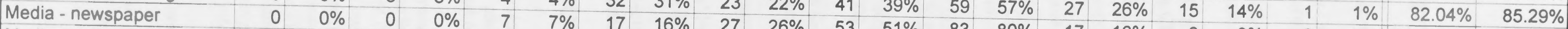

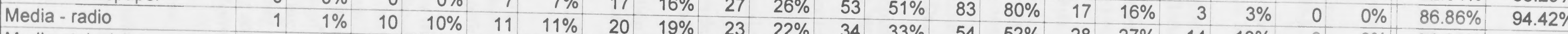

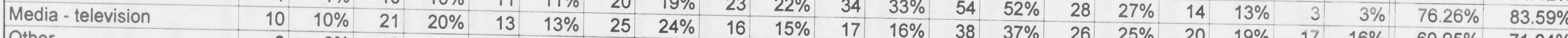

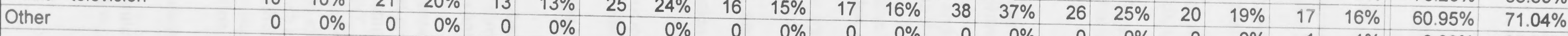

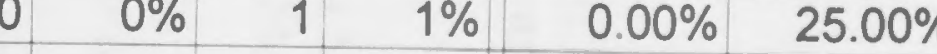

Section 2 of 3 (incoming)

\begin{tabular}{|c|c|c|c|c|c|c|c|c|c|c|c|c|c|c|c|c|c|c|c|c|c|c|}
\hline & & & & & & & & & & & & & & & & & & & & & & \\
\hline Telephone & 0 & $0 \%$ & 6 & $60 \%$ & $\frac{1}{6}$ & $1 \%$ & 18 & $17 \%$ & 9 & $9 \%$ & 9 & $9 \%$ & 10 & $10 \%$ & 21 & $20 \%$ & 23 & $22 \%$ & 32 & $31 \%$ & $47.70 \%$ & $52.62 \%$ \\
\hline Teleconference & 75 & $72 \%$ & 13 & $\begin{array}{r}6 \% \\
13 \%\end{array}$ & $\frac{6}{7}$ & $6 \%$ & 3 & $3 \%$ & 4 & $4 \%$ & 78 & $75 \%$ & 76 & $73 \%$ & 9 & $9 \%$ & 3 & $3 \%$ & 4 & $4 \%$ & $91.07 \%$ & $92.66 \%$ \\
\hline Videoconference & 91 & $88 \%$ & 3 & $\begin{array}{r}13 \% \\
3 \%\end{array}$ & 7 & $7 \%$ & 0 & $0 \%$ & 0 & $0 \%$ & 0 & $0 \%$ & 1. & $1 \%$ & 4 & $4 \%$ & 7 & $7 \%$ & 71 & $68 \%$ & $21.40 \%$ & $30.42 \%$ \\
\hline Mail & 2 & $2 \%$ & $\frac{v}{1}$ & $\begin{array}{l}3 \% \\
1 \%\end{array}$ & $\frac{0}{6}$ & $0 \%$ & 0 & $0 \%$ & 0 & $0 \%$ & 0 & $0 \%$ & 0 & $0 \%$ & 0 & $0 \%$ & 2 & $2 \%$ & 76 & $73 \%$ & $17.20 \%$ & $25.64 \%$ \\
\hline Direct mail & 13 & $13 \%$ & 13 & $13 \%$ & $\begin{array}{r}6 \\
27\end{array}$ & $6 \%$ & 5 & $5 \%$ & 13 & $13 \%$ & 72 & $69 \%$ & 77 & $74 \%$ & 10 & $10 \%$ & 6 & $6 \%$ & 1 & $1 \%$ & $90.74 \%$ & $93.35 \%$ \\
\hline Email & 70 & $67 \%$ & 13 & $13 \%$ & $\begin{array}{r}27 \\
3\end{array}$ & $26 \%$ & 14 & $13 \%$ & 1 & $1 \%$ & 14 & $13 \%$ & 19 & $18 \%$ & 17 & $16 \%$ & 25 & $24 \%$ & 18 & $17 \%$ & $53.86 \%$ & $61.71 \%$ \\
\hline Fax & 0 & $0 \%$ & 5 & $5 \%$ & $\begin{array}{r}3 \\
11\end{array}$ & $3 \%$ & 4. & $4 \%$ & 0 & $0 \%$ & 1 & $1 \%$ & 4 & $4 \%$ & 3 & $3 \%$ & 14 & $13 \%$ & 57 & $55 \%$ & $23.26 \%$ & $35.26 \%$ \\
\hline Internet & 85 & $82 \%$ & 4 & $4 \%$ & $\begin{array}{r}11 \\
0\end{array}$ & $11 \%$ & 28 & $27 \%$ & 19 & $18 \%$ & 31 & $30 \%$ & 47 & $45 \%$ & 25 & $24 \%$ & 14 & $13 \%$ & 2 & $2 \%$ & $77.30 \%$ & $83.24 \%$ \\
\hline EPN database & 0 & $0 \%$ & 0 & $0 \%$ & 0 & $\begin{array}{l}0 \% \\
0 \%\end{array}$ & 0 & $0 \%$ & 0 & $0 \%$ & 0 & $0 \%$ & 2 & $2 \%$ & 2 & $2 \%$ & 11 & $11 \%$ & 55 & $53 \%$ & $17.42 \%$ & $32.50 \%$ \\
\hline Face to face meetings & 1 & $1 \%$ & 4 & $4 \%$ & 9 & $\frac{0 \%}{9 \%}$ & 0 & $0 \%$ & 0 & $0 \%$ & 0 & $0 \%$ & 0 & $0 \%$ & 0 & $0 \%$ & 0 & $0 \%$ & 0 & $0 \%$ & $0.00 \%$ & $0.00 \%$ \\
\hline Media - newspaper & 9 & $9 \%$ & 12 & $12 \%$ & 15 & $\begin{array}{r}9 \% \\
14 \%\end{array}$ & 25 & $24 \%$ & 26 & $25 \%$ & 30 & $29 \%$ & 53 & $51 \%$ & 25 & $24 \%$ & 10 & $10 \%$ & 1 & $1 \%$ & $78.25 \%$ & $86.52 \%$ \\
\hline Media - radio & 13 & $13 \%$ & 18 & $17 \%$ & 13 & $\begin{array}{l}14 \% \\
13 \%\end{array}$ & 19 & $18 \%$ & 10 & $10 \%$ & 22 & $21 \%$ & 35 & $34 \%$ & 20 & $19 \%$ & 15 & $14 \%$ & 13 & $13 \%$ & $64.37 \%$ & $73.19 \%$ \\
\hline Media - television & 20 & $19 \%$ & 16 & $15 \%$ & 16 & $\begin{array}{l}13 \% \\
15 \%\end{array}$ & 14 & $13 \%$ & 10 & $10 \%$ & 20 & $19 \%$ & 25 & $24 \%$ & 18 & $17 \%$ & 19 & $18 \%$ & 18 & $17 \%$ & $59.47 \%$ & $65.63^{\circ}$ \\
\hline Other & 0 & $0 \%$ & 0 & $0 \%$ & 0 & $\begin{array}{r}15 \% \\
0 \%\end{array}$ & 12 & $12 \%$ & 9 & $9 \%$ & 13 & $13 \%$ & 13 & $13 \%$ & 18 & $17 \%$ & 18 & $17 \%$ & 23 & $22 \%$ & $52.52 \%$ & $57.29 \%$ \\
\hline & & & & & & & 0 & $0 \%$ & 0 & $0 \%$ & 0 & $0 \%$ & 1 & $1 \%$ & 0 & $0 \%$ & 0 & $0 \%$ & 0 & $0 \%$ & $0.00 \%$ & $0.95 \%$ \\
\hline
\end{tabular}




\section{Groups
URBAN}

Section 1 of 3 (outgoing)

\begin{tabular}{|c|c|c|c|c|c|c|c|c|c|c|c|c|c|c|c|c|c|c|c|c|c|c|}
\hline & \multirow{2}{*}{\multicolumn{2}{|c|}{ Never }} & \multirow{2}{*}{\multicolumn{2}{|c|}{ Rarely }} & \multirow{2}{*}{\multicolumn{2}{|c|}{ Sev Mth }} & \multirow{2}{*}{\multicolumn{2}{|c|}{ Sev Wk }} & \multirow{2}{*}{\multicolumn{2}{|c|}{ Sev Day }} & \multirow{2}{*}{\multicolumn{2}{|c|}{ Constant }} & \multirow{2}{*}{\multicolumn{2}{|c|}{ Rank 1}} & \multirow{2}{*}{\multicolumn{2}{|c|}{ Rank 2}} & \multirow{3}{*}{\multicolumn{2}{|c|}{ Rank 3}} & \multirow{3}{*}{\multicolumn{2}{|c|}{ Rank 4}} & \multirow[b]{4}{*}{$56.02 \%$} & \\
\hline & & & & & & & & & & & & & & & & & & & & & & \\
\hline Mobile Phone & 12 & $32 \%$ & 4 & $11 \%$ & 1 & $3 \%$ & 3 & $8 \%$ & 10 & $26 \%$ & 6 & $16 \%$ & 15 & $39 \%$ & 5 & & & & & & & \multirow[b]{2}{*}{$67.57 \%$} \\
\hline Telephone & 0 & $0 \%$ & 0 & $0 \%$ & 0 & $0 \%$ & 0 & $0 \%$ & 1 & $3 \%$ & 38 & $100 \%$ & 36 & & 0 & $13 \%$ & 8 & $21 \%$ & 9 & $24 \%$ & & \\
\hline Teleconference & 13 & $34 \%$ & 20 & $53 \%$ & 6 & $16 \%$ & 0 & $0 \%$ & 0 & $0 \%$ & 0 & & 36 & $95 \%$ & 1 & $3 \%$ & 0 & $0 \%$ & 1 & $3 \%$ & $99.57 \%$ & $97.37 \%$ \\
\hline Videoconference & 36 & $95 \%$ & 1 & $3 \%$ & 0 & $0 \%$ & 0 & $0 \%$ & 0 & $0 \%$ & & $0 \%$ & 1 & $3 \%$ & 4 & $11 \%$ & 12 & $32 \%$ & 21 & $55 \%$ & $30.34 \%$ & $40.13 \%$ \\
\hline Mail & 0 & $0 \%$ & 0 & $0 \%$ & 0 & $0 \%$ & 1 & $3 \%$ & 3 & $8 \%$ & $\frac{0}{27}$ & $0 \%$ & 0 & $0 \%$ & 0 & $0 \%$ & 1 & $3 \%$ & 35 & $92 \%$ & $17.12 \%$ & $25.69 \%$ \\
\hline Direct mail & 0 & $0 \%$ & 3 & $8 \%$ & 21 & $55 \%$ & 3 & $8 \%$ & 1 & $\begin{array}{l}8 \% \\
3 \%\end{array}$ & 37 & $97 \%$ & 36 & $95 \%$ & 0 & $0 \%$ & 2 & $5 \%$ & 1 & $3 \%$ & $97.97 \%$ & $95.51 \%$ \\
\hline EPN mail & 1 & $3 \%$ & 9 & $24 \%$ & 10 & $26 \%$ & 17 & $45 \%$ & 4 & $\begin{aligned} 3 \% \\
11 \%\end{aligned}$ & 7 & $18 \%$ & 14 & $37 \%$ & 13 & $34 \%$ & 7 & $18 \%$ & 1 & $3 \%$ & $60.95 \%$ & $78.57 \%$ \\
\hline Fax & 0 & $0 \%$ & 0 & $0 \%$ & 0 & $0 \%$ & 2 & $5 \%$ & 6 & $\frac{11 \%}{16 \%}$ & 1 & $3 \%$ & 11 & $29 \%$ & 11 & $29 \%$ & 15 & $39 \%$ & 4 & $11 \%$ & $56.75 \%$ & $67.68 \%$ \\
\hline Internet & 34 & $89 \%$ & 2 & $5 \%$ & 0 & $0 \%$ & 0 & $0 \%$ & 0 & $\begin{array}{r}16 \% \\
0 \%\end{array}$ & 32 & $84 \%$ & 35 & $92 \%$ & 2 & $5 \%$ & 1 & $3 \%$ & 2 & $5 \%$ & $95.83 \%$ & $93.75 \%$ \\
\hline EPN database & 0 & $0 \%$ & 3 & $8 \%$ & 8 & $21 \%$ & 10 & $26 \%$ & 8 & $\begin{aligned} 0 \% \\
21 \%\end{aligned}$ & 0 & $0 \%$ & 3 & $8 \%$ & 1 & $3 \%$ & 6 & $16 \%$ & 22 & $58 \%$ & $17.59 \%$ & $38.28 \%$ \\
\hline Face to face meetings & 0 & $0 \%$ & 0 & $0 \%$ & 1 & $3 \%$ & 7 & $18 \%$ & 11 & $\begin{array}{l}21 \% \\
29 \%\end{array}$ & 7 & $18 \%$ & 14 & $37 \%$ & 11 & $29 \%$ & 8 & $21 \%$ & 3 & $8 \%$ & $70.37 \%$ & $75.00 \%$ \\
\hline Media - newspaper & 0 & $0 \%$ & 0 & $0 \%$ & 6 & $16 \%$ & 9 & $24 \%$ & 11 & $\begin{array}{l}29 \% \\
29 \%\end{array}$ & 20 & $53 \%$ & 23 & $61 \%$ & 11 & $29 \%$ & 5 & $13 \%$ & 0 & $0 \%$ & $88.03 \%$ & $86.54 \%$ \\
\hline Media - radio & 1 & $3 \%$ & 7 & $18 \%$ & 7 & $18 \%$ & 8 & $21 \%$ & 8 & $\begin{array}{l}29 \% \\
21 \%\end{array}$ & 15 & $39 \%$ & 28 & $74 \%$ & 10 & $26 \%$ & 2 & $5 \%$ & 0 & $0 \%$ & $80.89 \%$ & $91.25 \%$ \\
\hline Media - television & 6 & $16 \%$ & 12 & $32 \%$ & 5 & $13 \%$ & 6 & $16 \%$ & 6 & $\begin{array}{l}21 \% \\
16 \%\end{array}$ & 4 & $11 \%$ & 13 & $34 \%$ & 14 & $37 \%$ & 7 & $18 \%$ & 1 & $3 \%$ & $62.86 \%$ & $77.86 \%$ \\
\hline \multirow[t]{2}{*}{ Other } & 0 & $0 \%$ & 0 & $0 \%$ & 0 & $0 \%$ & 0 & $0 \%$ & 0 & $\begin{array}{r}16 \% \\
0 \%\end{array}$ & 3 & $8 \%$ & 8 & $21 \%$ & 11 & $29 \%$ & 9 & $24 \%$ & 11 & $29 \%$ & $51.32 \%$ & $60.26 \%$ \\
\hline & & & & & & & & & & $0 \%$ & 0 & $0 \%$ & 0 & $0 \%$ & 0 & $0 \%$ & 0 & $0 \%$ & 0 & $0 \%$ & $0.00 \%$ & $0.00 \%$ \\
\hline \multirow{3}{*}{\multicolumn{23}{|c|}{ Section 2 of 3 (incoming) }} \\
\hline & & & & & & & & & & & & & & & & & & & & & & \\
\hline Mobile Phone & 5 & $13 \%$ & 15 & $39 \%$ & 2 & $5 \%$ & 5 & $13 \%$ & 5 & $13 \%$ & & & & & & & & & & & & \\
\hline Telephone & 0 & $0 \%$ & 0 & $0 \%$ & 3 & $8 \%$ & 1 & $3 \%$ & 2 & $\begin{aligned} 13 \% \\
5 \%\end{aligned}$ & 2 & $5 \%$ & 3 & $8 \%$ & 9 & $24 \%$ & 11 & $29 \%$ & 11 & $29 \%$ & $48.04 \%$ & $52.94 \%$ \\
\hline Teleconference & 32 & $84 \%$ & 3 & $8 \%$ & 0 & $0 \%$ & 0 & $0 \%$ & 0 & $\begin{array}{l}5 \% \\
0 \%\end{array}$ & 28 & $74 \%$ & 28 & $74 \%$ & 6 & $16 \%$ & 0 & $0 \%$ & 0 & $0 \%$ & $93.63 \%$ & $95.59 \%$ \\
\hline Videoconference & 34 & $89 \%$ & 0 & $0 \%$ & 0 & $0 \%$ & 0 & $0 \%$ & 0 & $0 \%$ & 0 & $0 \%$ & 1 & $3 \%$ & 0 & $0 \%$ & 0 & $0 \%$ & 34 & $89 \%$ & $18.10 \%$ & $27.14 \%$ \\
\hline Mail & 0 & $0 \%$ & 0 & $0 \%$ & 3 & $8 \%$ & 1 & $3 \%$ & 5 & $0 \%$ & 0 & $0 \%$ & 0 & $0 \%$ & 0 & $0 \%$ & 0 & $0 \%$ & 34 & $89 \%$ & $16.67 \%$ & $25.00 \%$ \\
\hline Direct mail & 5 & $13 \%$ & 3 & $8 \%$ & 6 & $16 \%$ & 5 & $13 \%$ & $\frac{3}{1}$ & $13 \%$ & 27 & $71 \%$ & 29 & $76 \%$ & 4 & $11 \%$ & 3 & $8 \%$ & 0 & $0 \%$ & $92.59 \%$ & $93.06 \%$ \\
\hline Email & 26 & $68 \%$ & 4 & $11 \%$ & 2 & $5 \%$ & 1 & $3 \%$ & $\begin{array}{l}1 \\
0\end{array}$ & $3 \%$ & 6 & $16 \%$ & 8 & $21 \%$ & 4 & $11 \%$ & 8 & $21 \%$ & 8 & $21 \%$ & $57.69 \%$ & $60.71 \%$ \\
\hline Eax & 0 & $0 \%$ & 0 & $0 \%$ & 6 & $16 \%$ & 12 & $32 \%$ & & $0 \%$ & 0 & $0 \%$ & 2 & $5 \%$ & 1 & $3 \%$ & 6 & $16 \%$ & 24 & $63 \%$ & $22.22 \%$ & $35.61 \%$ \\
\hline nternet & 31 & $82 \%$ & 1 & $3 \%$ & 0 & $0 \%$ & 0 & $0 \%$ & $\frac{9}{0}$ & $24 \%$ & 8 & $21 \%$ & 17 & $45 \%$ & 14 & $37 \%$ & 3 & $8 \%$ & 1 & $3 \%$ & $75.71 \%$ & $83.57 \%$ \\
\hline EPN database & 0 & $0 \%$ & 0 & $0 \%$ & 0 & $0 \%$ & 0 & $0 \%$ & 0 & $0 \%$ & 0 & $0 \%$ & 1 & $3 \%$ & 0 & $0 \%$ & 1 & $3 \%$ & 25 & $66 \%$ & $17.19 \%$ & $28.70 \%$ \\
\hline ace to face meetings & 0 & $0 \%$ & 0 & $0 \%$ & 3 & $8 \%$ & 6 & $\begin{array}{r}0 \% \\
16 \%\end{array}$ & 0 & $0 \%$ & 0 & $0 \%$ & 0 & $0 \%$ & 0 & $0 \%$ & 0 & $0 \%$ & 0 & $0 \%$ & $0.00 \%$ & $0.00 \%$ \\
\hline Media - newspaper & 2 & $5 \%$ & 5 & $13 \%$ & 9 & $24 \%$ & 9 & $\begin{array}{l}16 \% \\
24 \%\end{array}$ & 13 & $34 \%$ & 10 & $26 \%$ & 16 & $42 \%$ & 14 & $37 \%$ & 1 & $3 \%$ & 1 & $3 \%$ & $82.29 \%$ & $85.16 \%$ \\
\hline Media - radio & 5 & $13 \%$ & 7 & $18 \%$ & 8 & $21 \%$ & 5 & $\begin{array}{l}24 \% \\
13 \%\end{array}$ & 1 & $3 \%$ & 5 & $13 \%$ & 7 & $18 \%$ & 9 & $24 \%$ & 9 & $24 \%$ & 6 & $16 \%$ & $59.14 \%$ & $63.71 \%$ \\
\hline Media - television & 9 & $24 \%$ & 4 & $11 \%$ & 9 & $24 \%$ & 4 & $\begin{array}{l}13 \% \\
11 \%\end{array}$ & 1 & $3 \%$ & 5 & $13 \%$ & 6 & $16 \%$ & 6 & $16 \%$ & 9 & $24 \%$ & 9 & $24 \%$ & $52.69 \%$ & $57.50 \%$ \\
\hline \multirow{3}{*}{ Other } & 0 & $0 \%$ & 0 & $0 \%$ & 0 & $0 \%$ & 0 & \begin{tabular}{r|r|}
$11 \%$ \\
$0 \%$
\end{tabular} & 1 & $3 \%$ & 4 & $11 \%$ & 5 & $13 \%$ & 5 & $13 \%$ & 9 & $24 \%$ & 11 & $29 \%$ & $47.85 \%$ & $53.33 \%$ \\
\hline & & & & & & & & $0 \%$ & 0 & $0 \%$ & 0 & $0 \%$ & 1 & $3 \%$ & 0 & $0 \%$ & 0 & $0 \%$ & 0 & $0 \%$ & $0.00 \%$ & $2.56 \%$ \\
\hline & & & & & & & & & & & & & & & & & & & & & & \\
\hline & & & & & & & & & & & & & & & & & & & & & & \\
\hline
\end{tabular}




\begin{tabular}{|c|c|c|c|c|c|c|c|c|c|c|c|c|c|c|c|c|c|c|c|c|c|c|}
\hline Groups: & & & & & & & & & & & & & & & & & & & & & & \\
\hline & & & & & & & & & & & & & & & & & & & & & & \\
\hline Total: & 26 & & & & & & & & & & & & & & & & & & & & & \\
\hline \multirow{2}{*}{\multicolumn{23}{|c|}{ Section 1 of 3 (outgoing) }} \\
\hline & Nayar & & & & & & & & & & & & & & & & & & & & & \\
\hline Mobile Phone & 4 & & Rarely & & Sev M & & Sev $W$ & & Sev D & & Const: & & Rank & & Rank 2 & & Rank: & & Rank & & & \\
\hline $\begin{array}{l}\text { Mobile Phone } \\
\text { Telephone }\end{array}$ & $\frac{4}{0}$ & $15 \%$ & 3 & $12 \%$ & 3 & $12 \%$ & 4 & $15 \%$ & 6 & $23 \%$ & 6 & $23 \%$ & 11 & $42 \%$ & 6 & $23 \%$ & 4 & $15 \%$ & 4 & $15 \%$ & $64.74 \%$ & $74.00 \%$ \\
\hline $\begin{array}{l}\text { Telephone } \\
\text { Teleconference }\end{array}$ & 14 & $0 \%$ & 0 & $0 \%$ & 0 & $0 \%$ & 0 & $0 \%$ & 0 & $0 \%$ & 26 & $100 \%$ & 27 & $104 \%$ & 0 & $0 \%$ & 0 & $0 \%$ & 0 & $0 \%$ & $100.00 \%$ & $100.00 \%$ \\
\hline & 14 & $54 \%$ & 10 & $38 \%$ & 2 & $8 \%$ & 0 & $0 \%$ & 0 & $0 \%$ & 0 & $0 \%$ & 1 & $4 \%$ & 0 & $0 \%$ & 5 & $19 \%$ & 19 & $73 \%$ & $25.64 \%$ & $33.00 \%$ \\
\hline $\begin{array}{l}\text { Videoconference } \\
\text { Mail }\end{array}$ & & $96 \%$ & 1 & $4 \%$ & 0 & $0 \%$ & 0 & $0 \%$ & 0 & $0 \%$ & 0 & $0 \%$ & 0 & $0 \%$ & 0 & $0 \%$ & 1 & $4 \%$ & 24 & $92 \%$ & $1731 \%$ & $26.00 \%$ \\
\hline $\begin{array}{l}\text { Mail } \\
\text { Direct mail }\end{array}$ & 0 & $0 \%$ & 0 & $0 \%$ & 0 & $0 \%$ & 0 & $0 \%$ & 1 & $4 \%$ & 24 & $92 \%$ & 24 & $92 \%$ & 1 & $4 \%$ & 0 & $0 \%$ & 0 & $0 \%$ & $9933 \%$ & $9900 \%$ \\
\hline Direct mail & 0 & $0 \%$ & 6 & $23 \%$ & 14 & $54 \%$ & 0 & $0 \%$ & 0 & $0 \%$ & 5 & $19 \%$ & 8 & $31 \%$ & 11 & $42 \%$ & 6 & $23 \%$ & 1 & $4 \%$ & $56.00 \%$ & $75.00 \%$ \\
\hline EPN mail & 1 & $4 \%$ & 4 & $15 \%$ & 8 & $31 \%$ & 10 & $38 \%$ & 0 & $0 \%$ & 2 & $8 \%$ & 4 & $15 \%$ & 8 & $31 \%$ & 10 & $38 \%$ & 2 & $8 \%$ & $56.67 \%$ & $64.58 \%$ \\
\hline Fax & 0 & $0 \%$ & 0 & $0 \%$ & 0 & $0 \%$ & 1 & $4 \%$ & 0 & $0 \%$ & 25 & $96 \%$ & 26 & $100 \%$ & 1 & $4 \%$ & 0 & $0 \%$ & 0 & $0 \%$ & $98.72 \%$ & $99.07 \%$ \\
\hline Internet & 20 & $77 \%$ & 5 & $19 \%$ & 0 & $0 \%$ & 0 & $0 \%$ & 0 & $0 \%$ & 0 & $0 \%$ & 1 & $4 \%$ & 3 & $12 \%$ & 6 & $23 \%$ & 9 & $35 \%$ & $20.00 \%$ & $44.74 \%$ \\
\hline EPN database & 1 & $4 \%$ & 3 & $12 \%$ & 3 & $12 \%$ & 10 & $38 \%$ & 3 & $12 \%$ & 2 & $8 \%$ & 9 & $35 \%$ & 8 & $31 \%$ & 3 & $12 \%$ & 2 & $8 \%$ & $\begin{array}{l}20.00 \% \\
62.88 \%\end{array}$ & $77.27 \%$ \\
\hline Face to face meetings & 0 & $0 \%$ & 2 & $8 \%$ & 1 & $4 \%$ & 7 & $27 \%$ & 3 & $12 \%$ & 13 & $50 \%$ & 14 & $54 \%$ & 8 & $31 \%$ & 2 & $8 \%$ & 1 & $4 \%$ & $82.05 \%$ & $85.00 \%$ \\
\hline Media - newspaper & 0 & $0 \%$ & 0 & $0 \%$ & 0 & $0 \%$ & 4 & $15 \%$ & 6 & $23 \%$ & 16 & $62 \%$ & 22 & $85 \%$ & 3 & $12 \%$ & 0 & $0 \%$ & 0 & $0 \%$ & $9103 \%$ & $9700 \%$ \\
\hline Media - radio & 0 & $0 \%$ & 0 & $0 \%$ & 3 & $12 \%$ & 7 & $27 \%$ & 4 & $15 \%$ & 12 & $46 \%$ & 19 & $73 \%$ & 5 & $19 \%$ & 2 & $8 \%$ & 0 & $0 \%$ & $8269 \%$ & $91.35 \%$ \\
\hline Media - television & 3 & $12 \%$ & 4 & $15 \%$ & 5 & $19 \%$ & 7 & $27 \%$ & 2 & $8 \%$ & 4 & $15 \%$ & 13 & $50 \%$ & 4 & $15 \%$ & 4 & $15 \%$ & 3 & $12 \%$ & $58.67 \%$ & $78.13 \%$ \\
\hline \multirow[t]{2}{*}{$\begin{array}{l}\text { Wedra-television } \\
\text { Other }\end{array}$} & 0 & $0 \%$ & 0 & $0 \%$ & 0 & $0 \%$ & 0 & $0 \%$ & 0 & $0 \%$ & 0 & $0 \%$ & 0 & $0 \%$ & 0 & $0 \%$ & 0 & $0 \%$ & 1 & $4 \%$ & $0.00 \%$ & $25.00 \%$ \\
\hline \multirow{2}{*}{\multicolumn{23}{|c|}{ Section 2 of 3 (incoming) }} \\
\hline & & & & & & & & & & & & & & & & & & & & & & \\
\hline & & & & & & & & & & & & & & & & & & & & & & \\
\hline Mobile Phone & 6 & $23 \%$ & 8 & $31 \%$ & 3 & $12 \%$ & 4 & $15 \%$ & 2 & $8 \%$ & 1 & $4 \%$ & 2 & $8 \%$ & 7 & $27 \%$ & 3 & $12 \%$ & 9 & $35 \%$ & $43.75 \%$ & $52.38 \%$ \\
\hline Telephone & 0 & $0 \%$ & 1 & $4 \%$ & 1 & $4 \%$ & $\frac{4}{2}$ & $8 \%$ & 0 & $0 \%$ & 20 & $77 \%$ & 20 & $77 \%$ & 1 & $4 \%$ & 1 & $4 \%$ & 0 & $0 \%$ & $92.36 \%$ & $96.59 \%$ \\
\hline Teleconference & 17 & $65 \%$ & 5 & $19 \%$ & 1 & $4 \%$ & 0 & $0 \%$ & 0 & $0 \%$ & 0 & $0 \%$ & 0 & $0 \%$ & 1 & $4 \%$ & 2 & $8 \%$ & 17 & $65 \%$ & $21.74 \%$ & $30.00 \%$ \\
\hline Videoconference & 22 & $85 \%$ & 1 & $4 \%$ & 0 & $0 \%$ & 0 & $0 \%$ & 0 & $0 \%$ & 0 & $0 \%$ & 0 & $0 \%$ & 0 & $0 \%$ & 0 & $0 \%$ & 18 & $69 \%$ & $17.39 \%$ & $25.00 \%$ \\
\hline Mail & 0 & $0 \%$ & 0 & $0 \%$ & 1 & $4 \%$ & 1 & $4 \%$ & 3 & $12 \%$ & 19 & $73 \%$ & 21 & $81 \%$ & 1 & $4 \%$ & 1 & $4 \%$ & 0 & $0 \%$ & $9444 \%$ & 96740 \\
\hline Direct mail & 2 & $8 \%$ & 7 & $27 \%$ & 10 & $38 \%$ & 3 & $12 \%$ & 0 & $0 \%$ & 1 & $4 \%$ & 0 & $0 \%$ & 8 & $31 \%$ & 10 & $38 \%$ & 4 & $15 \%$ & $46.38 \%$ & $54.55 \%$ \\
\hline Email & 18 & $69 \%$ & 2 & $8 \%$ & 1 & $4 \%$ & $\frac{3}{1}$ & $4 \%$ & 0 & $0 \%$ & 0 & $0 \%$ & 1 & $4 \%$ & 0 & $0 \%$ & 4 & $15 \%$ & 14 & $54 \%$ & $21.97 \%$ & $34.21 \%$ \\
\hline Fax & 0 & $0 \%$ & 1 & $4 \%$ & 3 & $12 \%$ & 8 & $31 \%$ & 5 & $19 \%$ & 7 & $27 \%$ & 13 & $50 \%$ & 7 & $27 \%$ & $\frac{4}{2}$ & $8 \%$ & 0 & $0 \%$ & $76.39 \%$ & $8750 \%$ \\
\hline Internet & 20 & $77 \%$ & 2 & $8 \%$ & 0 & $0 \%$ & 0 & $0 \%$ & 0 & $0 \%$ & 0 & $0 \%$ & 0 & $0 \%$ & 1 & $4 \%$ & 6 & $23 \%$ & 11 & $42 \%$ & $1818 \%$ & $3611 \%$ \\
\hline EPN database & 0 & $0 \%$ & 0 & $0 \%$ & 0 & $0 \%$ & 0 & $0 \%$ & 0 & $0 \%$ & 0 & $0 \%$ & 0 & $0 \%$ & 0 & $0 \%$ & 0 & $0 \%$ & 0 & $0 \%$ & $000 \%$ & $0.00 \%$ \\
\hline Face to face meetings & 0 & $0 \%$ & 1 & $4 \%$ & 1 & $4 \%$ & 5 & $19 \%$ & 4 & $15 \%$ & 13 & $50 \%$ & 17 & $65 \%$ & 2 & $8 \%$ & 1 & $4 \%$ & 0 & $0 \%$ & $85.42 \%$ & $95.00 \%$ \\
\hline Media - newspaper & 1 & $4 \%$ & 4 & $15 \%$ & 3 & $12 \%$ & 7 & $27 \%$ & $\begin{array}{l}4 \\
3\end{array}$ & $12 \%$ & 5 & $19 \%$ & 11 & $42 \%$ & 5 & $19 \%$ & 4 & $15 \%$ & 2 & $8 \%$ & $\begin{array}{l}03.42 \% \\
65.94 \%\end{array}$ & $78.41 \%$ \\
\hline Media - radio & 3 & $12 \%$ & 3 & $12 \%$ & 3 & $12 \%$ & 5 & $19 \%$ & 4 & $15 \%$ & 5 & $19 \%$ & 9 & $35 \%$ & 6 & $23 \%$ & $\overrightarrow{3}$ & $12 \%$ & 3 & $12 \%$ & $63.77 \%$ & $75.00 \%$ \\
\hline Media - television & 4 & $15 \%$ & 5 & $19 \%$ & 5 & $19 \%$ & 3 & $12 \%$ & $\frac{4}{4}$ & $15 \%$ & 2 & $8 \%$ & 6 & $23 \%$ & 7 & $27 \%$ & 5 & $19 \%$ & 3 & $12 \%$ & $52.90 \%$ & $6905 \%$ \\
\hline \multirow[t]{3}{*}{ Other } & 0 & $0 \%$ & 0 & $0 \%$ & 0 & $0 \%$ & 0 & $0 \%$ & 0 & $0 \%$ & 0 & $0 \%$ & 0 & $0 \%$ & 0 & $0 \%$ & 0 & $0 \%$ & 0 & $\begin{array}{r}12 \% \\
0 \%\end{array}$ & $\begin{array}{r}0.00 \% \\
0.00 \%\end{array}$ & $0.00 \%$ \\
\hline & & & & & & & & & & & & & & & & & & & & & & \\
\hline & & & & & & & & & & & & & & & & & & & & & & \\
\hline
\end{tabular}




\section{Groups:}

LABOR Total:

Section 1 of 3 (outgoing)

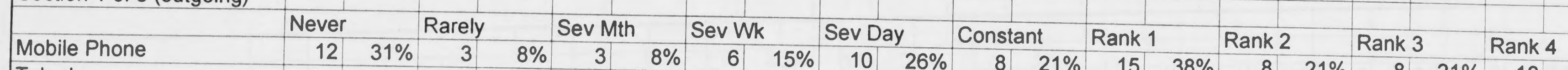

\begin{tabular}{|c|c|c|c|c|c|c|c|c|c|c|c|c|c|c|c|c|c|c|c|c|c|c|}
\hline & 12 & $31 \%$ & 3 & $8 \%$ & 3 & $8 \%$ & 6 & & & & & & & & & & & & 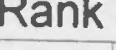 & & & \\
\hline Telephone & 0 & $0 \%$ & 0 & $0 \%$ & 0 & $0 \%$ & 0 & $0 \%$ & $\frac{10}{1}$ & $\frac{26 \%}{30 \%}$ & $\begin{array}{r}8 \\
40\end{array}$ & $21 \%$ & 15 & $38 \%$ & 8 & $21 \%$ & 8 & $21 \%$ & 10 & $26 \%$ & $59.13 \%$ & $67.07 \%$ \\
\hline Teleconference & 15 & $38 \%$ & 23 & $59 \%$ & 4 & $10 \%$ & 0 & $0 \%$ & 0 & $\begin{array}{l}3 \% \\
0 \%\end{array}$ & $\begin{array}{r}40 \\
0\end{array}$ & $103 \%$ & 39 & $100 \%$ & 1 & $3 \%$ & 0 & $0 \%$ & 1 & $3 \%$ & $99.59 \%$ & $97.56 \%$ \\
\hline Videoconference & 39 & $100 \%$ & 2 & $5 \%$ & 0 & $0 \%$ & 0 & $0 \%$ & 0 & $\begin{array}{l}0 \% \\
0 \%\end{array}$ & 0 & $0 \%$ & 1 & $3 \%$ & 2 & $5 \%$ & 8 & $21 \%$ & 30 & $77 \%$ & $28.97 \%$ & $34.15 \%$ \\
\hline Mail & 0 & $0 \%$ & 0 & $0 \%$ & 0 & $0 \%$ & 0 & $0 \%$ & 4 & $\begin{array}{r}0 \% \\
10 \%\end{array}$ & 0 & $0 \%$ & 0 & $0 \%$ & 0 & $0 \%$ & 1 & $3 \%$ & 38 & $97 \%$ & $17.48 \%$ & $25.64 \%$ \\
\hline irect mail & 1 & $3 \%$ & 7 & $18 \%$ & 22 & $56 \%$ & 0 & $0 \%$ & 0 & $\begin{aligned} 10 \% \\
0 \%\end{aligned}$ & 38 & $97 \%$ & 39 & $100 \%$ & 1 & $3 \%$ & 1 & $3 \%$ & 0 & $0 \%$ & $98.41 \%$ & $98.17 \%$ \\
\hline EPN mail & 2 & $5 \%$ & 8 & $21 \%$ & 7 & $18 \%$ & 19 & $49 \%$ & 5 & $\begin{array}{c}0 \% \\
13 \%\end{array}$ & 8 & $21 \%$ & 12 & $31 \%$ & 12 & $31 \%$ & 12 & $31 \%$ & 1 & $3 \%$ & 56 & $73.65 \%$ \\
\hline$a x$ & 0 & $0 \%$ & 0 & $0 \%$ & 0 & $0 \%$ & n & $0 \%$ & 6 & $\begin{array}{l}13 \% \\
15 \%\end{array}$ & 1. & $3 \%$ & 8 & $21 \%$ & 13 & $33 \%$ & 15 & $38 \%$ & 6 & $15 \%$ & $57.94 \%$ & $63.69 \%$ \\
\hline nternet & 37 & $95 \%$ & 2 & $5 \%$ & 0 & $0 \%$ & 0 & $0 \%$ & 0 & $\begin{array}{r}15 \% \\
0 \%\end{array}$ & 34 & $87 \%$ & 40 & $103 \%$ & 0 & $0 \%$ & 1 & $3 \%$ & 0 & $0 \%$ & 97 & $98.78 \%$ \\
\hline PN database & 0 & $0 \%$ & 7 & $18 \%$ & 5 & $13 \%$ & 13 & $33 \%$ & 5 & $\begin{array}{r}0 \% \\
13 \%\end{array}$ & 1. & $3 \%$ & 4 & $10 \%$ & 4 & $10 \%$ & 4 & $10 \%$ & 24 & $62 \%$ & & $41.67 \%$ \\
\hline Face to face meeting & 0 & $0 \%$ & 0 & $0 \%$ & 1 & $3 \%$ & 10 & $26 \%$ & 8 & $21 \%$ & $\frac{7}{21}$ & $18 \%$ & 14 & $36 \%$ & 11 & $28 \%$ & 10 & $26 \%$ & 2 & $5 \%$ & 66 & $75.00 \%$ \\
\hline Media - newspaper & 0 & $0 \%$ & 0 & $0 \%$ & 3 & $8 \%$ & 7 & $18 \%$ & 12 & $31 \%$ & 21 & $54 \%$ & 26 & $67 \%$ & 8 & $21 \%$ & 7 & $18 \%$ & 0 & $0 \%$ & $87.08 \%$ & $86.59 \%$ \\
\hline Media - radio & 1 & $3 \%$ & 4 & $10 \%$ & 4 & $10 \%$ & 9 & $23 \%$ & 8 & $\begin{array}{l}37 \% \\
21 \%\end{array}$ & 18 & $46 \%$ & 29 & $74 \%$ & 7 & $18 \%$ & 3 & $8 \%$ & 0 & $0 \%$ & $85.42 \%$ & $91.67 \%$ \\
\hline dia - television & 6 & $15 \%$ & 8 & $21 \%$ & 8 & $21 \%$ & 7 & $18 \%$ & 6 & $\frac{21 \%}{15 \%}$ & 13 & $33 \%$ & 14 & $36 \%$ & 15 & $38 \%$ & 8 & $21 \%$ & 1 & $3 \%$ & $74.79 \%$ & $77.63 \%$ \\
\hline ther & 0 & $0 \%$ & 0 & $0 \%$ & 0 & $0 \%$ & 0 & $0 \%$ & 0 & $0 \%$ & $\begin{array}{l}4 \\
0\end{array}$ & $\begin{array}{r}10 \% \\
0 \%\end{array}$ & $\begin{array}{r}10 \\
0\end{array}$ & $26 \%$ & 13 & $33 \%$ & 5 & $13 \%$ & 9 & $23 \%$ & $54.70 \%$ & $66.22 \%$ \\
\hline
\end{tabular}

Section 2 of 3 (incoming)

\begin{tabular}{|c|c|c|c|c|c|c|c|c|c|c|c|c|c|c|c|c|c|c|c|c|c|c|}
\hline & & & & & & & & & & & & & & & & & & & & & & \\
\hline & 8 & $21 \%$ & 10 & $26 \%$ & 3 & $8 \%$ & 5 & $13 \%$ & 5 & $13 \%$ & 3 & $8 \%$ & & & & & & & \multirow{2}{*}{\multicolumn{2}{|c|}{$14 \quad 36 \%$}} & \multirow[b]{2}{*}{$49.02 \%$} & \multirow[b]{2}{*}{$51.43 \%$} \\
\hline $\begin{array}{l}\text { Mobile Phone } \\
\text { Telephone } \\
\end{array}$ & 0 & $0 \%$ & 2 & $5 \%$ & 6 & $15 \%$ & 1 & $3 \%$ & 2 & $5 \%$ & 25 & $6 \%$ & $\frac{3}{25}$ & $8 \%$ & 10 & $26 \%$ & 8 & $21 \%$ & & & & \\
\hline Teleconference & 31 & $79 \%$ & 3 & $8 \%$ & 0 & $0 \%$ & 0 & $0 \%$ & 0 & $0 \%$ & 0 & & 25 & $64 \%$ & 6 & $15 \%$ & 3 & $8 \%$ & 0 & $0 \%$ & $86.11 \%$ & $91.18 \%$ \\
\hline Videoconference & 33 & $85 \%$ & 1 & $3 \%$ & 0 & $0 \%$ & 0 & $0 \%$ & U & $0 \%$ & 0 & $0 \%$ & 1 & $3 \%$ & 0 & $0 \%$ & 0 & $0 \%$ & 31 & $79 \%$ & $18.14 \%$ & $27.34 \%$ \\
\hline Mail & 0 & $0 \%$ & 0 & $0 \%$ & 4 & $10 \%$ & 1 & $3 \%$ & 6 & $15 \%$ & 24 & $\begin{array}{r}0 \% \\
20 \%\end{array}$ & 0 & $0 \%$ & 0 & $0 \%$ & 0 & $0 \%$ & 32 & $82 \%$ & $17.16 \%$ & $25.00 \%$ \\
\hline Direct mail & 5 & $13 \%$ & 6 & $15 \%$ & 11 & $28 \%$ & 3 & $8 \%$ & 1 & $3 \%$ & & $62 \%$ & 29 & $74 \%$ & 5 & $13 \%$ & 1 & $3 \%$ & 0 & $0 \%$ & $90.48 \%$ & $95.00 \%$ \\
\hline Email & 27 & $69 \%$ & 5 & $13 \%$ & 1 & $3 \%$ & 0 & $0 \%$ & 0 & $0 \%$ & & $8 \%$ & 7 & $18 \%$ & 5 & $13 \%$ & 10 & $26 \%$ & 7 & $18 \%$ & $48.85 \%$ & $60.34 \%$ \\
\hline Fax & 0 & $0 \%$ & 2 & $5 \%$ & 6 & $15 \%$ & 9 & $23 \%$ & 7 & $18 \%$ & 0 & $0 \%$ & 0 & $0 \%$ & 1 & $3 \%$ & 3 & $8 \%$ & 28 & $72 \%$ & $20.20 \%$ & $28.91 \%$ \\
\hline Internet & 35 & $90 \%$ & 1 & $3 \%$ & 0 & $0 \%$ & 0 & $0 \%$ & 0 & & 11 & $28 \%$ & 18 & $46 \%$ & 9 & $23 \%$ & 6 & $15 \%$ & 1 & $3 \%$ & $75.71 \%$ & $82.35 \%$ \\
\hline EPN database & 0 & $0 \%$ & 0 & $0 \%$ & 0 & $0 \%$ & 0 & $0 \%$ & 0 & $0 \%$ & 0 & $0 \%$ & 1 & $3 \%$ & 2 & $5 \%$ & 3 & $8 \%$ & 26 & $67 \%$ & $17.13 \%$ & $32.81 \%$ \\
\hline Face to face meetings & 0 & $0 \%$ & 1 & $3 \%$ & 4 & $10 \%$ & 5 & $13 \%$ & 12 & $\begin{array}{r}0 \% \\
31 \%\end{array}$ & 0 & $0 \%$ & 0 & $0 \%$ & 0 & $0 \%$ & 0 & $0 \%$ & 0 & $0 \%$ & $0.00 \%$ & $0.00 \%$ \\
\hline Media - newspaper & 3 & $8 \%$ & 4 & $10 \%$ & 8 & $21 \%$ & 6 & $15 \%$ & 3 & $31 \%$ & 15 & $38 \%$ & 21 & $54 \%$ & 11 & $28 \%$ & 3 & $8 \%$ & 1 & $3 \%$ & $82.88 \%$ & $86.11 \%$ \\
\hline Media - radio & 3 & $8 \%$ & 10 & $26 \%$ & 7 & $18 \%$ & 4 & $10 \%$ & $\frac{3}{2}$ & $8 \%$ & 9 & $23 \%$ & 12 & $31 \%$ & 5 & $13 \%$ & 8 & $21 \%$ & 6 & $15 \%$ & $64.65 \%$ & $68.55 \%$ \\
\hline Media - television & 8 & $21 \%$ & 6 & $15 \%$ & 7 & $18 \%$ & 7 & $18 \%$ & 3 & $8 \%$ & 7 & $18 \%$ & 8 & $21 \%$ & 4 & $10 \%$ & 9 & $23 \%$ & 10 & $26 \%$ & $57.35 \%$ & $58.06 \%$ \\
\hline \multirow[t]{3}{*}{ Other } & 0 & $0 \%$ & 0 & $0 \%$ & 0 & $0 \%$ & 0 & $\begin{array}{r}18 \% \\
0 \%\end{array}$ & 1 & $3 \%$ & 3 & $8 \%$ & 6 & $15 \%$ & 3 & $8 \%$ & 9 & $23 \%$ & 13 & $33 \%$ & $47.92 \%$ & $51.61 \%$ \\
\hline & & & & & & & & $0 \%$ & 0 & $0 \%$ & 0 & $0 \%$ & 0 & $0 \%$ & 0 & $0 \%$ & 0 & $0 \%$ & 0 & $0 \%$ & $0.00 \%$ & $0.00 \%$ \\
\hline & & & & & & & & & & & & & & & & & & & & & & \\
\hline
\end{tabular}




\section{Groups:}

NON-LABOR

Total:

Section 1 of 3 (outgoing)

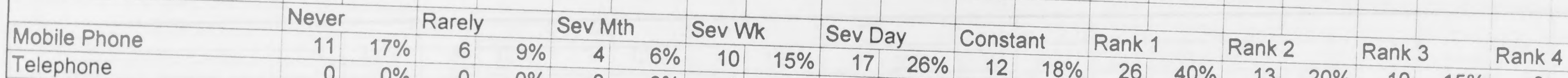

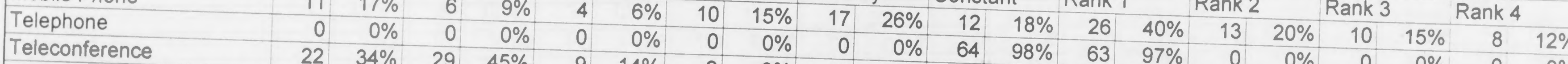

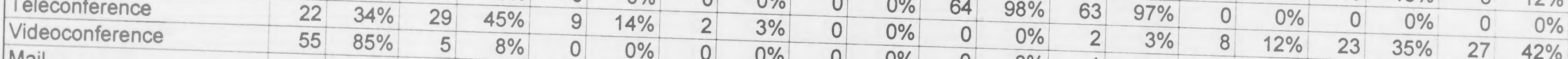

Mail

Direct mail

EPN mail

$55 \quad 85 \%$

Fax

Internet

EPN database

Face to face meetings

Media - newspaper

Media - radio

Media - television

0 $0 \%$

Section 2 of 3 (incoming)

Mobile Phone

Telephone

Teleconference

\begin{tabular}{|l|l|}
\hline 5 & $8 \%$ \\
\hline 0 & $0 \%$
\end{tabular}

$0 \%$

\begin{tabular}{|l|l|}
\hline & $3 \%$ \\
\hline & $0 \%$
\end{tabular}

$27 \quad 42 \%$

$64.44 \%$

$\quad 75.00 \%$ $12 \%$

$49 \%$ \begin{tabular}{|r|r|}
\hline 2 & $3 \%$ \\
\hline 7 & $11 \%$ \\
\hline
\end{tabular} \begin{tabular}{|l|r|r|r|r|}
\hline $5 \%$ & 59 & $91 \%$ & 59 & $91 \%$ \\
\hline
\end{tabular}

$2 \%$

Videoconference

$0 \%$

$40 \%$

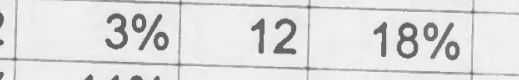

Mail

Direct mail

\begin{tabular}{r|r|r|}
\hline 53 & $82 \%$ \\
\hline 1 & $2 \%$ & 1 \\
\hline
\end{tabular}

$8 \%$

$1 \quad 2 \%$

\begin{tabular}{|l|l|l|l|}
\hline$\%$ & 4 & $6 \%$ & 3 \\
\hline & 0 & $0 \%$ & 0
\end{tabular}

\begin{tabular}{|l|l|l|l|l|l|l|}
\hline $11 \%$ & 5 & $8 \%$ & 17 & $26 \%$ & 25 & $31 \%$ \\
\hline
\end{tabular}

\begin{tabular}{l|l|}
5 & $8 \%$ \\
\hline & $3 \%$
\end{tabular}

$51 \quad 78 \%$

$30.91 \%$

$18.06 \%$

$98.18 \%$

$60.66 \%$

$61.98 \%$

$97.14 \%$

$18.64 \%$

$76.55 \%$

$78.84 \%$

$87.76 \%$

$77.22 \%$

$64.81 \%$

$0.00 \%$

$43.75 \%$

$28.51 \%$

$96.83 \%$

$77.42 \%$

$95.38 \%$

$38.33 \%$

$83.47 \%$

$0 \%$

\begin{tabular}{|r|}
\hline $9 \%$ \\
\hline $20 \%$ \\
\hline
\end{tabular}

\begin{tabular}{|r|r|r|r|r|r|r|}
\hline $11 \%$ & 11 & $17 \%$ & 15 & $23 \%$ & 21 & $32 \%$ \\
\hline
\end{tabular}

$\begin{array}{llll}0 & 0 \% & 0 & 0\end{array}$

\begin{tabular}{|r|r|r|r|}
\hline 0 & $0 \%$ & 0 & $0 \%$ \\
\hline
\end{tabular}

\begin{tabular}{r|r|}
\hline 10 & $15 \%$ \\
\hline 0 & $0 \%$
\end{tabular}

\begin{tabular}{|r|r|}
\hline & $20 \%$ \\
\hline 0 & $0 \%$
\end{tabular}

\begin{tabular}{|l|l|l|l|}
\hline 28 & $43 \%$ & 13 & $20 \%$ \\
\hline
\end{tabular}

\begin{tabular}{|r|r|r|}
\hline$\%$ & 6 & $9 \%$ \\
\hline
\end{tabular}

$3 \%$

$8.12 \%$

$96.09 \%$

$87.30 \%$ Email

Fax

Internet

EPN database

\begin{tabular}{|l|l|l|l|}
17 & $26 \%$ & 16 & $25 \%$ \\
\hline
\end{tabular}

4

\begin{tabular}{l|l|l}
$6 \%$ & 13 & $20 \%$
\end{tabular}

\begin{tabular}{|l|l|l|l|}
\hline 4 & & & \\
\hline & $6 \%$ & 6 & $9 \%$
\end{tabular}

\begin{tabular}{|r|r|r|}
\hline $0 \%$ & 2 & $3 \%$ \\
\hline $11 \%$ & 0 & $0 \%$ \\
\hline
\end{tabular}

\begin{tabular}{|l|r|r|r|}
\hline & $3 \%$ & 6 & $9 \%$ \\
\hline
\end{tabular}

$7 \quad 11 \%$

$+$

.

\begin{tabular}{|r|r|r|r|}
\hline 44 & $68 \%$ & 10 & $15 \%$ \\
\hline 58 & $89 \%$ & 2 & $3 \%$ \\
\hline
\end{tabular}

\begin{tabular}{|r|r|}
\hline 7 & $11 \%$ \\
\hline
\end{tabular}

$0 \%$

Face to face meetings
Media - newspaper

\begin{tabular}{l|l|l|l|}
58 & $89 \%$ & 2 & $3 \%$
\end{tabular}

\begin{tabular}{|l|l|l|l|l|}
\hline $0 \%$ & 0 & $0 \%$ & 0 & $0 \%$ \\
\hline
\end{tabular}

\begin{tabular}{|r|r|r|r|r|r|}
\hline $0 \%$ & 53 & $82 \%$ & 51 & $78 \%$ & 3 \\
\hline
\end{tabular}

3.

$17 \%$
$5 \%$

$15 \quad 23 \%$

\begin{tabular}{|r|r|r|r|}
\hline $3 \%$ & 4 & $6 \%$ \\
\hline $25 \%$ & 11 & $17 \%$ \\
\hline
\end{tabular}

$11 \%$

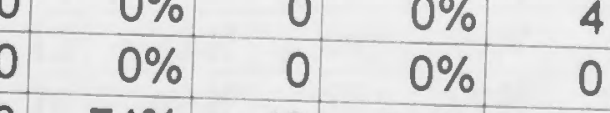

(20\%

\begin{tabular}{|r|r|r|}
\hline $6 \%$ & 7 & $11 \%$ \\
\hline
\end{tabular}

\begin{tabular}{|r|r|r|r|}
\hline 8 & $12 \%$ & 7 & $11 \%$ \\
\hline
\end{tabular}

\begin{tabular}{|r|r|r|}
\hline $25 \%$ & 11 & $17 \%$ \\
\hline $3 \%$ & 4 & $6 \%$ \\
\hline
\end{tabular}

$0 \%$

\begin{tabular}{|l|l|}
\hline 1 & $74 \%$ \\
\hline 1 & $17 \%$
\end{tabular}

\begin{tabular}{|l|l|l|}
\hline & $74 \%$ \\
\hline & $18 \%$ & \\
\hline
\end{tabular}

\begin{tabular}{|l|l|l|l|l|}
\hline $0 \%$ & 2 & $3 \%$ & 44 & $68 \%$ \\
\hline
\end{tabular}

$46.94 \%$

$93.99 \%$

$23.22 \%$

$17.22 \%$

$90.89 \%$

$56.60 \%$

$25.00 \%$

\begin{tabular}{|l|l|l|l|}
\hline 50 & $77 \%$ & 3 & $5 \%$ \\
\hline
\end{tabular}

\begin{tabular}{|r|r|r|}
\hline $8 \%$ & 19 & $29 \%$ \\
\hline
\end{tabular}

$2 \%$

\begin{tabular}{|l|r|r|r|r|r|r|}
\hline 4 & 2 & $18 \%$ & 15 & $23 \%$ & 11 & $17 \%$ \\
\hline
\end{tabular}

\begin{tabular}{|r|r|r|}
\hline $18 \%$ & 20 & $31 \%$ \\
\hline $0 \%$ & 0 & $0 \%$ \\
\hline
\end{tabular}

$45 \%$

Media - radio

Media-television

\begin{tabular}{|l|l|l|l|}
\hline 0 & $0 \%$ & 0 & $0 \%$ \\
\hline 1 & $2 \%$ & 3 & $5 \%$
\end{tabular}

$\begin{array}{lll}0 \% & 0 & 0 \%\end{array}$

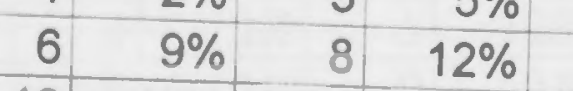

\begin{tabular}{|r|r|r|}
\hline $8 \%$ & 20 & $31 \%$ \\
\hline $11 \%$ & 13 & $20 \%$ \\
\hline
\end{tabular} $0 \quad 0 \%$

\begin{tabular}{|r|r|r|r|}
\hline 12 & $15 \%$ & 8 & $12 \%$ \\
\hline 0 & $0 \%$ & 10 & $15 \%$ \\
\hline
\end{tabular}

$9 \%$
$14 \%$

\begin{tabular}{|l|l|}
\hline 3 & $20 \%$ \\
\hline 0 & $15 \%$
\end{tabular}

$22 \%$

\begin{tabular}{|l|r|r|r|}
\hline 0 & $0 \%$ & 0 & $0 \%$ \\
\hline 5 & $23 \%$ & 32 & $49 \%$ \\
\hline
\end{tabular}

\begin{tabular}{l}
$3 \%$ \\
\hline 6
\end{tabular}

$17 \%$

$29 \quad 45 \%$

\begin{tabular}{l}
$7.61 \%$ \\
\hline
\end{tabular}

$32.24 \%$

\begin{tabular}{|r|r|}
\hline $75.29 \%$ & $86.79 \%$ \\
\hline
\end{tabular}

$64.20 \% \quad 75.96 \%$

$\begin{array}{llll}0 & 0 \% & 0 & 0 \%\end{array}$

\begin{tabular}{|r|r|}
\hline $14 \%$ \\
\hline $0 \%$ \\
\hline
\end{tabular}

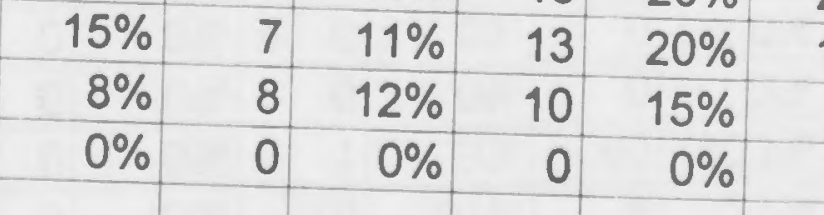

\begin{tabular}{|l|l|l|l|}
\hline 23 & $35 \%$ & 15 & $23 \%$ \\
\hline
\end{tabular}

\begin{tabular}{|r|r|r|r|r|}
\hline $26 \%$ & 14 & $22 \%$ & 10 \\
\hline $11 \%$ & 15 & $23 \%$ & 9 \\
\hline $2 \%$ & 0 & $0 \%$ & 0
\end{tabular}

$11 \%$

\begin{tabular}{|r|r|r|r|r|r|r|}
\hline $11 \%$ & 15 & $23 \%$ & 9 & $14 \%$ & 10 & $15 \%$ \\
\hline $2 \%$ & 0 & $0 \%$ & 0 & $0 \%$ & 0 & $0 \%$ \\
\hline
\end{tabular}

$60.80 \% \quad 70.41 \%$

\begin{tabular}{|l|l|}
\hline $55.25 \%$ & $61.59 \%$ \\
\hline
\end{tabular}

$0.00 \%$

$1.52 \%$ 


\section{Groups:}

W SENATE

N Total: 40 Section 1 of 3 (outgoing)

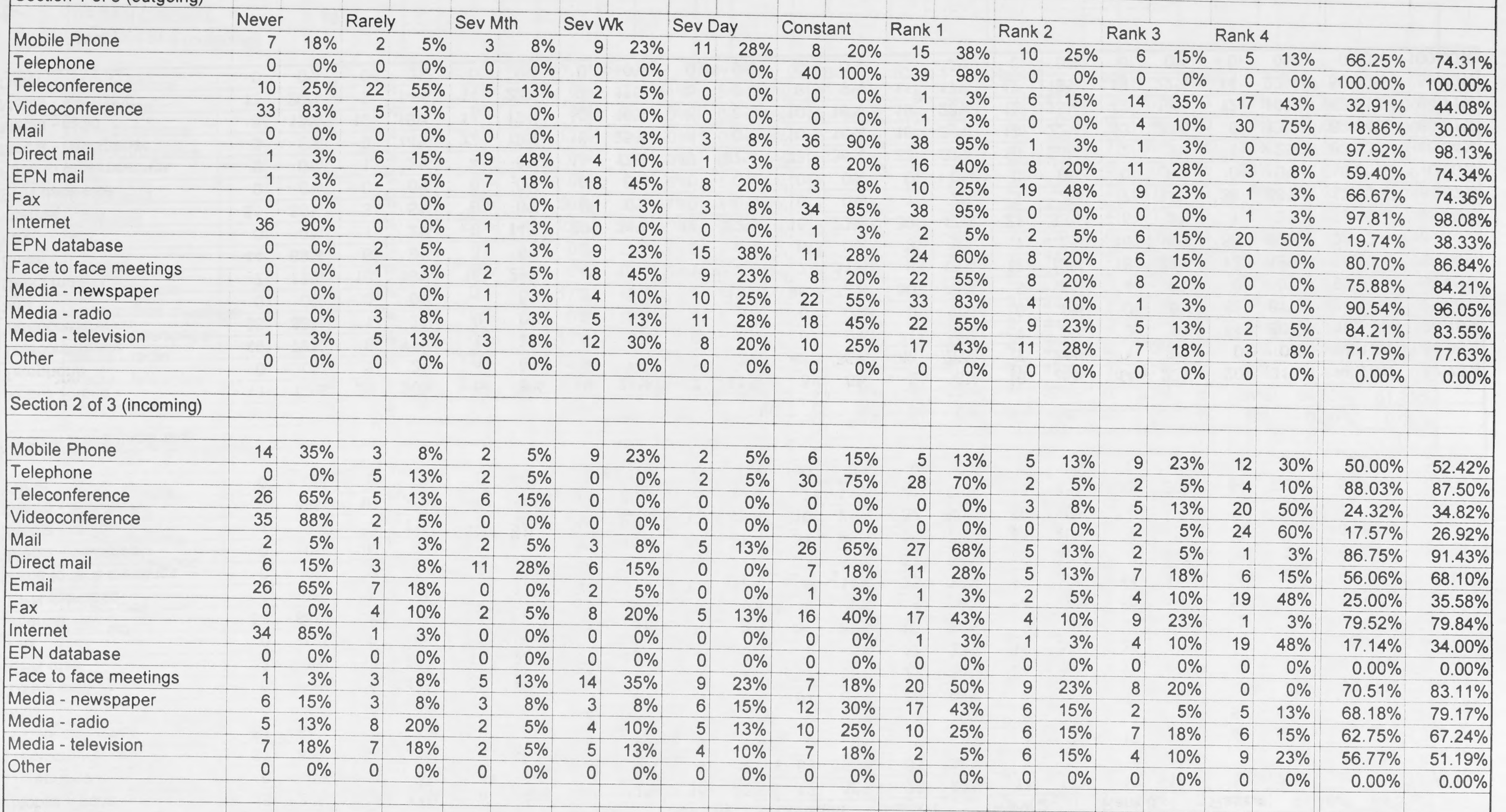




\begin{tabular}{|c|c|c|c|c|c|c|c|c|c|c|c|c|c|c|c|c|c|c|c|c|c|c|}
\hline Groups: & & & & & & & & & & & & & & & & & & & & & & \\
\hline NON-SENATE & & & & & & & & & & & & & & & & & & & & & & \\
\hline Total: & 64 & & & & & & & & & & & & & & & & & & & & & \\
\hline \multirow{2}{*}{\multicolumn{23}{|c|}{ Section 1 of 3 (outgoing) }} \\
\hline & & & & & & & & & & & & & & & & & & & & & & \\
\hline & Never & & Rarely & & Sev $M$ & & Sev $W$ & & Sev D & & Const: & ant & Rank & & Rank: & & Rank 3 & & Rank & & & \\
\hline Mobile Phone & 16 & $25 \%$ & 7 & $11 \%$ & 4 & $6 \%$ & 7 & $11 \%$ & 16 & $25 \%$ & 12 & $19 \%$ & 26 & $41 \%$ & 11 & $17 \%$ & 12 & $19 \%$ & 13 & $20 \%$ & $59.68 \%$ & $70.16 \%$ \\
\hline Telephone & 0 & $0 \%$ & 0 & $0 \%$ & 0 & $0 \%$ & 0 & $0 \%$ & 1 & $2 \%$ & 64 & $100 \%$ & 63 & $98 \%$ & 1 & $2 \%$ & 0 & $0 \%$ & 1 & $2 \%$ & $99.74 \%$ & $98.46 \%$ \\
\hline Teleconference & 27 & $42 \%$ & 30 & $47 \%$ & 8 & $13 \%$ & 0 & $0 \%$ & 0 & $0 \%$ & 0 & $0 \%$ & 2 & $3 \%$ & 4 & $6 \%$ & 17 & $27 \%$ & 40 & $63 \%$ & $28.46 \%$ & $37.30 \%$ \\
\hline Videoconference & 61 & $95 \%$ & 2 & $3 \%$ & 0 & $0 \%$ & 0 & $0 \%$ & 0 & $0 \%$ & 0 & $0 \%$ & 0 & $0 \%$ & 0 & $0 \%$ & 2 & $3 \%$ & 59 & $92 \%$ & $17.20 \%$ & $25.82 \%$ \\
\hline Mail & 0 & $0 \%$ & 0 & $0 \%$ & 0 & $0 \%$ & 1 & $2 \%$ & 4 & $6 \%$ & 61 & $95 \%$ & 60 & $94 \%$ & 1 & $2 \%$ & 2 & $3 \%$ & 1 & $2 \%$ & $98.48 \%$ & $96.88 \%$ \\
\hline Direct mail & 0 & $0 \%$ & 9 & $14 \%$ & 35 & $55 \%$ & 3 & $5 \%$ & 1 & $2 \%$ & 12 & $19 \%$ & 22 & $34 \%$ & 24 & $38 \%$ & 13 & $20 \%$ & 2 & $3 \%$ & $58.89 \%$ & $77.05 \%$ \\
\hline EPN mail & 2 & $3 \%$ & 13 & $20 \%$ & 18 & $28 \%$ & 27 & $42 \%$ & 4 & $6 \%$ & 3 & $5 \%$ & 15 & $23 \%$ & 19 & $30 \%$ & 25 & $39 \%$ & 6 & $9 \%$ & $56.72 \%$ & $66.54 \%$ \\
\hline Fax & 0 & $0 \%$ & 0 & $0 \%$ & 0 & $0 \%$ & 3 & $5 \%$ & 6 & $9 \%$ & 57 & $89 \%$ & 61 & $95 \%$ & 3 & $5 \%$ & 1 & $2 \%$ & 2 & $3 \%$ & $96.97 \%$ & $95.90 \%$ \\
\hline Internet & 54 & $84 \%$ & 7 & $11 \%$ & 0 & $0 \%$ & 0 & $0 \%$ & 0 & $0 \%$ & 0 & $0 \%$ & 4 & $6 \%$ & 4 & $6 \%$ & 12 & $19 \%$ & 31 & $48 \%$ & $18.58 \%$ & $40.69 \%$ \\
\hline EPN database & 1 & $2 \%$ & 6 & $9 \%$ & 11 & $17 \%$ & 20 & $31 \%$ & 11 & $17 \%$ & 9 & $14 \%$ & 23 & $36 \%$ & 19 & $30 \%$ & 11 & $17 \%$ & 5 & $8 \%$ & $67.53 \%$ & $75.86 \%$ \\
\hline Face to face meetings & 0 & $0 \%$ & 2 & $3 \%$ & 2 & $3 \%$ & 14 & $22 \%$ & 14 & $22 \%$ & 33 & $52 \%$ & 37 & $58 \%$ & 19 & $30 \%$ & 7 & $11 \%$ & 1 & $2 \%$ & $85.64 \%$ & $85.94 \%$ \\
\hline Media - newspaper & 0 & $0 \%$ & 0 & $0 \%$ & 6 & $9 \%$ & 13 & $20 \%$ & 17 & $27 \%$ & 31 & $48 \%$ & 50 & $78 \%$ & 13 & $20 \%$ & 2 & $3 \%$ & 0 & $0 \%$ & $84.83 \%$ & $93.46 \%$ \\
\hline Media - radio & 1 & $2 \%$ & 7 & $11 \%$ & 10 & $16 \%$ & 15 & $23 \%$ & 12 & $19 \%$ & 16 & $25 \%$ & 32 & $50 \%$ & 19 & $30 \%$ & 9 & $14 \%$ & 1 & $2 \%$ & $71.31 \%$ & $83.61 \%$ \\
\hline Media - television & 9 & $14 \%$ & 16 & $25 \%$ & 10 & $16 \%$ & 13 & $20 \%$ & 8 & $13 \%$ & 7 & $11 \%$ & 21 & $33 \%$ & 15 & $23 \%$ & 13 & $20 \%$ & 14 & $22 \%$ & $54.23 \%$ & $67.06 \%$ \\
\hline Other & 0 & $0 \%$ & 0 & $0 \%$ & 0 & $0 \%$ & 0 & $0 \%$ & 0 & $0 \%$ & 0 & $0 \%$ & 0 & $0 \%$ & 0 & $0 \%$ & 0 & $0 \%$ & 1 & $2 \%$ & $0.00 \%$ & $25.00 \%$ \\
\hline 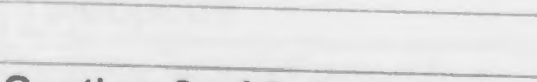 & & & & & & & & & & & & & & & & & & & & & & \\
\hline Section 2 of 3 (incoming) & & & & & & & & & & & & & & & & & & & & & & \\
\hline & & & & & & & & & & & & & & & & & & & & & & \\
\hline Mobile Phone & 11 & $17 \%$ & 23 & $36 \%$ & 5 & $8 \%$ & 9 & $14 \%$ & 7 & $11 \%$ & 3 & $5 \%$ & 5 & $8 \%$ & 16 & $25 \%$ & 14 & $22 \%$ & 20 & $31 \%$ & $46.26 \%$ & $52.73 \%$ \\
\hline Telephone & 0 & $0 \%$ & 1 & $2 \%$ & 4 & $6 \%$ & 3 & $5 \%$ & 2 & $3 \%$ & 48 & $75 \%$ & 48 & $75 \%$ & 7 & $11 \%$ & 1 & $2 \%$ & 0 & $0 \%$ & $93.10 \%$ & $95.98 \%$ \\
\hline Teleconference & 49 & $77 \%$ & 8 & $13 \%$ & 1 & $2 \%$ & 0 & $0 \%$ & 0 & $0 \%$ & 0 & $0 \%$ & 1 & $2 \%$ & 1 & $2 \%$ & 2 & $3 \%$ & 51 & $80 \%$ & $19.54 \%$ & $28.18 \%$ \\
\hline Videoconference & 56 & $88 \%$ & 1 & $2 \%$ & 0 & $0 \%$ & 0 & $0 \%$ & 0 & $0 \%$ & 0 & $0 \%$ & 0 & $0 \%$ & 0 & $0 \%$ & 0 & $0 \%$ & 52 & $81 \%$ & $16.96 \%$ & $25.00 \%$ \\
\hline Mail & 0 & $0 \%$ & 0 & $0 \%$ & 4 & $6 \%$ & 2 & $3 \%$ & 8 & $13 \%$ & 46 & $72 \%$ & 50 & $78 \%$ & 5 & $8 \%$ & 4 & $6 \%$ & 0 & $0 \%$ & $93.33 \%$ & $94.49 \%$ \\
\hline Direct mail & 7 & $11 \%$ & 10 & $16 \%$ & 16 & $25 \%$ & 8 & $13 \%$ & 1 & $2 \%$ & 7 & $11 \%$ & 8 & $13 \%$ & 12 & $19 \%$ & 18 & $28 \%$ & 12 & $19 \%$ & $52.38 \%$ & $58.00 \%$ \\
\hline Email & 44 & $69 \%$ & 6 & $9 \%$ & 3 & $5 \%$ & 2 & $3 \%$ & 0 & $0 \%$ & 0 & $0 \%$ & 3 & $5 \%$ & 1 & $2 \%$ & 10 & $16 \%$ & 38 & $59 \%$ & $22.12 \%$ & $35.10 \%$ \\
\hline Fax & 0 & $0 \%$ & 1 & $2 \%$ & 9 & $14 \%$ & 20 & $31 \%$ & 14 & $22 \%$ & 15 & $23 \%$ & 30 & $47 \%$ & 21 & $33 \%$ & 5 & $8 \%$ & 1 & $2 \%$ & $75.99 \%$ & $85.09 \%$ \\
\hline nternet & 51 & $80 \%$ & 3 & $5 \%$ & 0 & $0 \%$ & 0 & $0 \%$ & 0 & $0 \%$ & 0 & $0 \%$ & 1 & $2 \%$ & 1 & $2 \%$ & 7 & $11 \%$ & 36 & $56 \%$ & $17.59 \%$ & $31.67 \%$ \\
\hline PN database & 0 & $0 \%$ & 0 & $0 \%$ & 0 & $0 \%$ & 0 & $0 \%$ & 0 & $0 \%$ & 0 & $0 \%$ & 0 & $0 \%$ & 0 & $0 \%$ & 0 & $0 \%$ & 0 & $0 \%$ & $0.00 \%$ & $0.00 \%$ \\
\hline Face to face meetings & 0 & $0 \%$ & 1 & $2 \%$ & 4 & $6 \%$ & 11 & $17 \%$ & 17 & $27 \%$ & 23 & $36 \%$ & 33 & $52 \%$ & 16 & $25 \%$ & 2 & $3 \%$ & 1 & $2 \%$ & $83.63 \%$ & $88.94 \%$ \\
\hline Media - newspaper & 3 & $5 \%$ & 9 & $14 \%$ & 12 & $19 \%$ & 16 & $25 \%$ & 4 & $6 \%$ & 10 & $16 \%$ & 18 & $28 \%$ & 14 & $22 \%$ & 13 & $20 \%$ & 8 & $13 \%$ & $62.04 \%$ & $69.81 \%$ \\
\hline Media - radio & 8 & $13 \%$ & 10 & $16 \%$ & 11 & $17 \%$ & 10 & $16 \%$ & 5 & $8 \%$ & 10 & $16 \%$ & 15 & $23 \%$ & 12 & $19 \%$ & 12 & $19 \%$ & 12 & $19 \%$ & $57.41 \%$ & $64.71 \%$ \\
\hline Media - television & 13 & $20 \%$ & 9 & $14 \%$ & 14 & $22 \%$ & 7 & $11 \%$ & 5 & $8 \%$ & 6 & $9 \%$ & 11 & $17 \%$ & 12 & $19 \%$ & 14 & $22 \%$ & 14 & $22 \%$ & $50.00 \%$ & $59.80 \%$ \\
\hline Other & 0 & $0 \%$ & 0 & $0 \%$ & 0 & $0 \%$ & 0 & $0 \%$ & 0 & $0 \%$ & 0 & $0 \%$ & 1 & $2 \%$ & 0 & $0 \%$ & 0 & $0 \%$ & 0 & $0 \%$ & $0.00 \%$ & $100.00 \%$ \\
\hline
\end{tabular}




\begin{tabular}{|c|c|c|c|c|c|c|c|c|c|c|c|c|c|c|c|c|c|c|c|c|c|c|}
\hline & Neve & & Rare & & Sev & & Sev & & Sev & & Cons & $\tan t$ & Rank & & Rank & & Rank & & Rank & & Freq & Rank \\
\hline Mobile Phone & 3 & $17 \%$ & 2 & $11 \%$ & 0 & $0 \%$ & 2 & $11 \%$ & 5 & $28 \%$ & 2 & $11 \%$ & 6 & $33 \%$ & 3 & $17 \%$ & 3 & $17 \%$ & 3 & $17 \%$ & $61.90 \%$ & $70.00 \%$ \\
\hline Telephone & 0 & $0 \%$ & 0 & $0 \%$ & 0 & $0 \%$ & 0 & $0 \%$ & 0 & $0 \%$ & 18 & $100 \%$ & 17 & $94 \%$ & 0 & $0 \%$ & 0 & $0 \%$ & 0 & $0 \%$ & $100.00 \%$ & $100.00 \%$ \\
\hline Teleconference & 6 & $33 \%$ & 8 & $44 \%$ & 3 & $17 \%$ & 0 & $0 \%$ & 0 & $0 \%$ & 0 & $0 \%$ & 0 & $0 \%$ & 3 & $17 \%$ & 7 & $39 \%$ & 6 & $33 \%$ & $30.39 \%$ & $45.31 \%$ \\
\hline Videoconference & 16 & $89 \%$ & 0 & $0 \%$ & 0 & $0 \%$ & 0 & $0 \%$ & 0 & $0 \%$ & 0 & $0 \%$ & 0 & $0 \%$ & 0 & $0 \%$ & 0 & $0 \%$ & 15 & $83 \%$ & $16.67 \%$ & $25.00 \%$ \\
\hline Mail & 0 & $0 \%$ & 0 & $0 \%$ & 0 & $0 \%$ & 1 & $6 \%$ & 1 & $6 \%$ & 17 & $94 \%$ & 15 & $83 \%$ & 0 & $0 \%$ & 2 & $11 \%$ & 1 & $6 \%$ & $97.37 \%$ & $90.28 \%$ \\
\hline Direct mail & 0 & $0 \%$ & 0 & $0 \%$ & 10 & $56 \%$ & 3 & $17 \%$ & 1 & $6 \%$ & 1 & $6 \%$ & 6 & $33 \%$ & 6 & $33 \%$ & 2 & $11 \%$ & 1 & $6 \%$ & $58.89 \%$ & $78.33 \%$ \\
\hline EPN mail & 1 & $6 \%$ & 4 & $22 \%$ & 4 & $22 \%$ & 9 & $50 \%$ & 2 & $11 \%$ & 0 & $0 \%$ & 7 & $39 \%$ & 5 & $28 \%$ & 6 & $33 \%$ & 1 & $6 \%$ & $55.83 \%$ & $73.68 \%$ \\
\hline Fax & 0 & $0 \%$ & 0 & $0 \%$ & 0 & $0 \%$ & 2 & $11 \%$ & 2 & $11 \%$ & 14 & $78 \%$ & 14 & $78 \%$ & 2 & $11 \%$ & 0 & $0 \%$ & 2 & $11 \%$ & $94.44 \%$ & $88.89 \%$ \\
\hline Internet & 13 & $72 \%$ & 1 & $6 \%$ & 0 & $0 \%$ & 0 & $0 \%$ & 0 & $0 \%$ & 0 & $0 \%$ & 0 & $0 \%$ & 0 & $0 \%$ & 5 & $28 \%$ & 7 & $39 \%$ & $17.86 \%$ & $35.42 \%$ \\
\hline EPN database & 0 & $0 \%$ & 0 & $0 \%$ & 3 & $17 \%$ & 4 & $22 \%$ & 7 & $39 \%$ & 3 & $17 \%$ & 9 & $50 \%$ & 5 & $28 \%$ & 2 & $11 \%$ & 1 & $6 \%$ & $76.47 \%$ & $82.35 \%$ \\
\hline Face to face meetings & 0 & $0 \%$ & 0 & $0 \%$ & 0 & $0 \%$ & 5 & $28 \%$ & 6 & $33 \%$ & 6 & $33 \%$ & 9 & $50 \%$ & 8 & $44 \%$ & 0 & $0 \%$ & 0 & $0 \%$ & $84.31 \%$ & $88.24 \%$ \\
\hline Media - newspaper & 0 & $0 \%$ & 0 & $0 \%$ & 3 & $17 \%$ & 3 & $17 \%$ & 7 & $39 \%$ & 6 & $33 \%$ & 15 & $83 \%$ & 4 & $22 \%$ & 0 & $0 \%$ & 0 & $0 \%$ & $80.70 \%$ & $94.74 \%$ \\
\hline Media - radio & 0 & $0 \%$ & 3 & $17 \%$ & 4 & $22 \%$ & 1 & $6 \%$ & 6 & $33 \%$ & 1 & $6 \%$ & 9 & $50 \%$ & 3 & $17 \%$ & 3 & $17 \%$ & 0 & $0 \%$ & $64.44 \%$ & $85.00 \%$ \\
\hline Media - television & 2 & $11 \%$ & 6 & $33 \%$ & 2 & $11 \%$ & 2 & $11 \%$ & 5 & $28 \%$ & 1 & $6 \%$ & 5 & $28 \%$ & 4 & $22 \%$ & 6 & $33 \%$ & 5 & $28 \%$ & $54.63 \%$ & $61.25 \%$ \\
\hline Other & 0 & $0 \%$ & 0 & $0 \%$ & 0 & $0 \%$ & 0 & $0 \%$ & 0 & $0 \%$ & 0 & $0 \%$ & 0 & $0 \%$ & 0 & $0 \%$ & 0 & $0 \%$ & 0 & $0 \%$ & $0.00 \%$ & $0.00 \%$ \\
\hline
\end{tabular}

Section 2 of 3 (incoming)

\begin{tabular}{|l|r|r|r|r|r|r|r|l|l|l|l|l|l|l|l}
\hline & Never & Rarely & Sev Mth & Sev Wk & Sev Day & Constant & Rank 1 & Rank 2 & Rank 3 & Rank 4 \\
\hline Mobile Phone & 2 & $11 \%$ & 6 & $33 \%$ & 2 & $11 \%$ & 2 & $11 \%$ & 2 & $11 \%$ & 1 & $6 \%$ & 2 & $11 \%$ & 3
\end{tabular}

\begin{tabular}{|c|c|c|c|c|c|c|c|c|c|c|c|c|c|c|c|c|c|c|c|c|c|c|}
\hline Mobile Phone & 2 & $11 \%$ & 6 & $33 \%$ & $?$ & $110 \%$ & $?$ & & & & & & & & & & & & & & & \\
\hline Telephone & 0 & $0 \%$ & 0 & $0 \%$ & 0 & $0 \%$ & $\frac{2}{0}$ & $11 \%$ & 2 & $11 \%$ & 1. & $6 \%$ & 2 & $11 \%$ & 3 & $17 \%$ & 6 & $33 \%$ & 4 & $22 \%$ & $48.89 \%$ & $55.00 \%$ \\
\hline Teleconference & 15 & $83 \%$ & 1 & $6 \%$ & 0 & $0 \%$ & 0 & $0 \%$ & 2 & $11 \%$ & 13 & $72 \%$ & 14 & $78 \%$ & 1 & $6 \%$ & 0 & $0 \%$ & 0 & $0 \%$ & $97.78 \%$ & $98.33 \%$ \\
\hline Videoconference & 15 & $83 \%$ & 0 & $0 \%$ & 0 & $0 \%$ & 0 & $0 \%$ & 0 & $0 \%$ & 0 & $0 \%$ & 0 & $0 \%$ & 0 & $0 \%$ & 0 & $0 \%$ & 16 & $89 \%$ & $17.71 \%$ & $25.00 \%$ \\
\hline Mail & 0 & $0 \%$ & 0 & $0 \%$ & 0 & $0 \%$ & 0 & $0 \%$ & 0 & $0 \%$ & 0 & $0 \%$ & 0 & $0 \%$ & 0 & $0 \%$ & 0 & $0 \%$ & 15 & $83 \%$ & $16.67 \%$ & $25.00 \%$ \\
\hline Direct mail & 3 & $17 \%$ & 0 & $0 \%$ & 1. & $6 \%$ & 1 & $6 \%$ & 3 & $17 \%$ & 12 & $67 \%$ & 13 & $72 \%$ & 1 & $6 \%$ & 3 & $17 \%$ & 0 & $0 \%$ & $92.16 \%$ & $89.71 \%$ \\
\hline EPN mail & 10 & $56 \%$ & 2 & $11 \%$ & 3 & $17 \%$ & 2 & $11 \%$ & 0 & $0 \%$ & 3 & $17 \%$ & 4 & $22 \%$ & 2 & $11 \%$ & 3 & $17 \%$ & 3 & $17 \%$ & $57.58 \%$ & $64.58 \%$ \\
\hline Fax & 0 & $0 \%$ & 0 & $\begin{array}{r}17 \% \\
0 \%\end{array}$ & 1 & $6 \%$ & 1 & $6 \%$ & 0 & $0 \%$ & 0 & $0 \%$ & 2 & $11 \%$ & 0 & $0 \%$ & 3 & $17 \%$ & 9 & $50 \%$ & $25.00 \%$ & $41.07 \%$ \\
\hline Internet & 12 & $67 \%$ & 0 & $\begin{array}{l}0 \% \\
0 \%\end{array}$ & 1. & $6 \%$ & 6 & $33 \%$ & 6 & $33 \%$ & 3 & $17 \%$ & 8 & $44 \%$ & 7 & $39 \%$ & 1 & $6 \%$ & 0 & $0 \%$ & $78.13 \%$ & $85.94 \%$ \\
\hline Email & 0 & $0 \%$ & 0 & $0 \%$ & 0 & $0 \%$ & 0 & $0 \%$ & 0 & $0 \%$ & 0 & $0 \%$ & 0 & $0 \%$ & 0 & $0 \%$ & 0 & $0 \%$ & 10 & $56 \%$ & $16.67 \%$ & $25.00 \%$ \\
\hline Face to face meetings & 0 & $0 \%$ & 0 & $0 \%$ & 0 & $0 \%$ & 0 & $0 \%$ & 0 & $0 \%$ & 0 & $0 \%$ & 0 & $0 \%$ & 0 & $0 \%$ & 0 & $0 \%$ & 0 & $0 \%$ & $0.00 \%$ & $0.00 \%$ \\
\hline Media - newspaper & 1 & $6 \%$ & 2 & $11 \%$ & U & $0 \%$ & 5 & $28 \%$ & 5 & $28 \%$ & 3 & $17 \%$ & 6 & $33 \%$ & 7 & $39 \%$ & 0 & $0 \%$ & 0 & $0 \%$ & $80.77 \%$ & $86.54 \%$ \\
\hline Media - radio & 4 & $22 \%$ & 1 & $6 \%$ & 3 & $17 \%$ & 6 & $33 \%$ & 1 & $6 \%$ & 1 & $6 \%$ & 4 & $22 \%$ & 6 & $33 \%$ & 3 & $17 \%$ & 1 & $6 \%$ & $58.33 \%$ & $73.21 \%$ \\
\hline Media - television & 4 & $22 \%$ & 1 & $6 \%$ & 2 & $11 \%$ & 4. & $22 \%$ & 1 & $6 \%$ & 2 & $11 \%$ & 4 & $22 \%$ & 4 & $22 \%$ & 3 & $17 \%$ & 2 & $11 \%$ & $53.57 \%$ & $69.23 \%$ \\
\hline Other & 0 & $0 \%$ & 0 & $0 \%$ & $\begin{array}{l}4 \\
0\end{array}$ & $22 \%$ & 2 & $11 \%$ & 1 & $6 \%$ & 2 & $11 \%$ & 4 & $22 \%$ & 4 & $22 \%$ & 3 & $17 \%$ & 2 & $11 \%$ & $51.19 \%$ & $69.23 \%$ \\
\hline & & & & & & 70 & 0 & $0 \%$ & 0 & $0 \%$ & 0 & $0 \%$ & 1 & $6 \%$ & 0 & $0 \%$ & 0 & $0 \%$ & 0 & $0 \%$ & $0.00 \%$ & $5.26 \%$ \\
\hline
\end{tabular}




\begin{tabular}{|c|c|c|c|c|c|c|c|c|c|c|c|c|c|c|c|c|c|c|c|c|c|c|}
\hline Group: & & & & & & & & & & & & & & & & & & & & & & \\
\hline \multirow{2}{*}{\multicolumn{23}{|c|}{ Section 1 of 3 (outgoing) }} \\
\hline & & & & & & & & & & & & & & & & & & & & & & \\
\hline & \multicolumn{2}{|c|}{ Never } & \multicolumn{2}{|c|}{ Rarely } & \multicolumn{2}{|c|}{ Sev Mth } & \multicolumn{2}{|c|}{ Sev Wk } & \multicolumn{2}{|c|}{ Sev Day } & \multicolumn{2}{|c|}{ Constant } & \multicolumn{2}{|c|}{ Rank 1} & \multicolumn{2}{|c|}{ Rank 2} & \multicolumn{2}{|c|}{ Rank 3} & \multicolumn{2}{|c|}{ Rank 4} & & \\
\hline Mobile Phone & 9 & $45 \%$ & 2 & $10 \%$ & 1 & $5 \%$ & 1 & $5 \%$ & 5 & $25 \%$ & 4 & $20 \%$ & 9 & $45 \%$ & 2 & $10 \%$ & 5 & $25 \%$ & 6 & $30 \%$ & $52.27 \%$ & $65.91 \%$ \\
\hline Telephone & 0 & $0 \%$ & 0 & $0 \%$ & 0 & $0 \%$ & 0 & $0 \%$ & 1 & $5 \%$ & 20 & $100 \%$ & 19 & $95 \%$ & 1 & $5 \%$ & 0 & $0 \%$ & 1 & $5 \%$ & $99.21 \%$ & $95.24 \%$ \\
\hline Teleconference & 7 & $35 \%$ & 12 & $60 \%$ & 3 & $15 \%$ & 0 & $0 \%$ & 0 & $0 \%$ & 0 & $0 \%$ & 1 & $5 \%$ & 1 & $5 \%$ & 5 & $25 \%$ & 15 & $75 \%$ & $30.30 \%$ & $36.36 \%$ \\
\hline Videoconference & 20 & $100 \%$ & 1 & $5 \%$ & 0 & $0 \%$ & 0 & $0 \%$ & 0 & $0 \%$ & 0 & $0 \%$ & 0 & $0 \%$ & 0 & $0 \%$ & 1 & $5 \%$ & 20 & $100 \%$ & $17.46 \%$ & $26.19 \%$ \\
\hline Mail & 0 & $0 \%$ & 0 & $0 \%$ & 0 & $0 \%$ & 0 & $0 \%$ & 2 & $10 \%$ & 20 & $100 \%$ & 21 & $105 \%$ & 0 & $0 \%$ & 0 & $0 \%$ & 0 & $0 \%$ & $98.48 \%$ & $100.00 \%$ \\
\hline Direct mail & 0 & $0 \%$ & 3 & $15 \%$ & 11 & $55 \%$ & 0 & $0 \%$ & 0 & $0 \%$ & 6 & $30 \%$ & 8 & $40 \%$ & 7 & $35 \%$ & 5 & $25 \%$ & 0 & $0 \%$ & $62.50 \%$ & $78.75 \%$ \\
\hline EPN mail & 0 & $0 \%$ & 5 & $25 \%$ & 6 & $30 \%$ & 8 & $40 \%$ & 2 & $10 \%$ & 1 & $5 \%$ & 4 & $20 \%$ & 6 & $30 \%$ & 9 & $45 \%$ & 3 & $15 \%$ & $57.58 \%$ & $62.50 \%$ \\
\hline Fax & 0 & $0 \%$ & 0 & $0 \%$ & 0 & $0 \%$ & 0 & $0 \%$ & 4 & $20 \%$ & 18 & $90 \%$ & 21 & $105 \%$ & 0 & $0 \%$ & 1 & $5 \%$ & 0 & $0 \%$ & $96.97 \%$ & $97.73 \%$ \\
\hline Internet & 21 & $105 \%$ & 1 & $5 \%$ & 0 & $0 \%$ & 0 & $0 \%$ & 0 & $0 \%$ & 0 & $0 \%$ & 3 & $15 \%$ & 1 & $5 \%$ & 1 & $5 \%$ & 15 & $75 \%$ & $17.42 \%$ & $40.00 \%$ \\
\hline EPN database & 0 & $0 \%$ & 3 & $15 \%$ & 5 & $25 \%$ & 6 & $30 \%$ & 1 & $5 \%$ & 4 & $20 \%$ & 5 & $25 \%$ & 6 & $30 \%$ & 6 & $30 \%$ & 2 & $10 \%$ & $64.91 \%$ & $68.42 \%$ \\
\hline Face to face meetings & 0 & $0 \%$ & 0 & $0 \%$ & 1 & $5 \%$ & 2 & $10 \%$ & 5 & $25 \%$ & 14 & $70 \%$ & 14 & $70 \%$ & 3 & $15 \%$ & 5 & $25 \%$ & 0 & $0 \%$ & $90.91 \%$ & $85.23 \%$ \\
\hline Media - newspaper & 0 & $0 \%$ & 0 & $0 \%$ & 3 & $15 \%$ & 6 & $30 \%$ & 4 & $20 \%$ & 9 & $45 \%$ & 13 & $65 \%$ & 6 & $30 \%$ & 2 & $10 \%$ & 0 & $0 \%$ & $81.06 \%$ & $88.10 \%$ \\
\hline Media - radio & 1 & $5 \%$ & 4 & $20 \%$ & 3 & $15 \%$ & 7 & $35 \%$ & 2 & $10 \%$ & 3 & $15 \%$ & 4 & $20 \%$ & 11 & $55 \%$ & 4 & $20 \%$ & 1 & $5 \%$ & $61.67 \%$ & $72.50 \%$ \\
\hline Media - television & 4 & $20 \%$ & 6 & $30 \%$ & 3 & $15 \%$ & 4 & $20 \%$ & 1 & $5 \%$ & 2 & $10 \%$ & 3 & $15 \%$ & 7 & $35 \%$ & 3 & $15 \%$ & 6 & $30 \%$ & $48.33 \%$ & $59.21 \%$ \\
\hline \multirow[t]{2}{*}{ Other } & 0 & $0 \%$ & 0 & $0 \%$ & 0 & $0 \%$ & 0 & $0 \%$ & 0 & $0 \%$ & 0 & $0 \%$ & 0 & $0 \%$ & 0 & $0 \%$ & 0 & $0 \%$ & 0 & $0 \%$ & $0.00 \%$ & $0.00 \%$ \\
\hline \multirow{2}{*}{\multicolumn{23}{|c|}{ Section 2 of 3 (incoming) }} \\
\hline & & & & & & & & & & & & & & & & & & & & & & \\
\hline & \multicolumn{2}{|c|}{ Never } & \multicolumn{2}{|c|}{ Rarely } & \multicolumn{2}{|c|}{ Sev Mth } & \multicolumn{2}{|c|}{ Sev Wk } & \multicolumn{2}{|c|}{ Sev Day } & \multicolumn{2}{|c|}{ Constant } & Rank & & Rank & & Rank & & Ranl & & & \\
\hline Mobile Phone & 3 & $15 \%$ & 9 & $45 \%$ & 0 & $0 \%$ & 3 & $15 \%$ & 3 & $15 \%$ & 1 & $5 \%$ & 1 & $5 \%$ & 6 & $30 \%$ & 5 & $25 \%$ & 7 & $35 \%$ & $47.37 \%$ & $51.32 \%$ \\
\hline Telephone & 0 & $0 \%$ & 0 & $0 \%$ & 3 & $15 \%$ & 1 & $5 \%$ & 0 & $0 \%$ & 15 & $75 \%$ & 14 & $70 \%$ & 5 & $25 \%$ & 0 & $0 \%$ & 0 & $0 \%$ & $90.35 \%$ & $93.42 \%$ \\
\hline Teleconference & 17 & $85 \%$ & 2 & $10 \%$ & 0 & $0 \%$ & 0 & $0 \%$ & 0 & $0 \%$ & 0 & $0 \%$ & 1 & $5 \%$ & 0 & $0 \%$ & 0 & $0 \%$ & 18 & $90 \%$ & $18.42 \%$ & $28.95 \%$ \\
\hline Videoconference & 19 & $95 \%$ & 0 & $0 \%$ & 0 & $0 \%$ & 0 & $0 \%$ & 0 & $0 \%$ & 0 & $0 \%$ & 0 & $0 \%$ & 0 & $0 \%$ & 0 & $0 \%$ & 19 & $95 \%$ & $16.67 \%$ & $25.00 \%$ \\
\hline Mail & 0 & $0 \%$ & 0 & $0 \%$ & 2 & $10 \%$ & 0 & $0 \%$ & 2 & $10 \%$ & 15 & $75 \%$ & 16 & $80 \%$ & 3 & $15 \%$ & 0 & $0 \%$ & 0 & $0 \%$ & $92.98 \%$ & $96.05 \%$ \\
\hline Direct mail & 2 & $10 \%$ & 3 & $15 \%$ & 3 & $15 \%$ & 3 & $15 \%$ & 1 & $5 \%$ & 3 & $15 \%$ & 4 & $20 \%$ & 2 & $10 \%$ & 5 & $25 \%$ & 5 & $25 \%$ & $57.78 \%$ & $57.81 \%$ \\
\hline EPN mail & 16 & $80 \%$ & 2 & $10 \%$ & 1 & $5 \%$ & 0 & $0 \%$ & 0 & $0 \%$ & 0 & $0 \%$ & 0 & $0 \%$ & 1 & $5 \%$ & 3 & $15 \%$ & 15 & $75 \%$ & $20.18 \%$ & $31.58 \%$ \\
\hline Fax & 0 & $0 \%$ & 0 & $0 \%$ & 5 & $25 \%$ & 6 & $30 \%$ & 3 & $15 \%$ & 5 & $25 \%$ & 9 & $45 \%$ & 7 & $35 \%$ & 2 & $10 \%$ & 1 & $5 \%$ & $73.68 \%$ & $81.58 \%$ \\
\hline Internet & 19 & $95 \%$ & 1 & $5 \%$ & 0 & $0 \%$ & 0 & $0 \%$ & 0 & $0 \%$ & 0 & $0 \%$ & 1 & $5 \%$ & 0 & $0 \%$ & 1 & $5 \%$ & 15 & $75 \%$ & $17.50 \%$ & $30.88 \%$ \\
\hline Email & 0 & $0 \%$ & 0 & $0 \%$ & 0 & $0 \%$ & 0 & $0 \%$ & 0 & $0 \%$ & 0 & $0 \%$ & 0 & $0 \%$ & 0 & $0 \%$ & 0 & $0 \%$ & 0 & $0 \%$ & $0.00 \%$ & $0.00 \%$ \\
\hline Face to face meetings & 0 & $0 \%$ & 0 & $0 \%$ & 3 & $15 \%$ & 1 & $5 \%$ & 8 & $40 \%$ & 7 & $35 \%$ & 10 & $50 \%$ & 7 & $35 \%$ & 1 & $5 \%$ & 1 & $5 \%$ & $83.33 \%$ & $84.21 \%$ \\
\hline Media - newspaper & 1 & $5 \%$ & 3 & $15 \%$ & 6 & $30 \%$ & 3 & $15 \%$ & 0 & $0 \%$ & 4 & $20 \%$ & 3 & $15 \%$ & 3 & $15 \%$ & 6 & $30 \%$ & 5 & $25 \%$ & $59.80 \%$ & $55.88 \%$ \\
\hline Media - radio & 1 & $5 \%$ & 6 & $30 \%$ & 6 & $30 \%$ & 1 & $5 \%$ & 0 & $0 \%$ & 3 & $15 \%$ & 2 & $10 \%$ & 2 & $10 \%$ & 6 & $30 \%$ & 7 & $35 \%$ & $51.96 \%$ & $48.53 \%$ \\
\hline Media - television & 5 & $25 \%$ & 3 & $15 \%$ & 5 & $25 \%$ & 2 & $10 \%$ & 0 & $0 \%$ & 2 & $10 \%$ & 1 & $5 \%$ & 1 & $5 \%$ & 6 & $30 \%$ & 9 & $45 \%$ & $45.10 \%$ & $41.18 \%$ \\
\hline Other & 0 & $0 \%$ & 0 & $0 \%$ & 0 & $0 \%$ & 0 & $0 \%$ & 0 & $0 \%$ & 0 & $0 \%$ & 0 & $0 \%$ & 0 & $0 \%$ & 0 & $0 \%$ & 0 & $0 \%$ & $0.00 \%$ & $0.00 \%$ \\
\hline & & & & & & & & & & & & & & & & & & & & & & \\
\hline
\end{tabular}




\begin{tabular}{|c|c|c|c|c|c|c|c|c|c|c|c|c|c|c|c|c|c|c|c|c|c|c|}
\hline Group: & & & & & & & & & & & & & & & & & & & & & & \\
\hline RURAL LIBERAL & 19 & & & & & & & & & & & & & & & & & & & & & \\
\hline Section 1 of 3 (outgoing) & & & & & & & & & & & & & & & & & & & & & & \\
\hline & \multicolumn{2}{|c|}{ Never } & \multicolumn{2}{|c|}{ Rarely } & \multicolumn{2}{|c|}{ Sev Mth } & \multicolumn{2}{|c|}{ Sev Wk } & \multicolumn{2}{|c|}{ Sev Day } & \multirow{2}{*}{\multicolumn{2}{|c|}{ Constant }} & \multirow{2}{*}{\multicolumn{2}{|c|}{ Rank 1}} & \multirow{2}{*}{\multicolumn{2}{|c|}{ Rank 2}} & \multirow{2}{*}{\multicolumn{2}{|c|}{ Rank 3}} & & & & \\
\hline Mobile Phone & 4 & $21 \%$ & 3 & $16 \%$ & 2 & $11 \%$ & 3 & $16 \%$ & 2 & $11 \%$ & & & & & & & & & \multicolumn{2}{|c|}{ Rank 4} & & \\
\hline Telephone & 0 & $0 \%$ & 0 & $0 \%$ & 0 & $0 \%$ & 0 & $0 \%$ & 0 & & 4 & $21 \%$ & 7 & $37 \%$ & 4 & $21 \%$ & 3 & $16 \%$ & 3 & $16 \%$ & $57.41 \%$ & $72.06 \%$ \\
\hline Teleconference & 11 & $58 \%$ & 6 & $32 \%$ & 1 & $5 \%$ & 0 & $0 \%$ & 0 & $0 \%$ & 18 & $95 \%$ & 19 & $100 \%$ & 0 & $0 \%$ & 0 & $0 \%$ & 0 & $0 \%$ & $100.00 \%$ & $100.00 \%$ \\
\hline Videoconference & 18 & $95 \%$ & 0 & $0 \%$ & 0 & $0 \%$ & 0 & $0 \%$ & & $0 \%$ & 0 & $0 \%$ & 1 & $5 \%$ & 0 & $0 \%$ & 4 & $21 \%$ & 12 & $63 \%$ & $24.07 \%$ & $35.29 \%$ \\
\hline Mail & 0 & $0 \%$ & 0 & $0 \%$ & 0 & $0 \%$ & 0 & $0 \%$ & $\begin{array}{l}0 \\
1\end{array}$ & $0 \%$ & 0 & $0 \%$ & 0 & $0 \%$ & 0 & $0 \%$ & 1 & $5 \%$ & 16 & $84 \%$ & $16.67 \%$ & $26.47 \%$ \\
\hline Direct mail & 0 & $0 \%$ & 5 & $26 \%$ & 9 & $47 \%$ & 0 & $0 \%$ & 1. & $5 \%$ & 16 & $84 \%$ & 17 & $89 \%$ & 0 & $0 \%$ & 0 & $0 \%$ & 0 & $0 \%$ & $99.02 \%$ & $100.00 \%$ \\
\hline EPN mail & 0 & $0 \%$ & 2 & $11 \%$ & 8 & $42 \%$ & 5 & $\begin{array}{r}0 \% \\
26 \%\end{array}$ & 0 & $0 \%$ & 4 & $21 \%$ & 7 & $37 \%$ & 8 & $42 \%$ & 3 & $16 \%$ & 1 & $5 \%$ & $56.48 \%$ & $77.63 \%$ \\
\hline Fax & 0 & $0 \%$ & 0 & $0 \%$ & 0 & $0 \%$ & 1 & & 0 & $0 \%$ & 2 & $11 \%$ & 2 & $11 \%$ & 7 & $37 \%$ & 7 & $37 \%$ & 0 & $0 \%$ & $58.82 \%$ & $67.19 \%$ \\
\hline Internet & 13 & $68 \%$ & 4 & $21 \%$ & 0 & $0 \%$ & 0 & $\begin{array}{l}5 \% \\
0 \%\end{array}$ & 0 & $0 \%$ & 17 & $89 \%$ & 18 & $95 \%$ & 1 & $5 \%$ & 0 & $0 \%$ & 0 & $0 \%$ & $98.15 \%$ & $98.68 \%$ \\
\hline EPN database & 1 & $5 \%$ & 1 & $5 \%$ & 3 & $16 \%$ & 8 & \begin{tabular}{r|}
$0 \%$ \\
$42 \%$
\end{tabular} & 0 & $0 \%$ & 0 & $0 \%$ & 1 & $5 \%$ & 1 & $5 \%$ & 5 & $26 \%$ & 5 & $26 \%$ & $20.59 \%$ & $45.83 \%$ \\
\hline Face to face meetings & 0 & $0 \%$ & 2 & $11 \%$ & 1 & $5 \%$ & 6 & $42 \%$ & 2 & $11 \%$ & 0 & $0 \%$ & 5 & $26 \%$ & 7 & $37 \%$ & 1 & $5 \%$ & 2 & $11 \%$ & $60.00 \%$ & $75.00 \%$ \\
\hline Media - newspaper & 0 & $0 \%$ & 0 & $0 \%$ & 0 & $0 \%$ & & $32 \%$ & 2 & $11 \%$ & 7 & $37 \%$ & 9 & $47 \%$ & 5 & $26 \%$ & 2 & $11 \%$ & 1 & $5 \%$ & $76.85 \%$ & $82.35 \%$ \\
\hline Media - radio & 0 & $0 \%$ & 0 & $0 \%$ & 2 & \begin{tabular}{r|}
$0 \%$ \\
$11 \%$
\end{tabular} & 4 & $21 \%$ & 3 & $16 \%$ & 11 & $58 \%$ & 15 & $79 \%$ & 2 & $11 \%$ & 0 & $0 \%$ & 0 & $0 \%$ & $89.81 \%$ & $97.06 \%$ \\
\hline Media - television & 2 & $11 \%$ & 4 & $21 \%$ & 2 & & 6 & $32 \%$ & 3 & $16 \%$ & 7 & $37 \%$ & 13 & $68 \%$ & 4 & $21 \%$ & 1 & $5 \%$ & 0 & $0 \%$ & $80.56 \%$ & $91.67 \%$ \\
\hline \multirow{2}{*}{$\begin{array}{l}\text { Medıa - television } \\
\text { Other }\end{array}$} & 0 & $0 \%$ & 0 & $0 \%$ & 0 & \begin{tabular}{r|r}
$11 \%$ \\
$0 \%$
\end{tabular} & 6 & $32 \%$ & 0 & $0 \%$ & 3 & $16 \%$ & 9 & $47 \%$ & 2 & $11 \%$ & 4 & $21 \%$ & 2 & $11 \%$ & $56.86 \%$ & $76.47 \%$ \\
\hline & & & & & & $0 \%$ & 0 & $0 \%$ & 0 & $0 \%$ & 0 & $0 \%$ & 0 & $0 \%$ & 0 & $0 \%$ & 0 & $0 \%$ & 0 & $0 \%$ & $0.00 \%$ & $0.00 \%$ \\
\hline Section 2 of 3 (incoming) & & & & & & & & & & & & & & & & & & & & & & \\
\hline & \multicolumn{2}{|c|}{ Never } & \multicolumn{2}{|c|}{ Rarely } & \multirow{2}{*}{\multicolumn{2}{|c|}{ Sev Mth }} & & & & & & & & & & & & & & & & \\
\hline Mobile Phone & 5 & $26 \%$ & 7 & $37 \%$ & & & \multicolumn{2}{|c|}{ Sev Wk } & \multicolumn{2}{|c|}{ Sev Day } & \multicolumn{2}{|c|}{ Constant } & Rank & & Rank & & Rank & & Rank & & & \\
\hline Telephone & 0 & $0 \%$ & 1 & $5 \%$ & 1. & $5 \%$ & 3 & $16 \%$ & 1 & $5 \%$ & 1 & $5 \%$ & 2 & $11 \%$ & 4 & $21 \%$ & 2 & $11 \%$ & 7 & $37 \%$ & $41.67 \%$ & $51.67 \%$ \\
\hline Teleconference & 12 & $63 \%$ & 4 & $\begin{array}{r}5 \% \\
21 \%\end{array}$ & 0 & $0 \%$ & 2 & $11 \%$ & 0 & $0 \%$ & 15 & $79 \%$ & 15 & $79 \%$ & 1 & $5 \%$ & 0 & $0 \%$ & 0 & $0 \%$ & $92.59 \%$ & $98.44 \%$ \\
\hline Videoconference & 17 & $89 \%$ & $\begin{array}{l}4 \\
0\end{array}$ & & 1 & $5 \%$ & 0 & $0 \%$ & 0 & $0 \%$ & 0 & $0 \%$ & 0 & $0 \%$ & 1 & $5 \%$ & 2 & $11 \%$ & 11 & $58 \%$ & $22.55 \%$ & $32.14 \%$ \\
\hline Mail & 0 & $\begin{aligned} 89 \% \\
0 \%\end{aligned}$ & $\begin{array}{l}0 \\
0\end{array}$ & \begin{tabular}{l|}
$0 \%$ \\
$0 \%$
\end{tabular} & 0 & $0 \%$ & 0 & $0 \%$ & 0 & $0 \%$ & 0 & $0 \%$ & 0 & $0 \%$ & 0 & $0 \%$ & 0 & $0 \%$ & 12 & $63 \%$ & $16.67 \%$ & $25.00 \%$ \\
\hline Direct mail & 2 & $\begin{array}{r}0 \% \\
11 \%\end{array}$ & $\begin{array}{l}0 \\
5\end{array}$ & $\begin{array}{r}0 \% \\
26 \%\end{array}$ & 1 & $5 \%$ & 1 & $5 \%$ & 2 & $11 \%$ & 14 & $74 \%$ & 15 & $79 \%$ & 1 & $5 \%$ & 1 & $5 \%$ & 0 & $0 \%$ & $93.52 \%$ & $95.59 \%$ \\
\hline EPN mail & 13 & $\frac{11 \%}{68 \%}$ & $\begin{array}{l}5 \\
1\end{array}$ & $\begin{array}{r}26 \% \\
5 \%\end{array}$ & 6 & $32 \%$ & 3 & $16 \%$ & 0 & $0 \%$ & 1 & $5 \%$ & 0 & $0 \%$ & 5 & $26 \%$ & 7 & $37 \%$ & 4 & $21 \%$ & $47.06 \%$ & $51.56 \%$ \\
\hline Fax & 0 & & 1 & $\begin{array}{l}5 \% \\
5 \%\end{array}$ & 1 & $5 \%$ & 1 & $5 \%$ & 0 & $0 \%$ & 0 & $0 \%$ & 1 & $5 \%$ & 0 & $0 \%$ & 4 & $21 \%$ & 8 & $42 \%$ & $22.92 \%$ & $38.46 \%$ \\
\hline nternet & 14 & $\begin{array}{r}0 \% \\
74 \%\end{array}$ & 1. & $\begin{array}{r}5 \% \\
11 \%\end{array}$ & 2 & $11 \%$ & 8 & $42 \%$ & 4 & $21 \%$ & 3 & $16 \%$ & 8 & $42 \%$ & 7 & $37 \%$ & 1 & $5 \%$ & 0 & $0 \%$ & $72.22 \%$ & $85.94 \%$ \\
\hline Email & 0 & $\begin{array}{r}74 \% \\
0 \%\end{array}$ & 2 & $11 \%$ & 0 & $0 \%$ & 0 & $0 \%$ & 0 & $0 \%$ & 0 & $0 \%$ & 0 & $0 \%$ & 0 & $0 \%$ & 6 & $32 \%$ & 6 & $32 \%$ & $18.75 \%$ & $37.50 \%$ \\
\hline Face to face meetings & 0 & $\begin{array}{l}0 \% \\
0 \%\end{array}$ & 0 & $0 \%$ & 0 & $0 \%$ & 0 & $0 \%$ & 0 & $0 \%$ & 0 & $0 \%$ & 0 & $0 \%$ & 0 & $0 \%$ & 0 & $0 \%$ & 0 & $0 \%$ & $0.00 \%$ & $0.00 \%$ \\
\hline Media - newspaper & 1 & $\begin{array}{l}0 \% \\
5 \%\end{array}$ & 1 & $5 \%$ & 1 & $5 \%$ & 5 & $26 \%$ & 3 & $16 \%$ & 8 & $42 \%$ & 11 & $58 \%$ & 2 & $11 \%$ & 1 & $5 \%$ & 0 & $0 \%$ & $81.48 \%$ & $92.86 \%$ \\
\hline Media - radio & 2 & $\begin{array}{r}5 \% \\
11 \%\end{array}$ & 4 & $21 \%$ & 1 & $5 \%$ & 6 & $32 \%$ & 2 & $11 \%$ & 3 & $16 \%$ & 7 & $37 \%$ & 4 & $21 \%$ & 3 & $16 \%$ & 2 & $11 \%$ & $62.75 \%$ & $75.00 \%$ \\
\hline Media - television & 3 & & 3 & $16 \%$ & 2 & $11 \%$ & 4 & $21 \%$ & 3 & $16 \%$ & 3 & $16 \%$ & 5 & $26 \%$ & 5 & $26 \%$ & 3 & $16 \%$ & 2 & $11 \%$ & $61.76 \%$ & $71.67 \%$ \\
\hline Other & 0 & $\begin{array}{r}16 \% \\
0 \%\end{array}$ & 5 & $26 \%$ & 3 & $16 \%$ & 2 & $11 \%$ & 3 & $16 \%$ & 1 & $5 \%$ & 3 & $16 \%$ & 6 & $32 \%$ & 4 & $21 \%$ & 2 & $11 \%$ & $50.00 \%$ & $66.67 \%$ \\
\hline & & $0 \%$ & 0 & $0 \%$ & 0 & $0 \%$ & 0 & $0 \%$ & 0 & $0 \%$ & 0 & $0 \%$ & 0 & $0 \%$ & 0 & $0 \%$ & 0 & $0 \%$ & 0 & $0 \%$ & $0.00 \%$ & $0.00 \%$ \\
\hline
\end{tabular}




\begin{tabular}{|c|c|c|c|c|c|c|c|c|c|c|c|c|c|c|c|c|c|c|c|c|c|c|}
\hline Group: & & & & & & & & & & & & & & & & & & & & & & \\
\hline \multirow{2}{*}{\multicolumn{23}{|c|}{ Section 1 of 3 (outgoing) }} \\
\hline & & & & & & & & & & & & & & & & & & & & bits & & \\
\hline & \multicolumn{2}{|c|}{ Never } & \multicolumn{2}{|c|}{ Rarely } & \multicolumn{2}{|c|}{ Sev Mth } & \multicolumn{2}{|c|}{ Sev Wk } & \multicolumn{2}{|c|}{ Sev Day } & \multicolumn{2}{|c|}{ Constant } & \multicolumn{2}{|c|}{ Rank 1} & \multicolumn{2}{|c|}{ Rank 2} & \multicolumn{2}{|c|}{ Rank 3} & \multicolumn{2}{|c|}{ Rank 4} & & \\
\hline Mobile Phone & 0 & $0 \%$ & 0 & $0 \%$ & 1 & $14 \%$ & 1 & $14 \%$ & 4 & $57 \%$ & 2 & $29 \%$ & 4 & $57 \%$ & 2 & $29 \%$ & 1 & $14 \%$ & 1 & $14 \%$ & $81.25 \%$ & $78.13 \%$ \\
\hline Telephone & 0 & $0 \%$ & 0 & $0 \%$ & 0 & $0 \%$ & 0 & $0 \%$ & 0 & $0 \%$ & 8 & $114 \%$ & 8 & $114 \%$ & 0 & $0 \%$ & 0 & $0 \%$ & 0 & $0 \%$ & $100.00 \%$ & $100.00 \%$ \\
\hline Teleconference & 3 & $43 \%$ & 4 & $57 \%$ & 1 & $14 \%$ & 0 & $0 \%$ & 0 & $0 \%$ & 0 & $0 \%$ & 0 & $0 \%$ & 0 & $0 \%$ & 1 & $14 \%$ & 7 & $100 \%$ & $29.17 \%$ & $28.13 \%$ \\
\hline Videoconference & 7 & $100 \%$ & 1 & $14 \%$ & 0 & $0 \%$ & 0 & $0 \%$ & 0 & $0 \%$ & 0 & $0 \%$ & 0 & $0 \%$ & 0 & $0 \%$ & 0 & $0 \%$ & 8 & $114 \%$ & $18.75 \%$ & $25.00 \%$ \\
\hline Mail & 0 & $0 \%$ & 0 & $0 \%$ & 0 & $0 \%$ & 0 & $0 \%$ & 0 & $0 \%$ & 8 & $114 \%$ & 7 & $100 \%$ & 1 & $14 \%$ & 0 & $0 \%$ & 0 & $0 \%$ & $100.00 \%$ & $96.88 \%$ \\
\hline Direct mail & 0 & $0 \%$ & 1 & $14 \%$ & 5 & $71 \%$ & 0 & $0 \%$ & 0 & $0 \%$ & 1 & $14 \%$ & 1 & $14 \%$ & 3 & $43 \%$ & 3 & $43 \%$ & 0 & $0 \%$ & $54.76 \%$ & $67.86 \%$ \\
\hline EPN mail & 1 & $14 \%$ & 2 & $29 \%$ & 0 & $0 \%$ & 5 & $71 \%$ & 0 & $0 \%$ & 0 & $0 \%$ & 2 & $29 \%$ & 1 & $14 \%$ & 3 & $43 \%$ & 2 & $29 \%$ & $52.08 \%$ & $59.38 \%$ \\
\hline Fax & 0 & $0 \%$ & 0 & $0 \%$ & 0 & $0 \%$ & 0 & $0 \%$ & 0 & $0 \%$ & 8 & $114 \%$ & 8 & $114 \%$ & 0 & $0 \%$ & 0 & $0 \%$ & 0 & $0 \%$ & $100.00 \%$ & $100.00 \%$ \\
\hline Internet & 7 & $100 \%$ & 1 & $14 \%$ & 0 & $0 \%$ & 0 & $0 \%$ & 0 & $0 \%$ & 0 & $0 \%$ & 0 & $0 \%$ & 2 & $29 \%$ & 1 & $14 \%$ & 4 & $57 \%$ & $18.75 \%$ & $42.86 \%$ \\
\hline EPN database & 0 & $0 \%$ & 2 & $29 \%$ & 0 & $0 \%$ & 2 & $29 \%$ & 1 & $14 \%$ & 2 & $29 \%$ & 4 & $57 \%$ & 1 & $14 \%$ & 2 & $29 \%$ & 0 & $0 \%$ & $69.05 \%$ & $82.14 \%$ \\
\hline Face to face meetings & 0 & $0 \%$ & 0 & $0 \%$ & 0 & $0 \%$ & 1 & $14 \%$ & 1 & $14 \%$ & 6 & $86 \%$ & 5 & $71 \%$ & 3 & $43 \%$ & 0 & $0 \%$ & 0 & $0 \%$ & $93.75 \%$ & $90.63 \%$ \\
\hline Media - newspaper & 0 & $0 \%$ & 0 & $0 \%$ & 0 & $0 \%$ & 0 & $0 \%$ & 3 & $43 \%$ & 5 & $71 \%$ & 7 & $100 \%$ & 1 & $14 \%$ & 0 & $0 \%$ & 0 & $0 \%$ & $93.75 \%$ & $96.88 \%$ \\
\hline Media - radio & 0 & $0 \%$ & 0 & $0 \%$ & 1 & $14 \%$ & 1 & $14 \%$ & 1 & $14 \%$ & 5 & $71 \%$ & 6 & $86 \%$ & 1 & $14 \%$ & 1 & $14 \%$ & 0 & $0 \%$ & $87.50 \%$ & $90.63 \%$ \\
\hline Media - television & 1 & $14 \%$ & 0 & $0 \%$ & 3 & $43 \%$ & 1 & $14 \%$ & 2 & $29 \%$ & 1 & $14 \%$ & 4 & $57 \%$ & 2 & $29 \%$ & 0 & $0 \%$ & 1 & $14 \%$ & $62.50 \%$ & $82.14 \%$ \\
\hline \multirow[t]{2}{*}{ Other } & 0 & $0 \%$ & 0 & $0 \%$ & 0 & $0 \%$ & 0 & $0 \%$ & 0 & $0 \%$ & 0 & $0 \%$ & 0 & $0 \%$ & 0 & $0 \%$ & 0 & $0 \%$ & 1 & $14 \%$ & $0.00 \%$ & $25.00 \%$ \\
\hline & & & & & & & & & & & & & & & & & & & & & & \\
\hline Section 2 of 3 (incoming) & & & & & & & & & & & & & & & & & & & & & & \\
\hline & \multicolumn{2}{|c|}{ Never } & \multicolumn{2}{|c|}{ Rarely } & \multicolumn{2}{|c|}{ Sev Mth } & \multicolumn{2}{|c|}{ Sev Wk } & \multicolumn{2}{|c|}{ Sev Day } & Cons & $\tan t$ & Rank & & Rank & & Rank & & Rank & & & \\
\hline Mobile Phone & 1 & $14 \%$ & 1 & $14 \%$ & 2 & $29 \%$ & 1 & $14 \%$ & 1 & $14 \%$ & 0 & $0 \%$ & 0 & $0 \%$ & 3 & $43 \%$ & 1 & $14 \%$ & 2 & $29 \%$ & $50.00 \%$ & $54.17 \%$ \\
\hline Telephone & 0 & $0 \%$ & 0 & $0 \%$ & 1 & $14 \%$ & 0 & $0 \%$ & 0 & $0 \%$ & 5 & $71 \%$ & 5 & $71 \%$ & 0 & $0 \%$ & 1 & $14 \%$ & 0 & $0 \%$ & $91.67 \%$ & $91.67 \%$ \\
\hline Teleconference & 5 & $71 \%$ & 1 & $14 \%$ & 0 & $0 \%$ & 0 & $0 \%$ & 0 & $0 \%$ & 0 & $0 \%$ & 0 & $0 \%$ & 0 & $0 \%$ & 0 & $0 \%$ & 6 & $86 \%$ & $19.44 \%$ & $25.00 \%$ \\
\hline Videoconference & 5 & $71 \%$ & 1 & $14 \%$ & 0 & $0 \%$ & 0 & $0 \%$ & 0 & $0 \%$ & 0 & $0 \%$ & 0 & $0 \%$ & 0 & $0 \%$ & 0 & $0 \%$ & 6 & $86 \%$ & $19.44 \%$ & $25.00 \%$ \\
\hline Mail & 0 & $0 \%$ & 0 & $0 \%$ & 0 & $0 \%$ & 0 & $0 \%$ & 1 & $14 \%$ & 5 & $71 \%$ & 6 & $86 \%$ & 0 & $0 \%$ & 0 & $0 \%$ & 0 & $0 \%$ & $97.22 \%$ & $100.00 \%$ \\
\hline Direct mail & 0 & $0 \%$ & 2 & $29 \%$ & 4 & $57 \%$ & 0 & $0 \%$ & 0 & $0 \%$ & 0 & $0 \%$ & 0 & $0 \%$ & 3 & $43 \%$ & 3 & $43 \%$ & 0 & $0 \%$ & $44.44 \%$ & $62.50 \%$ \\
\hline EPN mail & 5 & $71 \%$ & 1 & $14 \%$ & 0 & $0 \%$ & 0 & $0 \%$ & 0 & $0 \%$ & 0 & $0 \%$ & 0 & $0 \%$ & 0 & $0 \%$ & 0 & $0 \%$ & 6 & $86 \%$ & $19.44 \%$ & $25.00 \%$ \\
\hline Fax & 0 & $0 \%$ & 0 & $0 \%$ & 1 & $14 \%$ & 0 & $0 \%$ & 1 & $14 \%$ & 4 & $57 \%$ & 5 & $71 \%$ & 0 & $0 \%$ & 1 & $14 \%$ & 0 & $0 \%$ & $88.89 \%$ & $91.67 \%$ \\
\hline Internet & 6 & $86 \%$ & 0 & $0 \%$ & 0 & $0 \%$ & 0 & $0 \%$ & 0 & $0 \%$ & 0 & $0 \%$ & 0 & $0 \%$ & 1 & $14 \%$ & 0 & $0 \%$ & 5 & $71 \%$ & $16.67 \%$ & $33.33 \%$ \\
\hline Email & 0 & $0 \%$ & 0 & $0 \%$ & 0 & $0 \%$ & 0 & $0 \%$ & 0 & $0 \%$ & 0 & $0 \%$ & 0 & $0 \%$ & 0 & $0 \%$ & 0 & $0 \%$ & 0 & $0 \%$ & $0.00 \%$ & $0.00 \%$ \\
\hline Face to face meetings & 0 & $0 \%$ & 0 & $0 \%$ & 0 & $0 \%$ & 0 & $0 \%$ & 1 & $14 \%$ & 5 & $71 \%$ & 6 & $86 \%$ & 0 & $0 \%$ & 0 & $0 \%$ & 0 & $0 \%$ & $97.22 \%$ & $100.00 \%$ \\
\hline Media - newspaper & 0 & $0 \%$ & 0 & $0 \%$ & 2 & $29 \%$ & 1 & $14 \%$ & 1 & $14 \%$ & 2 & $29 \%$ & 4 & $57 \%$ & 1 & $14 \%$ & 1 & $14 \%$ & 0 & $0 \%$ & $75.00 \%$ & $87.50 \%$ \\
\hline Media - radio & 1 & $14 \%$ & 0 & $0 \%$ & 1 & $14 \%$ & 1 & $14 \%$ & 1 & $14 \%$ & 2 & $29 \%$ & 4 & $57 \%$ & 1 & $14 \%$ & 0 & $0 \%$ & 1 & $14 \%$ & $69.44 \%$ & $83.33 \%$ \\
\hline Media - television & 1 & $14 \%$ & 0 & $0 \%$ & 2 & $29 \%$ & 1 & $14 \%$ & 1 & $14 \%$ & 1 & $14 \%$ & 3 & $43 \%$ & 1 & $14 \%$ & 1 & $14 \%$ & 1 & $14 \%$ & $61.11 \%$ & $75.00 \%$ \\
\hline Other & 0 & $0 \%$ & 0 & $0 \%$ & 0 & $0 \%$ & 0 & $0 \%$ & 0 & $0 \%$ & 0 & $0 \%$ & 0 & $0 \%$ & 0 & $0 \%$ & 0 & $0 \%$ & 0 & $0 \%$ & $0.00 \%$ & $0.00 \%$ \\
\hline & & & & & & & & & & & & & & & & & & & & & & \\
\hline 8002 & & & & & & & & & & & & & & & & & & & & & & \\
\hline
\end{tabular}


w

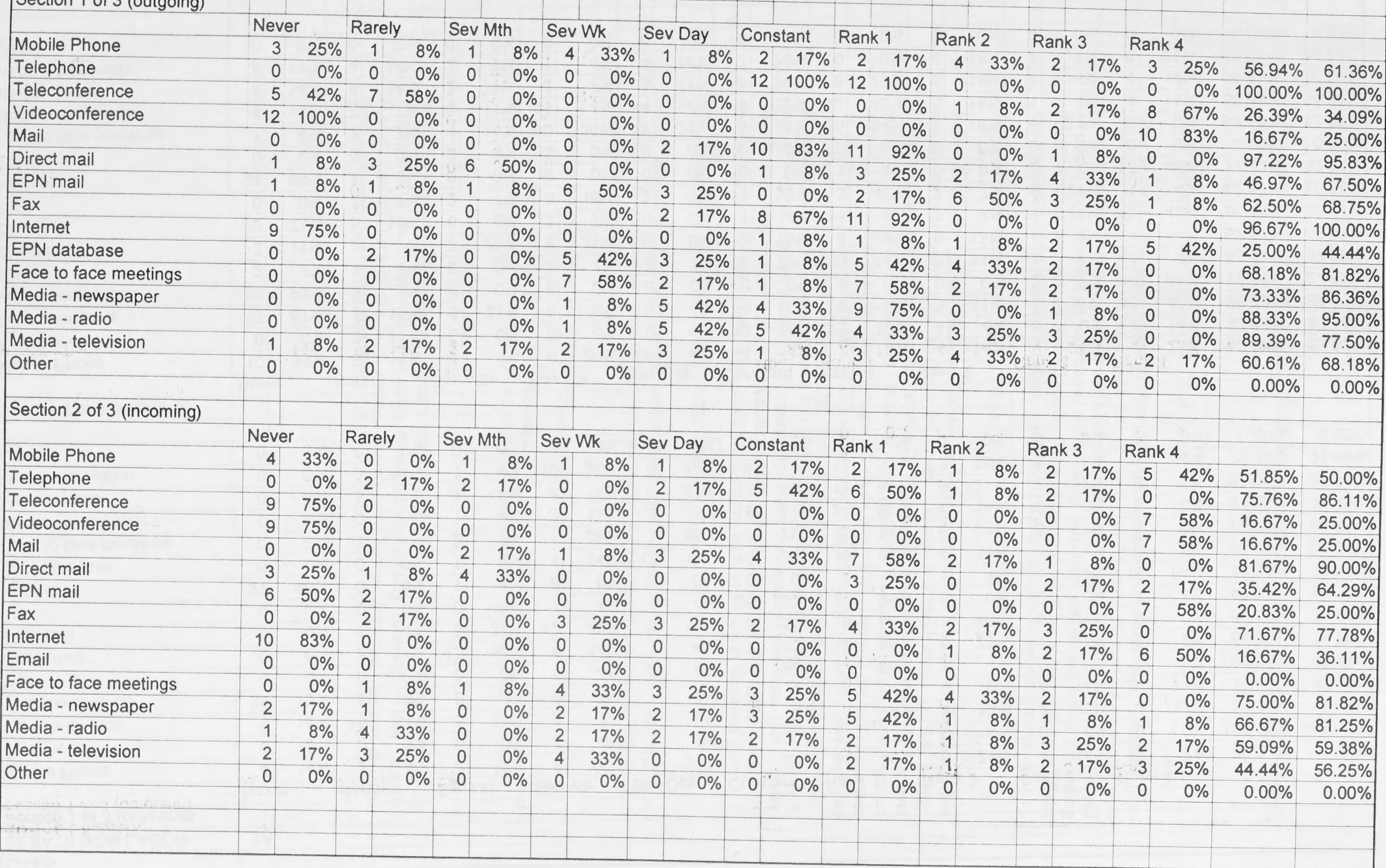




\begin{tabular}{|c|c|c|c|c|c|c|c|c|c|c|c|c|c|c|c|c|c|c|c|c|c|c|}
\hline Group: & & & & & & & & & & & & & & & & & & & & & & \\
\hline \multirow{2}{*}{\multicolumn{23}{|c|}{ Section 1 of 3 (outgoing) }} \\
\hline & & & & & & & & & & & & & & & & & & & & & & \\
\hline & \multicolumn{2}{|c|}{ Never } & \multicolumn{2}{|c|}{ Rarely - } & \multicolumn{2}{|c|}{ Sev Mth } & \multicolumn{2}{|c|}{ Sev Wk } & \multicolumn{2}{|c|}{ Sev Day } & \multicolumn{2}{|c|}{ Constant } & \multicolumn{2}{|c|}{ Rank 1} & \multicolumn{2}{|c|}{ Rank 2} & \multicolumn{2}{|c|}{ Rank 3} & \multicolumn{2}{|c|}{ Rank 4} & & \\
\hline Mobile Phone & 4 & $14 \%$ & 1 & $4 \%$ & 2 & $7 \%$ & 5 & $18 \%$ & 10 & $36 \%$ & 6 & $21 \%$ & 13 & $46 \%$ & 6 & $21 \%$ & 4 & $14 \%$ & 2 & $7 \%$ & $70.24 \%$ & $80.00 \%$ \\
\hline Telephone & 0 & $0 \%$ & 0 & $0 \%$ & 0 & $0 \%$ & 0 & $0 \%$ & 0 & $0 \%$ & 28 & $100 \%$ & 27 & $96 \%$ & 0 & $0 \%$ & 0 & $0 \%$ & 0 & $0 \%$ & $100.00 \%$ & $100.00 \%$ \\
\hline Teleconference & 5 & $18 \%$ & 15 & $54 \%$ & 5 & $18 \%$ & 2 & $7 \%$ & 0 & $0 \%$ & 0 & $0 \%$ & 1 & $4 \%$ & 5 & $18 \%$ & 12 & $43 \%$ & 9 & $32 \%$ & $35.80 \%$ & $48.15 \%$ \\
\hline Videoconference & 21 & $75 \%$ & 5 & $18 \%$ & 0 & $0 \%$ & 0 & $0 \%$ & 0 & $0 \%$ & O & $0 \%$ & 1 & $4 \%$ & 0 & $0 \%$ & 4 & $14 \%$ & 20 & $71 \%$ & $19.87 \%$ & $32.00 \%$ \\
\hline Mail & 0 & $0 \%$ & 0 & $0 \%$ & 0 & $0 \%$ & 1 & $4 \%$ & 1 & $4 \%$ & 26 & $93 \%$ & 27 & $96 \%$ & 1 & $4 \%$ & 0 & $0 \%$ & 0 & $0 \%$ & $98.21 \%$ & $99.11 \%$ \\
\hline Direct mail & 0 & $0 \%$ & 3 & $11 \%$ & 13 & $46 \%$ & 4 & $14 \%$ & 1 & $4 \%$ & 7 & $25 \%$ & 13 & $46 \%$ & 6 & $21 \%$ & 7 & $25 \%$ & 2 & $7 \%$ & $64.29 \%$ & $76.79 \%$ \\
\hline EPN mail & 0 & $0 \%$ & 1 & $4 \%$ & 6 & $21 \%$ & 12 & $43 \%$ & 5 & $18 \%$ & 3 & $11 \%$ & 8 & $29 \%$ & 13 & $46 \%$ & 6 & $21 \%$ & 0 & $0 \%$ & $68.52 \%$ & $76.85 \%$ \\
\hline Fax & 0 & $0 \%$ & 0 & $0 \%$ & 0 & $0 \%$ & 1 & $4 \%$ & 1 & $4 \%$ & 26 & $93 \%$ & 27 & $96 \%$ & 0 & $0 \%$ & 0 & $0 \%$ & 1 & $4 \%$ & $98.21 \%$ & $97.32 \%$ \\
\hline Internet & 27 & $96 \%$ & 0 & $0 \%$ & 1 & $4 \%$ & 0 & $0 \%$ & 0 & $0 \%$ & 0 & $0 \%$ & 1 & $4 \%$ & 1 & $4 \%$ & 4 & $14 \%$ & 15 & $54 \%$ & $17.86 \%$ & $35.71 \%$ \\
\hline EPN database & 0 & $0 \%$ & 0 & $0 \%$ & 1 & $4 \%$ & 4 & $14 \%$ & 12 & $43 \%$ & 10 & $36 \%$ & 19 & $68 \%$ & 4 & $14 \%$ & 4 & $14 \%$ & 0 & $0 \%$ & $85.80 \%$ & $88.89 \%$ \\
\hline Face to face meetings & 0 & $0 \%$ & 1 & $4 \%$ & 2 & $7 \%$ & 11 & $39 \%$ & 7 & $25 \%$ & 7 & $25 \%$ & 15 & $54 \%$ & 6 & $21 \%$ & 6 & $21 \%$ & 0 & $0 \%$ & $76.79 \%$ & $83.33 \%$ \\
\hline Media - newspaper & 0 & $0 \%$ & 0 & $0 \%$ & 1 & $4 \%$ & 3 & $11 \%$ & 5 & $18 \%$ & 18 & $64 \%$ & 24 & $86 \%$ & 4 & $14 \%$ & 0 & $0 \%$ & 0 & $0 \%$ & $91.36 \%$ & $96.43 \%$ \\
\hline Media - radio & 0 & $0 \%$ & 3 & $11 \%$ & 1 & $4 \%$ & 4 & $14 \%$ & 6 & $21 \%$ & 13 & $46 \%$ & 18 & $64 \%$ & 6 & $21 \%$ & 2 & $7 \%$ & 2 & $7 \%$ & $82.10 \%$ & $85.71 \%$ \\
\hline Media - television & 0 & $0 \%$ & 3 & $11 \%$ & 1 & $4 \%$ & 10 & $36 \%$ & 5 & $18 \%$ & 9 & $32 \%$ & 14 & $50 \%$ & 7 & $25 \%$ & 5 & $18 \%$ & 1 & $4 \%$ & $76.19 \%$ & $81.48 \%$ \\
\hline \multirow[t]{2}{*}{ Other } & 0 & $0 \%$ & 0 & $0 \%$ & 0 & $0 \%$ & 0 & $0 \%$ & 0 & $0 \%$ & 0 & $0 \%$ & 0 & $0 \%$ & 0 & $0 \%$ & 0 & $0 \%$ & 0 & $0 \%$ & $0.00 \%$ & $0.00 \%$ \\
\hline & & & & & & & & & & & & $=$ & & & & & 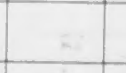 & & & & & \\
\hline \multirow{2}{*}{ Section 2 of 3 (incoming) } & & & & & \multirow{2}{*}{\multicolumn{2}{|c|}{ Sev Mth }} & & & & & & 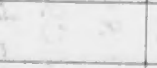 & & & & & & & & & & \\
\hline & \multicolumn{2}{|c|}{ Never } & \multicolumn{2}{|c|}{ Rarely } & & & \multicolumn{2}{|c|}{ Sev Wk } & \multicolumn{2}{|c|}{ Sev Day } & Cons & $\tan t$ & Rank & & Rank & & Rank & & Rank & & & \\
\hline Mobile Phone & 10 & $36 \%$ & 3 & $11 \%$ & 1 & $4 \%$ & 8 & $29 \%$ & 1 & $4 \%$ & 4 & $14 \%$ & 3 & $11 \%$ & 4 & $14 \%$ & 7 & $25 \%$ & -7 & $25 \%$ & $49.38 \%$ & $53.57 \%$ \\
\hline Telephone & 0 & $0 \%$ & 3 & $11 \%$ & 0 & $0 \%$ & 0 & $0 \%$ & 0 & $0 \%$ & 25 & $89 \%$ & 22 & $79 \%$ & 1 & $4 \%$ & 0 & $0 \%$ & 4 & $14 \%$ & $92.86 \%$ & $87.96 \%$ \\
\hline Teleconference & 17 & $61 \%$ & 5 & $18 \%$ & 6 & $21 \%$ & 0 & $0 \%$ & 0 & $0 \%$ & 0 & $0 \%$ & 0 & $0 \%$ & 3 & $11 \%$ & 5 & $18 \%$ & 13 & $46 \%$ & $26.79 \%$ & $38.10 \%$ \\
\hline Videoconference & 26 & $93 \%$ & 2 & $7 \%$ & 0 & $0 \%$ & 0 & $0 \%$ & 0 & $0 \%$ & 0 & $0 \%$ & 0 & $0 \%$ & 0 & $0 \%$ & 2 & $7 \%$ & 17 & $61 \%$ & $17.86 \%$ & $27.63 \%$ \\
\hline Mail & 2 & $7 \%$ & 1 & $4 \%$ & 0 & $0 \%$ & 2 & $7 \%$ & 2 & $7 \%$ & 22 & $79 \%$ & 20 & $71 \%$ & 3 & $11 \%$ & 1 & $4 \%$ & 1 & $4 \%$ & $88.51 \%$ & $92.00 \%$ \\
\hline Direct mail & 3 & $11 \%$ & 2 & $7 \%$ & 7 & $25 \%$ & 6 & $21 \%$ & 0 & $0 \%$ & 7 & $25 \%$ & 8 & $29 \%$ & 5 & $18 \%$ & 5 & $18 \%$ & 4 & $14 \%$ & $62.67 \%$ & $69.32 \%$ \\
\hline EPN mail & 20 & $71 \%$ & 5 & $18 \%$ & 0 & $0 \%$ & 2 & $7 \%$ & 0 & $0 \%$ & 1 & $4 \%$ & 1 & $4 \%$ & 2 & $7 \%$ & 4 & $14 \%$ & 12 & $43 \%$ & $26.19 \%$ & $39.47 \%$ \\
\hline Fax & 0 & $0 \%$ & 2 & $7 \%$ & 2 & $7 \%$ & 5 & $18 \%$ & 2 & $7 \%$ & 14 & $50 \%$ & 13 & $46 \%$ & 2 & $7 \%$ & 6 & $21 \%$ & 1 & $4 \%$ & $82.67 \%$ & $80.68 \%$ \\
\hline Internet & 24 & $86 \%$ & 1 & $4 \%$ & 0 & $0 \%$ & 0 & $0 \%$ & 0 & $0 \%$ & 0 & $0 \%$ & 1 & $4 \%$ & 0 & $0 \%$ & 2 & $7 \%$ & 13 & $46 \%$ & $17.33 \%$ & $32.81 \%$ \\
\hline Email & 0 & $0 \%$ & 0 & $0 \%$ & 0 & $0 \%$ & 0 & $0 \%$ & 0 & $0 \%$ & 0 & $0 \%$ & 0 & $0 \%$ & 0 & $0 \%$ & 0 & $0 \%$ & 0 & $0 \%$ & $0.00 \%$ & $0.00 \%$ \\
\hline Face to face meetings & 1 & $4 \%$ & 2 & $7 \%$ & 4 & $14 \%$ & 10 & $36 \%$ & 6 & $21 \%$ & 4 & $14 \%$ & 15. & $54 \%$ & 5 & $18 \%$ & 6 & $21 \%$ & 0 & $0 \%$ & $68.52 \%$ & $83.65 \%$ \\
\hline Media - newspaper & 4 & $14 \%$ & 2 & $7 \%$ & 3 & $11 \%$ & 1 & $4 \%$ & 4 & $14 \%$ & 9 & $32 \%$ & 12 & $43 \%$ & 5 & $18 \%$ & 1 & $4 \%$ & 4 & $14 \%$ & $68.84 \%$ & $78.41 \%$ \\
\hline Media - radio & 4 & $14 \%$ & 4 & $14 \%$ & 2 & $7 \%$ & 2 & $7 \%$ & 3 & $11 \%$ & 8 & $29 \%$ & 8 & $29 \%$ & 5 & $18 \%$ & 4 & $14 \%$ & 4 & $14 \%$ & $64.49 \%$ & $70.24 \%$ \\
\hline Media - television & 5 & $18 \%$ & 4 & $14 \%$ & 2 & $7 \%$ & 1 & $4 \%$ & 4 & $14 \%$ & 7 & $25 \%$ & 0 & $0 \%$ & 5 & $18 \%$ & 2 & $7 \%$ & 6 & $21 \%$ & $61.59 \%$ & $48.08 \%$ \\
\hline Other & 0 & $0 \%$ & 0 & $0 \%$ & 0 & $0 \%$ & 0 & $0 \%$ & 0 & $0 \%$ & 0 & $0 \%$ & 0 & $0 \%$ & 0 & $0 \%$ & 0 & $0 \%$ & 0 & $0 \%$ & $0.00 \%$ & $0.00 \%$ \\
\hline & & & & & & & & & & & & & & & & & & & & & & \\
\hline & & & & & & & & & & & & & & & & & & & & & & \\
\hline & & & & & & & & & & & & & & & & & & & & & & \\
\hline
\end{tabular}




\section{APPENDIX D}

\section{Analysis of 1993 Federal election results re the MPs interviewed, their attitude to direct mail and their election performance:}

\section{NSW hadian over:all swing of: $2.3 \%$ to Labor.}

Jim Snow (Labor, Eden-Monarö) who only occasionally used direct mail (generally from addresses in the tclephone book), had a $0.1 \%$ swing to Liberal. His was a rural seat with two provincial centres. Jeanette McHugh (Labor, Grandler) who was strongly opposed to dircet mail, achieved an impressive $5.5 \%$ swing to Labor, despite not being the sitting local Mcmbcr for part of the electorate (having been affected by a redistribution of the electoral boundary introducing a large, nominally-Liberal addition to the electorate).

Victoria had an overall swing of $4.3 \%$ to Labor

Neil O'Keefe (Labor, Burke) who did not use direct mail (except to welcome new constitucn(s) achieved a $6.7 \%$ swing to Labor. His was a rural seat. David Kêmp (Libcral, Goldstein) had a swing to Labor of $0.4 \%$, well below the state average. He used direct mail quite often. Michael Wooldridge (Liberal, Chisholm) had a swing against him of $3.4 \%$. lower than the state average. Of those interviewed, he was the most avid user of direct mail. Bob Charles (Liberal, Latrobe) had a swing of $1.0 \%$ to Labor, so performed well against the swing. He used direct mail quite often, though judiciously. Ken Aldred (Liberal, Deakin) had a swing to Labor of $1.1 \%$ so held well against the state swing. Hc used direct mail only occasionally, being concerned at the error rate. Peter Reith (Libcral, Flinders) had an exen better result in holding against the swing, with only $0.1 \%$ to Labor. He very rarely used direct mail, regarding it as useful in marginal seats.

\section{Queensland had an overall swing of $1.8 \%$ to the Coalition}

Alex Somlyay (Liberal, Fairfax) had a swing of $2.3 \%$ which was better than the state average. Hc occasionally used direct mail, but tended instead to consult closely with special busincss and industry groups.

Tasmania had a swing of $6.7 \%$ to Labor

Duncan Kerr (Labor, Denison) achieved an $8 \%$ swing to Labor. He occasionally used direct mail, bclieving, if genuine, it can improve communication between MP and voter.

ACT had a $2.7 \%$ swing to Labor

John Langmore (Labor, Fraser) had a swing of 1.5\%. He did not use direct mail, but is a high profilc local Member who holds numerous cornmunity meetings. Ros Kelly (Labor, Canberra) achieved a $3.7 \%$ swing, though other factors from the previous election were opcrating. She rarely used direct mail. 


\section{CONFIDENTIAL SECTION}

This material can be read as an extension of chapter three.

\section{Australian Labor Party (ALP) Surveys}

As a condition of reporting these surveys, I undertook to Gary Gray, ALP National Secretary, that they would be confidential to the examiners.

In fact, I think such precautions are unnecessary because the Liberals poll as extensively, if not more, than Labor. As has been indicated, it is the interpretation rather than the conducting of polls which is important. However, the ALP surveys were the only data I could gather to compare with the Fremantle survey of voter attitudes.

The ALP research was conducted by Insight West, WAOP and Consumer Contact and sponsored by the National Secretariat and John Della Bosca, NSW ALP Secretary. It covered Oxley, Queensland (1988), Victoria (1988), Western Australia (1989) and NSW (1991).

\section{ALP Campaign Techniques Research}

Gray, introducing the confidential report of the above name, wrote 'Direct Mail works! - We all know that!' He was of the opinion that it works best when it is informative or emotive, when it comes as local mail from a local Member, and when it is used outside the formal campaign.

The research aimed to evaluate different methods of getting the message across. TV advertising was rated the most effective but also the most expensive. Therefore, direct mail was judged to be the next best method. However, the surveys did not cost alternatives in dollar terms. 
Comparing the research results presents problems, as the methodology and, most importantly, the questions were differently worded even when covering the same general topic. However, as this is the only basis from which to draw some comparison over time, some tentative conclusions are drawn.

\section{Oxley (1988) survey}

From a base of all electors in the Oxley electorate, 11 percent had not read the direct mail, and would not, while 10 percent had not read it, but intended to; 26 percent of respondents were positive to direct mail, 22 percent negative; 8 percent responded that it was junk mail and they threw it away. Other responses were noncommittal.

So 33 percent of the survey were negative, or had not and would not read it, though a quarter of the sample were positive. The survey did not define whether any of these people were swinging voters. The percentages total only 70 percent, because reaction was asked for only if the voter acknowledged receiving direct mail in the previous week (see table 3.18).

Table 3.18 Comparisons on direct mail (percentages)

\begin{tabular}{||l|c|c||}
\hline \multicolumn{2}{|c|}{ ALP (Oxley) } & Fremantle \\
\hline Received & 83 & 87 \\
\hline Read & 79 & 60 \\
\hline Negative & 22 & 61 \\
\hline Positive & 26 & 31 \\
\hline
\end{tabular}

From these data, and with the caveats outlined above, it appears that the reaction to direct mail may be becoming more negative, which may bring into question its effectiveness. The 'Carmen factor' with Labor voters may account for the increased positive response.

The most informative source of information during the election was judged to be TV ( 44 percent), letters ( 22 percent), print (18 percent) and rest insignificant. 


\section{Victoria (1988)}

The Fremantle survey did not ask respondents to rate media outlets, but other surveys have also pointed to the importance of television news.

Direct mail rated better than radio advertisements, print ads or TV ads but it was news media (TV news, print news) which gained most attention.

It did not appear to make very much difference whether the direct mail was from the candidate or the party leader though, as Clive Bean's research on personal vote indicates, a centralised campaign may accompany local issues (see table 3.19).

Table 3.19 Voter attention to campaign avenues

\begin{tabular}{||l|c|c|c||}
\hline ATTENTION GIVEN TO: & A lot & Some & Not much \\
\hline TV News & 34 & 34 & 32 \\
\hline TV ads & 9 & 22 & 68 \\
\hline radio news & 21 & 29 & 48 \\
\hline radio ads & 3 & 12 & 83 \\
\hline Direct Mail (from candidate) & 9 & 30 & 61 \\
\hline leaflets & 8 & 28 & 63 \\
\hline print news & 24 & 32 & 43 \\
\hline print ads & 7 & 17 & 75 \\
\hline Direct Mail (from party leader) & 10 & 24 & 63 \\
\hline \hline
\end{tabular}


A generally negative reaction to effectivenss is apparent from all sources (see 'not very' column). TV news rated most highly, followed by print news and radio news. Radio advertisements were rated the least successful (see table 3.20).

Table 3.20 Voter opinion of campaign avenues' effectiveness (percentages)

\begin{tabular}{||l|c|c|c|c||}
\hline EFFECTIVENESS & Very & Fairly & Not very & Unsure \\
\hline TV news & 19 & 30 & 49 & 1 \\
\hline radio news & 15 & 24 & 58 & 3 \\
\hline TV ads & 6 & 15 & 78 & 1 \\
\hline radio ads & 1 & 10 & 86 & 3 \\
\hline DM ( from candidate) & 8 & 23 & 68 & 1 \\
\hline leaflets & 7 & 18 & 73 & 1 \\
\hline print news & 16 & 26 & 55 & 2 \\
\hline $\begin{array}{l}\text { print ads } \\
\text { DM (from state } \\
\text { premier) }\end{array}$ & 3 & 13 & 82 & 1 \\
\hline
\end{tabular}

The attention to direct mail divided almost equally between closely, not closely and not read. It was judged to be not credible by one-third and not helpful by two-thirds. Females and home duties were judged to be most likely to read direct mail, unlike the Fremantle findings (see table 3.21).

Table 3.21 Attention to and attitude towards direct mail (percentages)

\begin{tabular}{|l|c|c|c|c||}
\hline \hline \multicolumn{2}{|l|}{ DIRECT MAIL LETTER } & Closely & Not closely & Not read \\
\hline \multicolumn{2}{|l|}{ Attention to } & 31 & 38 & 31 \\
\hline & Very & Quite & Not & Don't know \\
\hline Credibility of & 8 & 51 & 32 & 9 \\
\hline Helpfulness of & 6 & 23 & $67+$ & 3 \\
\hline
\end{tabular}


About one-third of the sample would prefer not to get letters: 30 percent did not read them at all; a further 39 percent read them but did not remember the contents. - therefore, nearly 70 percent appeared unaffected by direct mail. Only 31 percent remembered the contents. Asked whether they wanted a visit from candidates, 42 percent said yes while 48 percent were not interested and 10 percent were not sure.

The 1989 WA state election may provide the clearest comparison with Fremantle 1994. Some conclusions are contrary to Fremantle findings, which may indicate changes over the intervening five years. Quoting from the confidential ALP report:

\section{“DIRECT MAIL}

Nineteen percent of respondents said letters were the most interesting and informative sources of election information.

Those most interested in letters were women (particulariy women at home), people in the middle aged age group, and people with higher levels of education. Women and retired people found them more influential in deciding their vote than other groups.

People say they are more interested in receiving letters from the local candidate than letters from the Premier or Opposition Leader. Young people are the ones where a significant proportion are interested in getting a letter from the leaders. People over 30 years of age are heavily oriented towards the local candidate. People also believe that letters from the local candidates are more likely to be accurate than letters from the leaders.

Some $11 \%$ of respondents said that the letters influenced their vote in this election. Again letters from the local candidate were more influential. However, letters from the leaders had more influence than the preference figures 
would suggest. This may be due to the actual number or nature of the letters received from each source.

The majority felt they had received too many letters during the course of the election campaign. The least affected by this were young people and industrial/technical workers. Those most affected were women at home and retired people.

Points to make about the letters:

- People place considerable importance on local issues and the quality of the local candidate.

- People want specific details in letters rather than generalisations.

- People prefer to receive letters that have information other than that widely available from other sources (particularly TV).

- Swinging voters look at the policy contents and credibility is an important issue for them.

- People feel they should hear from their local members regularly and not only at election time."

(National Secretariat, ALP, Gary Gray to all State Secretaries, Campaign Techniques Research, confidential commissioned research, September 3 1991).

As stated, when the thrust of the questionnaires and their purpose differs, comparisons are tenuous. The researchers must have known how positive the National Secretariat was towards direct mail and it could be that their research approach reflected the secretariat's attitude.

The 1991 NSW survey was qualitative, concentrating on attitudes to different letter formats, and differing words or phrases, and so is not particularly applicable to the thesis. 